
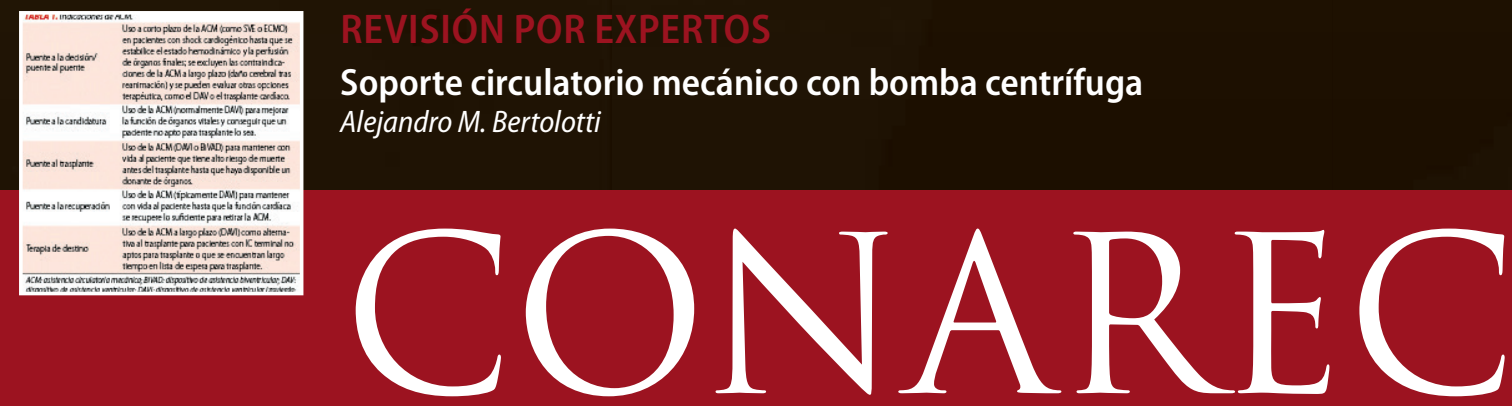

Noviembre - Diciembre de 2018 - Año 33 - № 147

\title{
. \\ Ventilación no invasiva en el tratamiento de la insuficiencia cardíaca
}

Diego A. Márquez, Guillermo R. Chiappero

\section{MONOGRAFÍA SELECCIONADA}

Desafíos estratégicos en insuficiencia cardíaca avanzada. Asistencia ventricular. ¿Está todo dicho?

Santillán J

\section{ARTÍCULOS ORIGINALES}

Gradiente posquirúrgico en pacientes con reemplazo valvular aórtico y su asociación con eventos cardiovasculares

Chattich $N$ y cols.

Factores de riesgo cardiovascular en residentes y cardiólogos argentinos. "Cómo se cuidan los que cuidan". Encuesta FRICCAR, CONAREC

Pulenta Hy cols.

Infarto agudo de miocardio con elevación del segmento ST: prevalencia de arteria según el sexo

Astesiano A y cols.

\section{CASOS CLÍNICOS}

Tronco coronario único que nace del seno coronario derecho Chacon Cy cols.

Causa infrecuente de infarto anterior: hematoma por disección aórtica

Hsu Ly cols.

\section{IMÁGENES EN CARDIOLOGÍA}

Pericarditis constrictiva asociada a miocardiopatía chagásica Wong EC y cols.

\section{GUÍAS CONAREC}

Algoritmo de manejo lipídico en el paciente con síndrome coronario agudo

Damonte Jly cols. 


\section{Gadocor}

Nebivolol 5 - $10 \mathrm{mg}$

SELECTIVO Y VASODILATADOR ${ }^{1}$

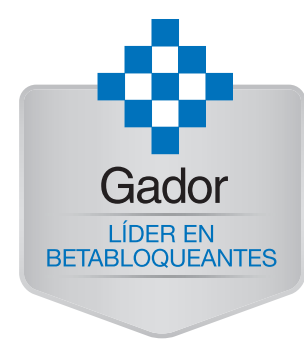

- Brinda un eficaz control de la presión arterial en el paciente hipertenso ${ }^{2}$

- Permite ser utilizado con seguridad en pacientes diabéticos o con síndrome metabólico ${ }^{3}$

- Preserva la función eréctil ${ }^{4}$

- Está indicado en pacientes con EPOC ${ }^{5}$

- No interfiere en el desarrollo de la actividad física del paciente ${ }^{6}$

Gadocor ${ }^{\star}$ permite que cada parte contenga la dosis correspondiente debido al diseño de sus comprimidos birranurados de $5 \mathrm{mg}$
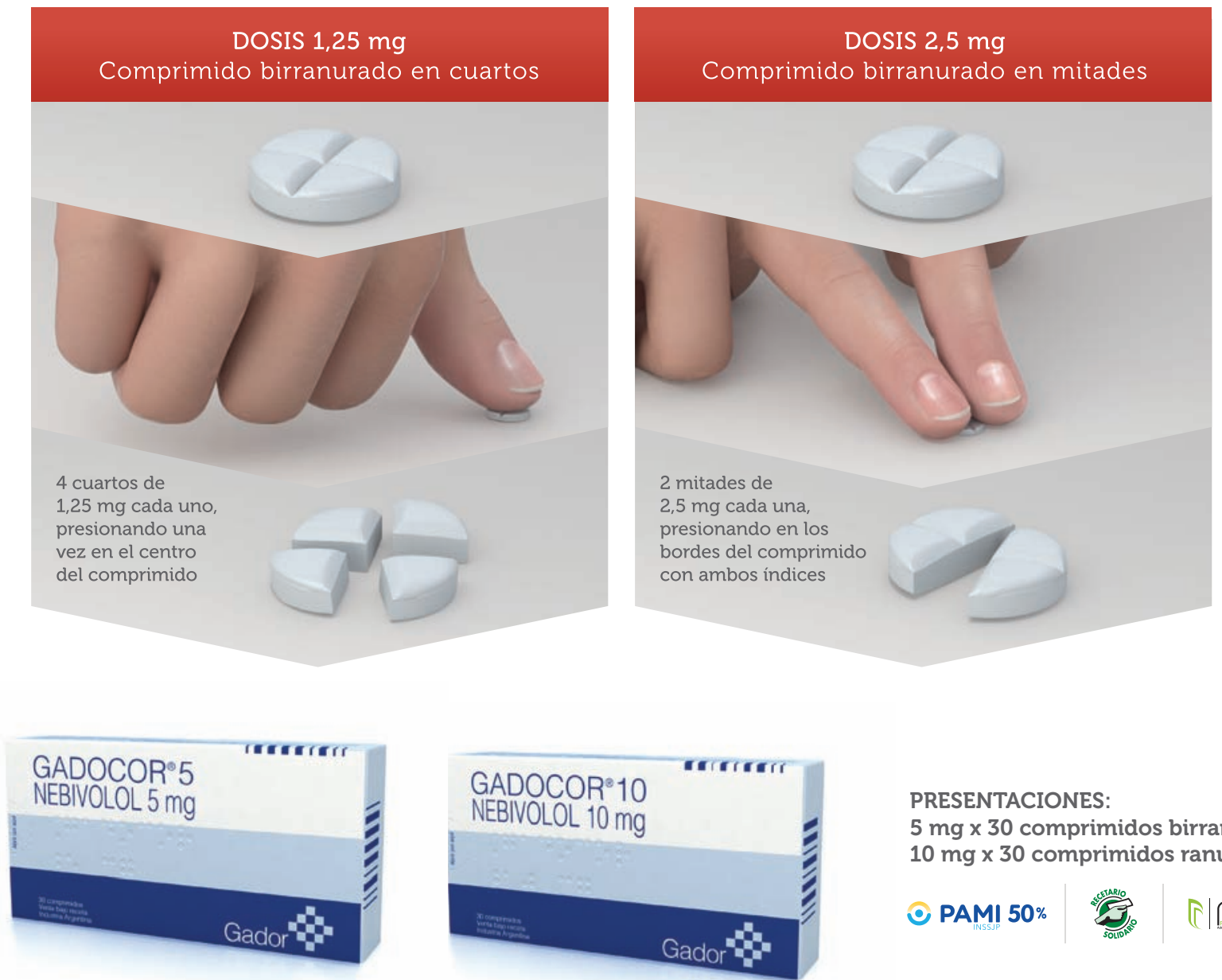

PRESENTACIONES:

$5 \mathrm{mg} \times 30$ comprimidos birranurados $10 \mathrm{mg} \times 30$ comprimidos ranurados

- PAMI 50\% 


\section{Artome $\mathbf{y}^{\circ}$}

\section{Máxima prevención en la enfermedad}

cardiovascular.

$\triangleright 44 \%$ de reducción de eventos cardiovasculares en prevención primaria. ${ }^{1}$

$\checkmark$ Control lipídico en alto riesgo cardiovascular. ${ }^{2}$

$\checkmark$ Estabiliza placas coronarias ricas en lípidos. ${ }^{3}$

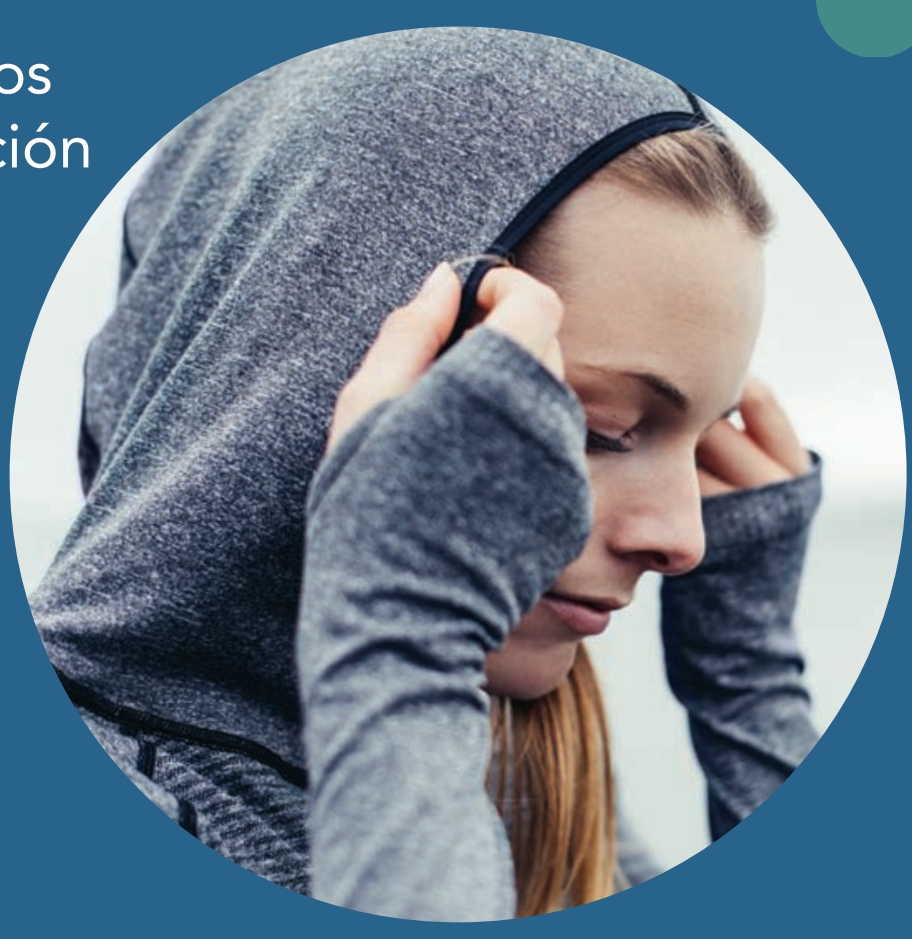

$\checkmark$ Reduce la progresión del volumen de placa de ateroma. ${ }^{4}$

$\checkmark$ Mayor eficacia para alcanzar las metas del NCEP ATP III. ${ }^{5}$

\section{REFERENCIAS BIBLIOGRÁFICAS}

1- Ridker P et al. Jupiter Trial N Eng J Med 2008; 359: 195-207 2- Shepherd J. Am J Cardiol" 2003; 91 (Suppl): 11c-19c

3- Soeda T et al. Circ J 2011; 75: 2621-7

4- Nissen S et al. Estudio Asteroid. JAMA 2006; 295: 1556-65

5- Shepherd J. Am J Cardiol: 2003; 91 (Suppl): 11c-19c
Presentaciones

Artomey ${ }^{\circledR} 5$ mg - 10 mg - 20 mg y 40 mg envases conteniendo 30 comp. recub. Artomey $^{\circledR} 10 \mathrm{mg}$ envases conteniendo 60 comp. recubiertos 


\section{DIRECTORA}

Lucrecia María Burgos

Instituto Cardiovascular de Buenos Aires |CABA

SUBDIRECTORES

Franco Facciuto

Instituto Cardiovascular de Rosario | Santa Fe

Sebastián Srur

Sanatorio Mitre |CABA

JEFE DE REDACCIÓN

Andreína Gil Ramírez

Instituto Cardiovascular de Buenos Aires|CABA

COORDINADORES

Elián Facundo Giordanino

Fundación Favaloro |CABA

Sebastián García Zamora

Hospital de Alta Complejidad "El Cruce"

Buenos Aires

COMITÉ DE REDACCIÓN

Bruno Nicolás Acosta

Hospital Escuela de Corrientes |Corrientes

Belén Aguilar

Sanatorio Güemes | CABA

Cecilina Arnaudo

Sanatorio Mitre|CABA

Ivana Bolzán

Sanatorio Adventista del Plata | Entre Ríos

Maximiliano Echevarría

Hospital JM Cullen | Santa Fe

Fanny Fritz

Hospital Durand |CABA

Carolina Gálvez Gil

Hospital Fernández |CABA

Andrea Gil Plozzer

Hospital Naval |CABA

Florencia Giménez

Hospital JM Cullen |Santa Fe

Juan Pablo Guzmán

Hospital Británico |CABA

Martina Labaqui

Hospital Naval ICABA

Belén Leguizamón

Hospital JM Cullen |Santa Fe

Benjamín Litre

Sanatorio Mitre |CABA

Nahuel Litwak

Fundación Favaloro |CABA

Nadia Martínez

Sanatorio Güemes |CABA

Fernanda Petrucci

Hospital Fernández |CABA

Lucia Rossi

Hospital JM Cullen | Santa Fe

Federico Swedzky

Instituto Modelo de Cardiología | Córdoba

Carolina Yanzon

Sanatorio Adventista del Plata| Entre Ríos

TRADUCCIONES AL INGLÉS

María Isabel Ayala

Traductora Literaria y Técnico-Científica

COMITÉ ASESOR

Antonio Bayés de Luna

Profesor en Medicina. Investigador Senior - ICCC. Fundación de In vestigación Cardiovascular. Hospital Sta. Creu y St. Pau, Barcelona, España.
Juan José Badimon, Ph.D. FACC, FAHA

Profesor en Medicina. Director, Atherothrombosis Research Unit, Cardiovascular Institute New York. Icahn School of Medicine at Mount Sinai.

Adrián Baranchuk MD FACC FRCPC FCCS

Profesor en Medicina. Queen's University. Presidente, International Society of Electrocardiology. Editor-in-Chief, Journal of Electrocardiology.

Lina Badimon

Profesora en Medicina. Director Cardiovascular Research Center (CSIC-ICCC). Hospital de la Santa Creu i Sant Pau. Vicepresidente de la European Society of Cardiology.

Julio A. Panza

Jefe de Cardiologíay Profesor de Medicina, Westchester Medical Center/New YorkMedical College.

Andrés Pérez-Riera

Médico, Universidad Nacional de Córdoba (1973). Revalidación médico, Federal University of Goiás (1979). Residencia en Medicina Interna, Hospital de Clínicas, Córdoba (1974-1975). Residencia en Cardiología, Dante Pazzanese Institute, São Paulo, Brazil (1976-1977). Título Cardiólogo "Instituto do Coração" Brazil (InCor) (1978). Título Métodos Gráficos en Cardiología, "Instituto do Coração" (InCor) (1979). Master Degree, São Paulo School of Medicine - São Paulo Hospital - Graphic Methods Area in the Cardiology Chair (1980-1981). Degree of Specialist by proficiency test in Cardiology-Brazilian Society of Cardiology (1980). Medalla de oro y Diploma, Universidad de Córdoba.

Julián Segura

Jefe de la Unidad de Hipertensión Arterial. Servicio de Nefrología Hospital Universitario 12 de Octubre. Presidente de la Sociedad Española de Hipertensión-Liga Española para la Lucha contra la Hipertensión Arterial.

David Prieto-Merino

Associate Professor, London School of Hygiene \& Tropical Medicine. Director de la Cátedra de Análisis Estadístico y Big Data de la Universidad Católica de Murcia España.

Manlio F. Márquez

Departamento de Electrofisiología, Instituto Nacional de Cardiología "Ignacio Chávez," México D.F. Exvicepresidente de la Sociedad Latinoamericana de Estimulación Cardiacay Electrofisiología.

Fernando Peñafort

Cardiólogo universitario SAC UBA. Especialista en Electrofisiología. Universidad de la Plata SADEC. Jefe de Electrofisiología: Hospital Español de Mendoza. Clínica de Cuyo. Hospital Santa Isabel de Hungría. Médico de planta, Servicio de Cardiología. Hospital Lagomaggiore, Mendoza. Miembro titular de la Federación Argentina de Cardiología y Sociedad Argentina de Cardiología.

Daniel Piskorz

Presidente Federación Argentina de Cardiología 2017. Presidente Sociedad Argentina de Hipertensión Arterial 2011-2013. Director Centro de Investigaciones Cardiovasculares del Sanatorio BritánicoSA de Rosario.

Eduardo R. Perna

Jefe División de Insuficiencia Cardíaca e Hipertensión Pulmonar Unidad de Cuidados Intensivos Coronarios Instituto de Cardiología "J. F. Cabral", Corrientes. Argentina.

Mario Bendersky

Profesor titular Farmacología Aplicada UNC

Director maestría HTA, Univ Católica Córdoba. Jefe unidad HTA Inst. Modelo Cardiología, Cba.

Néstor A. Vita

Jefe de Cardiologia del Hospital Italiano de Rosario. Ex presidente de Federación Argentina de Cardiología.

Jorge Thierer

Jefe Unidad Insuficiencia Cardíaca CEMIC. Director Asociado

Revista Argentina de Cardiología

\section{Ricardo Iglesias}

Ex Presidente CONAREC Expresidente Sociedad Argentina de Cardiología. Expresidente Fundación Cardiológica Argentina. Fellow American College of Cardiology.

Hernán C. Doval

Médico de Cardiología del Htal. Italiano de Bs. As. Director de la Revista Argentina de Cardiología.

Carlos Taje

Jefe de Cardiología Hospital El Cruce. Expresidente Sociedad Ar gentina de Cardiología.

Hugo Grancelli

Jefe del Servicio de Cardiología del Sanatorio Finochietto Director Carrera de Especialista en Cardiología. Universidad de Buenos Aires. Expresidente de la Sociedad Argentina de Cardiología.

José Horacio Casabé FACC, PhD

Jefe de Cardiología ICYCC. Hospital Universitario Fundación Favaloro. Miembro titular Sociedad Argentina de Cardiología. Laura Schreier

Doctora en Bioquímica, Profesora Titular Facultad de Farmacia y Bioguímica-UBA Jefe del Laboratorio de Lípidos y Aterosclerosis y Directora del Departamento de Bioquímica Clínica, Hospital de Clínicas, UBA. Secretaria Asuntos Internacionales de Sociedad Argentina de Lípidos, Miembro Comité Asesor del Consejo de Aterosclerosis y Trombosis, Sociedad Argentina de Cardiología.

Martín Donato

Profesor en Medicina. Instituto de Fisiopatología Cardiovascular. Facultad de Medicina, Universidad de Buenos Aires. Investigador CONICET

Alejandro Macchia

Fundación GESICA.

Roberto Héctor lermoli

Profesor en Medicina. Director de Docencia e Investigación, Hospital de Clínicas, UBA. Director del Dpto. de Medicina, Facultad de Medicina, UBA

Raul Borracci

Profesor de Bioestadística, Facultad de Ciencias Biomédicas, Universidad Austral. Servicio de Cirugía Cardiovascular, Facultad de Medicina, UBA. Director Adjunto de la Revista Argentina de Cardiología. Coordinador del Comité de Bioética de la Sociedad Argentina de Cardiología.

Hernán Cohen Araz

Cardiólogo CEMIC y centro médico Pilares. Magister en Efectividad Clínica y Sanitaria. Miembro titular, integrante del área de investigación y exdirector del Consejo de Emergencias Cardiovasculares. Sociedad Argentina de Cardiología. Exjefe de Cardiología FLENI.

COORDINADOR REVISIÓN ANUAL

Guillermo R. Chiappero

Hospital Fernández|CABA

MIEMBROS HONORARIOS

Dr. René Favaloro +

Dr. Carlos Bertolasi +

Dr. Arnaldo Angelino

SECRETARIA CONAREC

Mariela Tolcachier

Tel: (011) 1536772989

secretariaconarec@yahoo.com.ar

CORRESPONDENCIA

www.revistaconarec.com.a

conarecrevista@gmail.com

SEDE SOCIAL

Azcuénaga 980 - CABA 


\section{AUTORIDADES - CONAREC 2018}

\section{PRESIDENTE}

Sebastián García Zamora

Hospital de Alta Complejidad en Red "E

Cruce"

VICEPRESIDENTE

Hernán Pulenta

Hospital Lagomaggiore | Mendoza

TESORERA

Eliane Sasovsky

Trinidad Mitre |CABA

PROTESORERO

Pablo Schmidt

Sanatorio Güemes |Chaco

SECRETARIO

Emmanuel Scatularo

Fundación Favaloro $\mid C A B A$

PROSECRETARIO

Mariano Visconti

Instituto de Cardiología de Corrientes

VOCALES

\section{CABA y Gran Buenos Aires}

Macarena Cousirat Liendro

Clínica Bazterrica |CABA

Matías Anuati

UAI $\mid C A B A$

María Esperanza Raimundo

Malvinas Argentinas | Gran Buenos Aires

Chaco

Matías Villacorta

Sanatorio Güemes
Víctor Ramírez

Clínica del Valle

Córdoba

Cintia Sánchez

Sanatorio Allende

\section{Corrientes}

Mariana Andrea Candia

Instituto de Cardiología de Corrientes

Entre Ríos

Iván Vilar Evequoz

Hospital San Martin de Paraná

Formosa

Norali Miranda

Hospital de Alta Complejidad "Juan Domingo Perón"

Jujuy

Carolina Galarza

Sanatorio Nuestra Señora del Rosario

La Rioja

Juan Santillán

NCOR

\section{Mendoza}

Romano Trionfi

Hospital Español

Misiones

Angelo Zubrzycki

Hospital SAMIC El Dorado

\section{Neuquén}

Soledad Orazi

Hospital Provincial Neuquén

Rosario

María del Carmen Salvia

Hospital Provincial

Salta

Valentina Botelli

Hospital San Bernardo

\section{San Juan}

Carolina Robles

ICVO (Instituto Cardiovascular del Oeste)

\section{Santa Fe}

Leonel Moyano

Sanatorio Cullen

DIRECTORA REVISTA

Lucrecia Burgos

Instituto Cardiovascular de Buenos Aires |

CABA

SUBDIRECTORES

Franco Facciuto

Instituto Cardiovascular de Rosario I Santa Fe

Sebastián Srur

Sanatorio Mitre $\mid$ CABA

PÁGINA WEB

Director: Lin YuShan

Hospital Durand |CABA

Subdirector (CABA): Juan Pablo Cattáneo Sagrado Corazon | CABA

\section{COMITÉ CIENTÍFICO}

Ana Lía Gamarra

Hospital Italiano de Buenos Aires |CABA

Paula Berlien

Hospital "I. M. Cullen" | Santa Fe

Alan Sigal

Instituto Cardiovascular de Buenos Aires

CABA

ÓRGANO DE FISCALIZACIÓN

Y PERMANENCIA

Ignacio Cigalini

Instituto Cardiovascular de Buenos Aires | CABA

Darío lgolnikof

Hospital Austral | Buenos Aires

STAFF

Mariela Tolcachier

Secretaria Presidencia

\section{SEDES DE JORNADAS}

$\begin{array}{ll}\text { 1980: I } & \text { Buenos Aires } \\ \text { 1981: II } & \text { Buenos Aires } \\ \text { 1982: III } & \text { Buenos Aires } \\ \text { 1983: IV } & \text { Buenos Aires } \\ \text { 1984:V } & \text { Buenos Aires } \\ \text { 1985: VI } & \text { Buenos Aires } \\ \text { 1986: VII } & \text { Rosario } \\ \text { 1988: IX } & \text { San Juan } \\ \text { 1990:X } & \text { Buenos Aires } \\ \text { 1991: XI } & \text { Buenos Aires } \\ \text { 1992: XII } & \text { Córdoba } \\ \text { 1994: XIV } & \text { Rosario }\end{array}$

$\begin{array}{ll}\text { 1995: XV } & \text { Mendoza y San Juan } \\ \text { 1996: XVI } & \text { Tucumán } \\ \text { 1997: XVII } & \text { Corrientes } \\ \text { 1998: XVIII } & \text { San Juan } \\ \text { 1999: XIX } & \text { Buenos Aires } \\ \text { 2000: XX } & \text { Córdoba } \\ \text { 2001: XXI } & \text { Rosario } \\ \text { 2002: XXII } & \text { Entre Ríos } \\ \text { 2003: XXIII } & \text { Tucumán } \\ \text { 2004: XXIV } & \text { Corrientes } \\ \text { 2005: XXV } & \text { Córdoba } \\ \text { 2006: XXVI } & \text { San Juan }\end{array}$

$\begin{array}{ll}\text { 2007: XXVII } & \text { Buenos Aires } \\ \text { 2008: XXVIII } & \text { La Rioja } \\ \text { 2009: XXIX } & \text { Mendoza } \\ \text { 2010: XXX } & \text { Jujuy } \\ \text { 2011: XXXI } & \text { Córdoba } \\ \text { 2012: XXXII } & \text { Santa Fe } \\ \text { 2013: XXXIII } & \text { Rosario } \\ \text { 2014: XXXIV } & \text { Mar del Plata } \\ \text { 2015: XXXV } & \text { Mendoza } \\ \text { 2016: XXXVI } & \text { Rosario } \\ \text { 2017: XXXVII } & \text { Santa Fe }\end{array}$

\section{e conAREC}

\section{Fundada en 1985 por el Dr. Arnaldo Adrián Angelino}

\section{Publicación bimestral. @ CONAREC}

Registro de la Propiedad Intelectual № 572790. Reservados todos los derechos. Ninguna parte de esta publicación puede ser reproducida en forma o medio alguno, electrónico o mecánico, incluyendo fotocopias, grabaciones y otros sistemas de información sin la autorización por escrito del titular del Copyright.

ISSN: 0329-0433 | ISSN: 1853-2357 (en línea). Propietario: Consejo Nacional de Residentes de Cardiología (CONAREC). Se distribuye exclusivamente entre los profesionales de la medicina. Es una publicación del CONAREC, Azcuénaga 980 C1122AAJ |Ciudad Autónoma de Buenos Aires.

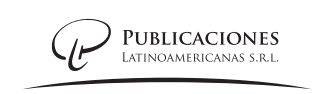

PRODUCCIÓN EDITORIAL, COMERCIAL Y GRÁFICA

PUBLICACIONES LATINOAMERICANAS S.R.L.

Piedras $13332^{\circ} \mathrm{C}$ C1240ABC Ciudad Autónoma de Buenos Aires | Argentina tel/fax (5411) 5217-0292 | e-mail info@publat.com.ar | http://www.publat.com.ar 


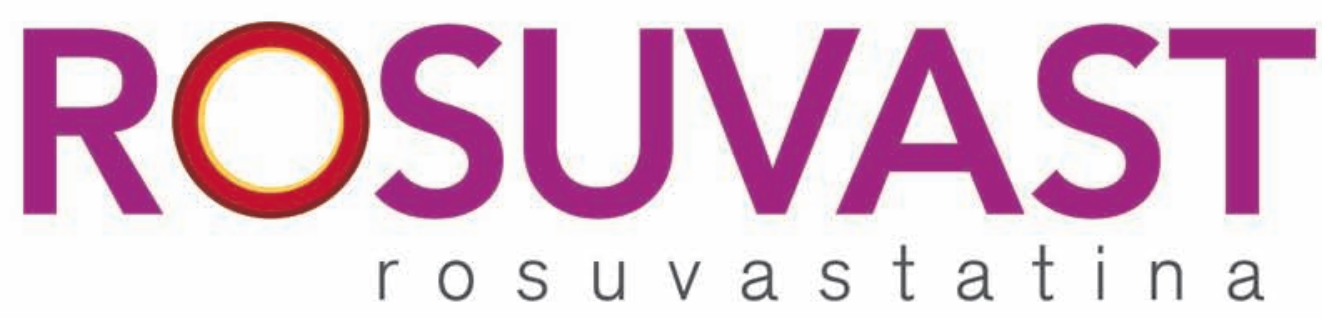

\section{Una categoría superior en estatinas, con máxima efectividad.}

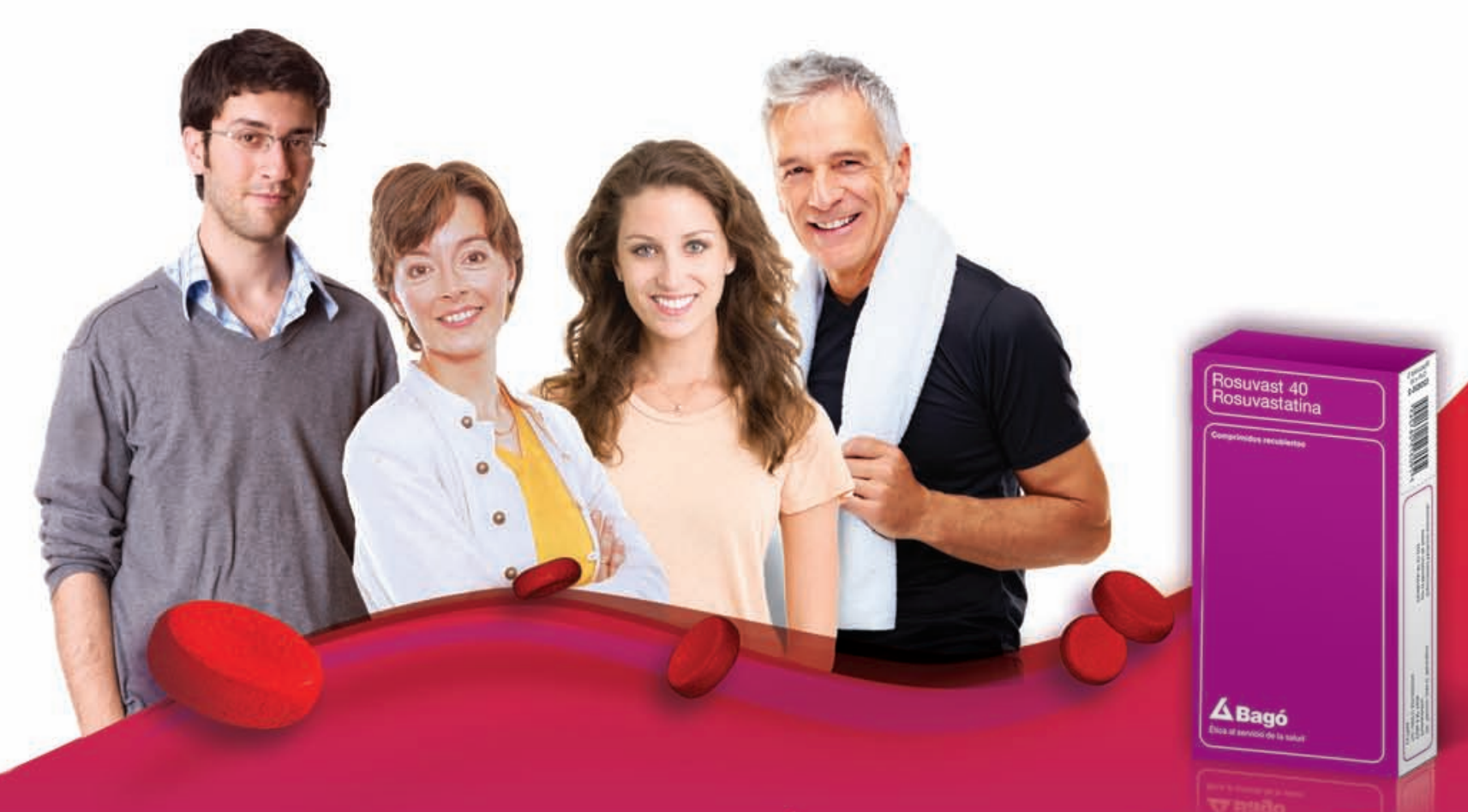

Rosuvast 10 mg: comprimidos $\times 14,28$ y 56.

Rosuvast 5/20/40 mg: comprimidos $\times 28$.
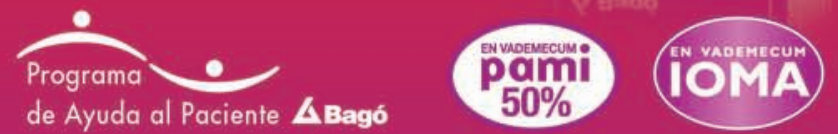

Composición: Cada comprimido recubierto contiene: Rosuvastatina 5, 10, 20 ó $40 \mathrm{mg}$. Acción Terapéutica: Inhibidor de la HMG-COA reductasa. Indicaciones: Hiperlipidemia y Dislipidemia Mixta. Hipertrigliceridemia. Disbetalipoproteinemia primaria (Hiperlipoproteinemia Tipo III). Hipercolesterolemia Familiar Homocigota. Enlentecimiento de la Progresión de la Aterosclerosis. Prevención de eventos cardiovasculares. Posologia: 5 a $40 \mathrm{mg}$ una vez por dia por via oral, con o sin alimentos; $40 \mathrm{mg}$, solo si no se alcanza el objetivo de colesterol-LDL con $20 \mathrm{mg}$. Dosis inicial habitual: $10 \mathrm{mg} / \mathrm{dia}$. Marcada hiperlipidemia y objetivos terapéuticos agresivos, dosis inicial: $20 \mathrm{mg}$. Los niveles lipidicos deben analizarse dentro de las 2 a 4 semanas y la dosis debe ajustarse. Hipercolesterolemia familiar homocigota dosis inicial $20 \mathrm{mg} /$ dia. Pacientes asiáticos: dosis inicial $5 \mathrm{mg} /$ dia. Con ciclosporina: limitar dosis a $5 \mathrm{mg}$ /dia. Con lopinavir y ritonavir: limitar dosis a $10 \mathrm{mg} / \mathrm{dia}$. Con niacina o fenofibrato: reducir la dosis. Con /dia. Con lopinavir y ritonavir: limitar dosis a $10 \mathrm{mg} /$ dia. Con niacina o fenofibrato: reducir la dosis. Con
gemfibrozil: $10 \mathrm{mg} /$ dia. Insuficiencia renal severa (no en hemodialisiss); inicial: $5 \mathrm{mg}$; no exceder $10 \mathrm{mg} / \mathrm{dia}$. Contraindicaciones: Hipersensibilidad a cualquier componente; enfermedad hepática activa o elevaciones persistentes inexplicables de transaminasas séricas; embarazo y lactancia. Advertencias y Precauciones: Se recomiendan pruebas de función hepática antes y a las 12 semanas del inicio $o$ al aumentar la dosis y semestralmente. Casos de rabdomiólisis con insuficiencia renal aguda debido a mioglobinuria, que aumentan con la dosis más alta. Precaución en pacientes con factores predisponentes para miopatia (deterioro renal, edad avanzada, hipotiroidismo tratado inadecuadamente). Discontinuar si se observan niveles elevados de creatina quinasa, o si se diagnostica o se sospecha una miopatia o si se presenta

una condición aguda (por ejemplo, sepsis, hipotensión, deshidratación, cirugía mayor, trauma, trastomos metabólicos, endocrinos o electroliticos severos, convulsiones no controladas). Advertir al paciente que informe de inmediato dolor. sensibilidad o debilidad muscular inexplicable, malestar o fiebre. Precaución con anticoagulantes cumarinicos, ketoconazol, espironolactona, y cimetidina. Considerar reducción de dosis en caso de proteinuria y/o hematuria persistentes inexplicables. Interacciones: Antiäcido combinado de hidróxido de magnesio y aluminio: ingerir al menos 2 horas después de Rosuvast. Reacciones adversas: Anormalidades de las enzimas hepáticas, rabdomiólisis con mioglobinuria y falla renal aguda y miopatia (incluyendo miositis). Condujeron a la discontinuación: náusea, mialgia, dolor abdominal. Informadas con mayor frecuencia ( $2 \%$ ): cefalea, mialgia, dolor abdominal, astenia, náuseas, Post-comercialización: artralgia, hepatitis, ictericia y pérdida de la memoria. Presentaciones: Rosuvast 10: Envases conteniendo 14,28 y 56 comprimidos recubiertos. Rosuvast 20: Envase conteniendo 28 comprimidos recubiertos. Rosuvast 5 y 40: Envases conteniendo 28 comprimidos recubiertos

Especialidad Medicinal autorizada por el Ministerio de Salud. Certificado $N^{\circ} 51.203$

Información completa para prescribir. consultar el prospecto (www.bago.com.ar) o comunicarse con Laboratorios Bagó S.A. - Información de Productos Departamento Médico: (011) 4344-2216 infoproducto@bago.com.ar 
CIUDAD AUTÓNOMA DE BUENOS AIRES Hospital General de Agudos Ramos Mejía Complejo Médico Policial "Churruca-Visca" Hospital Británico de Buenos Aires

Sanatorio "Sagrado Corazón"

Hospital Universitario Fundación Favaloro

Hospital Español (Univ. Abierta Interamericana)

Hospital General de Agudos Durand

Hospital General de Agudos Rivadavia

Hospital Alemán

Hospital Naval Buenos Aires P. Mallo

Sanatorio de la Trinidad Mitre

Sanatorio Municipal "Dr. Julio Méndez"

Sanatorio Otamendi y Miroli

Sanatorio Colegiales

Hospital General de Agudos Santojanni

Hospital de Clínicas "José de San Martín"

Sanatorio Güemes

Hospital Militar Central

Instituto Denton Cooley

Sanatorio Centro Gallego

Hospital General de Agudos Argerich

Policlínico Bancario

Hospital César Milstein

Clinica Bazterrica

Clinica Santa Isabel

Hospital Italiano de Buenos Aires

Instituto Cardiovasc. de Buenos Aires "ICBA"

Hospital General De Agudos Fernández

Hospital Aeronáutico Central

GRAN BUENOS AIRES

Hospital Central de San Isidro

Sanatorio Modelo Quilmes

Hptal. Gral. de Agudos "Eva Perón" (Ex Castex)

Hospital Interzonal de Agudos Gandulfo

Hospital "Juan D. Perón" - Malvinas Argentinas

Hospital Universitario Austral

Clínica IMA - Adrogué

Hospital Municipal "Dr. Larcade"- San Miguel

Sanatorio San Miguel

Hospital Nacional Posadas

(Ex Finochietto) CHUBU

Hospital Interzonal Gral de Agudos Evita - Lanús Clínica del Valle

Hospital El Cruce - Florencio Varela

CATAMARCA

$\mathrm{CHACO}$

de Urgencias

CÓRDOBA

Clínica Chutro

Clínica Sucre

\section{PROVINCIA DE BUENOS AIRES}

Htal Gral de Agudos"J. de San Martín" - La Plat Htal de Ag. y Crónicos "S. J. de Dios" - La Plata Htal Gral de Agudos "R. Rossi" - La Plata

Htal Gral de Agudos"O. Alende"- Mar del Plata Htal Privado de la Comunidad - Mar Del Plata

Htal Gral de Agudos "J. Penna"- Bahía Blanca

Clinica Privada Fumeba - Hospital Privado del

Sur - Bahía Blanca

Hospital San Nicolás de los Arroyos

Htal Gral Agudos Dr. Paroissien - I. Casanova

Instituto de Cardiología Intervencionista

Instituto del Corazón "CORDIS"

Gran Hospital Dr. Julio C. Perrando

Sanatorio Güemes

Centro Cardiovascular del Nordeste - Clínica

Clínica Privada Vélez Sarfield

Clínica Universitaria Reina Fabiola

Hospital Italiano de Córdob

Instituto Modelo de Cardiología

Sanatorio Allende

Sanatorio Mayo

Hospital Córdoba

Instituto Modelo de Cardiología Privado

Hospital Aeronáutico Córdoba

Hospital Privado Centro Médico de Córdoba

Hospital "San Roque"

Clínica Romagosa

Sanatorio del Salvador

Sanatorio Parque

Clínica Fusavim Privada

Clínica Privada de Especialidades - Villa María Instituto Médico Río Cuarto

Maria San

Instituto De Cardiologia Juana Francisca Cabral Sanatorio Británico

Hospital Escuela "José Francisco foris San Martín" Sanatorio Delta

Sanatorio Rosendo García

Sanatorio Parque

Sanatorio Adventista del Plata Sanatorio Los Alerces

FORMOSA

Hospital de Alta Complejidad “Juan D. Perón” SANTA FE

JUJUY

Sanatorio Nuestra Señora del Rosario

LA RIOJA

Instituto del Corazón (INCOR)

Clinica Privada E.R.

MENDOZA

Hospital Central

Hospital Españo

Hospital Italiano

Sociedad Española De Socorros Mutuos

Hospital Luis Carlos Lagomaggiore

Hospital Del Carmen

MISIONES

Hospital Dr Guillermo Rawson

dariaga Hospital "Dr. Marcial V. Quirog

NEUQUÉN

Hospital Provincial Neuquén Castro Rendón

RÍO NEGRO

Instituto Cardiovascular Del Sur

Sanatorio Juan XXIII

ROSARIO

Hospital Provincial De Rosario

Hospital Provincial Del Centenario

Sanatorio Los Arroyos

Sanatorio Plaza

Instituto Cardiovascular De Rosario

Hospital De Emergencias Clemente Alvarez

Instituto de Cardiología "González Sabathie"

Centro Materno Infantil Htal Italiano Garibaldi
Clínica de Nefrología, Urología y Enfermedades Cardiovasculares

Sanatorio Privado San Gerónimo

Sanatorio Médico de Diagnóstico y Tratamiento

Hospital Proviencial "J.M. Cullen"

Instituto Privado de Cardiología"Sagrada

Familia"

Sanatorio Mayo

Sanatorio Santa Fe

Sanatorio San Martín

Sanatorio Nosti

SALTA

Hospital "San Bernardo"

SAN JUAN

Centro Integral de Medicina de Alta Complejidad (Clinica El Castaño)

SANTIAGO DEL ESTERO

Centro Cardiovascular Clinica Yunes

Sanatorio Instituto de Cardiologia

TUCUMÁN

Inst. Tucumán de Enfermedades del Corazón Instituto de Cardiología de Tucumán

Hospital Centro De Salud Zenon J Santillan

Cardiología del Parque

Sanatorio 9 de Julio

Centro Modelo de Cardiología

Centro Privado de Cardiología

\section{MIEMBROS HONORARIOS}

Dr. Atdemar Álvarez +

Dr. Carlos Benjamín Álvarez

Dr. Roberto Basile

Dr. César Belziti

Dr. Carlos Bertolasi +

Dr. Daniel Boccardo

Dr. Arturo Cagide

Dr. Ramiro Castellanos

Dr. Carlos Crespo

Dr. Miguel Del Río

Dr. Hernán Doval

Dr. René Favaloro +

Dr. Francisco Gadaleta
Dr. Joaquín García
Dr. Hugo Grancelli
Dr. Pablo Heredia
Dr. Juan Humphreys
Dr. Ricardo Iglesias
Dr. Juan Krauss
Dr. Jorge Lerman
Dr. José Martínez Martínez +
Dr. Osvaldo Masoli
Dr. José Milei
Dr. Raúl Oliveri

Dr. Igor Palacios

Dr. Néstor Pérez Baliño

Dr. Horacio Pomes Iparraguirre

Dr. Rubén Posse +

Dr. Luis Pozzer

Dr. Osvaldo Robiolo

Dr. César Serra

Dr. Carlos Tajer

Dr. Jorge Trongé

Dr. Alejandro De Cerccio

Dr. Jorge Thierer

\section{COMITÉ ASESOR}

Dr. Andrés Ahuad Guerrero

Dr. Raúl J. Bevacqua

Dr. Rafael Cecch

Dr. Jorge González Zuelgaray

Dr. Hugo Grancelli

Dr. Delfor Hernández

Dr. José Hidalgo

Dr. Gabriel Martino

Dra. Margarita Morley

Dra. Viviana Perugini

\section{EXPRESIDENTES}

1982: Dr. Francisco Gadaleta

1983: Dr. Enrique Retyk

1984: Dr. Ricardo Iglesias

1985: Dr. Juan José Nasif

1986: Dr. Arnaldo Angelino

1987: Dr. Raúl J. Bevacqua

1988: Dr. Andrés Ahuad Guerrero

1989: Dr. Rafael Cecchi

1990: Dra. Viviana Perugini

1991: Dr. Rodolfo Sansalone
1992: Dra. Gladys Aranda 1993: Dr. Gerardo Bozovich

1994: Dr. Alejandro Cherro

1996: Dr. Sergio Baratta

1997: Dr. Félix Paredes

1998: Dr. Marcelo E. Halac

1999: Dr. Pablo Perel

2000: Dr. Esteban Ludueña Clos

2001: Dr. Juan Arellano

2002: Dra. Mariana Pizzella
2003: Dr. Marcelo M. Casas 2004: Dr. Humberto Bassani Molinas 2005: Dr. Martín Descalzo 2006: Dr. Bruno Linetzky 2007: Dr. Juan Cruz López Diez 2008: Dr. Fernando Guardiani 2009: Dr. Diego Lowenstein 2010: Dr. Pablo Pieroni

2011: Dr. Gonzalo Pérez 2012: Dr. Nicolás González
2013: Dr. Ezequiel Zaide

2014: Dr. Matías Galli

2015: Dr. Luciano Fallabrino

2016: Dr. Darío Igolnikof

2017: Dr. Ignacio Cigalini 


\section{SUMMARY}

REVISTA CONAREC 2018;33(147):271 | DOI:10.32407/RCON/2018147/0271-0271

EDITORIAL | EDITORIAL

CURIOSIDAD, INVESTIGACIÓN Y CONOCIMIENTO

CURIOSITY, RESEARCH AND KNOWLEDGE

Lucrecia M. Burgos

\section{REVISIÓN POR EXPERTOS | EXPERT REVIEW}

SOPORTE CIRCULATORIO MECÁNICO CON BOMBA

CENTRÍFUGA

MECHANICAL CIRCULATORY SUPPORT WITH CENTRIFUGAL PUMP

Alejandro M. Bertolotti

REVISIÓN ANUAL | ANNUAL REVIEW

VENTILACIÓN NO INVASIVA EN EL TRATAMIENTO DE LA INSUFICIENCIA CARDÍACA

NONINVASIVE VENTILATION IN THE TREATMENT OF HEART FAILURE

Diego A. Márquez, Guillermo R. Chiappero

MONOGRAFÍA SELECCIONADA I SELECTED MONOGRAPH

DESAFÍOS ESTRATÉGICOS EN INSUFICIENCIA CARDÍACA AVANZADA. ASISTENCIA VENTRICULAR. ¿ESTÁ TODO DICHO?

STRATEGIC CHALLENGES IN ADVANCED HEART FAILURE. VENTRICULAR ASSISTANCE. IS IT ALL SAID?

Jimena Santillán

\section{ARTÍCULOS ORIGINALES | ORIGINAL ARTICLES}

GRADIENTE POSQUIRÚRGICO EN PACIENTES CON REEMPLAZO VALVULAR AÓRTICO Y SU ASOCIACIÓN CON EVENTOS CARDIOVASCULARES

POST-SURGICAL GRADIENT IN PATIENTS WITH AORTIC VALVE REPLACEMENT AND ITS ASSOCIATION WITH CARDIOVASCULAR EVENTS

Natalia Chattich, Marilin Traviesa, Yanet Parisi, Alejandro López Rigo,

Sheila Y. Fernández, Mariana Candia

FACTORES DE RIESGO CARDIOVASCULAR EN RESIDENTES Y CARDIÓLOGOS ARGENTINOS. "CÓMO SE CUIDAN LOS QUE CUIDAN". ENCUESTA FRICCAR, CONAREC

CARDIOVASCULAR RISK FACTORS IN ARGENTINE RESIDENTS AND CARDIOLOGISTS.

"HOW TO CARE FOR THOSE WHO PROVIDE CARE". FRICCAR SURVEY, CONAREC Hernán Pulenta, Lucrecia M. Burgos, Ignacio Cigalini, Daniel Lorenzatti, Iván Vilar, Mauro Rossi Prat, Franco Giannasi, Elisa Ortiz, Agustín Roude,

Sebastián García-Zamora

\section{INFARTO AGUDO DE MIOCARDIO CON ELEVACIÓN} DEL SEGMENTO ST: PREVALENCIA DE ARTERIA SEGÚN EL SEXO ST-SEGMENT ELEVATION MYOCARDIAL INFARCTION: PREVALENCE OF ARTERY ACCORDING TO GENDER

Alfredo Astesiano, Nicolás F. Renna, María J. Torres, Rodrigo García, Mariano Grucci, Alberto G. Villasís, Marcia Zuloaga Puglisi, Romano M. Trionfi

CASOS CLÍNICOS | CLINICAL CASES

TRONCO CORONARIO ÚNICO QUE NACE DEL SENO CORONARIO DERECHO

SINGLE LEFT MAIN CORONARY ARTERY THAT IS BORN FROM THE RIGHT CORONARY SINUS

Carolina Chacon, Mauricio Priotti, Mariana Domanico, Francisco Ara, Nicolás Ferreri, Cintia Foco, Estefanía Peretti, Manuel Traghetti

CAUSA INFRECUENTE DE INFARTO ANTERIOR: HEMATOMA POR DISECCIÓN AÓRTICA

RARE CAUSE OF ANTERIOR INFARCTION: HEMATOMA BY AORTIC DISSECTION Luisa Hsu, Flavio Delfino, Leonardo Cáceres, Fernando Pinto, Agostina Barsotti, Francisco Saltos, Lisandro Olguín, Santiago Guelerman, Melisa Cuschie

IMÁGENES EN CARDIOLOGÍA | IMAGES IN CARDIOLOGY

PERICARDITIS CONSTRICTIVA ASOCIADA

A MIOCARDIOPATÍA CHAGÁSICA

CONSTRICTIVE PERICARDITIS ASSOCIATED WITH CHAGASIC CARDIOMYOPATHY

Evelyn C. Wong, Lucas Angiono, Jeremías Dorsch, Leonardo Pintor, Sergio Blanco, Enrique Morral, Flavio Tomán

GUÍAS CONAREC | CONAREC GUIDELINES

ALGORITMO DE MANEJO LIPÍDICO EN EL PACIENTE

CON SÍNDROME CORONARIO AGUDO

LIPID MANAGEMENT ALGORITHM IN PATIENT WITH ACUTE CORONARY SYNDROME

Juan Ignacio Damonte, Mateo Anquiz, Juan Manuel Domínguez, Luciano N. Fallabrino, Walter Masson Juárez, Pablo Corral, Juan José Badimon

REGLAMENTO DE PUBLICACIONES | RULES OF PUBLICATIONS 


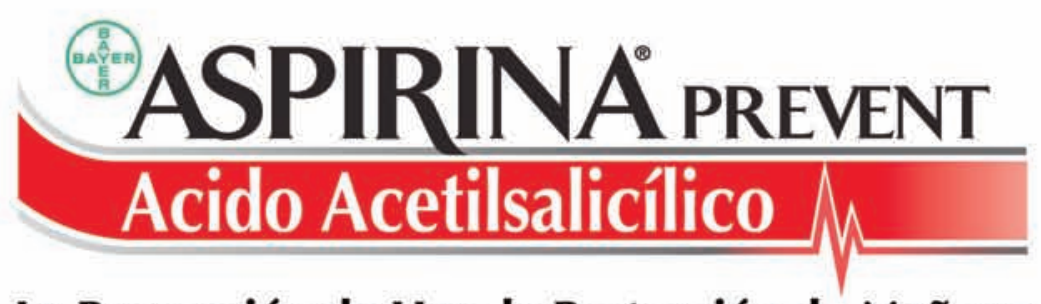

\section{La Prevención de Hoy, la Protección de Mañana}

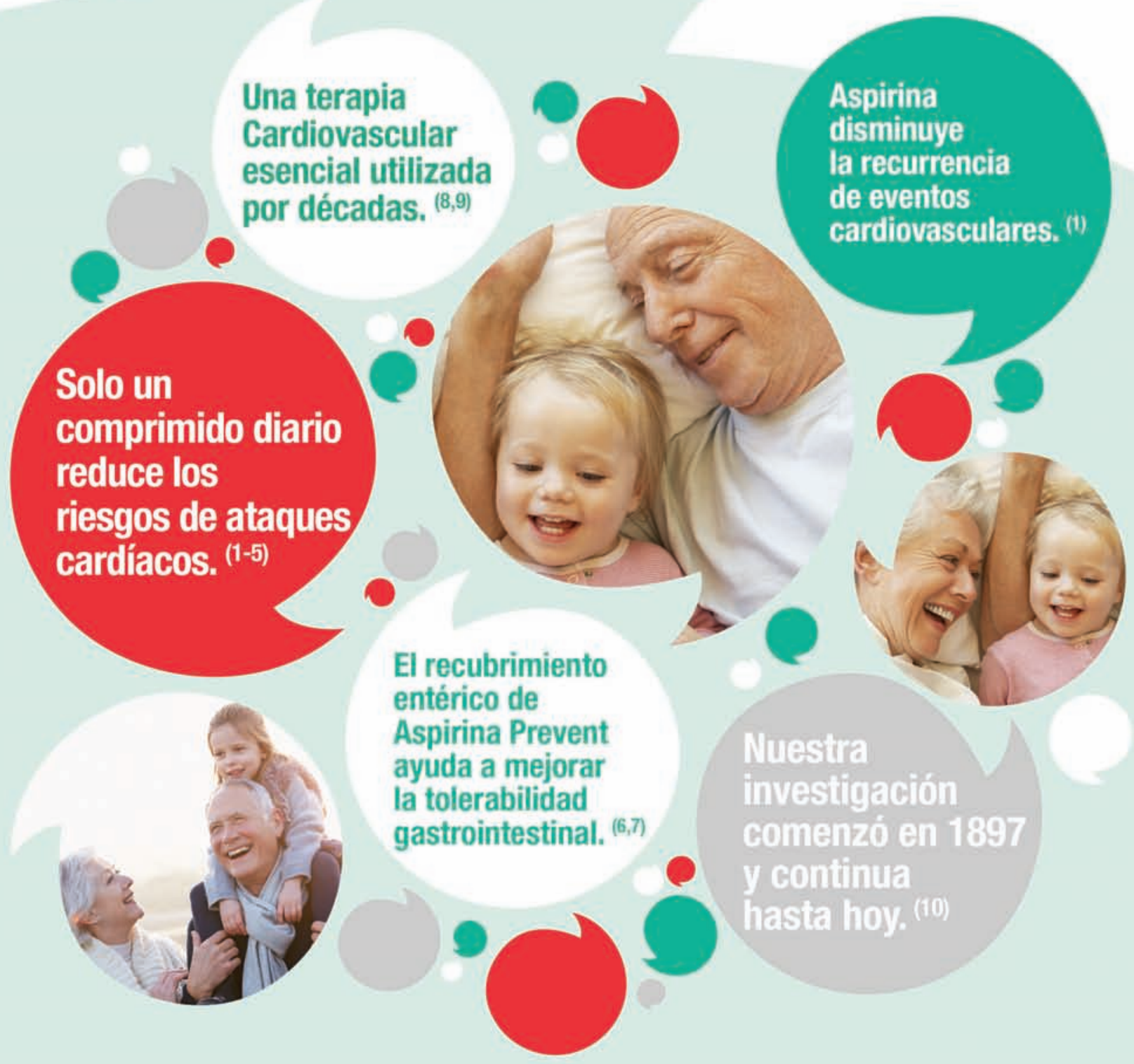

REFERENCLAS: 1. Antithrombotic Trialists' (ATT) Collaboration. Aspirin in the primary and secondary prevention of vascular disease: collaborative meta- analysis of individual participant data from randomised trial. Lancet 2009;373:1849-60. 2. Antithrombotic Trialist' (ATT) Collaboration. Collaborative meta- analysis of randomised trials of antiplatelet therapy for prevention of death, myocardia Infarction, and stroke in high risk patents. BMJ 2002;324 (7329):71-86. 3. BartolucciAA. Tendera M and Howard G. Meta- analysys of multiple primary prevention trials of cardiovascular events using aspirin. Am J Cardiol 2011; 107: 1796-801. 4. Ryden L, Frant PJ, Anker SD et al, ESC Guidelines on diabetes, pre-diabetes, and cardiovascular diseases developed in collaboration with the EASD: the Task Force on diabetes, pre- diabetes, and cardiovascular diseases of the European Society of Cardiology (ESC) and developed in collaboration with the European Association for the Study of Diabetes (EASD) Eur Heart 2013; J34: 3035-87. 5. Bayer Aspirin Cardio SmPC. Baver Healthcare 6. Banoob DW, McCloskey WW, Webster W. Risk of Gastric Injury with Enteric-Versus Noonenteric- Coated Aspirin. Ann Phat streptok 1988;2:349-60. 9. Baigent C, Collins R, Apple by P, et al. ISIS-2: 10 year survival among patents with suspected acute myocardial infarction in randomised comparison of intervenous streptokinase,

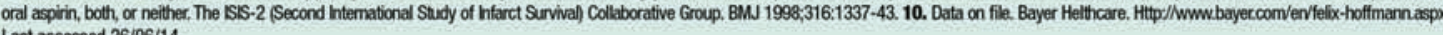
Last accessed 26/06/14.

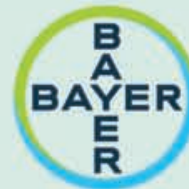




\section{(-ASPIRINÄ PREVENT Acido Acetilsalicílico -}

ASPIRINA PREVENT. COMPOSICIÓN Cada comprimido con cubierta entérica contiene: Ácido acetilsalicilico: 100 mg / 350mg. INDICACIONES 100mg: Reducción del riesgo de mortalidad en pacientes con sospecha de infarto agudo de miocardio. Reducción del riesgo de morbilidad y mortalidad en pacientes con antecedentes de infarto de miocardio. Reducción del riesgo de un primer episodio de infarto de miocardio en pacientes con factores de riesgo cardiovascular, p.ej. diabetes mellitus, hiperlipidemia, hipertensión, obesidad, fumadores, tercera edad. Prevención secundaria de accidentes cerebrovasculares. Reducción de riesgo de ataques isquémicos transitorios (TIA) y accidentes cerebrovasculares en pacientes con TIA. Reducción de riesgo de morbilidad y muerte en pacientes con angina de pecho estable o inestable. Prevención de tromboembolias luego de una cirugia vascular o intervenciones, p.ej. PTCA, endarterectomía carotidea, shunts arteriovenosos. Profilaxis de trombosis venosas profundas y embolias pulmonares luego de inmovilizaciones prolongadas, p.ej. Iuego de cirugias mayores. INDICACIONES $350 \mathrm{mg}$ : Reducción del riesgo de mortalidad en pacientes con sospecha de infarto agudo de miocardio. Reducción del riesgo de morbilidad y mortalidad en pacientes con antecedentes de infarto de miocardio. Reducción del riesgo de un primer episodio de infarto de miocardio en pacientes con factores de riesgo cardiovascular, p.ej. diabetes mellitus, hiperlipidemia, hipertensión, obesidad, fumadores, tercera edad. Prevención secundaria de accidentes cerebrovasculares. Reducción de riesgo de ataques isquémicos transitorios (TIA) y accidentes cerebrovasculares en pacientes con TIA. Reducción de riesgo de morbilidad y muerte en pacientes con angina de pecho estable o inestable. Prevención de tromboembolias luego de una cirugla vascular 0 intervenciones, p.ej.PTCA, endarterectomla carotidea, derivaciones arteriovenosas. Profilaxis de trombosis venosas profundas y embolias pulmonares luego de inmovilizaciones prolongadas, p ej. luego de cirugias mayores. POSOLOGIA Y FORMA DE ADMINISTRACIÓN $100 \mathrm{mg}$ : Salvo otra indicación médica, se recomienda en adultos la siguiente dosificación. Para reducir el riesgo de mortalidad en pacientes con sospecha de infarto agudo de miocardio: dosis inicial es de 200 a $300 \mathrm{mg}$ administrada tan pronto como se sospeche el IM. En caso de utilizarse en esta indicación, la aspirina con recubrimiento gastrorresistente deberá triturarse o masticarse para lograr una absorción más rápida. Para reducir el riesgo de morbilidad y mortalidad en pacientes con antecedentes de infarto de miocardio; para prevención secundaria de accidentes cerebrovasculares; para reducir el riesgo de ataques isquémicos transitorios (TIA); para reducir el riesgo de morbilidad y muerte en pacientes con angina de pecho estable o inestable; para prevención de tromboembolias luego de una cirugía vascular o intervenciones: 100 a $300 \mathrm{mg}$ por dia. Para reducir el riesgo de un primer episodio de infarto de miocardio en pacientes con factores de riesgo cardiovascular y para profilaxis de trombosis venosas profundas y embolias pulmonares luego de inmovilizaciones prolongadas: 100 a $200 \mathrm{mg}$ por dia o $300 \mathrm{mg}$ dia por medio. POSOLOGIA Y FORMA DE ADMINISTRACIÓN $350 \mathrm{mg}$ : Salvo otra indicación médica, se recomienda en adultos la siguiente dosificación. Para reducir el riesgo de mortalidad en pacientes con sospecha de infarto agudo de miocardio: 325 mg por día. La dosis de mantenimiento es de $325 \mathrm{mg}$ todos los dias hasta 30 dias posterior al infarto. Luego de los 30 dias deberá tenerse en cuenta la terapia adicional suministrada para evitar un nuevo infarto de miocardio. Para reducir el riesgo de morbilidad y mortalidad en pacientes con antecedentes de infarto de miocardio, para prevención secundaria de accidentes cerebrovasculares; para reducir el riesgo de ataques isquémicos transitorios (TIA); para reducir el riesgo de morbilidad y muerte en pacientes con angina de pecho estable o inestable; para prevención de tromboembolias luego de una cirugia vascular o intervenciones: $325 \mathrm{mg}$ por dia. Para reducir el riesgo de un primer episodio de infarto de miocardio en pacientes con factores de riesgo cardiovascular y para profilaxis de trombosis venosas profundas y embolias pulmonares luego de inmovilizaciones prolongadas: 325 mg dia por medio. CONTRAINDICACIONES. Úlcera gastrointestinal aguda. Diátesis hemorrágica. Hipersensibilidad al ácido acetilsalicilico, a salicilatos, 0 a algún otro componente de este producto. Antecedentes de asma inducido por la administración de salicilatos o sustancias con una acción similar, en especial drogas antiinflamatorias no esteroideas. Combinación con metotrexate en dosis de $15 \mathrm{mg}$ por semana o más. Último trimestre de embarazo. Falla renal severa. Falla hepática severa. Falla cardiaca severa. ADVERTENCIAS Y PRECAUCIONES. Hipersensibilidad a los analgésicos y a agentes antiinflamatorios/antirreumáticos y en presencia de otras alergias: en pacientes con fiebre de heno, múltiples pólipos nasales, asma bronquial o enfermedades respiratorias crónicas, el ácido acetilsalicílico puede precipitar un broncoespasmo e inducir ataques de asma u otras reacciones de hipersensibilidad. Debido al efecto inhibitorio sobre la agregación plaquetaria que persiste por varios dias luego de su administración, el ácido acetilsalicilico tiende a aumentar las hemorragias durante y luego de intervenciones quirúrgicas (incluyendo cirugias menores, p.ej. extracciones dentales). El paciente debe consultar con su médico acerca del uso de ácido acetilsalicilico. Tratamiento conjunto con anticoagulantes. Algunos AlNES, como el ibuprofeno y el naproxeno pueden atenuar el efecto inhibitorio del ácido acetilsalicilico sobre la agregación plaquetaria. El paciente deberá advertir al médico cuando esté bajo terapia con ácido acetilsalicilico y deba tomar ibuprofeno. En pacientes que sufren de graves deficiencias de la glucosa-S-fosfato deshidrogenasa (G6PD), el ácido acetilsalicilico puede inducir hemólisis o anemia hemolitica. Los factores que pueden aumentar el riesgo de hemólisis son, por ejemplo dosis altas, fiebre o infecciones agudas. A dosis bajas, el ácido acetilsalicilico reduce la excreción del ácido úrico. Esto puede favorecer la aparición de gota en pacientes predispuestos. Antecedentes de úlcera gastrointestinal incluyendo úlceras crónicas o recurrentes o antecedentes de hemorragias gastrointestinales. Daño de función renal y hepática. Los pacientes con insuficiencia renal o en pacientes con trastornos en la circulación cardiovascular el ácido acetilsalicílico pueden aumentar el riesgo de insuficiencia renal y falla renal aguda. Alteración de la función hepática. Los productos medicinales que contengan ácido acetilsalicilico/aspirina no deben ser utilizados en niños y adolescentes menores de 16 años que tengan enfermedades virales, con o sin fiebre sin consultar al médico. Existe el riesgo de que ciertas enfermedades virales, como ser influenza A, B y varicela provocar el sindrome de Reyé, una patología rara pero severa que requiere una intervención médica inmediata. REACCIONES ADVERSAS. Las reacciones adversas a medicamentos (RAM) enumeradas a continuación se basan en informes espontáneos postcomercialización con todas las formulaciones de aspirina de administración oral, incluyendo tratamientos a corto y largo plazo, por lo que una clasificación de acuerdo con las categorias CIOMS III de frecuencia no es pertinente: trastornos del sistema inmunitario: reacciones de hipersensibilidad con las respectivas manifestaciones clinicas y de laboratorio: sindrome de asma, reacciones leves a moderadas que puedan afectar a la piel, vias respiratorias, tracto gastrointestinal y sistema cardiovascular, incluyendo síntomas como ser sarpullido, urticaria, edema, prurito, rinitis, congestión nasal, insuficiencia cardiorrespiratoria y muy raramente reacciones severas, incluyendo shock anafiláctico; trastornos gastrointestinales: trastornos frecuentes del tracto gastrointestinal bajo y alto, asi como signos y sintomas de dispepsia, dolor abdominal y gastrointestinal, raramente trastornos como ser: inflamación gastrointestinal, ủlcera gastrointestinal que puede evolucionar muy raramente a una úlcera gastrointestinal sangrante y perforación con los correspondientes valores de laboratorio y los característicos signos clinicos y sintomas. Trastornos hepatobiliares: se han reportado casos aislados y transitorios de alteraciones de la función hepática. Trastornos de la sangre y del sistema linfático: debido al efecto inhibitorio sobre la agregación plaquetaria, el ácido acetilsalicilico puede ser asociado con un riesgo aumentado de sangrados. Se han observado sangrados, como ser hemorragias perioperatorias, hematomas, epistaxis, sangrados urogenitales y gingivales. Se han informado episodios raros a muy raros de sangrados severos, como ser hemorragia del tracto gastrointestinal, hemorragia cerebral (especialmente en pacientes con hipertensión no controlada y/o con administración concomitante de agentes anticoagulantes) que pueden ser, en casos aislados, fatales. Las hemorragias pueden provocar anemias agudas y crónicas secundarias a hemorragias/anemia ferropénica con los correspondientes valores de laboratorio los caracteristicos signos clinicos y sintomas, tales como astenia, palidez, hipoperfusión. Se ha reportado hemólisis y anemia hemolitica en pacientes con formas graves de deficiencia de glucosa-6-fosfato (G6PD). Trastornos del sistema nervioso: mareos y tinnitus son signos indicativos de sobredosis. Trastornos renales y urinarios: se han reportado casos de alteración de la función renal e insuficiencia renal aguda. PRESENTACIÓN Envases con 4, 10,20,30,50 y 100 comprimidos.

Bayer S.A., Ricardo Gutiérrez 3652, (B1605EHD), Munro, Bs. As., Argentina.

Director Téenico: José Luis Role, Farmacéutico.

Especialidad medicinal autorizada por el Ministerio de Salud. Certificado № 33575 Versión: CCDS v6 revisión: 09.2017 


\title{
SUMARIO ANALITICO
}

\author{
ANALYTICAL SUMMARY
}

REVISTA CONAREC 2018;33(147):274-275 | DOI:10.32407/RCON/2018147/0274-0275

\section{REVISIÓN POR EXPERTOS | EXPERT REVIEW}

279

\section{SOPORTE CIRCULATORIO MECÁNICO CON BOMBA CENTRÍFUGA ALEJANDRO M. BERTOLOTTI}

La insuficiencia cardíaca avanzada es una entidad compleja con prevalencia en aumento. Su abordaje incluye la combinación de estrategias farmacológicas, quirúrgicas y, cuando se agotan las opciones terapéuticas, terapias de destino o reemplazo, siendo estas últimas principalmente los dispositivos de asistencia circulatoria mecánica y el trasplante cardíaco. Las bombas centrífugas se destacan en nuestro medio como una alternativa de asistencia a corto/mediano plazo como puente a la decisión, a la recuperación o al tras plante cardíaco, permitiendo un soporte uni- o biventricular a estos pacientes críticos.

REVISIÓN ANUAL | ANNUAL REVIEW

\section{VENTILACIÓN NO INVASIVA EN EL TRATAMIENTO DE LA INSUFICIENCIA CARDÍACA \\ DIEGO A. MÁRQUEZ, GUILLERMO R. CHIAPPERO}

La insuficiencia cardíaca descompensada es uno de los motivos de consulta y hospitalización más frecuentes en cardiología. A pesar de los avances en el tratamiento farmacológico, la morbilidad y la mortalidad siguen siendo elevadas. Por ello, la terapia de ventilación con presión positiva representa una estrategia potencialmente beneficiosa, no invasiva y de fácil acceso, con el objetivo de mejorar la oxigenación, la hipoventilación y la hipercapnia, disminuir la poscarga del ventrículo izquierdo, la presión cardíaca transmural, y mejorar las funciones pulmonares y respiratorias. La elección del modo ventilatorio y la interfaz óptima depende de cada paciente, pero los más recomendados son la máscara facial total y el modo presión positiva continua en la vía aérea con la titulación progresiva de la presión ventilatoria hasta la mejoría clínica.

MONOGRAFÍA SELECCIONADA | SELECTED MONOGRAPH

\section{DESAFÍOS ESTRATÉGICOS EN INSUFICIENCIA CARDÍACA AVANZADA. ASISTENCIA VENTRICULAR. ¿ESTÁ TODO DICHO? \\ JIMENA SANTILLÁN}

La insuficiencia cardíaca avanzada es la etapa final de múltiples enfermedades cardiovasculares y constituye en sí misma una de las patologías más prevalentes y con mayor morbimortalidad a nivel mundial. Se sabe que el tratamiento médico óptimo ha demostrado mejorar la sobrevida en términos de progresión de enfermedad y muerte súbita, así como el cardiodesfibrilador implantable y la terapia de resincronización cardíaca.

A pesar de esto, un porcentaje no menor alcanza estadios avanzados en quienes el trasplante cardíaco puede ser una opción. Debido a las limitaciones actuales que esto implica, surgió el desarrollo de los dispositivos de asistencia ventricular (DAV).

El propósito de esta monografía es revisar los aspectos clínicos y tecnológicos de los DAV. Se realizará un análisis de su evolución desde las primeras asistencias, se evaluarán indicaciones, el momento oportuno para su implante así como sus contraindicaciones. Posteriormente, se realizará una revisión de los aspectos a tener en cuenta por parte del médico tratante para la evaluación precolocación, considerando los scores de riesgo disponibles, los aspectos psicosociales y el costo/beneficio de su utilización, para así poder evaluar el impacto y la factibilidad de su aplicación en la práctica clínica diaria.

\section{ARTÍCULOS ORIGINALES | ORIGINAL ARTICLES}

GRADIENTE POSQUIRÚRGICO EN PACIENTES CON REEMPLAZO VALVULAR AÓRTICO Y SU ASOCIACIÓN CON EVENTOS CARDIOVASCULARES

NATALIA CHATTICH, MARILIN TRAVIESA, YANET PARISI, ALEJANDRO LÓPEZ RIGO, SHEILA Y. FERNÁNDEZ, MARIANA CANDIA

Introducción. La cirugía de reemplazo valvular aórtico (CRVAo) constituye el tratamiento de elección en la estenosis aórtica (EAo) severa sintomática o con deterioro de la función ventricular. El gradiente posquirúrgico se ha visto asociado significativamente con la sobrevida y evolución a largo plazo. Sin embargo, su prevalencia y correlación con desenlaces clínicos en nuestro centro aún no ha prevalencia y correlación con
sido estudiada formalmente.

Objetivo. Evaluar el gradiente posquirúrgico valvular en pacientes sometidos a CRVAo y su asociación con eventos cardiovasculares en el Instituto de Cardiolo-

gía de Corrientes Juana F. Cabral. tes sometidos a CRVAo por EAo severa y se evaluaron los gradientes valvular aórticos pre- y posquirúrgicos con un seguimiento a 6 meses.

Resultados. Se incluyeron 199 pacientes. El 86,9\% presentó hipertensión arterial el 20,7\% diabetes mellitus, $29,8 \%$ dislipemia y el 10,1\% presentaba aorta bicúspide. Con respecto a los eventos cardiovasculares posquirúrgicos: 9,2\% presentó insuficiencia cardíaca, $1 \%$ bloqueo auriculoventricular completo, 1,5\% requirió implante de marcapasos definitivo, 2,1\% fibrilación auricular, 3,1\% derrame pericárdico severo y el $2,1 \%$ endocarditis infecciosa, sin encontrarse asociación entre los eventos cardiovasculares posquirúrgicos de ambas ramas. La mortalidad posoperatoria fue del 2,5\%. Comparando las variables ecocardiográficas pre- y posquirúrgicas se observó disminución de los gradientes y aumento del área valvular en forma significativa. Se observó que el $37,1 \%$ de los pacientes operados presentó disminución respecto al valor basal pero persistió con gradientes postquirúrgicos elevados. En dichos pacientes, se observó que el gradiente prequirúrgico medio era $10 \mathrm{mmHg}$ mayor con respecto a los pacientes que luego de la cirugía presentaron gradientes normales.

Conclusión. La prevalencia de gradiente posquirúrgico elevado en nuestro centro es elevada. El gradiente posquirúrgico elevado no se asoció con aumento de eventos cardiovasculares registrados.

\section{FACTORES DE RIESGO CARDIOVASCULAR EN RESIDENTES Y CARDIÓLOGOS ARGENTINOS. "CÓMO SE CUIDAN LOS QUE CUIDAN". ENCUESTA FRICCAR, CONAREC}

HERNÁN PULENTA, LUCRECIA M. BURGOS, IGNACIO CIGALINI, DANIEL LORENZATTI, IVÁN VILAR, MAURO ROSSI PRAT, FRANCO GIANNASI, ELISA ORTIZ, AGUSTÍN ROUDE, SEBASTIÁN GARCÍA-ZAMORA

Introducción. Si bien se ha avanzado en el conocimiento y tratamiento de los factores de riesgo cardiovascular (FRCV) en población general, se conoce menos respecto de la distribución de estos entre médicos.

Objetivos. Describir los FRCV presentes en residentes de cardiología y cardiólogos pertenecientes a residencias de Cardiología de todo el país.

Métodos. Se realizó una encuesta cerrada y prefijada, voluntaria y anónima, con un muestreo no probabilístico por conveniencia, en centros pertenecientes al Consejo Argentino de Residentes de Cardiología (CONAREC), durante los meses de agosto-noviembre de 2017.

Resultados. Se encuestaron 523 profesionales pertenecientes a 44 centros de todo el país. El 63,1\% de los participantes fueron hombres, y la mediana de edad fue 31 años (rango intercuartílico [RIC]: 28-38 años). El 52,8\% eran residentes, $5,9 \%$ jefes o instructores de residentes y $41,3 \%$ especialistas o fellow. Los principales FRCV detectados fueron: dislipemia 14,3\%, hipertensión arterial 5\%, enfermedad coronaria previa $1 \%$ y diabetes mellitus tipo $\| 0,8 \%$. Asimismo fumaban $16,8 \%$, y $12,6 \%$ eran extabaquistas. El $36,7 \%$ de los participantes manifestó no hacer ningún tipo de actividad física, y 33,8\% expresó que nunca se cuidaba de no agregar sal a los alimentos. Además, el 35,6\% expresó que no comían 
frutas ni verduras diariamente. La mediana de estatura de las mujeres fue 1,63 metros (RIC: 1,6-1,68), mientras que la de los hombres fue 1,75 metros (RIC: 1,71 1,81); la mediana del peso de las mujeres fue $58 \mathrm{~kg}$ (RIC: 55-63), en tanto la de los hombres fue $81 \mathrm{~kg}$ (RIC: 73-90). La mediana del índice de masa corporal fue 21,7 (RIC: 20,3-24) para mujeres y 26,1 (RIC: $24,2-28,1$ ) en hombres. De acuerdo con esto, $46,5 \%$ de los encuestados cumplían criterio de sobrepeso u obesidad. El perímetro abdominal de los hombres fue $90 \mathrm{~cm}$ (RIC: 84-99) y el de las mujeres 70 (RIC: 66-78). Respecto de los valores de presión arterial, el promedio sistólico fue de $115,7 \pm 11,9 \mathrm{mmHg}$ y diastólico $71,6 \pm 8,6 \mathrm{mmHg}$. Por otra parte, el $94,7 \%$ de los participantes manifestó tener algún tipo de cobertura médica, al tiempo que $41,9 \%$ del total de encuestados reconoció que había pasado más de 1 año desde su último control de salud.

Conclusión. Encontramos una elevada tasa de sobrepeso y obesidad entre los participantes, como también en sedentarismo, tabaquismo y dislipemia. Si bien la prevalencia de otros factores de riesgo fue baja, debe tenerse presente que los participantes fueron en su mayoría jóvenes. Consideramos esencial implementar estrategias para favorecer la práctica de estilos de vida más favorables entre profesionales de la salud de nuestro país.

\section{INFARTO AGUDO DE MIOCARDIO CON ELEVACIÓN} DEL SEGMENTO ST: PREVALENCIA DE ARTERIA SEGÚN EL SEXO

ALFREDO ASTESIANO, NICOLÁS F. RENNA, MARÍA J. TORRES, RODRIGO GARCÍA, MARIANO GRUCCI, ALBERTO G. VILLASÍS, MARCIA ZULOAGA PUGLISI, ROMANO M. TRIONFI

Introducción. A pesar de los grandes avances en el conocimiento de la fisiopatoogía del infarto agudo de miocardio con elevación del segmento ST (IAMCEST), aún se desconocen variables que influyen en el desenlace de esta patología y en particular la relación entre la anatomía coronaria afectada y el sexo. En Argentina existe información limitada sobre este aspecto.

Objetivo. Analizar las características clínicas de pacientes con IAMCEST en un centro privado de la provincia de Mendoza, con la intención de evaluar la arteria coronaria afectada según el sexo.

Métodos. Estudio observacional y retrospectivo, de pacientes que ingresaron a nuestro centro con diagnóstico de IAMCEST, en los que se les practicó cinecoronariografía de urgencia. Se analizaron variables clínicas como sexo, edad, factores de riesgo cardiovascular, arteria culpable, tipo de tratamiento y stent colocado. Resultados. Se incluyeron 153 pacientes. La edad media fue 70 años $( \pm 13)$ en mujeres y $61( \pm 12)$ en hombres. El factor de riesgo cardiovascular más prevalente en ambos grupos fue la hipertensión arterial, siendo 79,5\% en mujeres y $61,5 \%$ en hombres ( $p=0,04)$; seguido por tabaquismo (35,9\% mujeres y $53 \%$ hombres), diabetes mellitus $(35,9 \%$ mujeres y $21,4 \%$ hombres; $p=0,07)$ y obesidad $(28,2 \%$ mujeres y $29,1 \%$ hombres; $p=0,91$ ). No hubo diferencias de la arteria afectada según sexo $(p=0,38)$. La arteria culpable más prevalente fue la descendente anterior (DA) (39,5\% en mujeres y 37,9\% en hombres). Resultados similares se observaron con la arteria coronaria derecha, con una prevalencia ligeramente menor que la DA (34,2\% mujeres y 35,3\% hombres); la arteria circunfleja fue el vaso culpable en $18,42 \%$ sexo femenino y $17,2 \%$ sexo masculino, El $2,6 \%$ de las mujeres tuvo compromiso de tronco de la arteria coronaria izquierda (TCI), siendo mayor el porcentaje de hombres con compromiso de este vaso: $6 \%$. El puente venoso tuvo una baja prevalencia sin diferencias entre sexo (2,6\% mujeres y $3,4 \%$ hombres).

Conclusión. Más del 75\% de los infartos de miocardio con elevación del segmento ST fueron hombres, sin embargo las mujeres presentaron un perfil de riesgo cardiovascular diferente, siendo más prevalente la HTA y la edad avanzada. No hubo diferencias en la arteria coronaria afectada según el sexo, observando una tendencia no significativa en mayor enfermedad de TCl en el hombre.

CASOS CLÍNICOS | CLINICAL CASES

\section{TRONCO CORONARIO ÚNICO QUE NACE DEL SENO CORONARIO} DERECHO

CAROLINA CHACON, MAURICIO PRIOTTI, MARIANA DOMANICO, FRANCISCO ARA NICOLÁS FERRERI, CINTIA FOCO, ESTEFANÍA PERETTI, MANUEL TRAGHETTI

La anomalía más frecuente es el nacimiento de la arteria circunfleja desde el seno coronario derecho, pero algunas publicaciones plantean que más común sería la arteria coronaria derecha naciendo desde el seno coronario izquierdo. Igualmente, se ha planteado que la presencia de una arteria coronaria con un nacimiento anómalo se asocia a mayor grado de aterosclerosis. Actualmente la tomografía computada multicorte con 64 canales ofrece un excelente método para detección de las anomalías de las arterias coronarias, pudiendo detectar de manera rápida y mínimamente invasiva.

\section{CAUSA INFRECUENTE DE INFARTO ANTERIOR: HEMATOMA POR} DISECCIÓN AÓRTICA

LUISA HSU, FLAVIO DELFINO, LEONARDO CÁCERES, FERNANDO PINTO, AGOSTINA BARSOTTI, FRANCISCO SALTOS, LISANDRO OLGUÍN, SANTIAGO GUELERMAN, MELISA CUSCHIE

El infarto de miocardio asociado a disección aórtica (DA) se manifiesta predominantemente en cara inferior, con lo cual su diagnóstico es muy complejo dado que no corresponde a la causa más frecuente de síndrome coronario agudo (SCA). La DA implica un diagnóstico clínico que requiere confirmación urgente con angiotomografía de aorta con contraste endovenoso o ecocardiograma transtorácico o transesofágico, según la disponibilidad.

A continuación, se presenta el caso de un paciente masculino de 56 años con SCA con elevación del segmento ST en cara anterior asociado a una DA.

\section{IMÁGENES EN CARDIOLOGÍA | IMAGES IN CARDIOLOGY}

\section{PERICARDITIS CONSTRICTIVA ASOCIADA}

\section{A MIOCARDIOPATÍA CHAGÁSICA}

EVELYN C. WONG, LUCAS ANGIONO, JEREMÍAS DORSCH, LEONARDO PINTOR, SERGIO BLANCO, ENRIQUE MORRAL, FLAVIO TOMÁN

La pericarditis constrictiva (PC) en un síndrome clínico causado por un pericardio engrosado y rígido que dificulta el llenado ventricular. Es una enfermedad crónica, generalmente idiopática, que se presenta clínicamente como insuficiencia cardíaca congestiva (IC) con escasa respuesta al tratamiento médico y con evolución tórpida.

La enfermedad de Chagas es una miocardiopatía dilatada que causa sintomatología clínica de IC que no difiere demasiado de otras cardiopatías dilatadas, con manifestaciones que aparecen de forma progresiva.

Presentamos el caso clínico de una mujer de 41 años de edad que consultó por IC biventricular, la cual al ser estudiada mediante métodos complementarios se reinterpreta como $\mathrm{PC}$.

GUÍAS CONAREC | CONAREC GUIDELINES

\section{ALGORITMO DE MANEJO LIPÍDICO EN EL PACIENTE} CON SÍNDROME CORONARIO AGUDO

JUAN IGNACIO DAMONTE, MATEO ANQUIZ, JUAN MANUEL DOMÍNGUEZ, LUCIANO N. FALLABRINO, WALTER MASSON JUÁREZ, PABLO CORRAL, JUAN JOSÉ BADIMON 


\section{PRESIMAX Losartán}

EXPERIENCIA, SEGURIDAD Y EFICACIA EN HIPERTENSIÓN ARTERIAL

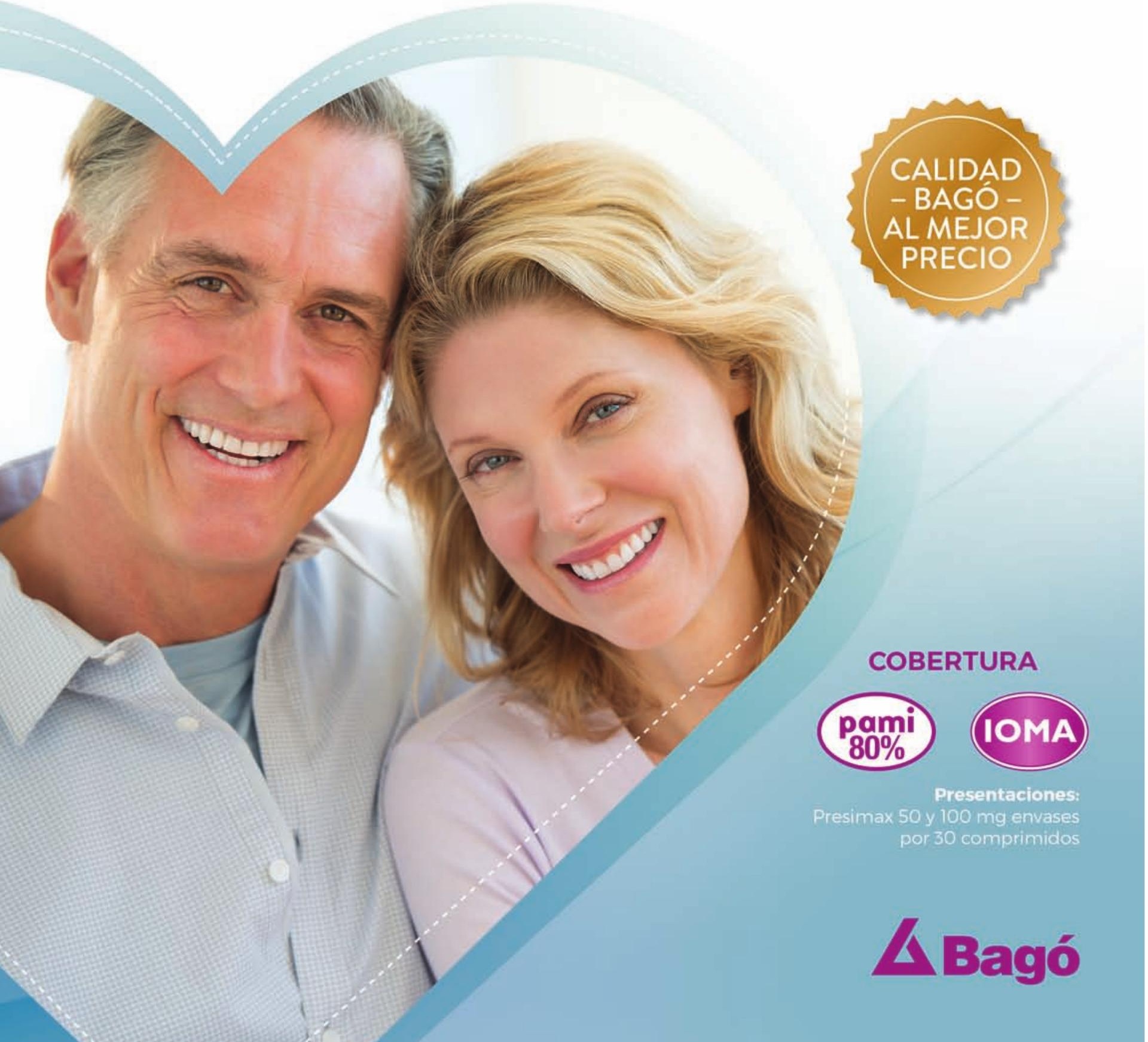


EDITORIAL | EDITORIAL

\title{
CURIOSIDAD, INVESTIGACIÓN Y CONOCIMIENTO
}

\author{
CURIOSITY, RESEARCH AND KNOWLEDGE
}

REVISTA CONAREC 2018;33(147):277-278 | DOI:10.32407/RCON/2018147/0277-0278

"Nuestra sociedad, en la que reina un urgente deseo de riquezas y lujos, no entiende el valor de la ciencia. No se da cuenta de que la ciencia es una de las partes más preciosas de su patrimonio moral. Ni ha asumido de modo suficiente el hecho de que la ciencia está en la base de todo el progreso que aligera la carga de la vida y disminuye su sufrimiento"

Maria Salomea Skłodowska-Curie

Marie Curie fue, si no la primera, la científica más importante de su tiempo. Adelantándose a la época, supo vencer los obstáculos impuestos a las mujeres con ambiciones intelectuales. La búsqueda de la verdad fue la meta primera y última de su existencia y soportó con estoicismo las condiciones más denigrantes y laboriosas que le impuso su trabajo de investigación, sobreponiéndose a obstáculos que a muchos les hubieran resultado insuperables. Fruto de su esfuerzo, fue la primera mujer en recibir un Premio Nobel y luego la primera persona en recibir este premio por segunda vez ${ }^{1,2}$.

Cuando nos involucramos en la investigación, ya sea para cumplir con el requisito, porque la sede tiene una suficiente tradición al respecto, o por puro deseo personal, aprendemos no solo metodología de la investigación sino formas de enfrentar el conocimiento, capacidad de reflexión, actitud de cuestionamiento continuo y otras competencias que ayudan a ser mejores clínicos 3 .

Existe una preocupación constante a nivel mundial por la disminución de los denominados médicos investigadores ${ }^{4}$. Zemlo et al..$^{5}$ y Rosenberg ${ }^{6}$ demostraron que la cantidad de médicos investigadores se ha visto reducida de forma importante en los últimos años, con disminución aún más significativa en el interés de los estudiantes por continuar realizando investigación en su vida profesional.

Todo lo anterior nos lleva a preguntarnos: ¿Debe un residente ser un consumidor de información? ¿O puede ser creador de esa información médica? ${ }^{4}$

La residencia es un momento crucial para la exploración de intereses personales y profesionales, así como para el autodescubrimiento. Las razones más frecuentes para que los residentes busquen iniciarse en la investigación incluyen curiosidad intelectual, exploración de posibles opciones de carrera dentro de la academia o una subespecialidad y cumplimiento de un requisito del programa?.

Estudios previos realizados en residencias de medicina interna demostraron que los residentes aprecian la capacitación en investigación durante la misma 8,9 ; sin embargo, en la actualidad la formación voluntaria en investigación es baja. Reconociendo como barreras al acceso: la falta de tiempo, de apoyo docente, de una red de investigación organizada, de conocimientos y habilidades, de incentivos y recompensas, de fondos de investigación y de un interés personal10.

Una experiencia en investigación puede contribuir a desarrollar hábitos duraderos de pensamiento crítico ${ }^{11}$. En un ensayo histórico, C. Wright Mills comentó que nunca hubo un momento en que no pensara, reflexionara, analizara y escribiera; siempre estaba trabajando en una idea. Esta es la mentalidad que puede acumular la investigación, y es seguramente la que se quiere en la medicina clínica, donde es vital la evaluación crítica de la nueva evidencia. Además de estimular el interés continuo en el aprendizaje, esta mentalidad intelectualmente curiosa contribuye a un sentimiento de satisfacción personal y entusiasmo por participar en el descubrimiento y el aprendizaje como parte de un equipo.

Lo primero que debe tener alguien que quiere investigar es la curiosidad científica para hacerlo. Posteriormente podríamos decir que es como aprender a andar en bicicleta. Algunos pueden hacerlo solos, otros requieren ayuda para subirse, y los más afortunados reciben una adecuada formación y un pequeño empujón antes de soltarse solos y continuar investigando ${ }^{12}$.

Para finalizar, quisiera agradecer a todos los que transcurrieron por estos 5 números de 2018, desde su lectura hasta la redacción, y especialmente a todo el Comité Editorial por su continuo y gran esfuerzo e invaluable dedicación. En nombre de todo el equipo que compone la revista, esperamos que hayan disfrutado estos cinco números tal como lo hicimos nosotros.

También aguardo con ilusión que comiencen sus primeros pequeños - pero firmes- pasos en investigación. Cerrando con otra frase de Marie Curie: "Me enseñaron que el camino del progreso no era rápido ni fácil". 


\section{BIBLIOGRAFÍA}

1. García PD, García BC. Marie Curie, una gran científica, una gran mujer. Rev Chil Radiol 2006;12(3):139-45

2. Binda MC. Marie Curie, una mujer pionera en su tiempo: Primera parte. Rev Argent Radiol 2009;73(3):265-70.

3. Lifshitz A. La modernización de la enseñanza clínica en las escuelas de medicina México: Facultad de Medicina; 2012.

4. Ávila MJ, Rodríguez-Restrepo A. The importance of research in undergraduate medical education. Medwave 2014;14(10):e6032.

5. Zemlo TR, Garrison HH, Partridge NC, Ley TJ. The physician-scientist: career issues and challenges at the year 2000. FASEB J 2000;14(2):221-30.

6. Rosenberg LE. MD/PhD programs - a call for an accounting. JAMA 2008;300(10):1208-9.
7. Hamann KL, Fancher TL, Saint S, Henderson MC. Clinical research during internal medicine residency: a practical guide. Am J Med 2006;119(3):277-83.

8. Kantor SM, Griner PF. Educational needs in general internal medicine as perceived by prior residents. J Med Educ 1981;56(9):748-56.

9. Kern DC, Parrino TA, Korst DR. The lasting value of clinical skills. JAMA 1985;254(1):70-6.

10. Gill S, Levin A, Djurdjev O, Yoshida EM. Obstacles to residents' conducting research and predictors of publication. Acad Med 2001;76(5):477.

11. Bennett C. Why all medical students need to experience research? Aust Med Student J. 2016.

12. Méndez Garcia T. Investigación y residentes: bicicletas, muros y otros obstáculos. Rev Clin Med Fam 2017;10(2):69-69. 


\title{
SOPORTE CIRCULATORIO MECÁNICO CON BOMBA CENTRÍFUGA
}

\author{
MECHANICAL CIRCULATORY SUPPORT WITH CENTRIFUGAL PUMP
}

\author{
ALEJANDRO M. BERTOLOTTI'
}

\section{RESUMEN}

La insuficiencia cardíaca avanzada es una entidad compleja con prevalencia en aumento. Su abordaje incluye la combinación de estrategias farmacológicas, quirúrgicas y, cuando se agotan las opciones terapéuticas, terapias de destino o reemplazo, siendo estas últimas principalmente los dispositivos de asistencia circulatoria mecánica y el trasplante cardíaco. Las bombas centrífugas se destacan en nuestro medio como una alternativa de asistencia a corto/mediano plazo como puente a la decisión, a la recuperación o al trasplante cardíaco, permitiendo un soporte uni- o biventricular a estos pacientes críticos.

Palabras clave: corazón auxiliar, shock cardiogénico, cuidados críticos

\section{ABSTRACT}

Advanced heart failure is a complex entity with an increasing prevalence. Its approach includes the combination of pharmacological, surgical strategies and, when the therapeutic options are exhausted, target or replacement therapies, the latter being mainly mechanical circulatory assistance devices and cardiac transplantation. Centrifugal pumps stand out in our area as an alternative of short/medium term assistance as a bridge to decision, recovery or heart transplantation, allowing uni or biventricular support to these critical patients.

Keywords: heart-assist devices, cardiogenic shock, critical care

REVISTA CONAREC 2018;33(147):279-282 | DOI:10.32407/RCON/2018147/0279-0282

\section{INTRODUCCIÓN}

La insuficiencia cardíaca avanzada es una entidad compleja con prevalencia en aumento. Su abordaje incluye la combinación de estrategias farmacológicas, quirúrgicas y, cuando se agotan las opciones terapéuticas, terapias de destino o reemplazo, siendo estas últimas principalmente los dispositivos de asistencia circulatoria mecánica (ACM) y el trasplante cardíaco!

Los dispositivos de ACM pueden clasificarse de distintas maneras tomando en cuenta diversas características como la durabilidad, el flujo y su ubicación anatómica, entre otros². En los pacientes con shock cardiogénico refractario al tratamiento médico, se prefieren los dispositivos de corto-mediano plazo para la rápida estabilización del paciente, como puente a una recuperación, a un dispositivo de largo plazo como terapia de destino o al trasplante cardíaco. En este grupo, se destacan en nuestro medio las bombas centrífugas (BC) de flujo continuo.

\section{DEFINICIÓN Y CARACTERÍSTICAS}

Las bombas centrífugas son dispositivos de uso temporario de corto plazo, para asistencia circulatoria mecánica en pacientes con un cuadro de shock cardiogénico severo refractario a otras terapias. Su im-

1. Jefe del Servicio de Trasplante Intratorácico e Insuficiencia Cardíaca. Hospital Universitario Fundación Favaloro, CABA.

$\triangle$ Correspondencia: Dr. Alejandro Mario Bertolotti. Av. Belgrano 1746 C1093AAS CABA, Rep.Argentina.bertolotti.alejandro66@gmail.com

Los autores declaran no poseer conflictos de intereses.

Recibido: 01/11/2018|Aceptado: 10/11/2018 plante requiere un procedimiento quirúrgico y permite asistir independientemente las funciones ventriculares izquierda, derecha o ambas (soporte uni- o biventricular). La interposición de una membrana oxigenadora extracorpórea permite la conversión a sistema de soporte vital con oxigenación sanguínea (ECMO).

Las BC proveen flujo de tipo radial y continuo, no pulsátil, mediante la generación de un diferencial de presión entre el sitio de ingreso y egreso de la sangre a la carcasa de la bomba, gracias a la rotación a altas velocidades del propulsor central.

Estos dispositivos requieren del uso de anticoagulación y/o antiagregación permanente, ya que el contacto de la sangre con elementos no biológicos (cánulas, tubuladuras, carcasa y propulsor) y las turbulencias que se generan en la circulación de la misma favorecen los fenómenos trombóticos por activación de la cascada de coagulación.

\section{SISTEMAS DISPONIBLES}

El sistema de soporte circulatorio agudo CentriMag ${ }^{\mathrm{TM}}$, se caracteriza por incorporar la tecnología de flujo Full-MagLev ${ }^{T M}$ mediante levitación magnética del propulsor permitiendo una mejor performance hemodinámica al evitar puntos de contacto entre la carcasa y el propulsor (Figura 1). Esta característica de funcionamiento disminuye notablemente las fuerzas de corte y fricción que favorecen la hemólisis y evita zonas de mayor turbulencia y estasis sanguíneas que generan mayor probabilidad de formación de trombos ${ }^{3,4}$. Este dispositivo cuenta con dos modelos de cabezal centrífugo, uno para niños hasta 10 kg de peso (PediVAS CentriMag ${ }^{\text {TM}}$ ) y otro para pacientes con mayor superficie corporal, que permite generar flujos de hasta 9,9 litros/min. Su utilización ha sido aprobada por un período de hasta 30 días, aunque existen reportes de su utilización por más de 90 días sin necesidad de cambios del dispositivo por complicaciones mayores o fallas de funcionamiento ${ }^{5}$. Esta tecnología ha sido utilizada en Argentina 

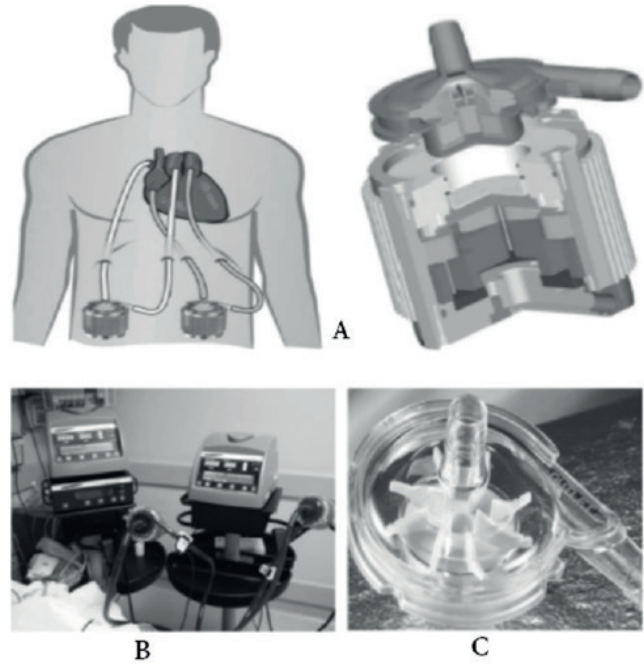

Figura 1. A. Dispositivo de asistencia biventricular y bomba con rotor. B. Consola con dos rotores electromagnéticos para asistencia biventricular. C. Bomba centrífuga. Modificado de Bertolotti AM et al. Experiencia con bomba centrífuga magnética en pacientes con shock cardiogénico (INTERMACS 1). Rev Argen Cardiol 2014;82(3):205-10.

desde el año $2007^{6}$ y cuenta para su uso con aprobación mediante resolución de ANMAT?

Existen otros dispositivos de BC para soporte circulatorio mecánico agudo disponibles en el país, como la bomba RotaFlow ${ }^{\mathrm{TM}}$ (Maquet, Getinge Group, US) y el sistema Revolution ${ }^{\text {TM }}$ (LivaNova PLC, UK). Estas BC, con características similares de funcionamiento y soporte hemodinámico, no utilizan la tecnología de levitación magnética.

\section{TÉCNICA QUIRÚRGICA DE IMPLANTE}

El implante de las BC para soporte ventricular derecho, izquierdo o biventricular requiere de un procedimiento quirúrgico cardiovascular central, mediante esternotomía mediana y utilización de circulación extracorpórea (CEC) para permitir las maniobras necesarias de canulación sin generar mayor compromiso hemodinámico en pacientes con shock cardiogénico.

Los sitios de colocación de las cánulas de egreso e ingreso varían según el tipo de soporte a implementar.

Para asistencia ventricular izquierda (AVI), la cánula de drenaje (o de ingreso al dispositivo) puede ser colocada directamente en la aurícula izquierda o en el ápex del ventrículo izquierdo (VI). La elección del sitio de canulación dependerá de la estrategia definida (p. ej.: puente a la recuperación con posible explante posterior, puente a la decisión o puente al trasplante), de la patología de base y causa del shock cardiogénico (p. ej.: miocardiopatía con ventrículo izquierdo restrictivo que limite el acceso a la cavidad ventricular, miocarditis aguda potencialmente recuperable, infarto agudo de miocardio) y/o antecedentes del paciente (p. ej.: cirugía cardíaca previa). Se han descrito nuevas técnicas para un implante seguro y hemostático en el ápex. La cánula de infusión (o egreso del dispositivo) se implanta en la aorta ascendente directamente o mediante interposición de una prótesis vascular. Se han descrito estrategias de AVI mediante técnicas quirúrgicas miniinvasivas que evitan el uso de CEC, accediendo al ápex del VI por una toracotomía mínima anterior izquierda. Para acceso de la aorta se realiza una esternotomía mínima parcial o canulación en alguna rama arterial central como las arterias axilares/subclavias derecha o izquierda.

Para asistencia ventricular derecha (AVD), la cánula de drenaje se implanta en la aurícula derecha (AD) por acceso directo a través de la pared libre de la misma. Otra opción es llegar a la AD por vía percutánea a través de los sistemas de venas cava superior o inferior, mediante punción de venas femorales o yugulares internas. La cánula de infusión, se implanta en el tronco de la arteria pulmonar.

Para asistencia biventricular (ABiV), se emplea la combinación de ambas técnicas de AVI y AVD.

\section{OBJETIVOS DE LA ACM Y MANEJO HEMODINÁMICO}

Los objetivos de la ACM con BC son:

- Lograr una adecuada perfusión y oxigenación de todos los sistemas orgánicos ajustado a la superficie corporal $(60 \mathrm{ml} / \mathrm{kg}$ de peso en adultos) y al cuadro actual del paciente.

- Lograr una adecuada descarga de las cavidades cardíacas afectadas (VI, ventrículo derecho [VD] o ambos) y disminución del estrés parietal del miocardio.

Todos los pacientes requieren monitorización invasiva con catéteres arteriales y venosos centrales de Swan Ganz para obtener información respecto de la precarga y la poscarga del VD e indirectamente la presión de precarga del VI mediante la presión de enclavamiento pulmonar. La presión venosa central idealmente debe mantenerse en un rango entre 10 y $15 \mathrm{mmHg}$ tanto para AVI, AVD o ABiV, de manera de asegurar una precarga adecuada. Las presión arterial media debe estar idealmente entre 60 y $70 \mathrm{mmHg}$ con precarga adecuada y resistencias vasculares entre 800 y $1200 \mathrm{dyn} \cdot \mathrm{s} \cdot \mathrm{cm}^{-5}$ La monitorización de la presión de la arteria pulmonar permite establecer estrategias de vasodilatación pulmonar (uso de óxido nítrico inhalatorio; o drogas inodilatadoras como milrinona o dobutamina) a los fines de disminuir la poscarga del VD y asegurar el correcto llenado de la Al. Esta estrategia favorece tanto el soporte de la función del VD en caso de AVI, como el correcto funcionamiento de la AVD o ABiV.

La utilización de ecografía cardíaca transesofágica (ETE) intraoperatoria es mandatoria para la correcta evaluación de la hemodinamia del paciente bajo soporte con ACM. Es necesario valorar el correcto posicionamiento de las cánulas de drenaje tanto en cavidades auriculares como en VI, ya que podrían originarse obstrucciones mecánicas del drenaje por inadecuado posicionamiento que deben ser corregidas en el quirófano (p. ej.: succión de las valvas de las válvulas auriculoventriculares, succión y obstrucción del extremo de las cánulas por cercanía de las paredes de las cámaras drenadas). El ETE permite además la valoración de la precarga (llenado y/o vaciado) de las cámaras cardíacas asistidas. La rectificación y posicionamiento central del septum interventricular es un indicador de adecuado drenaje de las cámaras, además de favorecer la función sistólica del VD en caso de AVI. Una cánula implantada incorrectamente o un llenado inadecuado de las cámaras drenadas pueden oca- 
TABLA 1. Indicaciones de ACM.

\begin{tabular}{|c|c|}
\hline $\begin{array}{l}\text { Puente a la decisión/ } \\
\text { puente al puente }\end{array}$ & $\begin{array}{l}\text { Uso a corto plazo de la ACM (como SVE o ECMO) } \\
\text { en pacientes con shock cardiogénico hasta } \\
\text { que se estabilice el estado hemodinámico y la } \\
\text { perfusión de órganos finales; se excluyen las } \\
\text { contraindicaciones de la ACM a largo plazo (daño } \\
\text { cerebral tras reanimación) y se pueden evaluar } \\
\text { otras opciones terapéutica, como el DAV o el } \\
\text { trasplante cardíaco. }\end{array}$ \\
\hline Puente a la candidatura & $\begin{array}{l}\text { Uso de la ACM (normalmente DAVI) para mejorar } \\
\text { la función de órganos vitales y conseguir que un } \\
\text { paciente no apto para trasplante lo sea. }\end{array}$ \\
\hline Puente al trasplante & $\begin{array}{l}\text { Uso de la ACM (DAVI o BiVAD) para mantener con } \\
\text { vida al paciente que tiene alto riesgo de muerte } \\
\text { antes del trasplante hasta que haya disponible un } \\
\text { donante de órganos. }\end{array}$ \\
\hline Puente a la recuperación & $\begin{array}{l}\text { Uso de la ACM (típicamente DAVI) para mantener } \\
\text { con vida al paciente hasta que la función cardíaca } \\
\text { se recupere lo suficiente para retirar la ACM. }\end{array}$ \\
\hline Terapia de destino & $\begin{array}{l}\text { Uso de la ACM a largo plazo (DAVI) como alterna- } \\
\text { tiva al trasplante para pacientes con IC terminal no } \\
\text { aptos para trasplante o que se encuentran largo } \\
\text { tiempo en lista de espera para trasplante. }\end{array}$ \\
\hline \multicolumn{2}{|c|}{$\begin{array}{l}\text { ACM: asistencia circulatoria mecánica; BiVAD: dispositivo de asistencia biventricular; DAV: } \\
\text { dispositivo de asistencia ventricular; DAVI: dispositivo de asistencia ventricular izquierda; } \\
\text { ECMO: oxigenador extracorporeo de membrana; IC: insuficiencia cardiaca; SVE: soporte } \\
\text { vital extracorporeo; TD: terapia de destino. }\end{array}$} \\
\hline
\end{tabular}

sionar problemas de funcionamiento, succión y colapso de la cámara, aumento de las presiones negativas generado por el dispositivo y formación de burbujas por el fenómeno de cavitación; con consecuencias graves de embolia aérea. La evaluación de la función ventricular por ETE permite establecer estrategias de asistencia univentricular o biventricular. Los parámetros más utilizados para valorar la función del VD son el desplazamiento sistólico del plano del aniIlo tricuspídeo (siglas en inglés, TAPSE), la integral velocidad tiempo (siglas en inglés, VTI) y el grado de suficiencia de la válvula tricuspídea. La confirmación de suficiencia valvular aórtica e indemnidad de los septum auricular y ventricular es necesaria para asegurar un correcto soporte circulatorio mecánico, evitando la recirculación y/o posibles embolias paradójicas.

\section{INDICACIONES DE ACM}

Las guías de la Sociedad Europea de Cardiología para el diagnóstico y tratamiento de la insuficiencia cardíaca aguda y crónica publicadas en 2016, describen las indicaciones actuales para el uso de ACM en pacientes con diagnóstico de falla cardíaca (Tabla 1$)^{9}$.

Las guías para soporte circulatorio mecánico de la Sociedad Internacional de Trasplante Cardíaco y Pulmonar establecen que todos los pacientes candidatos a ACM deben tener determinada su CF (NYHA) y ser clasificados según los perfiles hemodinámicos del registro INTERMACS (Recomendación Clase I, Nivel de evidencia: C) ${ }^{10}$. Si bien estas recomendaciones fueron establecidas fundamentalmente para dispositivos implantables de largo plazo, son apli- cables al manejo integral de pacientes candidatos a ACM con dispositivos de corto plazo. En Argentina el acceso a este tipo de tecnología se encuentra muy limitado, fundamentalmente debido al alto costo que conlleva su aplicación en un complejo sistema de salud basado en multipagadores. Situación similar se presenta en otros países de la región Latinoamericana, por lo que los dispositivos de menor costo como las BC se han transformado en una alternativa válida. Se han reportado experiencias favorables de ACM con CentriMag ${ }^{\text {TM }}$ en Argentina ${ }^{6,11,12}$, Chile ${ }^{13,14}$, Colombia ${ }^{15}$ y Brasi $^{16}{ }^{16}$ como puente a la recuperación, puente a la decisión y puente al trasplante/retrasplante cardíaco.

\section{COMPLICACIONES DE LA ACM CON BC}

Las complicaciones y efectos adversos en pacientes bajo soporte circulatorio son comunes a todos los dispositivos de ACM, ya sean temporarios o permanentes, y están relacionados con:

- El procedimiento de implante y canulación, ya sea central o accesos vasculares periféricos (taponamiento, sangrado aumentado posoperatorio, isquemia distal a la canulación en miembros).

- La necesidad de anticoagulación y/o antiagregación plaquetaria que favorece los procesos hemorrágicos y/o tromboembólicos, fundamentalmente los eventos neurológicos.

- Las infecciones asociadas a la interfase de la piel con la exteriorización de cánulas.

- Fallas mecánicas y la hemólisis provocada por los dispositivos.

En un metaanálisis de la tasa de eventos adversos en pacientes bajo soporte con BC CentriMag ${ }^{\text {TM }}$ publicado por Bosizenko et al., la media de ocurrencia de sangrado fue del 28\% (IC95\%: 23-32), de trombosis 7\% (IC95\%: 5-11\%), hemólisis 3\% (IC95\%: 1-6\%), complicaciones neurológicas 7\% (IC95\%: 4-11\%), infecciones 24\% (IC95\%: 19 30\%), complicaciones renales 28\% (IC95\%: 22-36\%) y falla del dispositivo 0,08\% (IC95\%: 0,0-0,5\%; 3 casos sobre 512 pacientes). La comparación de estos eventos entre las poblaciones adulta y pediátrica demostró que la tasa de eventos hemorrágicos (23 vs. 46\%) y trombosis (4 vs. 22\%) fue significativamente mayor en los pacientes pediátricos ${ }^{17}$.

\section{CONCLUSIÓN}

Actualmente, la insuficiencia cardíaca avanzada es una entidad compleja que requiere de un enfoque integral, siendo a veces necesario el sostén hemodinámico mediante dispositivos de asistencia circulatoria mecánica de corto o mediano plazo como puente a la decisión, a la recuperación o al trasplante cardíaco. Las BC constituyen una alternativa válida en nuestro medio que permiten un soporte uni o biventricular a estos pacientes críticos. 


\section{BIBLIOGRAFÍA}

1. KozikDJ, PlunkettMD. Mechanical circulatory support. Organogenesis 2011;7(1):50-63.

2. Nagpal AD, Singal RK, Arora RC, Lamarche Y. Temporary Mechanical Circulatory Support in Cardiac Critical Care: A State of the Art Review and Algorithm for Device Selection. Can J Cardiol 2017;33(1):110-8.

3. De Robertis F, Briks EJ, Rogers P, Dreyfus G, Pepper JR, Khaghani A. Clinical performance with the Levitonix CentriMag short-term ventricular assist device. J Heart Lung Transplant 2006;25(2):181-6.

4. Zhang J, Gellman B, Koert KA, Dasse KA, Gilbert RJ, Griffith BP, et al. Computational and experimental evaluation of the fluid dynamics and hemocompatibility of the CentriMag blood pump. Artif Organs 2006;30(3):168-77.

5. Mohite PN, Zych B, Popov AF, Sabashnikov A, Sáez DG, Patil NP, et al. CentriMag short term ventricular assist as a bridge to solution in patients with advanced heart failure: use beyond 30 days. Eur J Cardiothorac Surg 2013;44(5):e310-5.

6. Favaloro RR, Bertolotti A, Diez M, Favaloro L, Gómez C, Peradejordi M, et al. Ade quate systemic perfusion maintained by a CentriMag during acute heart failure. Tex Heart Inst J 2008;35(3):334-9.

7. Disposición 1509-14 ANMAT www.anmat.gov.ar/boletin_anmat/marzo_2014/ Dispo_1509-14.pdf

8. Shen TC, Tsai KT, Hu CY, Chen RJ. Skirted Cannula Technique for Apical Cannulation in Implantation of Centrimag Left Ventricular Assist Device. Ann Thorac Surg 2016;101(6):2404-6.

9. Ponikowski P, Voors AA, Anker SD, Bueno H, Cleland JG, Coats AJ, et al. 2016 ESC Guidelines for the diagnosis and treatment of acute and chronic heart failure: The Task Force for the diagnosis and treatment of acute and chronic heart failure of the European Society of Cardiology (ESC). Eur Heart $J$ 2016:37(27):2129-200
10. Feldman D, Pamboukian SV, Teuteberg JJ, Birks E, Lietz K, Moore SA. The 2013 International Society for Heart and Lung Transplantation Guidelines for mechanical circulatory support: Executive summary. J Heart Lung Transplant 2013;32(2):157-87.

11. Bertolotti AM, Peradejordi M, Favaloro L, Carballo M, Absi D, Favaloro LE, et al. EXperiencia con bomba centrífuga magnética en pacientes con shock cardiogénico (INTERMACS 1). Rev Argent Cardiol 2014;82(3):205-10.

12. Cohen Arazi H, Spampinato R, Waldman SV, Rodríguez W, Grancelli H, Schnetze $N$, et al. Asistencia circulatoria temporaria como puente al retrasplante. Rev Argent Cardiol 2010;78(6):516-7.

13. Villavicencio $M$, Larrea R, Larraín E, Turner F, Rivera J, Peralta JP, et al. Puente al trasplante de 4 semanas utilizando el sistema de asistencia ventricular Levitronix Centrimag ${ }^{\circledast}$ en el shock cardiogénico post-infarto al miocardio. Caso clínico. Rev Med Chile 2010;138(6):752-757.

14. Villavicencio M, Larraín E, Larrea R, Peralta JP, Lim JS, Rojo P, et al. Bridge to trans plant or recovery in cardiogenic shock in a developing country. Asian Cardiovasc Thorac Ann 2017;25(2):105-12.

15. Garzon-Rodriguez JD, Obando-Lopez C, Giraldo-Grueso M, Sandoval-Reyes N, Camacho J, Umaña JP. Mechanical circulatory support as bridge therapy for heart transplant: case series report. BMC Research Notes 2018;11(1):430.

16. Breda JR, Gaia DF, Macedo M, Motta P. Martins M, Alves D, et al. Ventricular assist device implantation with CentriMag VAS ${ }^{\circledR}$ for biventricular mechanical support. Rev Bras Cir Cardiovasc 2013;28(3):401-4.

17. Borisenko O, Wylie G, Payne J, Bjessmo S, Smith J Yonan N, et al Thoratec CentriMag for Temporary Treatment of Refractory Cardiogenic Shock or Severe Cardiopulmonary Insufficiency: A Systematic Literature Review and Meta-Analysis of Observational Studies. Asaio Journal 2014;60(5):487-97. 


\title{
VENTILACIÓN NO INVASIVA EN EL TRATAMIENTO DE LA INSUFICIENCIA CARDÍACA
}

\author{
NONINVASIVE VENTILATION IN THE TREATMENT OF HEART FAILURE
}

\author{
DIEGO A. MÁRQUEZ' ', GUILLERMO R. CHIAPPERO²
}

\section{RESUMEN}

La insuficiencia cardíaca descompensada es uno de los motivos de consulta y hospitalización más frecuentes en cardiología. A pesar de los avances en el tratamiento farmacológico, la morbilidad y la mortalidad siguen siendo elevadas. Por ello, la terapia de ventilación con presión positiva representa una estrategia potencialmente beneficiosa, no invasiva y de fácil acceso, con el objetivo de mejorar la oxigenación, la hipoventilación y la hipercapnia, disminuir la poscarga de ventrículo izquierdo, la presión cardíaca transmural, y mejorar las funciones pulmonares y respiratorias. La elección del modo ventilatorio y la interfaz óptima depende de cada paciente, pero los más recomendados son la máscara facial total y el modo presión positiva continua en la vía aérea con la titulación progresiva de la presión ventilatoria hasta la mejoría clínica.

Palabras clave: insuficiencia cardíaca, ventilación no invasiva.

\section{ABSTRACT}

Decompensated heart failure is one of the most frequent reasons for consultation and hospitalization in cardiology. Despite advances in pharmacological treatment, morbidity and mortality remain high; therefore, positive pressure ventilation therapy represents a potentially beneficial, noninvasive and easily accessible strategy; with the aim of improving oxygenation, hypoventilation and hypercapnia, decreasing afterload of the left ventricle and transmural cardiac pressure and improving pulmonary and respiratory functions. The choice of ventilatory mode and optimal interface depends on each patient, but the most recommended are the full face mask and the continuous positive airway pressure mode with progressive titration of ventilatory pressure until clinical improvement.

Keywords: heart failure, noninvasive ventilation.

REVISTA CONAREC 2018;33(147):283-287 | DOI:10.32407/RCON/2018147/0283-0287

\section{INTRODUCCIÓN}

La insuficiencia cardíaca (IC) es un síndrome clínico frecuente que representa la etapa terminal de varias cardiopatías y constituye un grave problema de salud pública. La media de edad de aparición de la

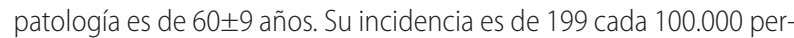
sonas y su prevalencia es del 1\%. La tasa de mortalidad al año es del 24,5\%, y aumenta en pacientes con fracción de eyección reducida, cardiopatía isquémica y enfermedad de Chagas'

La presentación aguda de la IC es uno de los motivos más frecuentes de consulta en la sala de urgencias y una causa habitual de hospitalización en unidades de cuidados intensivos. A pesar de los avances recientes en su tratamiento farmacológico, la morbilidad y la mortalidad siguen siendo elevadas², por lo que se ha buscado enfoques no farmacológicos que complementen la terapéutica convencional. La terapia de ventilación con presión positiva (PAP) representa una estrategia potencialmente beneficiosa que implica el mantenimiento de una determinada presión positiva en la vía respiratoria, de aplicación no invasiva (por medio de máscaras nasales, oronasales y facia-

1. Médico especialista en Terapia Intensiva. Hospital Juan A. Fernández. CABA

2. Jefe de Terapia Intermedia. Médico especialista en Terapia Intensiva, Neumonología y Medicina Interna. Docente Adscripto Medicina Interna Universidad de Buenos Aires (UBA). Director Carrera de especialista en Medicina Crítica y Terapia Intensiva sede Hospital Juan A. Fernández - UBA. Hospital Juan A. Fernández, CABA.

$\triangle$ Correspondencia:Dr.Diego A. Márquez.diegomarquez1981@gmail.com

Los autores declaran no poseer conflictos de intereses.

Recibido: 01/10/2018|Aceptado: 15/10/2018 les) (VNI) con la finalidad de optimizar la oxigenación, aliviar la hipoventilación y la hipercapnia, disminuir la poscarga del ventrículo izquierdo (VI), mejorar las funciones pulmonares y respiratorias, normalizando el patrón ventilatorio ${ }^{3}$.

\section{EFECTOS DE LA PRESIÓN POSITIVA EN PACIENTES SIN IC}

La PAP tiene varios efectos hemodinámicos. En primer lugar, disminuye el retorno venoso sistémico y la precarga del ventrículo derecho (VD) al aumentar la presión intratorácica. En segundo lugar, altera la resistencia vascular pulmonar total (RVP), que es la principal determinante de la poscarga del VD, a través de cambios que se producen en el volumen pulmonar mientras el paciente ventila.

En el parénquima pulmonar existen vasos intraalveolares, que se comprimen a medida que aumenta el volumen pulmonar, y vasos extraalveolares, que están expuestos a las fuerzas de dilatación a medida que aumenta dicho volumen. Por lo tanto, un cambio en la RVP total se caracteriza por una curva en forma de U (Figura 1), de acuerdo con las modificaciones del volumen pulmonar (la RVP más baja se puede observar en el volumen pulmonar alrededor de la capacidad residual funcional) ${ }^{4}$. Por ejemplo, cuando el volumen pulmonar aumenta desde el volumen residual hasta la capacidad residual funcional, predominarán los efectos de este aumento de volumen en los vasos extraalveolares y, así, la capacidad vascular aumentará. En consecuencia, la RVP total disminuirá. Cuando el volumen pulmonar continúa aumentando de la capacidad residual funcional a la capacidad pulmonar total, predominarán los efectos de este aumento adicional del volumen en los vasos intraaveolares; la capacitancia vascular disminuirá y la RVP total aumentará. 


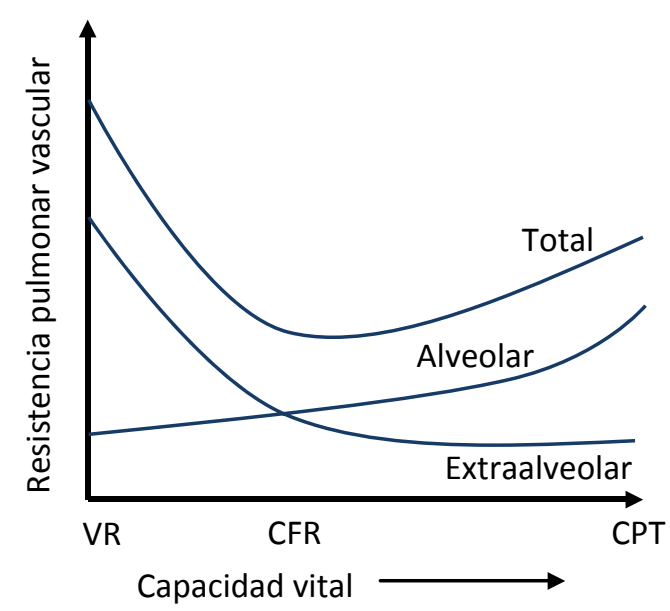

Figura 1. Relación entre volúmenes pulmonares y resistencia pulmonar vascular. VR: volumen residual. CFR: capacidad residual funcional. CPT: capacidad pulmonar total.

Aunque un bajo nivel de PAP aplicada sin un cambio excesivo en el volumen pulmonar no causa un aumento clínicamente importante en la poscarga del VD, es posible que esta última se incremente con aumentos ligeramente mayores de la presión. Powers et al. demostraron en 1973, al aplicar niveles de presión positiva de fin de espiración (PEEP) entre 5-10 $\mathrm{cm}$ de agua en pacientes con falla respiratoria aguda, un aumento de la RVP en 20 de 36 mediciones. En estos pacientes no se modificó el gasto cardíaco (GC) con fluidos o vasopresores, pero sí se observó su descenso en la mayoría de las mediciones, que se relacionaban de manera inversa con los cambios en la RVP (a mayor RVP menor GC).

En tercer lugar, una disminución de la precarga del VD (disminución del retorno venoso sistémico al VD) y un aumento de su poscarga (por aumento de la RVP) conducen a una reducción del retorno venoso pulmonar y limitaciones en el flujo y llenado del VI. Además, el aumento de la poscarga en el VD produce su dilatación, desplazamiento del septum interventricular, disminución del Ilenado del VI y consecuentemente reducción del GC y la perfusión sistémica.

En general, los pacientes sin IC son predominantemente dependientes de la precarga, especialmente en situaciones como hipovolemia o falla del VD. Por lo tanto, una reducción en la precarga cardíaca secundaria a la aplicación de presión positiva continua en la vía aérea (CPAP), puede disminuir el GC empeorando la condición hemodinámica del paciente.

\section{EFECTOS DE LA PRESIÓN POSITIVA EN PACIENTES CON IC}

La terapia con PAP en pacientes con IC se asocia a mejoras inmediatas en las variables respiratorias. El aumento de la presión inspiratoria y espiratoria incrementa el volumen corriente y descarga el trabajo de los músculos inspiratorios, disminuye el espacio muerto mejorando la ventilación alveolar, expande los alvéolos inundados y contrarresta la PEEP intrínseca. Además, previene las atelectasias y coloca al sistema ventilatorio en una posición más favorable dentro de la curva de presión/volumen.
El llenado y vaciado efectivo del corazón está determinado en parte por la diferencia de presión entre el interior del mismo y la presión intratorácica, conocida como presión transmural cardíaca (PTM). La amplitud de las oscilaciones inspiratorias es mayor en pacientes con IC y conduce a un aumento de la PTM6 . Mientras más positiva sea la PTM durante la diástole, mayor será el llenado cardíaco (precarga). Mientras más positiva sea la PTM durante la sístole, mayor será la carga de trabajo (poscarga). Durante la diástole, el aumento de la presión intratorácica inducida por la PAP reduce el retorno venoso, disminuye la precarga biventricular, y mejora la mecánica en un ventrículo sobrecargado. En la sístole, la CPAP aumenta la presión pericárdica, reduciendo la PTM y de ese modo disminuye la poscarga. Aunque puede disminuir el GC en personas sin IC como se describió previamente, en pacientes con disfunción sistólica el índice cardíaco aumenta ${ }^{7}$. No obstante, en pacientes con disfunción diastólica que requieren una presión de llenado comparativamente alta, los efectos de la terapia de PAP comprometen el retorno venoso, lo que resulta en un deterioro de la hemodinamia.

\section{ELECCIÓN DEL EQUIPO E INTERFASE}

En general, el equipo necesario para aplicación de VNI incluye: ventiladores, tubuladuras (una o dos ramas según el dispositivo a utilizar) y varios tipos de interfases para el paciente. Los ventiladores que se utilizan en la atención crítica estándar para la ventilación invasiva también se pueden utilizar para aplicar VNI, ya que la mayoría de estos cuentan con un módulo específico dentro de su software que les permite compensar la fuga que pudiera producirse por la inadecuada adaptación del paciente a la interfase. Además, hay varios dispositivos pequeños y simplificados que pueden proporcionar solo uno o dos modos para cuidados menos intensivos en las salas de cardiología general o para la atención domiciliaria en pacientes con fases subagudas o crónicas de la IC.

Las interfases son dispositivos que conectan las tubuladuras del ventilador a la cara del paciente, lo que permite el suministro de gas presurizado a las vías respiratorias durante la VNI. Las interfases disponibles actualmente incluyen máscaras nasales, oronasales y escafandras. La selección de una interfaz cómoda que se ajuste adecuadamente es de vital importancia para el éxito de VNI. En el contexto agudo, las máscaras oronasales son preferibles a las máscaras nasales porque los pacientes disneicos son en general respiradores bucales, lo que predispone a una mayor fuga de aire durante la ventilación con máscara nasal. Un tipo de máscara oronasal es la máscara facial total, fabricada con plástico transparente y que utiliza un borde de silicona suave que sella alrededor del perímetro de la cara. Se han desarrollado nuevos modelos de máscara facial con el objetivo de mejorar la comodidad del paciente y el rendimiento de la interfaz, con diseño liviano, conector de sellado para sonda de alimentación y un soporte de máscara que incorpora más de 4 puntos de fijación para asegurar las correas de la cabeza, que facilitan la adaptación del paciente ${ }^{8}$. En sujetos no hipercápnicos, existe la posibilidad de aplicar presión positiva utilizando una escafandra en vez de una máscara estándar. Las principales ventajas incluyen una interacción más satisfactoria de los pacientes con el entorno, me- 


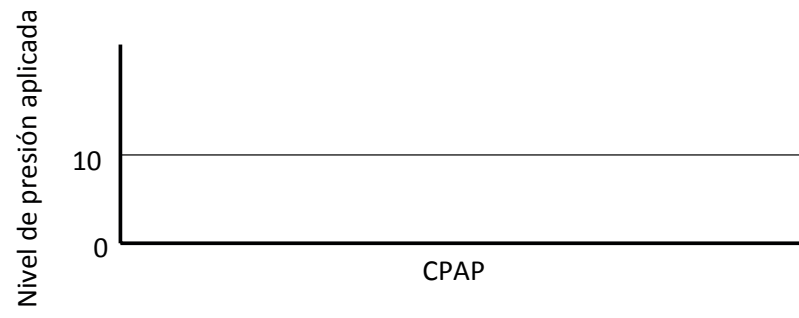

Figura 2. Presión positiva continua en la vía aérea. Provee un nivel de presión positiva continua durante la ventilación espontánea. CPAP: presión positiva continua en la vía aérea.

nor riesgo de lesiones en la piel, y en comparación con la máscara, aplicabilidad más fácil a cualquier paciente independientemente del contorno de la cara9

Un enfoque de trabajo puede basarse en elegir, mientras dure la necesidad de VNI, diferentes interfases en el mismo paciente eligiendo en cada ciclo la que otorgue mejor adaptación. Un efecto adverso frecuente con el uso de VNI prolongada es la sequedad oronasal. Se puede utilizar un humidificador activo interpuesto entre la salida del equipo de VNI y la interfase ${ }^{10}$. Una posible desventaja de este tipo de dispositivos incluye la acumulación de condensación dentro de las tubuladuras, que puede causar una disminución de la presión inspiratoria y un retraso de activación cuando se usan modos bilevel. Para resolver estos problemas de condensación, están disponibles sistemas de tubuladuras calentadas que contienen cables de cobre o sistemas de tubuladuras con trampas de agua.

\section{MODOS VENTILATORIOS}

En el tratamiento de la IC pueden ser consideradas numerosas modalidades de aplicación de presión positiva, si bien cada modo posee características distintivas de funcionamiento. En general, los más utilizados en la práctica clínica son dos: CPAP y BiPAP que se describen a continuación.

CPAP es el modo más utilizado de VNI en pacientes con IC. Proporciona un nivel constante de presión para mantener la permeabilidad de las vías respiratorias durante la ventilación espontánea y evitar el colapso alveolar. Solo proporciona un nivel constante de presión durante todo el ciclo respiratorio y no aumenta la presión durante la inspiración (Figura 2). En la práctica general, CPAP se utiliza con más frecuencia para el tratamiento de patología respiratoria del sueño. Algunos de estos dispositivos de CPAP están diseñados para detectar diversos grados de obstrucción de las vías respiratorias superiores y luego ajustar el nivel de presión para mantener abierta la vía aérea (Auto CPAP) (Figura 3) ${ }^{11}$. Algunos pacientes que no toleran CPAP manifiestan dificultad al exhalar contra la presión de la vía aérea generada por el dispositivo, especialmente en pacientes cuya presión terapéutica necesaria es alta (p. ej.: $>10 \mathrm{cmH}_{2} \mathrm{O}$ ). Para resolver este problema, algunos aparatos utilizan algoritmos específicos, como alivio de presión de fase espiratoria temprana ${ }^{12}$. Con estos algoritmos, la presión disminuye en la fase inicial de espiración para mejorar la comodidad y adaptación, pero la presión vuelve a la presión crítica

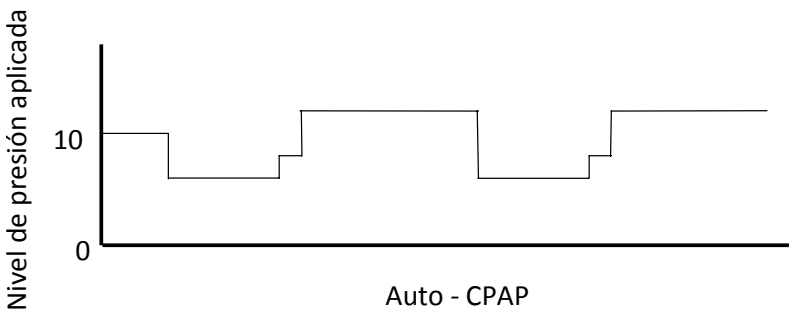

Figura 3. Los dispositivos auto-CPAP detectan distintos niveles de obstrucción de la vía aérea y adecuan la presión entregada para mantenerla abierta. CPAP: presión positiva continua en la vía aérea.

necesaria para mantener abiertas las vías respiratorias antes de la siguiente inspiración. El alivio temprano de la presión espiratoria se puede aplicar en combinación con otros modos ventilatorios. Debido a que los pacientes con IC no requieren presiones elevadas, incluso aquellos que a su vez presentan apneas obstructivas del sueño, y debido a que CPAP a altas presiones puede reducir el GC en algunos casos ya mencionados, rara vez se usa un algoritmo de alivio de presión para tratar este tipo de pacientes.

La modalidad bilevel proporciona dos niveles fijos de presión positiva en la vía aérea: un mayor nivel de presión durante la inspiración presión inspiratoria positiva de las vías respiratorias (IPAP) - y un menor nivel de presión durante la espiración -presión positiva espiratoria de las vías respiratorias (EPAP)- (Figura 4). Su principal diferencia con CPAP es que proporciona un apoyo de presión (presión de soporte) durante la inspiración. El nivel de soporte está determinado por la diferencia entre IPAP y EPAP, siendo el nivel de IPAP el que juega un papel importante en la descarga de los músculos respiratorios, reduciendo el trabajo ventilatorio, manteniendo la ventilación alveolar, reduciendo la presión parcial del dióxido de carbono $\left(\mathrm{PaCO}_{2}\right)$. EPAP produce efectos ventilatorios y hemodinámicos similares a los que proporciona CPAP.

Bilevel puede ser utilizado para pacientes que requieren CPAP a alta presión para controlar apneas obstructivas o para aquellos que no pueden tolerar la exhalación contra niveles de CPAP elevados. En la terapéutica de la IC, el objetivo del tratamiento con presión de dos niveles incluye reducir la hipercapnia en algunos pacientes con IC aguda descompensada o aquellos con EPOC o síndrome de hipoventilación por obesidad e IC coexistentes.

\section{EVIDENCIAS EN LA ELECCIÓN DEL MODO VENTILATORIO}

La superioridad del modo bilevel sobre la terapia estándar para el tratamiento de la IC aguda está claramente demostrada pero la cuestión de interés es si es superior a CPAP. Se han realizado numerosos ensayos aleatorios que intentaron responder a esta pregunta. En el trabajo publicado por Mehta et al. ${ }^{13}$, se asignaron de forma aleatoria pacientes para recibir CPAP nasal $\left(10 \mathrm{CmH}_{2} \mathrm{O}\right)$ o bilevel (IPAP $15 \mathrm{cmH}_{2} \mathrm{O} /$ EPAP $5 \mathrm{cmH}_{2} \mathrm{O}$ ). Aunque el grupo bilevel tuvo mayores reducciones en la presión arterial sistólica, la presión arte- 


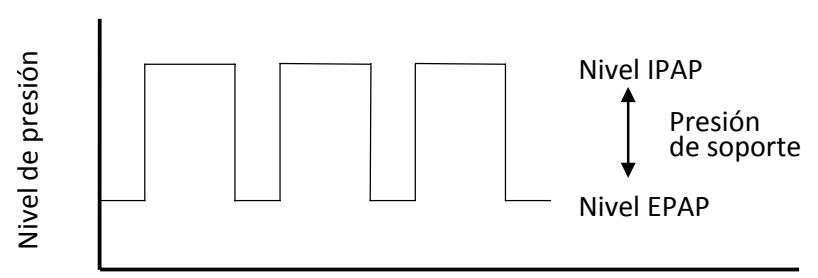

Tiempo

Figura 4. Modo bilevel: provee dos niveles de presión fijos IPAP/EPAP generando soporte durante la inspiración. IPAP: presión inspiratoria positiva. EPAP: presión espiratoria positiva.

rial media y la hipercapnia en comparación con el grupo CPAP, las tasas de infarto de miocardio fueron más altas en el primer grupo (71\%) que en el segundo (31\%), motivando la detención prematura del estudio. Si bien esta diferencia podría haber sido atribuible a la asignación al azar desigual (más pacientes en el grupo bilevel presentaban dolor torácico), los resultados, no obstante, plantearon inquietudes sobre la seguridad de las técnicas ventilatorias utilizadas para tratar la patología.

Por otro lado, Park et al..$^{14}$ y Bellone et al. ${ }^{15}$ demostraron que bilevel era tan efectivo como CPAP en el tratamiento de la IC y que ambos métodos mejoraron la ventilación y los signos vitales. No se encontraron diferencias significativas en la mortalidad hospitalaria y las tasas de infarto agudo de miocardio en pacientes con IC aguda en comparación con el empleo de CPAP. Más recientemente, Crane et al. ${ }^{16}$ asignaron al azar a 60 pacientes que presentaban IC aguda para recibir oxigenoterapia convencional, CPAP $\left(10 \mathrm{cmH}_{2} \mathrm{O}\right)$ o ventilación bilevel (IPAP $15 \mathrm{cmH}_{2} \mathrm{O}$, EPAP $5 \mathrm{cmH}_{2} \mathrm{O}$ ). Aunque el éxito del tratamiento ocurrió en tres pacientes en el grupo control, siete en el grupo CPAP y nueve en el grupo bilevel, 14 pacientes del grupo control sobrevivieron al alta hospitalaria, en comparación con 20 en el grupo CPAP y 15 en el grupo bilevel.

En una revisión sistemática en Cochrane ${ }^{17}$, se evaluaron los resultados de 32 ensayos clínicos aleatorizados dentro de los cuales 14 comparaban CPAP y bilevel mostrando que ambas terapéuticas reducen la mortalidad hospitalaria, la intubación endotraqueal, la estadía en la terapia intensiva y la frecuencia respiratoria en comparación con el estándar clásico de cuidados, sin mostrar diferencias significativas entre los resultados obtenidos entre las dos modalidades ventilatorias. También es importante destacar en esta revisión que, en comparación con los cuidados clásicos de la IC, el uso de VNI ya sea bilevel o CPAP, no aumentó la incidencia de infarto agudo de miocardio. Sin embargo, se identificó una menor incidencia de eventos adversos importantes en pacientes que recibieron bilevel, como un menor riesgo de progresión de insuficiencia respiratoria y coma. Entre los estudios que realizaron la comparación directa entre ambas modalidades, se observó una incidencia menor de arritmias con CPAP. El único evento adverso del uso de VNI identificado fue el daño a la piel generado por la utilización de máscaras, demostrando su efectividad y seguridad como terapia adyuvante para el tratamiento de la IC.

Sin embargo, en los diferentes estudios no queda claro cuándo utilizar una u otra forma de presión positiva. En general parece obje- tivarse un mayor beneficio con CPAP, a lo que habría que añadir su mayor facilidad de manejo y la existencia de dispositivos valvulares sencillos que permiten su aplicación, incluso, en la atención extrahospitalaria, con menores necesidades de entrenamiento por parte del personal que la utiliza. La ventilación bilevel quedaría restringida para los pacientes con hipercapnia o pacientes con enfermedad pulmonar obstructiva crónica e IC, donde el apoyo inspiratorio aportaría un beneficio extra. También podría manejarse en los pacientes que no responden adecuadamente con CPAP de inicio, como último intento antes de pasar a la intubación orotraqueal

\section{INDICACIONES PARA EL USO DE VNI}

Esta decisión se basa en criterios clínicos y gasométricos:

- Clínicos: sensación de disnea con frecuencia respiratoria mayor de 25-30 ventilaciones por minuto, empleo de músculos accesorios, aleteo nasal, ventilación paradójica, esfuerzo espiratorio aumentado.

- Gasométricos: pH menor a 7,35 y/o $\mathrm{PaCO}_{2}$ mayor a 45 mmHg o bien PAFI menor a 200.

\section{CONTRAINDICACIONES PARA EL USO DE VNI}

- Necesidad de intubación orotraqueal (paro cardiorrespiratorio inminente, frecuencia respiratoria mayor a 35, pH menor a 7,20, hipoxemia severa)

- Deterioro del sensorio que impida colaborar con la maniobra o proteger la vía aérea.

- Deformidad facial o trauma incompatible con la utilización de la mascarilla facial.

- Intervención quirúrgica reciente del esófago.

- Hemorragia digestiva alta grave

- Inestabilidad hemodinámica (shock) o arritmia cardíaca con descompensación hemodinámica.

\section{IMPLEMENTACIÓN}

Una vez decidido que el paciente tiene indicación de iniciar VNI, se debe tener en cuenta cuál va a ser el lugar elegido para aplicar la terapéutica. Si el paciente presenta alguna otra condición que requiera monitoreo avanzado o se evalúa que su estado clínico puede deteriorarse rápidamente, es preferible ingresar al paciente a la unidad de cuidados intensivos donde existe personal entrenado e infraestructura necesaria para el manejo de situaciones de alta complejidad.

Posteriormente, es necesario obtener el equipo con el que va a aplicar PAP (ventilador microprocesado/equipo de flujo contínuo) y la interfaz adecuada de acuerdo con la necesidad del paciente (en general máscara oronasal o facial completa).

El paciente debe estar en posición semisentada, y es fundamental comunicarle oralmente en qué consiste la maniobra y la importancia de su colaboración.

Como inicio en la elección de los niveles de presión, los trabajos recomiendan ${ }^{18}$ :

- CPAP: iniciar con $5 \mathrm{cmH}_{2} \mathrm{O}$, progresando posteriormente cada 1520 minutos hasta un máximo de $15 \mathrm{cmH}_{2} \mathrm{O}$. 
- Bilevel: comenzar con IPAP $8 \mathrm{cmH}_{2} \mathrm{O}$, EPAP $4 \mathrm{cmH}_{2} \mathrm{O}$ e incrementar hasta un máximo de 20-25 de IPAP y 12-15 de EPAP.

En todos los casos se debe aportar además oxígeno suplementario (desde el ventilador o adaptado a la interfase) para alcanzar un nivel de saturación por encima de $92 \%$.

Tras seleccionar los parámetros, poner en marcha el ventilador y apoyar suavemente la máscara en la cara del paciente sosteniéndola con la mano, evaluando constantemente la presencia de fugas y la adaptación del paciente. Una vez conforme con la respuesta a la maniobra, se debe fijar el arnés procurando que esté lo suficientemente ajustado como para evitar fugas pero que no genere lesiones en la piel (se puede proteger con parche hidrocoloide antes de colocar la interfase). Tras el inicio con los parámetros previamente citados, realizar incrementos progresivos de los niveles de presión buscando la mejoría clínica, que se define como un descenso de la frecuencia respiratoria y la desaparición de la utilización de músculos accesorios. Aproximadamente una hora posterior al inicio es necesario realizar una toma de muestra de sangre arterial para evaluar la gasometría.

\section{FINALIZACIÓN DE LA MANIOBRA}

Los motivos por los que se suspende la VNI son dos: mejoría o fracaso de la misma. Es necesario reconocer los factores de fracaso precoz de la VNI y proceder a la intubación orotraqueal ya que la persistencia de la situación de hipoxemia, acidosis y disnea y el retraso de la ventilación invasiva aumenta la mortalidad. No está claro cuál es el tiempo adecuado para evaluar la respuesta, pero en general se recomienda entre 30 minutos y 2 a 4 horas $^{19}$.

Los criterios de mejoría incluyen la resolución o estabilización de la causa desencadenante, la estabilidad clínica y hemodinámica, la disminución de la frecuencia respiratoria, la mejoría de la PAFI y el pH. Si el paciente evoluciona favorablemente se realizará un descenso progresivo de las presiones programadas hasta los niveles iniciales y posteriormente se retirará la máscara para colocar en caso de necesidad oxígeno suplementario.

\section{CONCLUSIÓN}

La utilización de CPAP tiene una clara indicación en el tratamiento de la IC descompensada como adyuvante al tratamiento convencional. A lo largo del tiempo se ha demostrado en ensayos clínicos su seguridad y eficacia en cuanto a la disminución de la mortalidad, la necesidad de intubación orotraqueal y la estadía en unidad cerrada, prácticamente sin aumentar las complicaciones. Si bien su aplicación es sencilla, y puede iniciarse inclusive en la atención prehospitalaria, requiere de personal entrenado y conocimientos de su funcionamiento y limitaciones para lograr mejores resultados.

\section{BIBLIOGRAFÍA}

1. Ciapponi A, Calderon M, Alcaraz A, Matta MG, Chaparro M, Soto N, et al. Carga de enfermedad de la insuficiencia cardíaca en América Latina: revisión sistemática y metaanálisis. Rev Esp Cardiol 2016;69(11):1051-60.

2. Lloyd-Jones D, Adams R, Carnethon M, De Simone G, Ferguson TB, Flegal K, et al. Heart disease and stroke statistics - 2009 update: a report from the American Heart Association Statistics Committee and Stroke Statistics Subcommittee. Circulation 2009:119(3):21-181.

3. Organized jointly by the American Thoracic Society, The European Respiratory Society, the European Society of Intensive Care Medicine, and the Societe de Reanimation de Langue Francaise, and approved by ATS board of Directors. International Consensus Conferences in Intensive Care Medicine: noninvasive positive pressure ventilation in acute respiratory failure. Am J Respir Crit Care Med 2001;163(1):283-91.

4. Guarracino F, Ambrosino N. Noninvasive ventilation in cardio-surgical patients. Minerva Anestesiol 2011;77(7):734-41.

5. Tomicic VF, Andresen M, Romero CP, Mercado MF. Impacto hemodinámico de la presión positiva de fin de espiración (PEEP) durante la falla respiratoria grave: visión actual. Rev Med Chile 2002;130(12):1429-30.

6. Naughton MT, Rahman MA, Hara K, Floras JS, Bradley TD. Effect of continuous positive airway pressure on intrathoracic and left ventricular transmural pressures in patients with congestive heart failure. Circulation 1995;91(6):1725-31.

7. Lenique F, Habis M, Lofaso F, Dubois-Randé JL, Harf A, Brochard L. Ventilatory and hemodinamyc effects of continuous positive airway pressure in left heart failure. Am J Resp Crit Care Med 1997;155(2):500-505.

8. Gabrielli A, Layon JA, Yun M. Civetta, Taylor and Kirby's Critical Care. (2009, Cuarta edición, 1939-1959). Philadelphia: Lippincott Williams \& Wilkins Publishers.

9. Antonelli M, Conti G, Pelosi P, Gregoretti C, Pennisi MA, Costa R, et al. New treatment of acute hypoxemic respiratory failure: noninvasive pressure support ventilation delivered by helmet a pilot controlled trial. Crit Care Med 2002;30(3):602-608.

10. Nishida T, Nishimura M, Fujino Y, Mashimo T. Performance of heated humidifiers with a heated wire according to ventilatory settings. J Aerosol Med 2001;14(1):43-51.
11. Ueno K, Kasai T, Brewer G, Takaya H, Maeno K, Kasagi S, et al. Evaluation of the apnea-hypopnea index determined by the S8 auto-CPAP, a continuous positive airway pressure device, in patients with obstructive sleep apnea-hypopnea syndrome. J Clin Sleep Med 2010;6(2):146-151.

12. Engleman HM, Asgari-Jirandeh N, McLeod Al, Ramsay CF, Deary IJ, Douglas NJ. Self-reported use of CPAP and benefits of CPAP therapy: a patient survey. Chest 1996;109(6):1470-1476.

13. Mehta S, Jay GD, Woolard RH, Hipona RA, Connolly EM, Cimini DM, et al. Randomized, prospective trial of bilevel versus continuous positive airway pressure in acute pulmonary edema. Crit Care Med 1997;25(4):620-628

14. Park M, Lorenzi-Filho G, Feltrim MI, Viecili PR, Sangean MC, Volpe M, et al. Oxygen therapy, continuous positive airway pressure, or noninvasive bilevel positive pres sure ventilation in the treatment of acute cardiogenic pulmonary edema. Ara Bras Cardiol 2001;76(3):221-30

15. Bellone A, Monrai A, Cortellaro F, Vettorello M, Arlati S, Coen D. Myocardial infarction rate in acute pulmonary edema: Noninvasive pressure support ventilation versus continuous positive airway pressure. Crit Care Med 2004;32(9):1860-65.

16. Crane SD, Eliott MV, Guiligan P, Richards K, Gray AJ. Randomized controlled comparison of continuous positive airways pressure, bilevel noninvasive ventilation, and standard treatment in emergency department patients with acute cardiogenic pulmonary edema. Emerg Med J 2004;21(2):155-61.

17. Vital FM, Ladeira MT, Atallah AN. Noninvasive positive pressure ventilation (CPAP or bilevel NPPV) for cardiogenic pulmonary oedema. Cochrane Database Syst Rev 2013;31(5):CD005351.

18. Gray A, Goodacre S, Newby DE, Masson M, Sampson F, et al. Noninvasive ventilation in acute cardiogenic pulmonary edema. New Engl J Med 2008;359(2):142-51.

19. Antonelli M, Conti G, Moro ML, Esquinas A, Gonzalez-Diaz G, Confalonieri M, et al. Predictors of failure of noninvasive positive ventilation in patients with acute hypoxemic respiratory failure: a multi-center study. Intensive Care Med 2001;27(11):1718-28. 


\section{Magnefen}

El fenofibrato más ventajoso en dislipemia aterogénica

- El fenofibrato de colina se disocia a su forma activa, ácido fenofíbrico, en el tubo digestivo

- El ácido fenofíbrico no requiere metabolismo de primer paso hepático para su activación

- El ácido fenofíbrico tiene mayor biodisponibilidad plasmática que el fenofibrato

- Tratamiento de elección en dislipemia mixta e hipertrigliceridemia severa

- Efectivo co-administrado con estatinas

- Óptima tolerabilidad en monoterapia como en combinación

- Puede administrarse con o sin alimentos

\section{INDICACIONES}
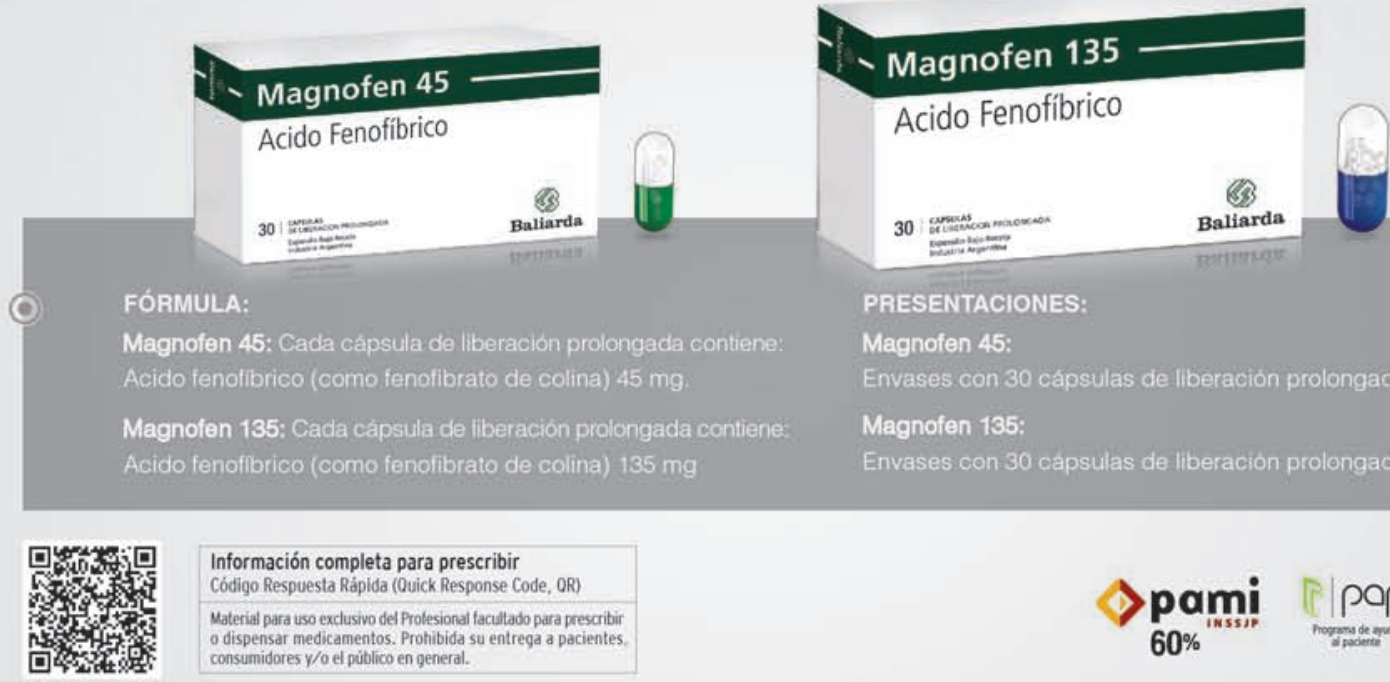

\section{PRESENTACIONES:}

Magnofen 45:

Envases con 30 cápsulas de liberación prolongada

Magnofen 135:

Envases con 30 cápsulas de liberación prolongada

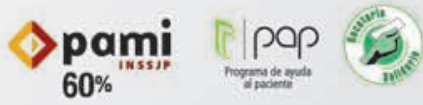

\section{Baliarda}




\title{
DESAFÍOS ESTRATÉGICOS EN INSUFICIENCIA CARDÍACA AVANZADA. ASISTENCIA VENTRICULAR. ¿ESTÁ TODO DICHO?
}

\author{
STRATEGIC CHALLENGES IN ADVANCED HEART FAILURE. VENTRICULAR \\ ASSISTANCE. IS IT ALL SAID?
}

\section{JIMENA SANTILLÁN}

\section{RESUMEN}

La insuficiencia cardíaca avanzada es la etapa final de múltiples enfermedades cardiovasculares y constituye en sí misma una de las patologías más prevalentes y con mayor morbimortalidad a nivel mundial. Se sabe que el tratamiento médico óptimo ha demostrado mejorar la sobrevida en términos de progresión de enfermedad y muerte súbita, así como el cardiodesfibrilador implantable y la terapia de resincronización cardíaca.

A pesar de esto, un porcentaje no menor alcanza estadios avanzados en quienes el trasplante cardíaco puede ser una opción. Debido a las limitaciones actuales que esto implica, surgió el desarrollo de los dispositivos de asistencia ventricular (DAV). El propósito de esta monografía es revisar los aspectos clínicos y tecnológicos de los DAV. Se realizará un análisis de su evolución desde las primeras asistencias, se evaluarán indicaciones, el momento oportuno para su implante así como sus contraindicaciones. Posteriormente, se realizará una revisión de los aspectos a tener en cuenta por parte del médico tratante para la evaluación precolocación, considerando los scores de riesgo disponibles, los aspectos psicosociales y el costo/beneficio de su utilización, para así poder evaluar el impacto y la factibilidad de su aplicación en la práctica clínica diaria.

Palabras clave: corazón auxiliar, insuficiencia cardíaca, trasplante de corazón.

\section{ABSTRACT}

Advanced heart failure is the final stage of multiple cardiovascular diseases, constituting in itself one of the most prevalent pathologies and with the highest morbidity and mortality worldwide. It is known that optimal medical treatment has been shown to improve survival in terms of disease progression and sudden death, as well as the implantable cardioverter defibrillator and cardiac resynchronization therapy. Despite this, a non-minor percentage reaches advanced stages in whom heart transplantation may be an option. Due to the current limitations that this implies, the development of ventricular assist devices (VAD) arose.

The purpose of this monograph is to review the clinical and technological as pects of VADs. An analysis of their evolution will be carried out from the first devices, indications will be evaluated, the opportune time for its implantation, as well as its contraindications. Subsequently, a review will be made on the aspects to be taken into account by the attending physician for the pre-placement evaluation, taking into account the risk scores available, psychosocial aspects and their cost / benefit; in order to evaluate the impact and feasibility of its application in daily clinical practice.

Keywords: heart-assist devices, heart failure, heart transplantation.

REVISTA CONAREC 2018;33(147):289-303 | DOI:10.32407/RCON/2018147/0289-0303

\section{INTRODUCCIÓN}

La insuficiencia cardíaca avanzada (ICA) es la etapa final de múltiples enfermedades cardiovasculares (ECV), y conforma en sí misma una de las patologías más prevalentes y con mayor morbimortalidad a nivel mundial. Se define por la presencia de deterioro severo de la fracción de eyección del ventrículo izquierdo (FEVI), síntomas graves progresivos y/o persistentes a pesar de máximo tratamiento médico, de dispositivos y quirúrgico constituyendo el estadio D de la clasificación de la American Heart Association (AHA) (Figura 1, Tabla 1) ${ }^{1-4}$.

En la última década se ha observado un aumento significativo en relación a cambios epidemiológicos que incluyen el envejecimiento poblacional, con el concomitante incremento de las comorbilidades, el desarrollo de nuevos métodos diagnósticos y tratamientos que prolongan la sobrevida y predisponen a múltiples reinternaciones ${ }^{5}$. En Argentina, la tasa de mortalidad por ECV fue en el 2014 de 148 por cien mil habitan-

1. Residente de Cardiología. Hospital Alemán. CABA.

$\triangle$ Correspondencia: Dra. Jimena Santillán. Av. Pueyrredón 1640. C1118AAT CABA. Rep.Argentina.jimenasantillan75@gmail.com.

Los autores declaran no poseer conflictos de intereses.

Recibido: 11/11/2017| Aceptado: 12/1/2018 tes y la insuficiencia cardíaca (IC) fue la principal causa de muerte ${ }^{6}$, representando el $18 \%$ del total en adultos mayores de 45 años $^{7}$.

A nivel mundial, la IC también lidera la causa de muerte: en los Estados Unidos (EE.UU.) la prevalencia excede los 5,8 millones y cada año se diagnostican más de 550.000 casos nuevo ${ }^{5}$ con una tasa de mortalidad anual de aproximadamente 280 mil pacientes, de los cuales 250 mil presentan IC severa ${ }^{8}$. Las cardiomiopatías y la enfermedad coronaria constituyen las principales causas subyacentes ${ }^{9}$.

En el estudio de Framingham se señaló que la incidencia de IC se duplica por cada década de vida, siendo el ascenso más pronunciado en la mujer que en el hombre ${ }^{10}$. Además, la prevalencia es de $1 \%$ para menores de 50 años, $5 \%$ entre los 50 y 70 años, con un aumento del 10\% por cada década a partir de los 70 años ${ }^{8}$.

Se sabe que el tratamiento médico óptimo, que incluye inhibidores de la enzima convertidora de la angiotensina (IECA), betabloqueantes (BB), inhibidores de la aldosterona, antagonistas del receptor de la angiotensina II (ARA) -los cuales han demostrado mejorar la sobrevida en términos de progresión de enfermedad y muerte súbita- actualmente incorpora dispositivos como el cardiodesfibrilador implantable (CDI) y la terapia de resincronización cardíaca (TRC) por haber demostrado similares beneficios. A pesar de estos avances, un porcentaje no menor alcanza estadios avanzados; en estos, las estrategias terapéuticas son complejas y en muchas ocasiones no accesibles ${ }^{1-4}$.

El primer trasplante cardíaco realizado en 1967 revolucionó el pronóstico de la ICA, aportando una nueva opción al paciente refractario. Sin embar- 
Tabla 1. Estadios de la insuficiencia cardíaca propuestos por ACCF/AHA y la Clasificación Funcional de la NYHA.

\section{Clase funcional de la NYHA}

\section{Estadios de la ACCF/AHA

\begin{abstract}
estructuralt.
\end{abstract} \\ Estadios de la ACCF/AHA \\ B Pacientes asintomáticos con cardiopatía estructuralt.

\author{
Síntomas actuales o pasados de ICC asociados con cardiopatía estructural
} subyacente.†$$
\text { C subyacente. }
$$ \\ Pacientes asintomáticos con cardiopatía estructuralt.}

Insuficiencia cardíaca avanzada: Cardiopatía estructural avanzada y síntomas

- severos en reposo, a pesar de terapia médica máxima. Se requieren intervenciones especializadas, como el tratamiento inotrópico hospitalario, trasplante o dispositivos de asistencia circulatoria

I Sin limitaciones de la actividad física.
I Sin limitaciones en la actividad física.
II Asintomático en reposo. La actividad habitual provoca síntomas
de IC.

III Marcada limitación de la actividad física. Asintomático en reposo.

\begin{abstract}
CF NYHA: Clase funcional New York Heart Association. ACCF: American College of Cardiology Foundation. AHA: American Heart Association. *: Hipertensión arterial, diabetes mellitus, obesidad, enfermedad coronaria (se excluyen de esta definición los pacientes con antecedentes de infarto agudo de miocardio). t: Antecedentes de infarto agudo de miocardio, disfunción sistólica, disfunción diastólica, hipertrofia del ventrículo izquierdo (determinadas por ecocardiograma o electrocardiograma), dilatación del ventrículo izquierdo, patologías valvulares, trastornos de la motilidad regional. Modificado de: Yancy CW, Jessup M, Bozkurt B, Butler J, Casey DE Jr, Drazner MH et al. 2013 ACCF/AHA guideline for the management of heart failure: a report of the American College of Cardiology Foundation/American Heart Association Task Force on practice guidelines. Circulation 2013;128(16):240-327.
\end{abstract}

go, nos enfrentamos al obstáculo que implica la desproporción en la relación donantes/receptor con listas de espera que superan los 80 días, con una media en pacientes en lista de urgencia de hasta 293 días ${ }^{11,12}$

Dicha escasez estaría explicada por diferentes motivos según las poblaciones analizadas: las nuevas leyes de tránsito y el perfeccionamiento de la industria automovilística, junto con las mejoras en leyes de seguridad y trabajo, que han resultado en un descenso de las muertes relacionadas a accidentes. Por otro lado, el continuo envejecimiento de la población llevó no solo a que el número de donantes haya disminuido sino también a que, los órganos procurados sean provenientes de personas de mayor edad, lo que se asocia a peores desenlaces postrasplante ${ }^{11,12}$. Es posible concluir por ello que, debido a las largas listas de espera por la escasa procuración de órganos, el número creciente de donantes con medidas de sostén avanzadas, los tiempos de isquemia condicionados por la extensión territorial y la ausencia de programas de gestión de salud, se ha hecho indispensable la búsqueda de alternativas al tratamiento médico y al trasplante cardíaco. Surge ante esta problemática el desarrollo de los dispositivos de asistencia ventricular (DAV), en un principio de corto plazo y en la actualidad de larga duración.

El propósito de esta monografía es revisar los aspectos clínicos y tecnológicos de los DAV. Se realizará un análisis de su evolución desde las primeras asistencias, se evaluarán indicaciones, el momento oportuno para su implante así como sus contraindicaciones. Posteriormente se realizará una revisión de los aspectos a tener en cuenta por parte del médico tratante para la evaluación precolocación considerando los scores de riesgo disponibles, aspectos psicosociales y el costo/beneficio de su empleo, para así poder evaluar el impacto y la factibilidad de su aplicación en la práctica clínica diaria.

\section{MATERIALES Y MÉTODOS}

Para realizar la siguiente investigación bibliográfica se utilizaron artículos originales, revisiones, editoriales, guías y diferentes publicaciones buscadas a través de los portales de Internet de la base de datos de la Biblioteca Nacional de los Estados Unidos Medline (PubMed) y Embase, en la base de revisiones sistemáticas Cochrane y en las bases de las principales revistas internacionales de cardiología y de medicina interna de la actualidad, así como en registros epidemiológicos nacionales y exper- tos en el tema. Se utilizó una restricción de idioma a inglés y español y sin restricción en las fechas de publicación.

Para la búsqueda se utilizaron los siguientes términos aislados o en combinación: "epidemiology of heart failure," "epidemiology of heart transplant", "history of VAD" "ventricular assist devices bridge to transplantation", "VAD bridge to transplant", "LVAD bridge to candidacy", "LVAD destination therapy", "ventricular circulatory support "', advanced heart failure," "complications of VAD", "mortality of VADs," "congestive heart failure therapy", "depression in heart failure," "prognosis of patients on wait list", "prolong wait list in heart failure" "evaluation of psychosocial risk in LVAD", "LVAD risk," "INTERMACS" El material fue clasificado por fecha y relevancia. En primer término, se analizaron los trabajos de revisión que luego generaron nuevas búsquedas bibliográficas. En segunda instancia, se consideraron los artículos originales, guías y editoriales con el objetivo de realizar un análisis crítico y profundo del tema.

\section{INSUFICIENCIA CARDÍACA AVANZADA Y EL DESARROLLO DE LAS ASISTENCIAS VENTRICULARES}

Conceptualmente la asistencia ventricular incluye a diversos dispositivos capaces de generar flujo circulatorio para sustituir parcial o totalmente la función del corazón en situaciones de falla aguda o crónica severas que no responden a otros tratamientos ${ }^{12}$.

En estudios recientes la disfunción sistólica se encuentra presente en el 5,5\% de las IC de la población anciana. En Estados Unidos (EE.UU.) la prevalencia de la IC excede los 5,8 millones, y de cada 550.000 casos diagnosticados por año cerca del $5 \%$ constituyen el estadio D de la $\mathrm{AHA}^{4}$ Por lo mencionado previamente acerca de la desproporción donante/ receptor, surge como alternativa la necesidad del implante de soporte circulatorio temporal hasta disponer del órgano apropiado o incluso en algunos casos como terapia final en aquellos que no son candidatos a trasplantarse $\mathrm{e}^{13-15}$.

En la década de 1950, con el advenimiento de las técnicas modernas de cirugía cardíaca, John Gibbon introdujo el uso clínico del bypass cardiopulmonar. De este modo se hizo posible realizar procedimientos de mayor complejidad y se establecieron los cimientos para el desarrollo de las asistencias ventriculares, llevando poco después a la introducción del 
soporte circulatorio fuera del quirófano. Los primeros en implantar un DAV para el tratamiento del shock cardiogénico fueron Cooley en 1960 y luego Liotta en 1963 $3^{16,17}$.

En 1964 el National Institutes of Health de EE.UU. desarrolló el Artificial Heart Program ${ }^{16}$ luego de la primera implantación exitosa de una asistencia ventricular izquierda (left ventricular assist device [LVAD]) con una duración de 10 días en un posquirúrgico de cirugía cardíaca. Poco después y luego del primer trasplante exitoso de corazón en 1967, se comenzaron a utilizar diferentes tipos de asistencia como puente a trasplante. El primer éxito con un corazón artificial total fue comunicado por Cooley et al. en 1969'16,17.

Debido a las complicaciones posquirúrgicas del trasplante, y con el apoyo del entonces recién formado National Heart and Lung and Blood Institute, se empezó a desarrollar en forma exponencial el campo de los DAV mecánica; es así como nacen los de primera generación. La década de los años 80 fue el acmé de los mismos, con el primer dispositivo de duración prolongada (112 días), el Jarvik-7 Total Artificial Heart (TAH). En el año 1984 se diseñaron nuevas bombas de asistencia de cámara única como puente a trasplante y con ellas se desarrolló la codificación de las distintas estrategias para su uso, lo que posibilitó lograr no solo el objetivo como puente a trasplante (bridge to transplant [BTT]) sino también como terapia de destino (destination therapy [DT]) y como puente a la recuperación (bridge to recovery [BTR]), como será explicado más adelante ${ }^{16,18}$.

Por lo anteriormente señalado, a partir del año 2003 los DAV dejaron de ser solo opciones terapéuticas para los pacientes elegibles para el trasplante, y comenzaron a utilizarse como DT. En el año 2006 nace la Interagency Registry of Mechanically Assisted Circulatory Support (INTERMACS) con el objetivo de ayudar a avanzar en la comprensión y aplicación de los DAV para mejorar la morbimortalidad y el estado de salud en pacientes con ICA ${ }^{16,18}$

Es por ello que INTERMACS ${ }^{19}$ ha definido siete perfiles clínicos en los pacientes con ICA antes de la implantación de un DAV, los cuales permiten la estratificación de los mismos en función de su perfil hemodinámico y el grado de daño de órgano blanco. Estos escenarios permiten mejor definición de la limitación y el grado de severidad de los pacientes ${ }^{1,2,19} \mathrm{y}$ se enumeran a continuación:

- Nivel 1. Shock cardiogénico, "crash and burn": pacientes hemodinámicamente inestables con hipoperfusión de órganos blanco a pesar de dosis máximas de inotrópicos y/o soporte mecánico.

- Nivel 2. Deterioro progresivo a pesar del soporte inotrópico, "sliding on inotropes": soporte inotrópico endovenoso permanente, manteniendo buena tensión arterial media (TAM) pero con un rápido deterioro de la función renal, estado nutricional o signos de congestión.

- Nivel 3. Estable pero dependiente de inotrópicos, "dependent stability": estabilidad hemodinámica con dosis bajas o intermedias de inotrópicos, necesarias para mantener TAM, evitar síntomas o falla renal.

- Nivel 4. Síntomas en reposo, "frequent flyer": paciente en clase funcional (CF) IV de la New York Heart Association (NYHA) ambulatorio, con síntomas recurrentes y sobrecarga de volumen.

- Nivel 5. Intolerancia al esfuerzo, "housebound": es también un paciente ambulatorio en CF IV de la NYHA que cesó toda actividad física, estable en el reposo pero con frecuente retención de líquido moderada y en algunos casos falla renal.
- Nivel 6. Esfuerzo limitado, "walking wounded": NYHA CF III. Limitación menor en la actividad física y ausencia de congestión en reposo. Se fatiga fácilmente con mínimos esfuerzos.

- $\quad$ Nivel 7. "Placeholder": paciente en CF III de NYHA sin desequilibrio en el balance hidrosalino actual o reciente.

Esta clasificación tiene el objetivo de unificar criterios en la descripción del estado clínico de los pacientes con ICA, optimizar la predicción de su riesgo perioperatorio y clarificar las indicaciones de cada una de las alternativas terapéuticas disponibles ${ }^{20}$. Actualmente la escala INTERMACS ha demostrado su valor para predecir mortalidad ${ }^{19,20} \mathrm{y}$ complicaciones posoperatorias ${ }^{21}$.

Esto fue analizado en un estudio retrospectivo por Barge Caballeroa et al. ${ }^{20} \mathrm{Al}$ utilizar los diferentes perfiles citados, observó el valor pronóstico posoperatorio en los pacientes con ICA trasplantados en carácter de urgencia. Como resultado del estudio se concluye que la mortalidad de los pacientes en el nivel 1 es tres veces superior que la de los pacientes en nivel 2 y cuatro veces superior que en aquellos en nivel 3 y 4 .

Con el avance tecnológico los DAV se fueron mejorando y desarrollando hasta la actualidad, en donde encontramos los de segunda y tercera generación con la aprobación del HeartMate // en el 2010, con más del $80 \%$ de supervivencia al año de la implantación y, con el nuevo corazón artificial bioprostético publicado recientemente por Carpentier et al. ${ }^{22}$ Actualmente las asistencias ventriculares se convirtieron en un paradigma en el tratamiento de la ICA pudiendo ser esta década la más prometedora para las mismas ${ }^{23}$.

Luego de este breve desarrollo histórico de la introducción de la asistencia ventricular en el tratamiento de la ICA, se describirán con más detalle las características, las ventajas y desventajas y los diferentes tipos de dispositivos disponibles.

\section{CLASIFICACIÓN Y HEMODINAMIA DE LOS DISPOSITIVOS DE ASISTENCIA VENTRICULAR}

Actualmente la industria se esfuerza por encontrar un dispositivo ideal, que sea durable, biocompatible, no trombogénico, resistente a la infección y de un costo razonable.

El primer dispositivo desarrollado fue el balón de contrapulsación intraaórtico (intraaortic balloon pump [IABP]) y continúa aún siendo el más comúnmente utilizado. Excede los propósitos de este trabajo su descripción pero básicamente fue diseñado para mejorar la relación entre el aporte y la demanda de oxígeno miocárdico. El IABP produce una modesta reducción de la sobrecarga ventricular, produce aumento de la TAM y del flujo coronario. Pero para su utilización los pacientes deben mantener algún grado de preservación de la función ventricular ${ }^{23}$.

Los nuevos DAV fueron diseñados para descargar de forma efectiva tanto el ventrículo izquierdo (VI) como el ventrículo derecho (VD). La sangre se obtiene de la aurícula izquierda o del propio VI, retornando a la aorta. Por consiguiente, se reducen las presiones y volúmenes intraventriculares, con reducción del estrés parietal y del consumo miocárdico de oxígeno ${ }^{24-26}$.

Si bien existen pocos estudios aleatorizados que comparan ambos tipos de asistencias, en un análisis de 117 pacientes con shock cardiogénico 


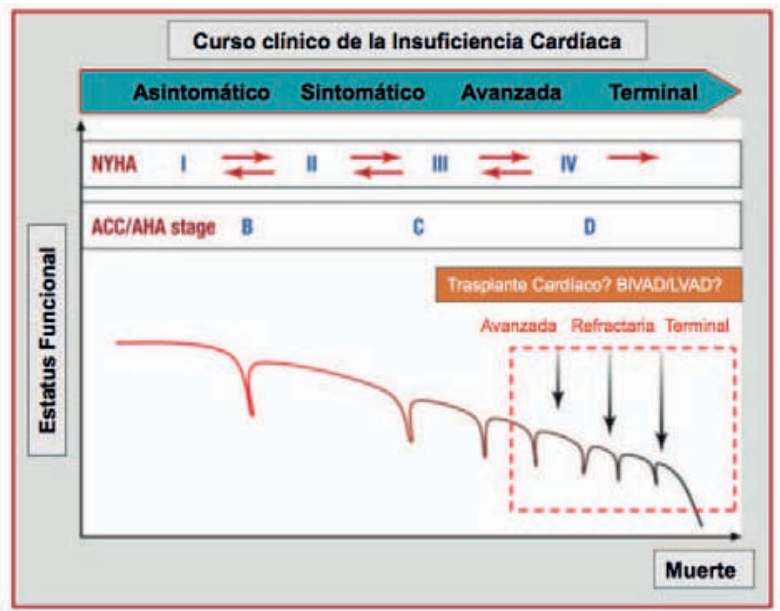

Figura 1. Curso Clínico de la insuficiencia cardíaca. Diferentes etapas y momentos oportunos para indicación de trasplante y/o dispositivos de asistencia ventricular. ACC: American College of Cardiology; AHA: American Heart Association; BiVAD: biventricular assist device (dispositivo de asistencia biventricular); LVAD: left ventricular assist device (dispositivo de asistencia ventricular izquierda); NYHA: New York Heart Association. Modificado de Tronchu JN. Left Ventricle assist devide: when and which patients should we refer?. Arch Cardiovasc Dis 2012;105(2):114-21.

refractario al IABP y/o vasopresores, Kar et al. ${ }^{27}$ observaron mejorías significativas en el índice cardíaco, la presión arterial sistólica, presión capilar pulmonar y función renal, con el uso de DAV durante un tiempo de implante promedio de 6 díass $^{28}$.

\section{DISPOSITIVOS DE PRIMERA GENERACIÓN}

Los primeros DAV fueron grandes sistemas de flujo pulsátil con una cámara de reservorio interna con válvulas de entrada y salida de flujo (Figura 2). Antes del año 2008 todas los DAV implantados en los EE.UU. usaban sistemas de flujo pulsátil con energía neumática (Abiomed BVS 5000, Thoratec VAD System, HeartMate 1000 IP LVAS, Berlin Heart, etc.) o eléctrica (Novacor N-100 LVAS, HeartMate 1000 XVE LVAS, LionHeart). Estos tenían excelente perfil hemodinámico y aumentaban la sobrevida pero con grandes limitaciones particularmente en cuanto a la duración a largo plazo, la necesidad de cirugías extensas para su colocación y largos cables extracorpóreos. Por estas características mencionadas eran más propensos a infección y la necesidad de una constitución corporal mediana a grande, un funcionamiento de la bomba audible y ruidoso, y con mayores complicaciones por ruptura del dispositivo hicieron que su uso decayera a lo largo de los años ${ }^{12,29}$ (Figura 3)

En el estudio Long-Term use of a left ventricular assist device for end stage heart failure del grupo Randomized Evaluation of Mechanical Assistance for the Treatment of Congestive Heart failure (REMATCH) $)^{30}$ la tasa de falla del dispositivo HeartMate 1000 XVE LVAS luego de 2 años fue del 35\% con una mortalidad del 10\%. Es así que desde que la Food and Drug Administration (FDA) aprobó el dispositivo HeartMate /l para BTT y luego para DT. el uso de los dispositivos de primera generación disminuyó desde el año 2007 de 316 implantes a 20 en 2013, representando los dispositivos de flujo continuo actualmente a más del $90 \%$ de las asistencias intracorpóreas 12,23,29,31.

\section{DISPOSITIVOS DE SEGUNDA GENERACIÓN}

Estos dispositivos fueron desarrollados con el objetivo de mantener la asistencia ventricular a mediano y largo plazo. Son bombas de flujo continuo que tienen sólo una parte en movimiento, el rodillo o rotor inter-

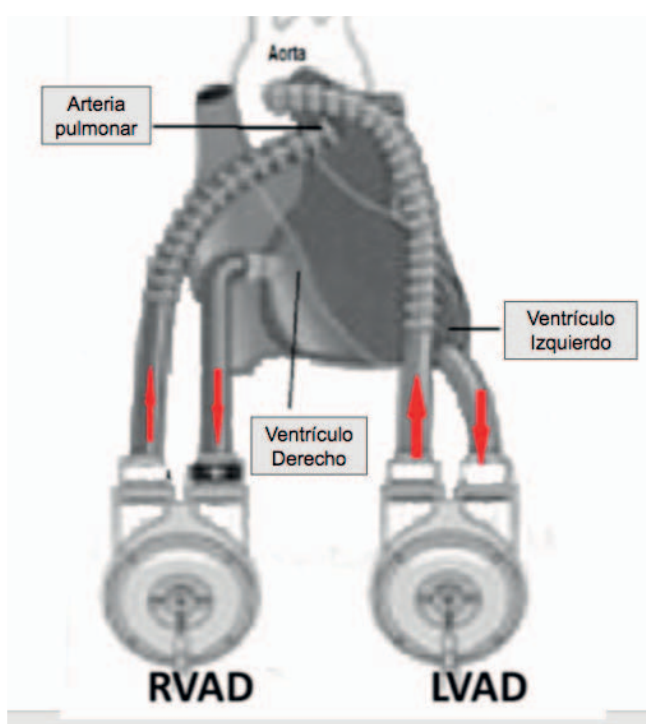

Figura 2. Esquema de Dispositivos de asistencia ventricular de primera generación. Uni o Biventriculares como en este caso. Extracorpóreos y de flujo pulsátil. RVAD: "right ventricular as sist device" (disposirivo de asistencia ventricular derecha). LVAD: "left ventricular assist device" (dispositivo de asistencia ventricular izquierda). Extraida y traducida del inglés de: Ferrari M, Kruzliak P, Spiliopoulos K. An insight into short and long term mechanical circulatory support systems. Clin Res Cardiol 2015;104(2):95-111.

no, eliminando la cámara de reservorio y las válvulas de entrada y salida siendo por lo tanto, mucho más duraderas. Tienen un soporte de contacto que guía el movimiento y reduce la fricción entre las partes móviles e inmóviles. Son más pequeños, silenciosos y la implantación quirúrgica es menos traumática. Las bombas de flujo continuo también tienen líneas de conducción pequeñas, tienden a tener menores tasas de infección y pueden generar gastos de hasta $10 \mathrm{l} / \mathrm{min}$. Al eliminar las válvulas generan menos complicaciones tromboembólicas a 2 años y menores tasas de fallo del dispositivo $0^{12,29,31}$.

En aquellos pacientes en quienes se produjo falla del dispositivo, el tiempo medio para el intercambio del mismo o mal funcionamiento fue 539,7 días, aunque esto varía en las diferentes series ${ }^{32}$. La etiología principal de fallo reportada es la trombosis. Esto se explicaría por el lavado incompleto de la estasis sanguínea a nivel del soporte que se encuentra en íntimo contacto con el rodillo ${ }^{31}$.

Están controlados y alimentados desde consolas portátiles y se han utilizado en numerosos casos como terapia definitiva. Se ha conseguido supervivencias de 4 años ${ }^{12,29,31}$ (duración media de soporte ventricular izquierdo de 504,7 días), y la incidencia estimada de fallo del dispositivo fue relativamente baja, de 3,9\% en las diferentes series ${ }^{32}$

Los sistemas de flujo axial que emplean poseen una cánula con una turbina eléctrica en su interior que girando a gran velocidad, expulsa por inercia la sangre desde el VI a la aorta. Los dispositivos más utilizados y aprobados por la FDA son el el HeartMate I/ (Figura 4) y el Jarvik2000

\section{Ila. HeartMate II}

El HeartMate ll fue el primero en ser aprobado por la FDA para DT y como BTT. Consta básicamente de tres partes: una bomba, cánulas de entrada y de salida, y un equipo controlador. El prototipo actual emplea un rotor axial de titanio con palas helicoidales que envuelven un eje central y un estator o circuito fijo, cuya función es asegurar un flujo laminar a la sali- 


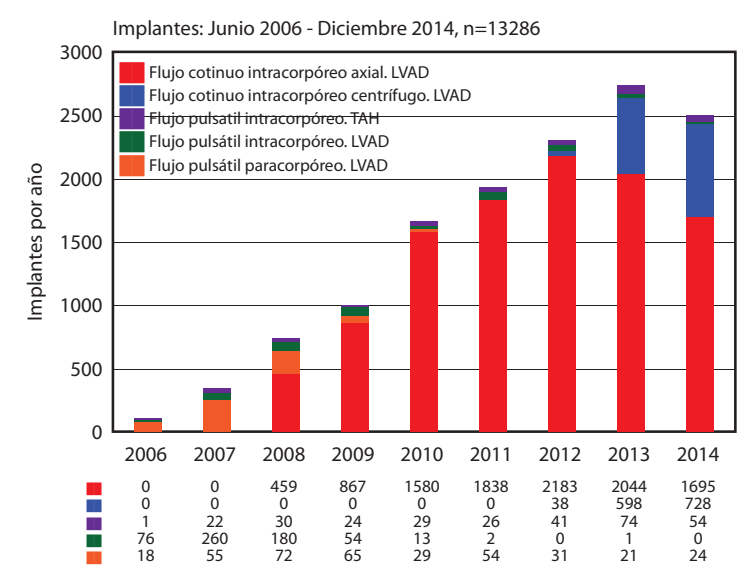

Figura 3. Distribución de dispositivos por tipo y año de implante. Se resalta el aumento del uso de los DAV de segunda generación (flujo axial) desde el año 2010 y el aumento del uso de los de tercera generación (centrifugos) a partir del 2013. LVAD: "left ventricular assist device" (dispositivo de asistencia ventricular izquierda). TAH: flujo pulsátil intracorpóreo. Modificado de: Kirklin JK, Naftel DC, Pagani FD, Kormos RL, Stevenson LW, Blume ED, et al. Seventh INTERMACS annual report: 15,000 patients and counting. J Heart Lung Transplant. 2015;34(12):1495-504

da de la bomba. La bomba se coloca debajo del reborde costal izquierdo, la cánula de entrada es metálica de titanio, en ángulo recto y cuenta con un manguito de filtro para ser suturado al ápex del ventrículo izquierdo (Figura 4). Una única línea de conducción eléctrica sale a través de la piel hacia el controlador que ajusta la velocidad de la bomba en respuesta a la demanda fisiológica. En la actualidad se encuentra en desarrollo un sistema transcutáneo de trasmisión de energía con el objeti-

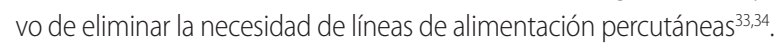

\section{Ilb. Jarvik 2000}

Es una bomba de flujo axial continuo que se caracteriza por ser un dispositivo silencioso, fácilmente implantable y portátil, consiste en una pequeña turbina que se sitúa en el ápex del VI, prácticamente encapsulada por el miocardio nativo. La sangre se impulsa a la aorta torácica descendente sin cánula de entrada ni válvulas, produciendo una corriente de alto flujo que lava continuamente la pequeña cámara a través de un tornillo de Arquímedes modificado que gira en el intervalo de las 1000 revoluciones por minuto, proporcionando un flujo continuo de hasta 10 litros por minuto. Todo ello reduce el riesgo de formación de trombos y hemólisis. La energía necesaria para su funcionamiento procede de una línea de conexión percutánea al sistema de baterías. La necesidad de anticoagulación en estos pacientes no está aún claramente establecida. Se ha utilizado en muchos casos como terapia definitiva, consiguiendo supervivencias de más de tres años ${ }^{35}$.

\section{DISPOSITIVOS DE TERCERA GENERACIÓN}

Son también dispositivos de flujo continuo que fueron diseñados con el objeto de mejorar el rendimiento, los aspectos mecánicos y la durabilidad de los DAV de segunda generación cuyo principal inconveniente es el desgaste por fricción en el soporte de contacto y el rodillo que tienen una vida útil (sumergida en sangre), de aproximadamente 5 años, siendo necesario en la DT una duración de aproximadamente 10 años ${ }^{31}$. Como consecuencia, se desarrollaron dispositivos de flujo continuo que utilizan bombas centrífugas más compactas, que no poseen soporte de contacto dado que utilizan la levitación magnética y/o hidrodinámica

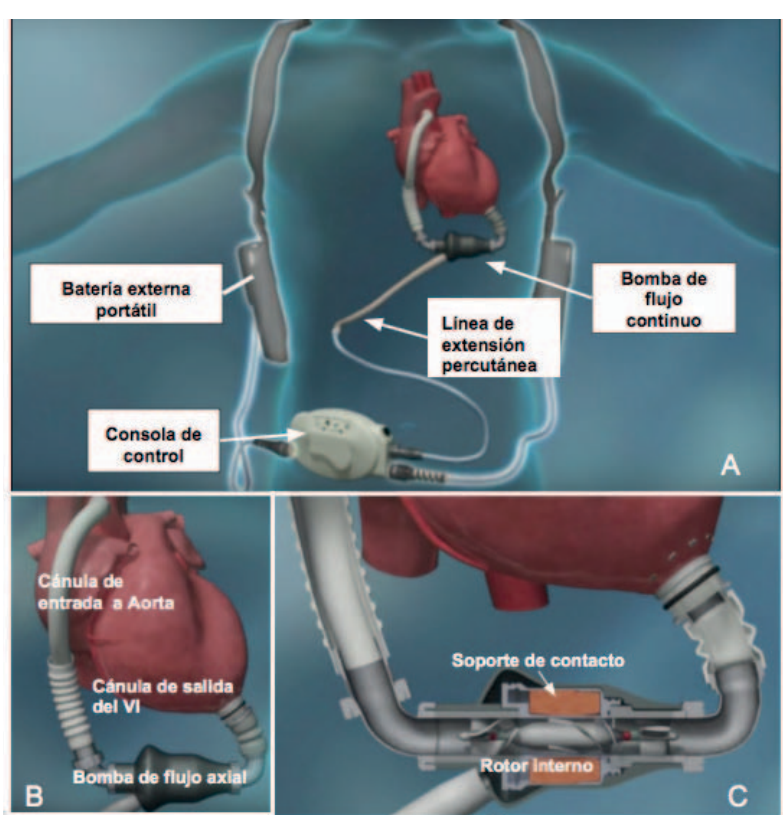

Figura 4. Heart Mate II. A: Ubicación intracorpórea del dispositivo, Baterías y consola externa. Unica línea de extensión percutánea. B y C: Conexiones. Nótese el rotor interno con las palas helicoidales en íntimo contacto con el soporte. VI: ventrículo izquierdo. Imagen extraída de video informativo en: http://heartmateii.com/heartmate-ii-system.aspx de @2014 Thoratec Corporation.

con esto se logra la suspensión del impulsor, las partes "flotan", no hay fricción, produciendo un menor desgaste en el rodillo. Además, este entorno libre de contacto está diseñado para optimizar la hemocompatibilidad. Al reducir el trauma sanguíneo mediante una suave manipulación del fluido con mayor flujo alrededor del impulsor que mejora el lavado, reduce la formación de trombos y de esta forma la necesidad de mantener valores elevados de Razón Normalizada Internacional (RIN) ${ }^{30,31}$

En cuanto a tamaño, son un poco más grandes que los de segunda generación. En algunos casos requieren de una inserción en un bolsillo a nivel abdominal, aunque se han diseñado dispositivos pequeños que pueden ser insertados en el espacio pericárdico. Si bien se espera que estos dispositivos duren por largos periodos todavía no se cuenta con estudios de seguimiento a más de 2 años 29,31 .

\section{Illa. HeartWare Ventricular Assist Device}

Es una bomba centrífuga miniatura (volumen de 50cc, pesa 160 gramos) que puede ser utilizada como LVAD (Figura 5) o biventricular (Biventricular assist device BiVAD) que utiliza un impulsor de hoja ancha (única parte móvil del dispositivo) suspendida por un sistema de soporte híbrido, magnético e hidrodinámico para evitar el contacto mecánico y el desgaste y así lograr un rendimiento óptimo, hemocompatibilidad y la fiabilidad a largo plazo. Es implantada en el espacio pericárdico y está diseñada tanto para pacientes internados como ambulatorios ${ }^{36,37}$. El Bridge to transplant HeartWare Left Ventricular Assist Device for the Treatment of Advanced Heart Failure (ADVANCE) study ${ }^{38}$ comparó 140 pacientes BTT sometidos al implante de un HeartWare, con 499 pacientes en un grupo de control de INTERMACS que eran en gran medida apoyados el HeartMate II. Las tasas de supervivencia a 1 año fueron 90,7\% en el grupo HeartWare y 90,1\% en el grupo control, lo que llevó a que la FDA apruebe el uso del HeartWare para los candidatos BTT y una expansión de las indicaciones más allá de las fronteras europeas. 


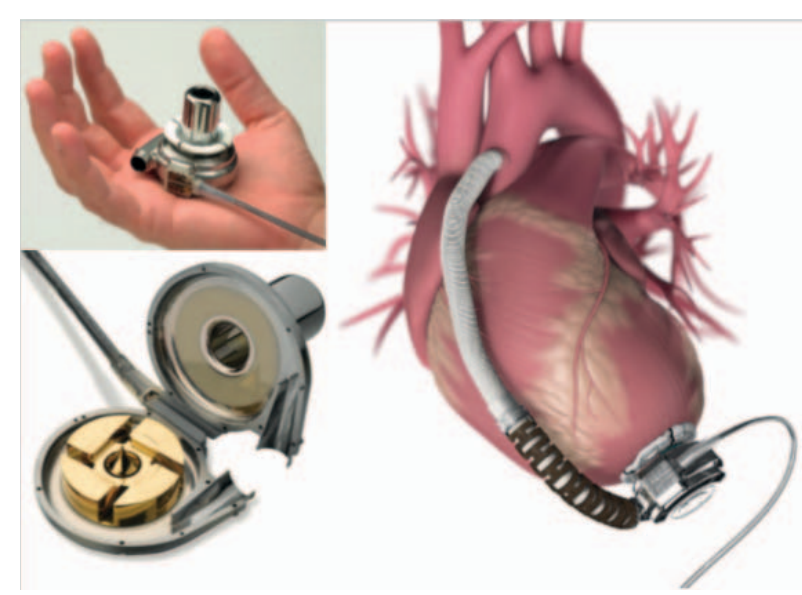

Figura 5. HeartWare LVAD: Mínimo tamaño de la bomba, con el impulsor de hoja ancha Implantado en el espacio pericárdico. Única línea de salida percutánea. Imagen de elaboración propia en base a: video informativo en https://www.heartware.com/products-technology/pump-design y Expert Rev Med Devices. $2013 \mathrm{Jul} ; 10$ (4):441-52.

En el estudio de no inferioridad ENDURANCE ${ }^{39}$ se compararon los resultados en los pacientes en DT en soporte con el HeartWare contra el actual líder de la industria, el HeartMate ll. Es un estudio multicéntrico prospectivo que incluyó 450 pacientes, los cuales fueron seguidos por 24 meses. Se randomizaron 2:1 a HeartWare o HeartMate II. Hacia el tercio final del estudio se realizaron cambios en el dispositivo HeartWare: en la cánula de flujo de entrada de la bomba, en el sistema de corte apical, y en las dosis antiplaquetarias y el régimen de anticoagulación (aspirina aumentó de 81 a 325 mg y el RIN de 2,0 - 3,0), lo que hizo suponer a los autores que durante dicha etapa se produciría una reducción de los eventos adversos. Se realizó una evaluación temporal para determinar el impacto de estos cambios. Se evidenció menor accidente cerebrovascu$\operatorname{lar}(\mathrm{ACV})$ hemorrágico y fallo ventricular derecho en el HeartMate ll. Pero estas diferencias se neutralizaron al analizar el grupo de pacientes ingresados luego de las modificaciones mencionadas. No hubo diferencias en cuanto al requerimiento de cambio de dispositivo en la cohorte completa $(89,7 \%$ vs $83,3 \%, p=0,066)$, pero fue significativamente menos frecuente en la cohorte HeartWare en el análisis del tercio final (96,3\% vs $85,0 \%, p=0,026)$. Los autores concluyeron que las mejoras en el dispositivo conllevan a una selección optimizada de los pacientes, a menos tasas de complicaciones y menor requerimiento de recambio. Así mismo resulta necesario para evitar mayores eventos de sangrado fatales y no fatales el ajuste óptimo de los fármacos antitrombóticos ${ }^{39}$.

\section{IIIb. Heart Mate III}

El HeartMate III (Figura 6) es un dispositivo de flujo continuo con una bomba centrífuga con un rotor con doble función: motora y de levitación magnética rotacional y radial. Ambas se logran en una sola unidad integrada que incorpora todos los componentes electrónicos de control en la carcasa inferior del dispositivo, lo que resulta en un rendimiento eficiente y compacto. Los grados de libertad. movimiento axial y de inclinación, se consiguen mediante soporte magnético pasivo sin consumo de energía ${ }^{31,33}$. El dispositivo continúa en evaluación y está pendiente su aprobación.

\section{SOPORTE BIVENTRICULAR}

Actualmente se cuenta con la aplicación del HeartWare como BiVAD y del SynCardia TAH (Figura 7). Este es solo para pacientes con superficie

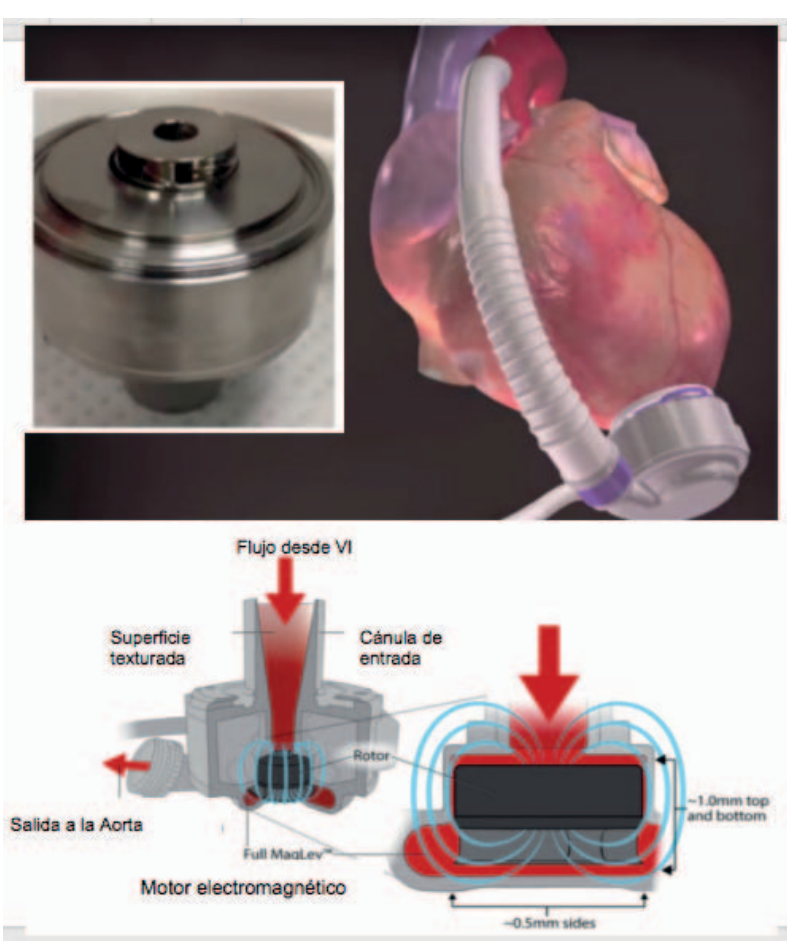

Figura 6. HeartMate III LVAD con sus diferentes partes: motor electromagnético y cánulas de entrada y salida. VI: ventrículo izquierdo. VI: ventrículo izquierdo. Imagen de elaboración en base a: Netuka I, BeyersdorfF, Garbade J, Krabatsch T, Marasco S, Morshuis M, et al. HeartMate 3 fully magnetically levitated LVAD for the treatment of advanced heart failure: results from the CE Mark Trial. Presented at the 19th Annual Meeting of the Heart Failure Society of America (HFSA); 2015

corporal de más de 0,7 m² y consiste en dos ventrículos semirrígidos cubiertos con cuatro diafragmas flexibles de poliuretano que separa las cámaras sangrientas de las cámaras de aire de poliuretano. Está aprobado para su uso en los EE.UU., Canadá y Europa. Se implantó por primera vez en un paciente en la Universidad de Arizona en 1988, y más de 1.100 pacientes ya han recibido el apoyo de la SynCardia TAH siendo el soporte más largo de 1374 días antes del trasplante de corazón con éxito ${ }^{24}$. Se encuentra en estudio el corazón bioprotésico de Carpentier et al. ${ }^{22}$ el CARMAT TAH, con solo 2 pacientes reportados. Es una bomba pulsáti que usa energía electrohidráulica. Todos los componentes están incorporados en un solo dispositivo colocado en el saco pericárdico después de la escisión de los ventrículos nativos. Promete ser biocompatible y tener un comportamiento más fisiológico.

\section{EVALUACIÓN PARA EL IMPLANTE DE LOS DAV}

\section{INDICACIONES}

En los pacientes con ICA, los avances tecnológicos han facilitado el uso de los dispositivos de asistencia ventricular tanto izquierda o derecha como biventricular, implantables quirúrgicamente como puente a la recuperación, puente para el trasplante, para su uso como terapia permanente (destino) y, actualmente puente a la candidatura (bridge to candidacy $[\mathrm{BTC}])^{40,41}$.

Según se desprende de lo analizado previamente, independientemente de la causa que lleve al implante de un dispositivo, como principales beneficios se busca:

- Mantener una adecuada perfusión de órganos vitales. 


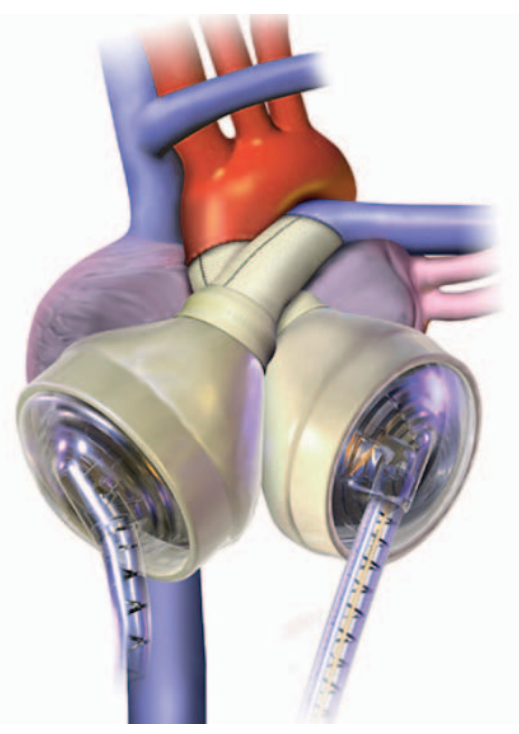

Figura 7. Syncardia Total Artificial Heart. 2 ventrículos semirrígidos cubiertos con cuatro diafragmas flexibles de poliuretano. Imagen extraída de: www.syncardia.com

- Disminuir las presiones intraventriculares y así bajar la congestión pulmonar.

- Disminuir los volúmenes ventriculares, el estrés parietal y el consumo de oxígeno.

- Aumentar la perfusión coronaria.

- Apoyo circulatorio durante intervenciones cardíacas y electrofisiológicas complejas.

La guía de IC de la Sociedad Europea de Cardiología 2016 divide las indicaciones según las características clínicas de los pacientes:

1) Pacientes potencialmente elegibles para la implantación del $L V A D$, refiriéndose a pacientes con más de 2 meses de síntomas severos a pesar de tratamiento médico óptimo, TRC o colocación de CDI, y alguna de las siguientes:

- $\mathrm{FEVI}<25 \%$ y consumo máximo de oxígeno $<12 \mathrm{ml} / \mathrm{kg} / \mathrm{min}$.

- Más de 3 hospitalizaciones en los últimos 12 meses sin una causa precipitante.

- Dependencia de inotrópicos endovenosos.

- Disfunción progresiva de órgano blanco (empeoramiento del daño renal o hepático) debido a mala perfusión y no a presiones inadecuadas del llenado ventricular (presión capilar pulmonar $>20$ mmHg, presión sistólica <80-90 o índice cardiaco <2 l/min/m²).

- Ausencia de disfunción ventricular derecha junto con insuficiencia tricuspídea severa.

2) Recomendaciones (Clase de evidencia lla. Nivel C) para la implantación de LVAD en paciente con ICA:

- Un LVAD debe ser considerada en pacientes que tienen IC con deterioro severo de la FEVI en fase terminal a pesar del tratamiento médico y el dispositivo óptimo y que son elegibles para el trasplante de corazón con el fin de mejorar los síntomas, reducir el riesgo de hospitalización por insuficiencia cardíaca y el riesgo de muerte prematura (BTT).

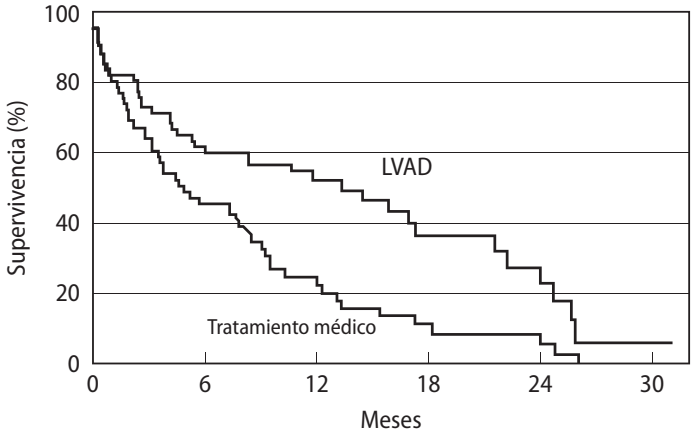

№ en riesgo

$\begin{array}{lllllll}\text { LVAD } & 68 & 38 & 22 & 11 & 5 & 1\end{array}$

$\begin{array}{lllllll}\text { Trat. médico } & 61 & 27 & 11 & 4 & 3 & 0\end{array}$

Figura 8. Curva de Kaplan-Meier. LVAD: left ventricular assist device (dispositivo de asistencia ventricular izquierda). Modificado de: Rose EA, et al. Long-term use of a left ventricular assist device for end-stage heart failure. Randomized Evaluation of Mechanical Assistance for the Treatment of Congestive Heart Failure (REMATCH). N Engl J Med 2001;345(20):1435

- Un LVAD debe ser considerada en pacientes IC con deterioro severo de la FEVI en etapa terminal a pesar del tratamiento médico y el dispositivo óptimo y que no son elegibles para el trasplante de corazón para reducir el riesgo de muerte prematura (DT).

Según las variables mencionadas del INTERMACS ${ }^{19}$ y las recomendaciones de las guías arriba mencionadas existen diferentes contextos clínicos para la indicación de los DAV.

\section{la. Puente a trasplante}

Es uno de los principales escenarios en el cual se propone el uso de los DAV en aquellos pacientes seleccionados con ICA que serían candidatos a trasplante y en los cuales no hay disponible un donante. En los EE.UU., la indicación BTT se realiza para estabilizar la circulación hemodinámica en pacientes con muy mala función cardiaca, para lograr una mejor perfusión y función de órganos nobles al momento del trasplante 25,29 .

En estos pacientes se utilizan fundamentalmente las asistencias pulsátiles, tanto en situación intra como paracorpórea. Los mejores resultados se obtienen en series en las que el implante es precoz y se realiza en forma electiva, contrario a lo observado en los casos indicados en carácter de urgencia ${ }^{42}$.

La evidencia y el uso aún siguen siendo controvertidos. En EE.UU. se realizó un estudio prospectivo en 5 centros en el que se comparó la seguridad y la eficacia del sistema Syncardia CardioWest como puente a trasplante en 81 pacientes con IC avanzada, contra un grupo histórico de características balanceadas. Era una población en CF IV de la NYHA, con un índice cardíaco $<2 \mathrm{l} / \mathrm{min} / \mathrm{m}^{2}$, tensión arterial sistólica $<90$ mmHg o una presión venosa $>18$ mmHg bajo tratamiento inotrópico o IABP. El 79\% de los pacientes del grupo con DAV se trasplantó con éxito y con diferencia significativa respecto al otro grupo en el que fue del $46 \%(p<0,001)$. Al año la diferencia en la supervivencia fue del 70\% versus el 31\%, significativo también para el grupo tratamiento ${ }^{12}$

En otra revisión retrospectiva realizada en el Hospital Universitario de Pensilvania entre los años 1995-2007; se analizaron 266 pacientes que recibieron: LVAD, BiVAD programada y un tercer grupo en donde se debió implantar un BiVAD de urgencia. Al observar los resultados en los que eran pacientes en plan de trasplante cardíaco $(n=141)$ aquellos que recibieron LVAD en el 79\% fueron trasplantados sin diferencias significa- 


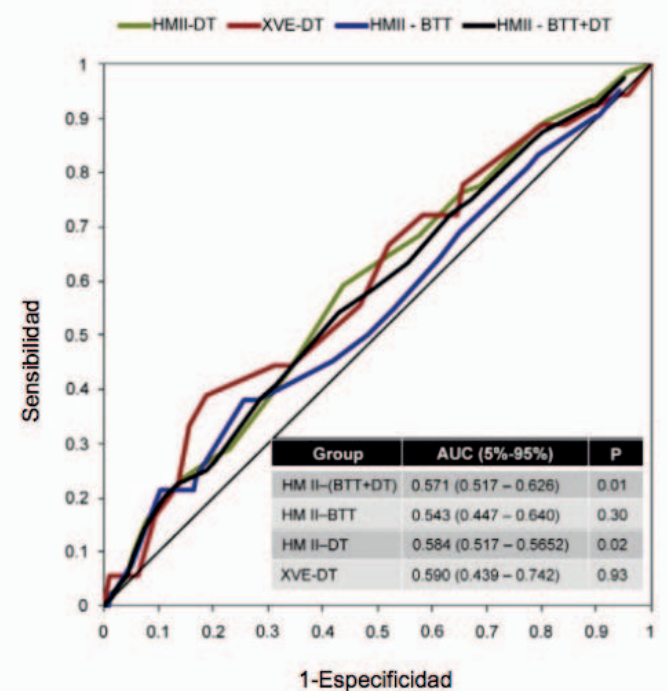

Figura 9. Curva ROC que evidencia moderada sensibilidad del Destination Therapy Risk Score. HM II: Heart Mate II. BTT: "bridge to trasplantationt" (puente a trasplante). DT: "destination therapy" (terapia de destino). XVE Modificado de Teuteberg JJ, Ewald GA, Adamson RM, Lietz K. Miller LW, Tatooles AJ et al. Risk assessment for continuous flow left ventricular assist devices: does the destination therapy risk score work? An analysis of over 1,000 patients.J Am Coll Cardiol. 2012;60(1):44-51

tivas con los que presentaron BiVAD programada (65\%). Si presentaron diferencias significativas en sobrevida al comparar el grupo de LVAD vs. BiVAD de urgencia (10/22 $p=0.0009)$. Estos resultados se mantuvieron al analizar la tasa de egreso hospitalario y sobrevida extrahospitalaria. Por lo que los autores destacan que en este grupo de pacientes es importante la decisión inicial más que el tipo de asistencia elegida ${ }^{41}$

\section{Ib. Terapia de destino}

En pacientes seleccionados con ICA que no son aptos para trasplante cardíaco, reciben DAV como DT para mejorar no solo la sobrevida sino también la calidad de vida y los síntomas. Ésta estrategia ha constituido el mayor porcentaje de pacientes con LVAD desde $2011^{29}$.

En el estudio REMATCH ${ }^{30}$ se validó el beneficio de los DAV en 129 pacientes con ICA con contraindicaciones para el trasplante cardíaco. Los criterios de inclusión fueron la presencia de CF IV durante al menos 90 días, FEy $<25 \%$ y un consumo de oxígeno $<12 \mathrm{ml} / \mathrm{kg} / \mathrm{min}$ o la necesidad de tratamiento inotrópico. Fueron asignados al azar para recibir tratamiento médico óptimo o un HeartMate I LVAD como DT. La supervivencia a un año en el grupo de asistencia ventricular izquierda fue de 52\% comparado con el $25 \%$ en el grupo de terapia médica óptima $(p=0,002)$, a dos años la supervivencia fue del $23 \%$ comparado con el $8 \%$ en el grupo de terapia médica $(p=0,09)$. En general, la mortalidad por todas las causas se redujo en un 48 por ciento mediante la inserción de la asistencia ventricular izquierda (Figura 8). Hubo una mejoría de la CF y las mediciones de la calidad de vida mejoraron de forma significativa a un año de seguimiento en el grupo de asistencia ventricular izquierda. La IC fue la principal causa de muerte en el grupo tratamiento médico, mientras que en grupo LVAD lo fueron la sepsis y la falla del dispositivo ${ }^{30}$.

Estos hallazgos son consistentes en todas las series y como ya se mencionó anteriormente las nuevas tecnologías aplicadas a DT como en el estudio ENDURANCE ${ }^{39}$ con el HeartWare y el HeartMate II, refieren mejoría de la sobrevida, la calidad de vida, y menor impacto psicológico en los pacientes. Esto sugiere que los beneficios de la restauración de un perfil hemodinámico relativamente normal podrían superar el riesgo quirúrgico y las complicaciones posteriores ${ }^{34,39,42}$

Como principales candidatos a esta indicación se han propuesto los pacientes con IC con más del 50\% de mortalidad esperada al año y que no sean candidatos a trasplante: pacientes en shock cardiogénico, con IC crónica con bajo gasto y daño de órgano blanco, dependientes de inotrópicos en CF IV, pacientes con IC crónica con caquexia cardíaca, consumo de $\mathrm{O}_{2}$ máximo $<10 \mathrm{ml} / \mathrm{kg} / \mathrm{min}$, hiponatremia o insuficiencia renal progresiva ${ }^{12}$

\section{Ic. Puente a la recuperación}

Los DAV en combinación con terapias optimizadas pueden, al desprecargar el VI, inducir la recuperación del miocardio en un subgrupo de pacientes con miocardiopatía no isquémico necrótica ${ }^{41}$. Si luego de la evaluación del paciente y de su función ventricular a bajo o mínimo soporte mecánico hay pruebas de significativo remodelado reverso miocárdico, estos paciente en terapia "puente a la recuperación" pueden ser considerados para el retiro de la asistencia ${ }^{43}$. Hay reportes de casos con exitosa explantación del dispositivo y recuperación completa de la fracción de eyección ventricular izquierda $(\mathrm{FEVI})^{44}$.

Birks et al. ${ }^{45}$ reportaron $70 \%$ de explantes del Heartmate VAD en una serie de 15 pacientes tratados con IECA, BB, ARA, espironolactona y clenbuterol. Esta cohorte tuvo una tasa de supervivencia de $82 \%$ a 4 años y e 88\% evolucionaron libres de IC recurrente. Todavía está en estudio la forma de weaning del LVAD. La combinación de la terapia agresiva médica, descarga del VI y el programa de vigilancia cuidadosa podría ser una estrategia con excelentes resultados a corto y medio plazo.

En la práctica, esta indicación es minoritaria, representa sólo el 6\% de los DAV implantados entre el 2003-2004 en un Registro Internacional ${ }^{46}$ En este escaso porcentaje se observó explantación en el 50\% de los casos, con una supervivencia a largo plazo de entre 25 y 30\%. Varios estudios observacionales y registros han intentado buscar predictores clínicos, hemodinámicos, ecocardiográficos, neurohormonales, anatomopatológicos capaces de identificar aquellos pacientes que podrían presentar recuperación ventricular, sin encontrar ninguno significativo hasta el momento 44,46

Las principales indicaciones para esta estrategia son: miocarditis aguda, fallo agudo primario del injerto postrasplante y miocardiopatía periparto, además del shock cardiogénico?.

\section{Id. Puente a la candidatura}

Desde que el trasplante cardíaco es una opción más realista después de la terapia con DAV en EE.UU., se utilizan en los casos en los que la indicación de trasplante no es claro, como "puente a la candidatura" bajo la indicación de DT. Esta opción da tiempo para investigar la idoneidad de trasplante, mientras se estabiliza y, a menudo se mejoran los parámetros críticos como el aumento de la resistencia vascular pulmonar, un marcador de riesgo de falla ventricular derecha luego del trasplante ${ }^{27}$. Por lo tanto, se indica habitualmente a pacientes con ICA o compromiso de órgano blanco con contraindicaciones relativas al trasplante en los cuales el perfil hemodinámico podría mejorar pudiendo considerarse de nuevo la opción del trasplante o de lo contrario la DT 1,47.

Además, los DAV pueden ser una opción aceptable para pacientes con una enfermedad oncológica reciente que pueda ser curada y 
en quien no se llegaría a cumplir los 5 años libres de enfermedad requeridos típicamente para el trasplante ${ }^{1,2,47}$.

\section{II. ¿CUÁL ES EL MOMENTO OPORTUNO PARA LA COLOCACIÓN DE UN DAV?}

En la IC aguda los pacientes sin disfunción cardíaca previa que requieren soporte hemodinámico se someten a DAV como "tratamiento de rescate". El enfoque actual en muchos centros es estabilizar la circulación y mejorar la perfusión de los órganos blanco ${ }^{41}$ con estrategias como la oxigenación por membrana extracorpórea (ECMO) o IABP o bombas de circulación extracorpórea, al intentar recuperar la función del corazón con revascularización o tratamiento médico. Los pacientes que no logran una recuperación temprana de la FEVI pueden ser considerados para un DAV de larga duración, predominantemente izquierdo (LVAD) o BiVAD'. El registro INTERMACS muestra mejores resultados en los pacientes implantados con un nivel INTERMACS 4 a 7, aunque la mayoría se realizan casi en un 60\% en los niveles 1 a $3^{29,48}$. La colocación temprana del DAV (INTERMACS 4 a 7), se evaluó en un ensayo reciente que reveló mejores resultados que en aquellos pacientes que continuaron con el tratamiento médico ${ }^{49}$.

Por lo general, los pacientes con IC avanzada considerados para DAV dado el estadio avanzado de la enfermedad, pueden estar con soporte inotrópico continuo o manifestar una disminución de la función de los órganos diana. Se quejan principalmente de limitaciones en su vida diaria, con disnea y fatiga presentes en reposo o durante el mínimo esfuerzo, lo que les confina a la cama o a permanecer en el hogar. Para los pacientes ambulatorios, las salidas son excursiones temidas y raras, y caminar es limitado. Padecen episodios repetitivos de retención de sal y agua o episodios de bajo gasto cardiaco lo que los lleva a las reinternaciones frecuentes (Figura 1). Todo lo mencionado con anterioridad, ocurre a pesar de de la optimización del tratamiento 2,50 .

Si bien, como fue comentado, en el estadío D de la ICA se han asociado otras terapias (CDI y TRC) por sobre el tratamiento médico, la evolución es hacia un progresivo deterioro con respuesta transitoria o escasa. Con el avance de la enfermedad, incluso la titulación de fármacos basados en la evidencia se dificulta debido a la hipotensión, insuficiencia renal, debilidad profunda, entre otras comorbilidades?

La evolución clínica se asocia al deterioro hemodinámico, por lo que es crucial no solo controlar la FEVI, sino también los diámetros sisto/diastólicos, la presencia de insuficiencia mitral y llevar a cabo una evaluación completa de la función del VD, ya que su disfunción es un factor pronóstico determinante ya que aumenta en gran medida la mortalidad perioperatoria ${ }^{50}$.

Por consiguiente, los pacientes con ICA deben ser referidos en forma temprana a los equipos de IC experimentados con el fin de discutir la terapia, evaluar el pronóstico y organizar un plan de atención que permita la implantación electiva de un LVAD si es necesario y adelantarse a la evolución natural con mal pronóstico de la enfermedad.

\section{CONTRAINDICACIONES:}

Las contraindicaciones absolutas incluyen enfermedad sistémica con una expectativa de vida de menos de 2 años, o malignidad en los próximos 5 años, disfunción renal o hepática terminal, enfermedad pulmonar obstructiva crónica (EPOC) severa u otra enfermedad con falla multiorgánica (FMO) irreversible, ACV reciente, desorden psiquiátrico que pueda comprometer la adherencia al tratamiento? Contraindicaciones relativas que pueden mejorarse y replantear la colocación: problemas en las pruebas de coagulación, hemorragia no controlada, sepsis no controlada, o infección por virus de inmunodeficiencia humana.

La edad del paciente no es una contraindicación formal y dependiendo del estado general del paciente y la presencia de comorbilidades. La implantación de la asistencia mecánica puede ser propuesto en pacientes $>65$ años ${ }^{29,51}$. Adamson et al.52 evaluaron el uso de HeartMate // en la población mayor de 70 años y observaron no solamente aumento de la sobrevida sin diferencias significativas con respecto a la población de menor edad sino también una mejoría significativa de la calidad de vida en ambos grupos, lo que ampliaría las opciones a un grupo excluido del trasplante.

La hipertensión venocapilar pulmonar no es una contraindicación si la función del VD está conservada o levemente deprimida. Así como tampoco lo son una toracotomía o válvulas mitrales mecánicas previas o insuficiencia aórtica. Sólo llevarán a modificar la ruta de acceso y llevarán al recambio de válvula por una biológica y a la reparación aórtica en la misma cirugía².

Los factores psicosociales desempeñan un papel importante en la evaluación de la candidatura para el DAV. Los dispositivos implantados requieren una vigilancia constante para reconocer y manejar las complicaciones. Los pacientes sin estructuras de apoyo adecuadas y aquellos cuya vigilancia puede verse afectada por la enfermedad psiquiátrica, disfunción cognitiva o la adicción a las drogas o el alcohol no son buenos candidatos, tema que será ampliado posteriormente.

\section{PREIMPLANTE DEL DISPOSITIVO}

Como vimos anteriormente, muchos factores relacionados al paciente pueden disminuir la sobrevida post implante del DAV e incluso al coexistir varias comorbilidades pueden hacer que no sea un candidato adecuado para la colocación de los mismos. La fragilidad preoperatoria es un factor asociado a mayor mortalidad posoperatoria y readmisión hospitalaria ${ }^{53}$.

Por ello, en los pacientes que tendrían indicación de colocación del DAV la evaluación preimplante es fundamental y se basa en detectar aquellos parámetros que estén relacionados con peores desenlaces luego de la implantación del dispositivo ${ }^{54}$. Esto requiere la evaluación del paciente según la gravedad de la IC, el riesgo quirúrgico, la estabilidad psicosocial, y la capacidad de adherirse al régimen de auto-cuidado post colocación del DAV. El médico tratante debería ser capaz de identificar y comunicar cualquier condición o comorbilidad al equipo de IC y, dar todas las opciones disponibles al paciente ${ }^{55}$.

\section{ROL DE LOS SCORE DE RIESGO EN ICA}

En la evaluación cardiovascular del riesgo múltiples variables han sido asociadas a mayor mortalidad en pacientes con IC, es por eso que cobran importancia los diferentes scores que permiten estratificar a los pacientes y predecir la mortalidad antes y después de la colocación del dispositivo ${ }^{47}$

El Seattle Heart Failure Risk score $e^{56}$ establece diferentes variables que permiten predecir la evolución hospitalaria, la estadía y la supervivencia al 
año. Entre ellas: edad, sexo, CF de la NYHA, el peso, la FEVI, la presión arterial sistólica, la presencia de cardiopatía isquémica, furosemida diaria equivalente de dosis, el uso de inotrópicos, estatinas, allopurinol, tratamiento médico de IC, CDI, parámetros de laboratorio (hemoglobina, porcentaje de linfocitos, ácido úrico, colesterol sérico, y el sodio sérico). El mismo fue validado para los pacientes en plan de colocación de LVAD en el año 2010 al agregarle dos variable: uso de IABP, uso de inotrópicos ${ }^{57}$.

Por otro lado, Ketchum et al..$^{57}$ identificaron correctamente qué pacientes tenían un riesgo lo suficientemente alto como para requerir la implantación del LVAD, y qué grupo, por no depender de inotrópicos y ser ambulatorios, podrían beneficiarse con la colocación programada con el uso del mismo score

La puntuación de Lietz-Miller fue desarrollada a partir de un registro de pacientes que recibieron soporte como DT. El Destination Therapy Risk Score basado en parámetros de laboratorio y variables clínicas fue capaz de identificar a aquellos que presentan un riesgo relativamente bajo en comparación a los que tienen mayor riesgo de mortalidad. Inicialmente fue evaluado en paciente con dispositivos de primera generación (HeartMate XVE), y luego se validó tomando una cohorte de más de 1.000 pacientes con HeartMate II. El score logró discriminar entre aquellos con alta y baja mortalidad hospitalaria a los 90 días, pero no pudo distinguir entre los grupos de bajo y medio riesgo. El receiver-operator characteristic curves (ROC) demostró solo modesta capacidad para discriminar riesgo de mortalidad hospitalaria a los 90 días en pacientes con LVAD flujo continuo (Figura 9) ${ }^{58}$.

Las puntuaciones desarrollados para evaluar la función de órganos extra cardíacos también se aplicaron a la evaluación pre implante de los DAV. El Modelo de la Enfermedad Hepática en Fase Terminal (MELD) ${ }^{59}$ ha demostrado ser un predictor de eventos adversos en INTERMACS ${ }^{60}$ y estos hallazgos fueron validados por Yang et al. ${ }^{61}$ en un estudio de 200 pacientes.

Los scores de riesgo ganan interés especialmente en las personas mayores. Utilizando la base de datos de ensayos clínicos HeartMate // de 1.122 pacientes, Cowger et al (64) desarrolló un score de riesgo para los pacientes considerados para asistencias ventriculares de flujo continuo, dado de que los scores previos se realizaron con los antiguos dispositivos de flujo pulsátil. Los componentes del HeartMate II multivariable risk score (HMRs) incluyeron la edad (década), la albúmina sérica (mg/dl), la creatinina sérica (mg/dl), el RIN, y la experiencia del centro aumentando el riesgo anual con un volumen del centro menor a $15^{62}$.

En segundo lugar, la falla del VD resulta en un mal llenado del VI y por lo tanto, menor flujo de salida en la LVAD. La falla del VD pre implante está asociada a mayor mortalidad, mayor riesgo de sangrado y de re operación, mayor tiempo de estadía hospitalaria y mayores tasas de insuficiencia renal ${ }^{62}$

Matthews et al. ${ }^{63}$ desarrollaron un score para evaluar principalmente falla de VD, y determinar qué variables clínicas y de laboratorio se asocian a su presencia prediciendo mortalidad posoperatoria en pacientes con terapia de destino. Los investigadores encontraron como predictores independientes el uso de vasopresores, aspartato aminotransferasa por encima de $80 \mathrm{UI} / \mathrm{l}$, valores de bilirrubina mayores a $2 \mathrm{mg} / \mathrm{dl}$, y niveles de creatinina mayores a 2,3 mg/dl. El área bajo la curva del score fue de $0,73 \pm 0,04$.

\section{EVALUACIÓN DE FRAGILIDADY ASPECTOS PSICOSOCIALES}

Al igual que los candidatos a trasplante los pacientes candidatos a un DAV deben ser evaluados por profesionales de la salud mental y asistentes del servicio social para asegurar los cuidados postoperatorios y la adherencia al tratamiento antes de la decisión de colocación del mismo ${ }^{40}$. Muchas veces las largas listas de espera generan, en los pacientes internados en plan de trasplante, tanto depresión como aislamiento socia lo que conlleva peor pronóstico independientemente de los factores biomédicos. En un estudio prospectivo ${ }^{64} \mathrm{y}$ en el análisis extendido del Waiting for a New Heart Study ${ }^{65}$ se vio la importancia de los factores de riesgo psicosociales los cuales se asociaron a un peor pronóstico al momento del trasplante y un mayor requerimiento de DAV en aquellos que se encontraban en lista de espera. Los pacientes refirieron gran estrés a mantenerse aislados, a ser separados de las personas de confianza, miedo al estar solos durante la espera del órgano o al recibir la llamada el día del trasplante. Dichas preocupaciones denotan problemas emocionales y ambivalentes frente a la situación del trasplante, produciendo progresión de la enfermedad y deterioro físico y hemodinámico.

En algunos casos el principal síntoma es la ansiedad extrema y no la depresión, siendo en algunos casos más prevalente la ansiedad en el preoperatorio y la depresión en el postoperatorio ${ }^{65,66}$.

Si bien el período posterior a la colocación de un DAV es de adaptación, uno de los efectos esperados es la mejoría de calidad de vida y la capacidad funcional y, con ello la disminución de los síntomas de depresión y ansiedad. En el estudio de Reynard et al. ${ }^{67}$, se investigó el curso de estos síntomas en una cohorte de pacientes ambulatorios con LVAD y se vio que ambos, ansiedad y depresión, mejoraron después de la colocación del dispositivo y se mantuvieron estables por lo menos un año.

Esto es importante para el seguimiento puesto que tanto la depresión como los trastornos de ansiedad, el consumo de drogas ilegales y de alcohol, se han visto relacionados con un aumento de la morbimortalidad, mayores readmisiones hospitalarias, mayores tasas de infecciones del dispositivo principalmente debido a una disminución del cuidado personal y la mayor tendencia a no ser adherentes al tratamiento ${ }^{40,68-70}$

Otra observación importante de mencionar es que luego del primer período, los pacientes suelen regresar a sus actividades habituales y roles sociales, a tener más confianza en su autocuidado, reconocen los problemas y limitaciones de sus dispositivos y, potencialmente, hacen frente a los síntomas de IC y a los relacionadas con el DAV71. Si bien aún, el trasplante hoy en día continúa siendo el mejor tratamiento y más efectivo en cuanto a los alcances en la mejoría de calidad de vida ${ }^{72}$.

Dado que la carga emocional luego del egreso hospitalario en este tipo de pacientes es alta, involucra al núcleo familiar, requiere preciso cuidado en las prescripciones médicas, reconocer los signos de alarma, concurrir a la rehabilitación cardiovascular, entre otros, se ha propuesto en los últimos años la integración al equipo de IC de médicos especialistas en cuidados paliativos ${ }^{40,73}$

Un manejo progresivo por parte del especialista en cuidados paliativos puede dirigir la educación y la comunicación tanto a la familia, cuidadores y paciente, ayudando a comprender mejor su enfermedad, las opciones de tratamiento y el pronóstico, y acompañar en la toma de decisiones médicas. Es por eso que estos pacientes tan complejos deben ser seguidos por 
un típico equipo multidisciplinario compuesto por médicos, enfermeras, trabajadores sociales, fisioterapeutas y psicólogos, todo lo cual genera mejor satisfacción, comunicación y reduce el estrés y la ansiedad ${ }^{73,74}$.

Por otro lado, el cuidador, normalmente un miembro de la familia u otro allegado, debe administrar un régimen de medicación compleja, cambiar los apósitos estériles, monitorear los signos vitales del paciente y pesos, y aprender el funcionamiento del LVAD. La sobrecarga de los cuidadores puede ser significativa. En los primeros meses, muchos acompañantes describen "un sentido abrumador de miedo y ansiedad"75. Es por ello que cobra especial importancia el equipo de salud tanto para la educación, la preparación y el soporte emocional del paciente y su entorno familiar.

\section{COMPLICACIONES Y COSTO/EFICACIA DE LOS DAV}

Son múltiples las complicaciones que pueden llegar a presentarse luego de la implantación de los dispositivos. En una revisión sistemática de 40 estudios $^{76}$ se vio que a los 12 meses de colocación, los pacientes sufrieron una variedad de complicaciones graves. Los estudios informaron amplios rangos para los eventos adversos: 4-27\% hemorragia que requirió transfusión siendo la hemorragia gastrointestinal la más frecuente con una prevalencia de $22 \%$ en los pacientes con LVAD33 1,5-40\% de ACV; infección 3,3-48\%; fallo del dispositivo 1-14\%; 3-30\% de IC; $11-32 \%$ de reintervenciones; e insuficiencia renal $3-53 \% 76$

En el último registro de INTERMACS ${ }^{29}$ la curva de supervivencia para dispositivos implantados de flujo continuo desde el año 2008 muestra una supervivencia a 1 año en su conjunto del $80 \%$ y 2 años de supervivencia del 70\%. En el mismo registro los eventos neurológicos, IC derecha y FMO fueron las causas o modos de muerte temprana más frecuentes después de la implantación del DAV. La infección, la FMO y eventos neurológicos mayores fueron las principales causas de mortalidad tardía. En este análisis, el riesgo de muerte por mal funcionamiento del dispositivo fue bajo y constante en el tiempo.

Las complicaciones eran más frecuentes en aquellos dispositivos pulsátiles de primera generación ${ }^{29,33}$, por lo que se realizaron análisis de rentabilidad comparando el uso de los mismos como puente a trasplante con el tratamiento médico resultando los LVAD más caros y menos beneficiosos ${ }^{77}$. Los actuales de segunda y tercera generación fueron evaluados en comparación con el tratamiento médico en un estudio de Clarke et al..$^{78}$ en donde los outcomes fueron medidos como quality-adjusted life-year (años de vida ajustados por calidad AVAC). En este estudio se vio que proporcionan mayores beneficios a costos más altos, siendo en Gran Bretaña, un valor de $£ 20.000$ a $£ 30.000$ LVAD / AVAC por lo que concluyen que no son rentables en aquel país.

En el estudio de Ammirati et al. ${ }^{79}$, en donde se comparó en un sólo centro italiano a 213 pacientes con ICA que se trataron con LVAD o con trasplante cardíaco. Se encontró que la supervivencia a medio plazo de los pacientes con LVAD no fue estadísticamente diferente. La mortalidad perioperatoria fue similar en la cohorte general y en todos los subgrupos, aunque es importante destacar que aquellos con DAV se encontraban en peores condiciones preoperatorias.

En la era actual de los DAV de flujo continuo, la carga de eventos adversos se ha reducido, pero sigue siendo alta, ya que sólo el 30\% de los pacientes están libres de cualquier complicación importante en 1 año ${ }^{78}$. Si bien las mejoras en los dispositivos y en el seguimiento, así como la detección temprana de complicaciones, con su consecuente reducción, en la última era persisten aún como principales causas de readmisión hospitalaria el sangrado gastrointestinal debido al desarrollo de las malformaciones arteriovenosas a causa de la disminución de la presión de pulso por el flujo continuo que generan 29,80, seguido en frecuencia por el ACV y la trombosis.

\section{ROL DE LA ECOCARDIOGRAFÍA}

Actualmente el uso de la valoración ecocardiográfica tanto preoperatoria como en el seguimiento posoperatorio de los pacientes con LVAD cobró interés al conocerse mejor tanto el funcionamiento y las posibles complicaciones que estos dispositivos pueden traer.

Es así que la Sociedad Americana de Ecocardiografía publicó el año pasado las recomendaciones para la evaluación de pacientes con LVAD basada fundamentalmente en la evaluación de los dispositivos HeartMate lly HeartWare los más frecuentemente usadas como BTT y DT ${ }^{81}$.

Ambos dispositivos comparten características en su estructura: una cánula de entrada colocada en el VI cerca del vértice, un impulsor mecánico, y una cánula de salida anastomosada a la aorta ascenden-

te (Figuras 4 y 5). La ecocardiografía permite la visualización directa de estos componentes, pero no del impulsor mecánico. El impulsor de HeartMate // y su estructura de alojamiento son implantados por debajo del diafragma, mientras que el impulsor HeartWare y su estructura de alojamiento se implantan por encima del diafragma, dentro del saco pericárdico. El posicionamiento del impulsor es el factor de diferenciación primaria en la evaluación ecocardiográfica del flujo de entrada de estos dos dispositivos ${ }^{24,39}$.

La evaluación del candidato a LVAD debe ser realizada por un ecocardiografista experimentado en ICA y en los parámetros hemodinámicos de los DAV. Generalmente un ecocardiograma transtoráciCo (ETT) es la evaluación de primera línea, tratando de buscar alteraciones anatómicas y funcionales que podrían impedir la colocación del soporte ventricular como por ejemplo, un pequeño tamaño del VI, trombos intracavitarios, aneurisma apical del VI, defectos en el septum interventricular, un VD dilatado o disfuncionante, así como también anormalidades valvulares ${ }^{81}$.

La correcta cuantificación de la FEVI es central, puesto que la determinación de una FEVI menor de 25\% es un requerimiento para ser un potencial candidato a LVAD así como también es necesaria para el cálculo de los score de riesgo. Se recomienda la cuantificación de la misma con el método tridimensional o por el bidimensional utilizando el método de Simpson, considerando la realización de contraste para mejorar la definición del endocardio y así obtener mejor precisión. Los diámetros internos del VI y el volumen de fin de diástole deben medirse para así obtener una mejor cuantificación de la disminución de la precarga del VI en posoperatorio ${ }^{81.82}$

Teniendo en cuenta el impacto de la disfunción del VD, existe un renovado interés en el uso de los parámetros ecocardiográficos para su evaluación. Signos ecocardiográficos de disfunción del VD incluyen deterioro de la función sistólica del VD y/o dilatación del VD, aumento de la presión de la aurícula derecha (comprobada por el tamaño de la vena cava inferior y su colapso), la insuficiencia tricuspídea moderada o severa ${ }^{81}$ 
Investigadores de la Cleveland Clinic utilizan medidas cuantitativas de la función del VD para evaluar el riesgo de falla del VD por ecocardiografía. En el trabajo de Grant et al. ${ }^{83}$ los pacientes que requerían un DAV derecha o soporte inotrópico prolongado (4-14 días) eran más propensos a tener reducido el strain de la pared libre del VD. Un punto de corte de $-9.6 \%$ para la máxima deformación se asoció con mayor sensibilidad y especificidad para predecir la insuficiencia del VD. En el estudio de Vivo et al. ${ }^{84}$, se vio una relación de diámetro VD/NI de $\geq 0,75$ se asoció significativamente con el outcome primario de falla ventricular derecha y el end point secundario de falla ventricular derecha a los 30 días o muerte entre los pacientes con LVAD de flujo continuo.

Clínicamente una disfunción biventricular severa perioperatoria puede incitar al equipo de IC a considerar un BiDAV en forma precoz, ya que esto puede conducir a mejores resultados que la posterior conversión de un LVAD a una asistencia biventricular tal como se vio en el estudio de Fitzpatrick et al. ${ }^{41}$ en donde el grupo de asistencia biventricular precoz tenía una supervivencia superior al alta que los pacientes en el grupo de demora a la BiVAD (51 vs. 29\%, p <0,05).

Algunos pacientes con menor disfunción del VD en la evaluación preoperatoria desarrollarán severa disfunción ventricular derecha después de la implantación del LVAD. Esta complicación, que se define por INTERMACS ${ }^{85}$ como la exigencia de un dispositivo de asistencia ventricular derecho (right ventricular assist device [RVAD]) o > 14 días consecutivos de soporte inotrópico por vía intravenosa, tiene una prevalencia estimada del 13 al 44\% y se asocia con una morbimortalidad significativa, particularmente porque el perfil hemodinámico y las características de quienes requieren un BiVAD denotan peor estado general. En el trabajo de Cleveland et al. ${ }^{86}$, el mayor requerimiento de inotrópicos, los peores parámetros de laboratorio presentaron mejores desenlaces con la colocación precoz de una BiVAD.

Dada la falta de consenso hasta el momento en relación con el valor predictivo de cualquier parámetro ecocardiográfico aislado, las guías de práctica clínica ${ }^{81}$ no recomienda utilizar un sólo parámetro para evaluar la disfunción derecha sino, utilizar tanto parámetros izquierdos y derechos para la decisión de un BiVAD.

Al momento de la colocación del DAV un ecocardiograma transesofágico (ETE) debe ser realizado en el quirófano, antes de la colocación de la misma para confirmar lo previamente analizado. Se monitoriza por ETE el momento de encender el equipo. Se buscan posibles complicaciones post implante como derrame pericárdico, mayor disfunción ventricular secundaria a disminución brusca de la carga ventricular, falla del VD, presiones de llenado inadecuadas por dimensiones demasiado pequeñas del VI que pueden deberse a falla derecha o a una velocidad excesiva de la bomba. Otra consecuencia de una velocidad elevada es la succión que puede generar el dispositivo viéndose un segmento de miocardio que ocluye parcialmente la cánula de entrada y reduce flujo de entrada de la bomba ${ }^{81}$.

Luego de implantado el dispositivo se deben realizar evaluaciones ecocardiográficas a diferentes intervalos de tiempo para evaluar la respuesta del paciente al dispositivo, siendo estas coordinadas con las visitas de rutina que se hace al equipo de IC, en donde además del examen físico de rutina se indica para valoración de todos los parámetros antedichos para la búsqueda de posibles complicaciones asociadas al DAV ${ }^{81}$.

\section{DISCUSIÓN}

Actualmente, la mayor partre de la literatura a nivel mundial se refiere a la IC como una enfermedad epidémica, por su aumento progresivo en incidencia, prevalencia, morbimortalidad y los costos que implica esto en la salud pública. En consecuencia, también aumenta el número de pacientes en ICA, (estadio D de la AHA) 1,3. En esta instancia, el manejo del paciente es complejo, llegando a la necesidad de evaluar al paciente como candidato a trasplante.

Así como se han producido cambios epidemiológicos en la IC, lo mismo ha sucedido con la población con indicación de trasplante con una desproporción donante/receptor. En este contexto surgen como estrategias posibles y aún en desarrollo: los cuidados paliativos y los DAV.

Aunque desde el primer trasplante cardíaco, se han ido perfeccionando las técnicas quirúrgicas, conociéndose mejor el manejo de los pacientes en el postoperatorio y se ha avanzado en la búsqueda de mejores tratamientos inmunosupresores, su escasez ha llevado a que los DAV vayan ganando terreno en el tratamiento de la ICA, intentando mejorar la sobrevida y la calidad de vida de los pacientes en estadios finales de la enfermedad ${ }^{7,11,12}$.

Con los DAV se genera un flujo circulatorio que sustituye parcial o totalmente la función del corazón tanto en situaciones de falla aguda o crónica severas que no responden al máximo tratamiento médico disponible. Estos han pasado por cambios y mejoras tecnológicas en búsqueda del dispositivo ideal: mayor durabilidad, menores tasas de complicaciones, costo razonable y mayor confort al paciente, según el escenario clínico de su implantación.

Por lo antedicho se clasifican en primera, segunda y tercera generación. Las diferencias entre ellos se relacionan principalmente con aspectos técnicos pero que se traducen en que los más nuevos se caracterizan por:

- Mayor durabilidad, alcanzando los 5 años. El desafío que afrontan los más recientes es superar este límite y así poder ser verdaderas terapias de destino.

- Menor tamaño y menor exposición de cables y tubuladuras, logrando mejor calidad de vida para el paciente, menores tiempos quirúrgicos para su implante y menores tasas de infecciones, a su vez mejor destete del dispositivo en aquellos en los que se puede llegar a explantar el mismo.

- Menor fricción entre sus componentes, aportando mejoría en la hemocompatibilidad, reduciendo las tasas de trombosis y permitiendo controles de RIN menos elevados.

Al conocerse mejor la hemodinamia de las asistencias y su efecto a nivel miocárdico, se empezaron a estudiar nuevas formas de aplicar la tecnología abarcando no sólo los pacientes con ICA crónica en plan de trasplante sino los excluidos del mismo, y aquellos con posibilidades de recuperar la función miocárdica ${ }^{41,43}$. Surgen así diferentes indicaciones para su utilización:

- Puente a trasplante.

- Terapia de destino.

- Puente a recuperación.

El conocimiento de estas indicaciones hace que durante la evaluación y el seguimiento del paciente el cambio de una estrategia a otra sea algo 
dinámico y no totalmente estructurado, por lo que en los últimos años se habla del puente a candidatura, según la evolución clínica y la decisión del paciente y su familia.

A la hora de pensar en las posibles indicaciones de los DAV, los médicos tratantes deben definir qué perfil hemodinámico posee el paciente y qué beneficios le esperan. Para ello en el año 2006 INTERMACS definió siete perfiles clínicos que permiten estratificar a los pacientes en estadio $D$ en función de variables hemodinámicas, grado de daño de órgano blanco, y así establecer la severidad de cada paciente y definir el implante de un DAV. Posteriormente, las diferentes sociedades cardiológicas y de trasplante han establecido grados de recomendaciones para las indicaciones de las mismas, así como contraindicaciones previamente enumeradas ${ }^{1,247,49}$.

En el séptimo INTERMACS ${ }^{29}$ los pacientes que recibieron un dispositivo alcanzaron un $\mathrm{N}$ de 15.000 lo que demuestra la rápida expansión de esta estrategia terapéutica. En forma más frecuente, así mismo un mayor número de centros no sólo los utilizan como puente a trasplante sino que a raíz de los resultados de los trabajos como el REMATCH ${ }^{35}$ la estrategia de terapia de destino constituye un porcentaje considerable y en crescendo, siendo en los últimos años la principal indicación ${ }^{29}$.

Uno de los mayores avances fue el campo de la recuperación miocárdica luego de la implantación del DAV, aunque la explantación con éxito del LVAD parece tener resultados razonables y prometedores, aún queda mucho por aprender acerca de esta estrategia. No se sabe si las características del paciente o de la etiología de la miocardiopatía predicen éxito. Además, se desconoce el momento y protocolo óptimo para el destete. Aunque los resultados de seguimiento a corto y medio plazo sugieren que la función del ventrículo izquierdo se mantiene estable, se necesita de mayor seguimiento para confirmar esta hipótesis.

Son consistentes los hallazgos a lo largo de los diferentes trabajos las diferentes indicaciones y el momento de oportuno de la colocación de los DAV. Siendo los perfiles de INTERMACS más altos los que más se benefician de una terapia con LVAD o BiVAD en cualquiera de sus indicaciones ${ }^{29,47,48}$. Lo que pone énfasis en que todos los pacientes con ICA deben ser evaluados por médicos especialistas en IC que puedan optimizar el tratamiento médico y la colocación de TRC y/o CDI, así como también establecer equipos multidisciplinarios para la toma de decisiones y el manejo no sólo del paciente sino también de sus familiares y acompañantes. Para ello es necesaria la rápida identificación de los síntomas y signos de ICA.

A pesar de todo esto, en las diferentes series la mayoría de los DAV son indicados a niveles de INTERMACS más bajos, cuando los pacientes se encuentran más deteriorados con mayor fallo hemodinámico, mayor porcentaje de depresión y mayores índices de fragilidad, con un mayor requerimiento de BiVAD, lo cual empeora los desenlaces y acrecienta los costos $2,29,47,48$.

Diversas variables clínicas y biológicas deben alertar al médico tratante para la correcta derivación oportuna al equipo de IC, los cuales mediante los diferentes score de riesgo podrían facilitar la toma de decisiones y establecer las mejores estrategias de tratamiento².
Así como se fueron definiendo variables estrictamente relacionadas con la enfermedad, el mejor conocimiento de la evolución de estos pacientes y seguimientos más largos han llevado a establecer que existen factores extra cardíacos que también deben intervenir en la compleja toma de decisiones. Si bien en los últimos años se puso énfasis en el manejo de los pacientes ambulatorios, los mismos criterios y cuidados deben aplicarse a pacientes internados. Es imprescindible contar con estructuras de apoyo adecuadas, multidisciplinarias, aplicar scores de riesgos ya mencionados y evaluar, tratar y no subestimar factores psicosociales, principalmente la ansiedad y la depresión tanto en el pre- como en e posimplante, que pueden llevar a mayores complicaciones relacionadas con el dispositivo y a peores desenlaces tanto posimplante del DAV como postrasplante cardíaco ${ }^{52}$.

Uno de los grandes logros del desarrollo tecnológico en este campo fue el hecho de que los pacientes que antes estaban confinados a largos días de espera internados puedan volver al hogar reduciéndose así, el aislamiento social, la depresión y ansiedad, consiguiendo que el paciente pueda volver a insertarse socialmente, gane confianza en su cuidado con un mejor soporte emocional, $62-65,70$.

Todo esto lleva a la integración de especialistas en cuidados paliativos al cuidado de este tipo de pacientes y su familia, donde la sobrecarga del cuidador es uno de los puntos preocupantes que conlleva esta terapia. El arte de poder comunicarse con la familia, el paciente y de transmitirles todas las posibilidades de tratamiento así como el momento oportuno del switch off del dispositivo 71,72 .

A su vez, a pesar de los logros y mejoras mencionadas en los DAV y en la selección de pacientes, aún siguen siendo complejas las decisiones y su implementación en la práctica clínica. Siguen siendo frecuentes las complicaciones relacionadas con el dispositivo: hemorragia gastrointestinal, el ACV y las infecciones son las que lideran los porcentajes, lo que lleva a que el análisis de costos en algunos países los definan como no rentables, no solo por su costo sino por la estructura y el financiamiento educativo que conllevan.

\section{CONCLUSIÓN}

Ya desde la definición de los diferentes estadios de la AHA en el 2005 se plantea la posibilidad que aquellos en estadio $D$ podrían beneficiarse de un DAV. Como fue analizado, su uso fue extendido a diferentes contextos clínicos. En su evolución se ha logrado mejoría de las tecnologías y disminución de las complicaciones.

Sin embargo, los DAV persisten como una realidad con difícil aplicabilidad dado los costos y el escaso entrenamiento médico para su manejo. Persisten grandes expectativas a futuro y se espera que puedan ir ganando terreno en aquellos lugares que todavía no pueden financiarlos, generando lo que alguna vez el advenimiento del trasplante hizo: programas de salud y entrenamiento de los profesionales. 


\section{BIBLIOGRAFÍA}

1. Ponikowski P, Voors A, Anker SD, Bueno H, Cleland J, Coats A et al. 2016 ESC Guidelines for the diagnosis and treatment of acute and chronic heart failure. The Task Force for the diagnosis and treatment of acute and chronic heart failure of the European Society of Cardiology (ESC). Eur J Heart Fail 2016;18(37):891-975.

2. Trochua JN, Leprinceb P, Bielefeld-Gomezc M, Bastiend O, Beauvaise F, Gueffeta JP et al. Left ventricle assist device: When and which patients should we refer? Arch Cardiovasc Dis 2012;105(12):114-21.

3. Chaudhry SP, Stewart GC.Advanced Heart Failure: Prevalence, Natural History, and Prognosis. Heart Fail Clin 2016;12(2):323-33.

4. Yancy CW, Jessup M, Bozkurt B, Butler J, Casey DE Jr, Drazner MH, et al. 2013 ACCF/AHA guideline for the management of heart failure: a report of the American College of Cardiology Foundation/American Heart A ssociation Task Force on practice guidelines. Circulation 2013;128(16):e240-327.

5. Roger V. Epidemiology of Heart Failure. Circ Res 2013:113(6):646-659.

6. Síntesis Estadística 1:2016. Ministerio de Salud de la Nación. Dirección de Estadísticas e información de salud.

7. Marconi EH. Estadísticas vitales, información básica. Secretaria de politicas, regulacion e institutos. Dirección de estadísticas e información de salud. Ministerio de Salud de la Nación 2013;5:57.

8. Mozaffarian D, Benjamin EJ, Go A, Arnett D, Blaha MJ, Cushman M, et al. American Heart Association: 2001 Heart and Stroke Statistical Update. Circulation 2015;132(4):e29-322.

9. Edwards L Kucheryavaya A Benden C Christie J, Dipchand A Dobbels F et al. The Registry of the International Society for Heart and Lung Transplantation: Thir ty-first Official Adult Heart Transplant Report-2014; Focus Theme: Retransplantation. J Heart Lung Transplant 2014:33(10):996-1008.

10. Ho KKL, Pinsky JL, Kannel WB, Levy D.The epidemiology of heart failure: the Framingham Study. J Am Coll Cardiol 1993;22(4):6A-13A.

11. Stehlik J, Stevenson LW, Edwards LB, Crespo-Leiro MG, Delgado JF, Dorent $R$, et al. Organ Allocation Around the World: Insights From the ISHLT International Registry for Heart and Lung Transplantation. J Heart Lung Transplant 2014:33(10):975-84.

12. Gómez Bueno M, Segovia Cubero J, Alonso-Pulpón Rivera L. Asistencia mecánica circulatoria y trasplante cardiaco. Indicaciones y situación en España. Rev Esp Cardiol 2006:6(6):82F-94F

13. Buggey J, Mentz RJ, Galanos AN. End-of-life Heart Failure Care in the United States. Heart Fail Clin 2015;11(4):615-23

14. Van Riet EE, Hoes AW, Wagenaar KP, Limburg A, Landman MA, Rutten FH. EPidemiology of heart failure: the prevalence of heart failure and ventricular dysfunction in older adults over time. A systematic review. Eur J Heart Fail 2016;18(19):242-52.

15. Levy D, Kenchalah S, Larson MG, Benjamin, Kupka. Long term trends in the incidence and survival with heart failure. N Engl J Med 2002;347(18):1397-402.

16. Helman DN, Rose EA. History of Mechanical Circulatory Support. Prog CardiovasC Dis 2000;43(1):1-4

17. Tang DG1, Oyer PE, Mallidi HR. Ventricular Assist Devices: History, Patient Selec tion, and Timing of Therapy. J Cardiovasc Trans/ Res 2009:2(2):159-67.

18. Miller MA, Ulisney K, Baldwin JT. INTERMACS (Interagency Registry for Mechani cally Assisted Circulatory Support): a new paradigm for translating registry data into clinical practice. J Am Coll Cardiol 2010;56(9):738-40.

19. Stevenson L, Pagani F, Young JB, Jessup M, Miller L, Kormos RL et al. INTERMACS Profiles of Advanced Heart Failure: The Current Picture. J Heart Lung Transplant 2009:28(6):535-41.

20. Barge Caballeroa E, Paniagua M, Marzoa Rivasa M, Campo Pereza R. Utilidad de la escala INTERMACS para estratificar el pronóstico tras el trasplante cardiaco urgente. Rev Esp Cardiol 2011;64(3):193-200.

21. Alba AC, Rao V, Ivanov J, Ross HJ, Delgado DH. Usefulness of the INTERMACS scale to predict outcomes after mechanical assist device implantation. J Heart Lung Transplant 2009:28(8):827-33.

22. Carpentier A, Latrémouille C, Cholley B, Smadja DM, Roussel JC, Boissier J et al. First clinical use of a bioprosthetic total artificial heart: report of two cases. Lancet 2015:386(10003):1556-63.

23. Stewart GC, Givertz MM.Mechanical circulatory support for advanced heart failure: patients and technology in evolution. Circulation 2012;125(10):1304-15.

24. Kantrowitz A, Tjonneland S, Freed PS, Phillips SJ, Butner AN, Sherman JL Jr. Initial clinical experience with intraaortic balloon pumping in cardiogenic shock. JAMA 1968;203(2):113-8

25. Mussivand T. Mechanical circulatory devices for the treatment of Heart Failure. $J$ Card Surg 1999;14(3):218-28

26. Delgado DH, Rao V, Ross HJ, Verma S, Smedira NG. Mechanical Circulatory Assistance State of Art. Circulation 2002;106(8):2046-50.

27. Kutty RS, Parameshwar J, Lewis $C$, Catarino PA, Sudarshan $C D$, Jenkins DP, et al. Use of centrifugal left ventricular assist device as a bridge to candidacy in severe heart failure with secondary pulmonary hypertension. Eur I Cardiothorac Surg 2013:43(6):1237-42.
28. Kar B, Gregoric ID, Basra SS, Idelchik GM, Loyalka P. The percutaneous ven tricular assist device in severe refractory cardiogenic shock. J Am Coll Cardio 2011;57(6):688-96

29. Kirklin JK, Naftel DC, Pagani FD, Kormos RL, Stevenson LW, Blume ED, et al. Seventh INTERMACS annual report: 15,000 patients and counting. J Heart Lung Transplant 2015;34(12):1495-504

30. Rose EA, Gelijns AC, Moskowitz AJ, Heitjan DF, Stevenson LW, Dembitsky W et al Long-term use of a left ventricular assist device for end-stage heart failure. Randomized Evaluation of Mechanical Assistance for the Treatment of Congestive Heart Failure (REMATCH). N Engl J Med 2001;345(20):1435.

31. Nguyen $D Q$, Thourani VH. Third-generation continuous flow left ventricular assis devices. Innovations (Phila) 2010;5(4):250-8.

32. Ashleigh Xie, Kevin Phan, Tristan D. Yan Durability of continuous-flow left ventric ular assist devices: a systematic review Ann Cardiothorac Surg 2014:3(6):547-556.

33. Netuka I, Beyersdorf F, Garbade J, Krabatsch T, Marasco S, Morshuis M, et al HeartMate 3 fully magnetically levitated LVAD for the treatment of advanced heart failure: results from the CE Mark Trial. Presented at the 19th Annual Meeting of the Heart Failure Society of America (HFSA) 2015;12(1):23.

34. Burke DJ, Burke E, Parsaie F, Poirier V, Butler K, Thomas D et al. The Heartmate II: design and development of a fully sealed axial flow left ventricular assist system. Artif Organs 2001;25(2):380-5

35. Frazier OH, Myers TJ, Westaby S, Gregoric ID. Clinical experience with an im plantable, intracardiac, continuous flow circulatory support device: physiologic implications and their relationship to patient selection. Ann Thorac Surg 2004; $77(1): 133-42$

36. Sabashnikov A Mohite PN Simon AR Popov AF HeartWare miniaturized intrapericardial ventricular assist device: advantages and adverse events in comparison to contemporary devices. Expert Rev Med Devices 2013;10(4):441-52.

37. Capdeville M. Smedira NG. Advances and future directions for mechanical circulatory support. Anesthesiol Clin 2013;31(2):321-53.

38. Hanke JS, Rojas SV, Avsar M, Bara C, Ismail I, Haverich A, et al. HeartWare left ventricular assist device for the treatment of advanced heart failure. Future Cardio 2016;12(1):17-26.

39. Milano CA, Pagani FD, Tatooles AJ, Mokadam NA, Miller J, Wozniak TC, et al. Temporal Changes in Adverse Events in the ENDURANCE Trial. J Heart Lung Transplant 2013;32(2):10

40. Rihal CS, Naidu SS, Givertz MM, Szeto W, Burke J, Kapur N, Srihari SN, et al. 2015 SCAI/ACC/HFSA/STS Clinical Expert Consensus Statement on the Use of Percutaneous Mechanical Circulatory Support Devices in Cardiovascular Care: Endorsed by the American Heart Association, the Cardiological Society of India, and Sociedad Latino Americana de Cardiología Intervencionista; Affirmation of Value by the Canadian Association of Interventional Cardiology-Association Canadienne de Cardiologie dintervention. J Am Coll Cardiol. 2015:65(19):e7-e26.

41. Fitzpatrick JR, Frederick JR, Hiesinger W, Hsu VM, McCormick RC, Kozin ED, et al. Early planned institution of biventricular mechanical circulatory support results in improved outcomes compared with delayed conversion of a left ventricular assist device to a biventricular assist device. J Thorac Cardiovasc Surg 2009;137(4):971-7.

42. Rogers JG, Butler J, Lansman SL, Gass A, Portner PM, Pasque MK, Pierson RN. Chronic mechanical circulatory support for inotrope-dependent heart failure patients who are not transplant candidates: results of the INTrEPID Trial. J Am Coll Cardiol. 2007:50(8):741-7.

43. Birks EJ, George RS, Hedger M, Bahrami T, Wilton P, Bowles CT, et al. Reversal of severe heart failure with a continuous-flow left ventricular assist device and pharmacological therapy: a prospective study. Circulation 2011:123(4):381-90.

44. Akil A, Fischer D, Holthaus AJ, Martens S, Scherer M, Sindermann JR. Left Ventricular Assist Devices as Bridge to Cardiac Recovery in Nonischemic Heart Failure: Keeping Weaning from the Device in Mind. Thorac Cardiovasc Surg. 2016;64(6):483-6.

45. Birks EJ, Tansley PD, Hardy J, George RS, Bowles CT, Burke M et al. Left ventricular assist device and drug therapy for the reversal of heart failure. N Engl I Med 2006;355(18):1873-84.

46. Deng MC, Edwards LB, Hertz MI, Rowe AW, Keck BM, Kormos $R$, et al. Mechanical Circulatory Support Device Database of the International Society for Heart and Lung Transplantation: second annual report-2004. J Heart Lung Transplant. 2004;23(9):1027-34

47. Miller LW, Guglin M. Patient selection for ventricular assist devices: a moving target. J Am Coll Cardiol. 2013;61(12):1209-21

48. Jorde UP, Kushwaha SS, Tatooles AJ, Naka Y, Bhat G, Long JW et al. Results of the destination therapy post food and drug administration approval study with continuous flow left ventricular assist device: a prospective study using the INTERMACS registry (Interagency Registry for Mechanically Assisted Circulatory Support). J Am Coll Cardiol 2014;63(17):1751-1757. 
49. Estep JD, Starling RC, Horstmanshof DA, Milano CA, Selzman CH, Shah KB, et al. Risk assessment and comparative effectiveness of left ventricular assist device and medical management in ambulatory heart failure patients: results from the ROADMAP study. J Am Coll Cardiol 2015;66(16):1747-1761.

50. Metra M, Ponikowski P, Dickstein K, McMurray JJ, Gavazzi A, Bergh CH, et al. Advanced chronic heart failure: a position statement from the Study Group on Advanced Heart Failure of the Heart Failure Association of the European Society of Cardiology. Eur J Heart Fail 2007;9(6-7):684-94.

51. Adamson RM, Stahovich M, Chillcott S, Baradarian S, Chammas J, Jaski B et al. Clinical strategies and outcomes in advanced heart failure patients older than 70 years of age receiving the HeartMate II left ventricular assist device: a community hospital experience. J Am Coll Cardiol 2011;57(25):2487-95.

52. Feldman D, Pamboukian SV, Teuteberg JJ, Birks E, Lietz K, Moore SA et al. International Society for Heart and Lung Transplantation. The 2013 International Society for Heart and Lung Transplantation Guidelines for mechanical circulatory support: executive summary. J Heart Lung Transplant 2013:32(2):157-87.

53. Dunlay SM, Park SJ, Joyce LD, Daly RC, Stulak JM, MCNallan SM et al. Frailty and outcomes after implantation of left ventricular assist device as destination therapy. J Heart Lung Transplant 2014;33(4):359-65.

54. Mancini D, Lietz K. Selection of Cardiac Transplantation Candidates in 2010. Circulation 2010;122(2):173-183.

55. Peura JL, Colvin-Adams M, Francis GS, Grady KL, Hoffman TM, Jessup M, Recommendations for the use of mechanical circulatory support: device strategies and patient selection: a scientific statement from the American Heart Association. Circulation 2012:126(22):2648-67.

56. Levy WC, Mozaffarian D, Linker DT, Sutradhar SC, Anker SD, Cropp AB et al. The Seattle Heart Failure Model: prediction of survival in heart failure. Circulation 2006:113(11):1424-33.

57. Ketchum ES, Moorman AJ, Fishbein DP, Mokadam NA, Verrier ED, Aldea GS et al. Predictive value of the Seattle Heart Failure Model in patients undergoing left ventricular assist device placement. J Heart Lung Transplant 2010;29(9):1021-5.

58. Teuteberg JJ, Ewald GA, Adamson RM, Lietz K, Miller LW, Tatooles AJ et al. Risk assessment for continuous flow left ventricular assist devices: does the destina tion therapy risk score work? An analysis of over 1,000 patients.J Am Coll Cardiol 2012;60(1):44-51

59. Kamath PS, Wiesner RH, Malinchoc M, Kremers W, Therneau TM, Kosberg CL, et al. A model to predict survival in patients with end-stage liver disease. Hepatology 2001;33(2):464-70.

60. Matthews JC, Pagani FD, Haft JW, Koelling TM, Naftel DC, Aaronson KD. Model for end-stage liver disease score predicts left ventricular assist device operative transfusion requirements, morbidity, and mortality. Circulation 2010;121(2):214-20.

61. Yang JA, Kato TS, Shulman BP, Takayama H, Farr M, Jorde UP, et al. Liver dysfunction as a predictor of outcomes in patients with advanced heart failure requiring ventricular assist device support: Use of the Model of End-stage Liver Disease (MELD) and MELD excluding INR (MELD-XI) scoring system. J Heart Lung Transplant 2012;31(6):601-10.

62. Cowger J, Sundareswaran K, Rogers JG. Predicting survival in patients receiving continuous flow left ventricular assist devices: the HeartMate II risk score. J Am Coll Cardiol 2013;61(3):313-21.

63. Matthews JC, Koelling TM, Pagani FD, Aaronson KD. The right ventricular failure risk score a pre operative tool for assessing the risk of right ventricular failure in left ventricular assist device candidates. J Am Coll Cardiol 2008;51 (22):2163-72.

64. Spaderna H, Mendell NR, Zahn D, Wang Y, Kahn J, Smits JM et al. Social isolation and depression predict 12-month outcomes in the "waiting for a new heart study." J Heart Lung Transplant 2010;29(12):247-54

65. Spaderna H, Weidner G, Koch KC, Kaczmarek I, Wagner FM, Smits JM. Medical and psychosocial predictors of mechanical circulatory support device implantation and competing outcomes in the Waiting for a New Heart Study. J Heart Lung Transplant 2012;31(12):16-26.

66. Ye C, Zhuang Y, Zhang Y, Lin Y, Ji J, Chen H. Anxiety, depression, and associated factors among inpatients waiting for heart transplantation. Shanghai Arch Psychiatry 2013;25(21):165-73.

67. Reynard AK, Butler RS, MCKee MG, Starling RC, Gorodeski EZ. Frequency of depression and anxiety before and after insertion of a continuous flow left ventricular assist device. Am J Cardiol 2014;114(3):433-40.
68. Bruce CR, Delgado E, Kostick K, Grogan S, Ashrith G, Trachtenberg B, et al. Ventric ular assist devices: a review of psychosocial risk factors and their impact on outcomes.J Card Fail 2014;20(12):996-1003

69. Gordon RJ, Weinberg AD, Pagani FD, Slaughter MS, Pappas PS, Naka Y et al. Prospective, multicenter study of ventricular assist device infections. Circulation 2013;127(6):691-702.

70. Snipelisky D, Stulak JM, Schettle SD, Sharma S, Kushwaha SS, Dunlay SM. Psychosocial characteristics and outcomes in patients with left ventricular assist device implanted as destination therapy. Am Heart J 2015;170(5):887-94.

71. Grady KL, Magasi S, Hahn EA, Buono S, McGee EC Jr, Yancy C. Health-related quality of life in mechanical circulatory support: Development of a new conceptual model and items for self-administration. J Heart Lung Transplant 2015;34(10):1292-304.

72. Emin A, Rogers CA, Banner NR. Quality of life of advanced chronic heart failure: medical care, mechanical circulatory support and transplantation. Eur J Cardiothorac Surg 2016;50(2):269-73.

73. Luo N, Rogers JG, Dodson GC, Patel CB, Galanos AN, Milano CA, O'Connor CM, Mentz RJ. Usefulness of Palliative Care to Complement the Management of Pa tients on Left Ventricular Assist Devices. Am J Cardiol 2016:1:118(5):733-8.

74. Swetz KM, Ottenberg AL, Freeman MR, Mueller PS. Palliative care and end-of-life issues in patients treated with left ventricular assist devices as destination therapy Curr Heart Fail Rep 2011;8(3):212-8.

75. Kitko LA, Hupcey JE, Gilchrist JH, Boehmer JP. Caring for a spouse with end-stage heart failure through implantation of a left ventricular assist device as destination therapy. Heart Lung 2013:42(3):195-201.

76. Sutcliffe P, Connock M, Pulikottil-Jacob R, Kandala NB, Suri G, Gurung T, et al. Clinical effectiveness and cost-effectiveness of second-and third-generation left ventricular assist devices as either bridge to transplant or alternative to transplant for adults eligible for heart transplantation: systematic review and cost-effectivenes model. Health Technol Assess 2013;17(53):1-499.

77. Clegg AJ, Scott DA, Loveman E, Colquitt J, Hutchinson J, Royle P, et al. The clinical and cost-effectiveness of left ventricular assist devices for end-stage heart failure: a systematic review and economic evaluation. Health Technol Assess 2005;9(45):1-132.

78. Clarke A, Pulikottil-Jacob R, Connock M, Suri G, Kandala NB, Maheswaran H, et al. Cost- effectiveness of left ventricular assist devices (LVADs) for patients with advanced heart failure: analysis of the British NHS bridge to transplant (BTT) program. Int J Cardiol 2014;171(3):338-45.

79. Ammirati E, Oliva FG, Colombo T, Russo CF, Cipriani MG, Garascia A et al. Midterm survival after continuous-flow left ventricular assist device versus heart transplantation. Heart Vessels 2016;31(5):722-33.

80. Patel CB, Cowger JA, Zuckermann A. A contemporary review of mechanical circulatory support. J Heart Lung Transplant 2014;33(7):667-74.

81. Stainback RF, Estep JD, Agler DA, Birks EJ, Bremer M, Hung J et al. Echocardiogra phy in the Management of Patients with Left Ventricular Assist Devices: Recom mendations from the American Society of Echocardiography. J Am Soc Echocardiogr. 2015;28(8):853-909

82. Lang RM, Badano LP, Mor-Avi V, Afilalo J, Armstrong A, Ernande L, et al. Recommendations for cardiac chamber quantification by echocardiography in adults: an update from the american society of echocardiography and the European as sociation of cardiovascular imaging. J Am Soc Echocardiogr 2015;28(1):1-39.

83. Grant $A D$, Smedira NG, Starling $R C$, Marwick TH. Independent and incremental role of quantitative right ventricular evaluation for the prediction of right ventricular failure after left ventricular assist device implantation. J Am Coll Cardiol 2012;60(6):521-8.

84. Vivo RP, Cordero-Reyes AM, Qamar U, Garikipati S, Trevino AR, Aldeiri M et al. Increased right-to-left ventricle diameter ratio is a strong predictor of right ventricular failure after left ventricular assist device. J Heart Lung Transplant 2013;32(8):792-9.

85. Kirklin JK, Naftel DC, Kormos RL, Stevenson LW, Pagani FD, Miller MA, et al. Fifth INTERMACS annual report: risk factor analysis from more than 6,000 mechanical circulatory support patients. J Heart Lung Transplant 2013;32(2):141-56.

86. Cleveland JC Jr, Naftel DC, Reece TB, Murray M, Antaki J, Pagani FD, Kirklin JK. Survival after biventricular assist device implantation: an analysis of the Interagency Registry for Mechanically Assisted Circulatory Support database. J Heart Lung Transplant 2011;30(8):862-9. 

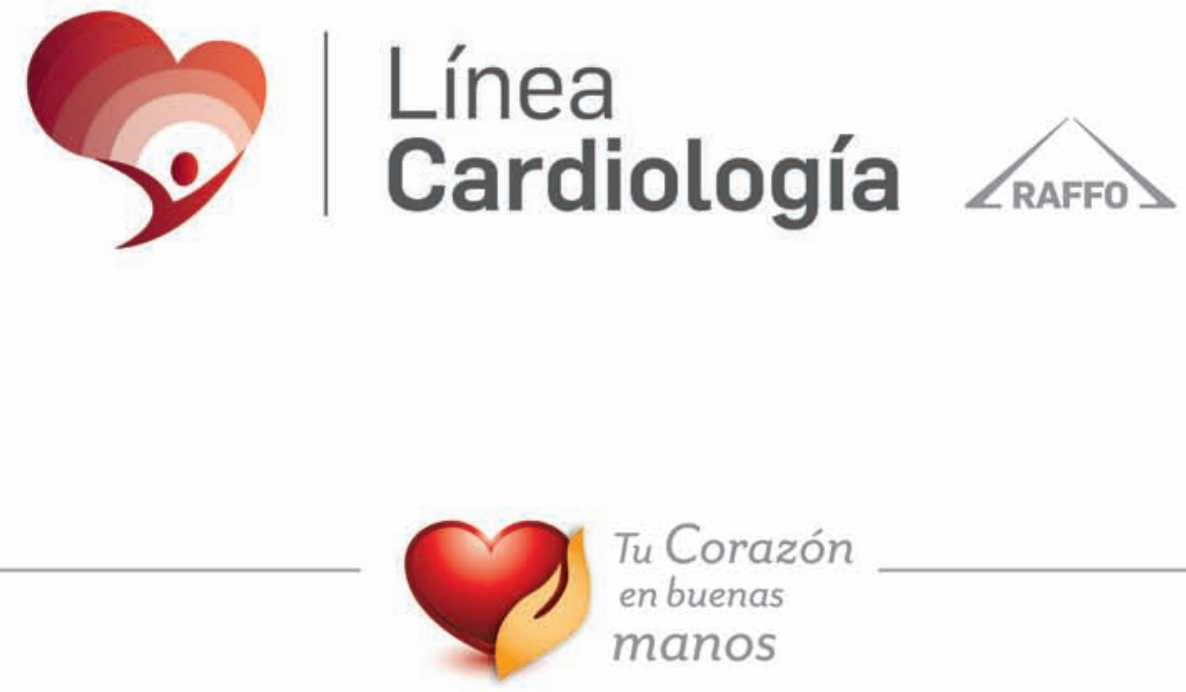

Tu Corazón

en buenas

manos

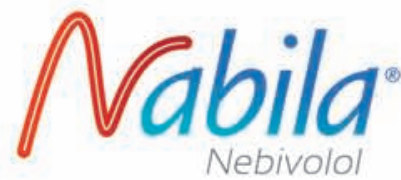

l. LIPIFEN

NǑSTER

NŨSTER'D

AMLODIPINA \VALSARTAN

AMLODIPINA / VALSARTAN / HCTZ

à Alpertan:

चAlpertan:D
COLMัMBE.
atorvastatina / ezetimibe
Nabratín
ROSSUFEN"
(2) ZOLPLAT 


\title{
GRADIENTE POSQUIRÚRGICO EN PACIENTES CON REEMPLAZO VALVULAR AÓRTICO Y SU ASOCIACIÓN CON EVENTOS CARDIOVASCULARES
}

\author{
POST-SURGICAL GRADIENT IN PATIENTS WITH AORTIC VALVE \\ REPLACEMENT AND ITS ASSOCIATION WITH CARDIOVASCULAR EVENTS
}

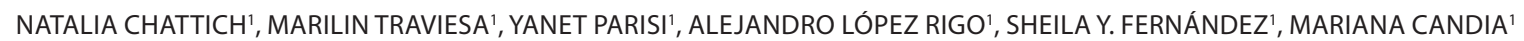

\section{RESUMEN}

Introducción. La cirugía de reemplazo valvular aórtico (CRVAo) constituye el tratamiento de elección en la estenosis aórtica (EAo) severa sintomática o con deterioro de la función ventricular. El gradiente posquirúrgico se ha visto asociado significativamente con la sobrevida y evolución a largo plazo. Sin embargo, su prevalencia y correlación con desenlaces clínicos en nuestro centro aún no ha sido estudiada formalmente.

Objetivo. Evaluar el gradiente posquirúrgico valvular en pacientes sometidos a CRVAo y su asociación con eventos cardiovasculares en el Instituto de Cardiología de Corrientes Juana F. Cabral.

Métodos. Estudio observacional, retrospectivo, unicéntrico. Se incluyeron pacientes sometidos a CRVAo por EAo severa y se evaluaron los gradientes valvular aórticos pre- y posquirúrgicos con un seguimiento a 6 meses.

Resultados. Se incluyeron 199 pacientes. El 86,9\% presentó hipertensión arterial, el $20,7 \%$ diabetes mellitus, 29,8\% dislipemia y el 10,1\% presentaba aorta bicúspide. Con respecto a los eventos cardiovasculares posquirúrgicos: 9,2\% presentó insuficiencia cardíaca, $1 \%$ bloqueo auriculoventricular completo, 1,5\% requirió implante de marcapasos definitivo, 2,1\% fibrilación auricular, 3,1\% derrame pericárdico severo y el 2,1\% endocarditis infecciosa, sin encontrarse asociación entre los eventos cardiovasculares posquirúrgicos de ambas ramas. La mortalidad posoperatoria fue del 2,5\%. Comparando las variables ecocardiográficas pre- y posquirúrgicas se observó disminución de los gradientes y aumento del área valvular en forma significativa. Se observó que el $37,1 \%$ de los pacientes operados presentó disminución respecto al valor basal pero persistió con gradientes postquirúrgicos elevados. En dichos pacientes, se observó que el gradiente prequirúrgico medio era $10 \mathrm{mmHg}$ mayor con respecto a los pacientes que luego de la cirugía presentaron gradientes normales.

Conclusión. La prevalencia de gradiente posquirúrgico elevado en nuestro centro es elevada. El gradiente posquirúrgico elevado no se asoció con aumento de eventos cardiovasculares registrados.

Palabras clave: estenosis de la válvula aórtica, cirugía cardíaca.

\section{ABSTRACT}

Introduction. Aortic valve replacement surgery (AVR) is the treatment of choice in severe aortic stenosis (AS) that is symptomatic or has deteriorated ventricular function. The postoperative gradient has been significantly associated with long term survival and evolution. However, its prevalence and correlation with clinical outcomes in our center has not yet been formally studied.

Objective. To evaluate the postoperative valvular gradient in patients undergoing AVR and its association with cardiovascular events in the Corrientes Institute of Cardiology, Juana F. Cabral.

Methods: Observational, retrospective, single-center study. We included patients undergoing AVR due to severe AS, and the aortic valve gradients before and after surgery were evaluated during a 6-month follow-up.

Results. 199 patients were included. 86.9\% presented hypertension, 20.7\% diabetes mellitus, $29.8 \%$ dyslipidemia, and $10.1 \%$ had bicuspid aorta. With respect to postsurgical cardiovascular events: $9.2 \%$ presented heart failure, $1 \%$ complete atrioventricular block, $1.5 \%$ required permanent pacemaker implantation, $2.1 \%$ atrial fibrillation, 3.1\% severe pericardial effusion and $2.1 \%$ infective endocarditis, with no association between postsurgical cardiovascular events of both branches. The postoperative mortality was $2.5 \%$. Comparing the preoperative and post-surgical echocardiographic variables, a decrease in the gradients and a significant increase in the valve area were observed. It was observed that $37.1 \%$ of the operated patients presented decrease with respect to the baseline value but persisted with high postoperative gradients. In these patients, it was observed that the average presurgical gradient was $10 \mathrm{mmHg}$ higher than in patients who presented normal gradients after surgery.

Conclusion. The prevalence of a high postoperative gradient in our center is high. The elevated post-surgical gradient was not associated with an increase in recorded cardiovascular events.

Keywords: aortic stenosis, cardiac surgery.

REVISTA CONAREC 2018;33(147):305-307 | DOI:10.32407/RCON/2018147/0305-0307

\section{INTRODUCCIÓN}

La estenosis aórtica constituye una de las afectaciones valvulares cardíacas de mayor prevalencia a nivel mundial, que aumenta de manera directamente proporcional con la edad ${ }^{1}$

No existen dudas respecto del beneficio que otorga la cirugía de reemplazo valvular en lo referente al curso evolutivo y pronóstico de los pacientes afectados por esta valvulopatía. A pesar de esto, la sobrevida alejada, sobre todo de los pacientes jóvenes sometidos a dicho proce-

1. Residente de Cardiología

Instituto de Cardiología de Corrientes Juana F. Cabral

$\triangle$ Correspondencia: Dra. Natalia Chattich. Bolivar 1334, Corrientes, provincia de Corrientes, Rep.Argentina.natichattich@hotmail.com

Los autores declaran no tener conflictos de intereses.

Recibido: 10/12/2018| Aceptado: 15/12/2018 dimiento, es inferior a la de la población general. Si bien esto puede responder en parte al tipo de prótesis valvular elegida, está fundamentalmente ligado a las características particulares de cada paciente².

La mortalidad hospitalaria del procedimiento está relacionada con las características basales de la población y con la necesidad o no de realizar otro tipo de intervención asociada3.

La sobrevida y la evolución a largo plazo se encuentran determinadas

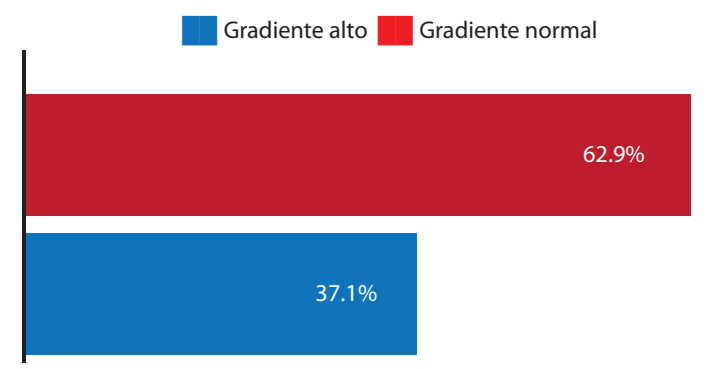

Figura 1. Porcentaje de pacientes que presentaron gradiente normal y gradiente alto en el posquirúrgico. 
Gradiente valvular alto $\square$ Gradiente valvular normal

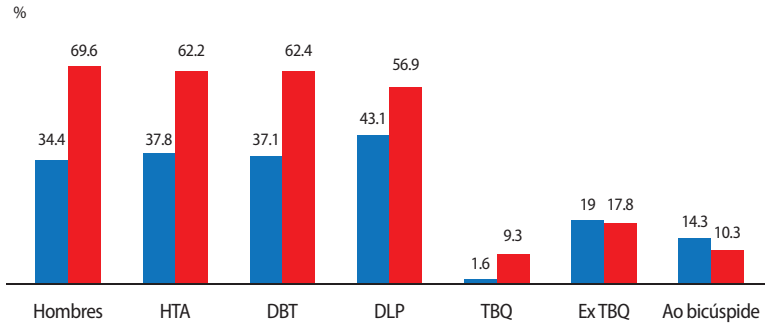

Figura 2. Características basales de los pacientes teniendo en cuenta el gradiente valvula post-quirúrgico normal y alto. G: gradiente. HTA: hipertensión arterial. DBT: diabetes mellitus. DLP: dislipemia. TBQ: tabaquismo. EX TBQ: extabaquismo. Ao: aorta.

por la edad, la función ventricular previa, la existencia o no de otras comorbilidades y el tipo de sustituto valvular, que también tendrá influencia en términos de clase funcional y calidad de vida ${ }^{4,5}$.

Con respecto al tipo de prótesis seleccionada y sus complicaciones, las mecánicas presentan mayor durabilidad pero son más propensas a sufrir complicaciones tromboembólicas debido al mismo material, por lo que requieren anticoagulación crónica con los riesgos propios de esta terapéutica. Los implantes biológicos se comportan en forma opuesta: habitualmente no requieren anticoagulación pero suelen sufrir procesos degenerativos más temprano.

El gradiente posquirúrgico elevado (definido como una velocidad transvalvular mayor a $3 \mathrm{~m} / \mathrm{s}$ según las últimas guías internacionales) se ha asociado significativamente en forma negativa en la sobrevida y evolución a largo plazo ${ }^{6}$.

Es por esto que posterior al reemplazo valvular aórtico (RVA) los pacientes deben ser evaluados en forma periódica incluyendo examen físico, radiografía de tórax, electrocardiograma, análisis de laboratorio y ecocardiograma a fin de determinar la aparición de complicaciones clínicas y relacionadas con la prótesis, tales como insuficiencia cardiaca, disfunción valvular, arritmias o endocarditis infecciosa $a^{7,8}$.

El objetivo de este trabajo es evaluar la prevalencia de gradientes valvulares posquirúrgicos aumentados en pacientes sometidos a cirugía de reemplazo valvular aórtico y su asociación con eventos cardiovasculares en nuestro centro.

\section{MATERIALES Y MÉTODOS}

Estudio observacional, retrospectivo, unicéntrico. Se incluyeron pacientes sometidos a CRVAo por EAo severa según las clasificaciones clínicas y ecocardiográficas vigentes, en el período comprendido desde enero del año 2013 hasta enero del año 2016. Los datos fueron recolectados de historias clínicas y de la base de datos del Servicio de Cirugía Cardiovascular del Instituto de Cardiología "Juana F. Cabral". Para determinar la diferencia entre gradientes pre- y posquirúrgico se tomaron en cuenta los ecocardiogramas pre- y posquirúrgicos de los pacientes. El seguimiento a los 6 meses luego de la intervención quirúrgica se realizó a través de la recolección de datos de historias clínicas en las que se confirmó internación por insuficiencia cardiaca, derrame pericárdico severo, endocarditis infecciosa, disfunción valvular o muerte. Se revisaron además datos demográficos como edad y sexo, factores

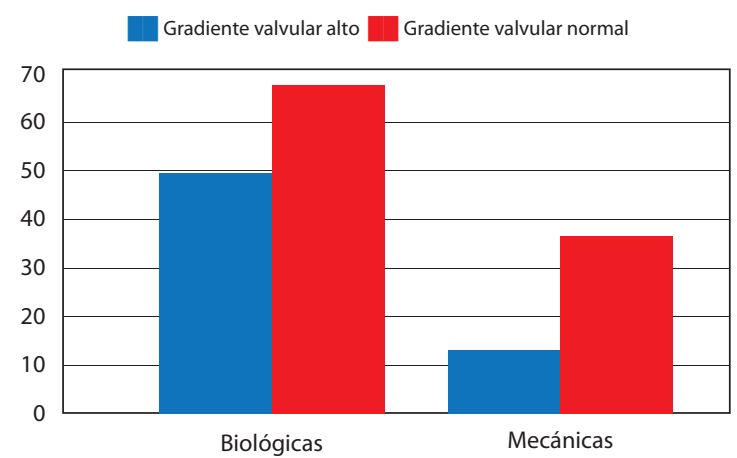

Figura 3. Comparación en cuanto al tipo de válvula y gradiente posquirúrgico normal o alto G. Valv: gradiente valvular

de riesgo cardiovascular como hipertensión arterial, diabetes mellitus, dislipidemia, tabaquismo y extabaquismo, así como la presencia o no de válvula aórtica bicúspide previa a la cirugía.

Los criterios de exclusión fueron los siguientes: pacientes sometidos a doble reemplazo valvular, pacientes con cirugía cardíaca previa, reemplazo valvular en contexto de disección aórtica con afección valvular y aquellos pacientes que no presentaran ecocardiograma realizado en el Instituto de Cardiología de Corrientes dentro de los 6 meses del posoperatorio.

\section{ANÁLISIS ESTADÍSTICO}

Las variables categóricas se expresaron mediante números y porcentajes, y las continuas, según su distribución, como media o mediana, con su correspondiente desvío estándar o intervalo intercuartílico. Para evaluar la asociación entre las variables continuas se utilizó el test de U de Mann-Whitney o test de T.Y para establecer asociación entre variables cualitativas se utilizó el test de Chi cuadrado y el análisis de riesgo asociado mediante el cálculo del odds ratio, con un intervalo de confianza del $95 \%$. El punto de corte utilizado para la significación estadística fue una $p<0,05$. Los datos recabados fueron registrados en una planilla de cálculo de Microsoft Excel. El análisis estadístico se realizó con el programa SPSS 21 para Windows.

\section{RESULTADOS}

Fueron incluidos 170 pacientes y excluidos 29. Del total de pacientes incluidos se observó que un 62,9\% presentó gradiente normal posquirúrgico y $37,1 \%$ gradiente aumentado, teniendo en cuenta un valor de velocidad transvalvular $>3 \mathrm{~m} / \mathrm{s}$ según las últimas recomendaciones de las guías de práctica clínica ${ }^{9}$ (Figura 1).

En cuanto a las características basales de los pacientes se observó que, del grupo con gradiente normal en el posquirúrgico, 63,6\% eran hombres, el 62,2\% tenía hipertensión arterial, el 62,4\% diabetes mellitus, 56,9\% dislipemia, 9,3\% tabaquismo, el 17,8\% extabaquismo y 10,3\% presentaban aorta bicúspide; mientras que dentro del grupo con gradiente alto $36,4 \%$ eran hombres, 37,8\% tenían hipertensión arterial, el 37,1\% diabetes mellitus, 43,1\% dislipemia, 1,6\% tabaquismo, 19\% extabaquismo y 14,3\% con aorta bicúspide (Figura 2).

Respecto al tipo de válvula, se observó que de aquellos con válvula biológica, 50 pacientes (42\%) presentaron gradiente alto y 69 (58\%) gradiente normal; de los pacientes con prótesis mecánica, 13 (26\%) presentaron gradiente aumentado y 38 (74\%) gradiente norma

(Figura 3). Comparando los valores de los pacientes con gradientes 


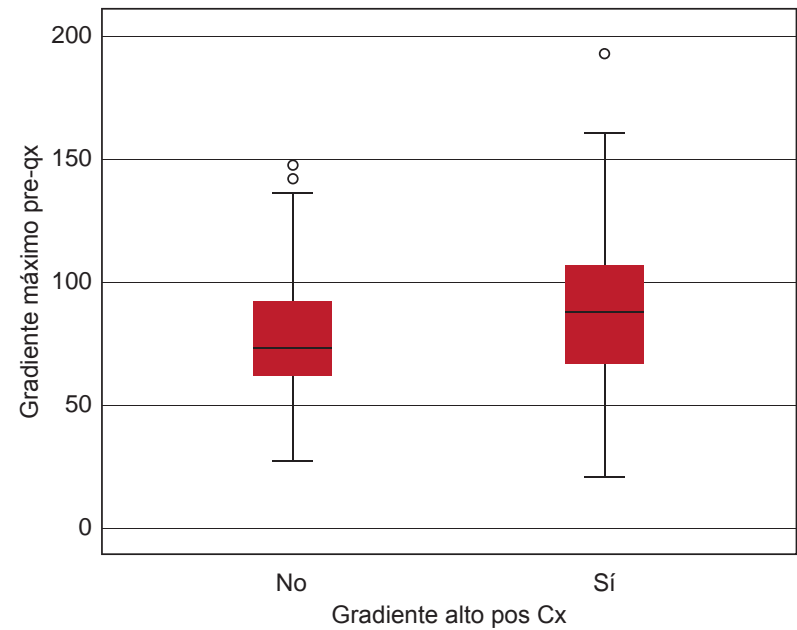

Figura 4. Comparación de medias de pacientes que presentaron gradientes normales vs. gradientes altos. Se observa que los pacientes que presentaron gradiente alto posquirúrgico presentaban gradientes prequirúrgicos más elevados. Gradiente máx pre-qx: gradiente máximo prequirúrgico. Gradiente alto pos $C x$ : gradiente alto posquirúrgico

postquirúrgicos normales, aquellos con gradientes aumentados presentaron una media de $10 \mathrm{mmHg}$ por encima del valor del primer grupo, con áreas valvulares más pequeñas. (Figura 4).

Finalmente no se registraron diferencias estadísticamente significativas con respecto a los eventos cardiovasculares posquirúrgicos comparando ambos grupos: se registró insuficiencia cardiaca en 9,5 vs. 11,3\% ( $p=0,464)$, bloqueo auriculoventricular completo 3,2 vs. $0 \%$ ( $p=0,138)$, requerimiento de marcapasos definitivo 4,8 vs. $0 \%(p=0,5)$, fibrilación auricular 3,2 vs. $1,9 \%(p=0,471)$, derrame pericárdico severo 4.9 vs. $2.9 \%$ ( $p=0,392)$, necesidad de pericardiocentesis 4,8 vs. 1,9\% ( $p=0,263)$, endocarditis 4,8 vs. $0,9 \%$ ( $p=0,147)$ y muerte 3,2 vs. $0,9 \%(p=0,309)$, respectivamente (Figura 5).

\section{DISCUSIÓN}

En este trabajo se observó que, en nuestro centro, un 37,1\% de los pacientes sometidos a CRVA persistió con gradiente posquirúrgico elevado sin que esto se haya asociado a una mayor tasa de eventos cardiovasculares.

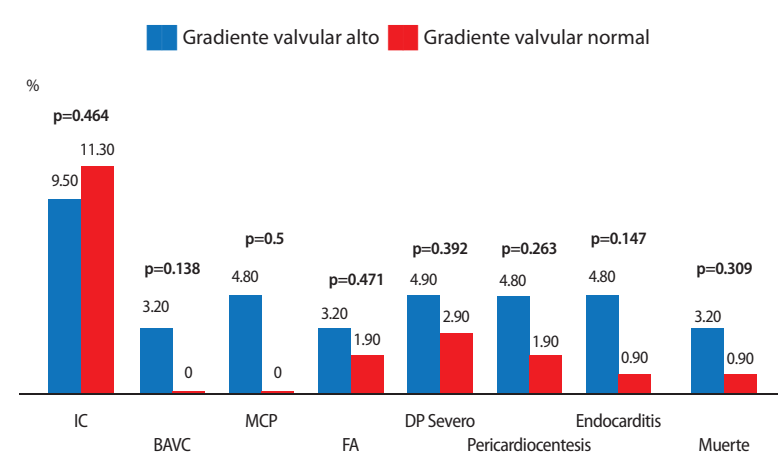

Figura 5. Eventos cardiovasculares postquirúrgicos registrados y su relación con gradientes normales o altos. No se encontraron diferencias significativas estadísticamente. IC: insuficiencia cardiaca. BAVC: bloqueo auriculoventricular completo. MCP: marcapasos. FA: fibrilación auricular. DP: derrame pericárdico.

Una de las limitaciones de nuestro trabajo consistió en no contar con el dato de la velocidad del tracto de salida del ventrículo izquierdo en los ecocardiogramas posquirúrgicos, con la cual se podría evaluar la disfunción valvular como una de las causas de dicho gradiente elevado.

Otro problema potencial a descartar en estos pacientes sería la discordancia prótesis-paciente (DPP), la cual se presenta cuando el área del orificio efectivo de una prótesis que funciona normalmente, es demasiado pequeña en relación al tamaño del cuerpo del paciente ${ }^{5,6}$. Algunos estudios han demostrado que la presencia de DPP afecta negativamente la reversión de la hipertrofia ventricular, la capacidad funcional e incluso la sobrevida en algunos subgrupos ${ }^{3,4}$.

Consideramos que estos datos pueden servir como base para futuros estudios y así ampliar los hallazgos encontrados.

\section{CONCLUSIÓN}

En este estudio se observó una elevada prevalencia de gradientes postquirúrgicos altos, sin esto asociarse significativamente con aumento de los eventos cardiovasculares registrados.

\section{BIBLIOGRAFÍA}

1. Lax J, Stutzbach P, Beck M, Perea FM, Cianciulli T, Grancelli H, et al. Consenso de Valvulopatías. Rev Argent Cardiol 2015;83(2).

2. Carmona-Ruiz HA, Arias-Godínez JA, Ávila-Vanzzini N, Romero-Aragonés C, Roldán-Gómez FJ, Ruiz-Esparza-Dueñas ME, et al. Evaluación postquirúrgica por ecocardiografía del paciente sometido a reemplazo valvular aórtico. ¿Se aplican las recomendaciones de las guías?. Rev Mex Cardiol 2014;25(3):158-62.

3. Vohra HA, Whistance RN, de Kerchove L, Glineur D, Noirhomme P, El Khoury G. Influence of higher valve gradient on long-term outcome after aortic valve repair. Ann Cardiothorac Surg 2013;2(1):30-9.

4. Koene BM, Soliman Hamad MA, Bouma W, Mariani MA, Peels KC, van Dantzig JM, et al. Can postoperative mean transprosthetic pressure gradient predict survival after aortic valve replacement?. Clin Res Cardiol 2014;103(2):133-40.

5. Nishimura RA, Otto CM, Bonow RO, Carabello BA, Erwin JP III, Guyton RA, et al. 2014 AHA/ACC Guideline for the Management of Patients With Valvular Heart Disease: executive summary: a report of the American College of Cardiology/American Heart Association Task Force on Practice Guidelines. Circulation 2014; 129(23):2440-92.

6. Zoghbi WA, Chambers JB, Dumesnil JG, Foster E, Gottdiener JS, Grayburn PA, et al. Rec ommendations for evaluation of prosthetic valves with echocardiography and doppler ultrasound: a report From the American Society of Echocardiography's Guidelines and Standards Committee and the Task Force on Prosthetic Valves, developed in conjunction with the American College of Cardiology Cardiovascular Imaging Committee, Cardiac Imaging Committee of the American Heart Association, the European Association of Echocardiography, a registered branch of the European Society of Cardiology, the Japanese Society of Echocardiography and the Canadian Society of Echocardiography, endorsed by the American College of Cardiology Foundation, American Heart Association, European Association of Echocardiography, a registered branch of the European Society of Cardiology, the Japanese Society of Echocardiography, and Canadian Society of Echocardiography. J Am Soc Echocardiogr 2009;22(9):975-1014.

7. Bach DS. Echo/Doppler evaluation of hemodinamics after aortic valve replacement: principles of interrogation and evaluation of high gradients. JACC Cardiovasc Imaging 2010;3(3):296-304.

8. Del Corro I, Contreras A, Brenna E. ¿Es posible predecir gradientes transvalvulares elevados en la cirugía valvular aórtica? Rev Fed Arg Cardiol 2013;43(1)14-17. 


\title{
FACTORES DE RIESGO CARDIOVASCULAR EN RESIDENTES Y CARDIÓLOGOS ARGENTINOS. "CÓMO SE CUIDAN LOS QUE CUIDAN". ENCUESTA FRICCAR, CONAREC
}

\author{
CARDIOVASCULAR RISK FACTORS IN ARGENTINE RESIDENTS AND \\ CARDIOLOGISTS. "HOWTO CARE FOR THOSE WHO PROVIDE CARE". \\ FRICCAR SURVEY, CONAREC
}

HERNÁN PULENTA, LUCRECIA M. BURGOS, IGNACIO CIGALINI, DANIEL LORENZATTI, IVAN VILAR, MAURO ROSSI PRAT, FRANCO GIANNASI, ELISA ORTIZ, AGUSTÍN ROUDE, SEBASTIÁN GARCÍA-ZAMORA*

\section{RESUMEN}

Introducción. Si bien se ha avanzado en el conocimiento y tratamiento de los factores de riesgo cardiovascular (FRCV) en población general, se conoce menos respecto de la distribución de estos entre médicos.

Objetivos. Describir los FRCV presentes en residentes de cardiología y cardiólogos pertenecientes a residencias de Cardiología de todo el país.

Métodos. Se realizó una encuesta cerrada y prefijada, voluntaria y anónima, con un muestreo no probabilístico por conveniencia, en centros pertenecientes a Consejo Argentino de Residentes de Cardiología (CONAREC), durante los meses de agosto-noviembre de 2017.

Resultados. Se encuestaron 523 profesionales pertenecientes a 44 centros de todo el país. El 63,1\% de los participantes fueron hombres, y la mediana de edad fue 31 años (rango intercuartílico [RIC]: 28-38 años). El 52,8\% eran residentes, $5,9 \%$ jefes o instructores de residentes y $41,3 \%$ especialistas o fellow. Los princi pales FRCV detectados fueron: dislipemia 14,3\%, hipertensión arterial 5\%, enfermedad coronaria previa $1 \%$ y diabetes mellitus tipo $\| 0,8 \%$. Asimismo fumaban $16,8 \%$, y $12,6 \%$ eran extabaquistas. El $36,7 \%$ de los participantes manifestó no hacer ningún tipo de actividad física, y 33,8\% expresó que nunca se cuidaba de no agregar sal a los alimentos. Además, 35,6\% expresó que no comían frutas ni verduras diariamente. La mediana de estatura de las mujeres fue 1,63 metros (RIC 1,6-1,68), mientras que la de los hombres fue 1,75 metros (RIC: 1,71-1,81); la mediana del peso de las mujeres fue $58 \mathrm{~kg}$ (RIC: 55-63), en tanto la de los hom bres fue $81 \mathrm{~kg}$ (RIC: 73-90). La mediana del índice de masa corporal fue 21,7 (RIC: 20,3-24) para mujeres y 26,1 (RIC: $24,2-28,1$ ) en hombres. De acuerdo con esto, $46,5 \%$ de los encuestados cumplían criterio de sobrepeso u obesidad. El perímetro abdominal de los hombres fue $90 \mathrm{~cm}$ (RIC: 84-99) y el de las mujeres 70 (RIC 66-78). Respecto de los valores de presión arterial, el promedio sistólico fue de $115,7 \pm 11,9 \mathrm{mmHg}$ y diastólico $71,6 \pm 8,6 \mathrm{mmHg}$. Por otra parte, el 94,7\% de los participantes manifestó tener algún tipo de cobertura médica, al tiempo que $41,9 \%$ del total de encuestados reconoció que había pasado más de 1 año desde su último control de salud.

Conclusión. Encontramos una elevada tasa de sobrepeso y obesidad entre los participantes, como también de sedentarismo, tabaquismo y dislipemia. Si bien la prevalencia de otros factores de riesgo fue baja, debe tenerse presente que los participantes fueron en su mayoría jóvenes. Consideramos esencial implementa estrategias para favorecer la práctica de estilos de vida más favorables entre profesionales de la salud de nuestro país.

Palabras clave: factores de riesgo; obesidad, hipertensión, tabaquismo, hipercolesterolemia, cardiología.

\section{ABSTRACT}

Introduction: Although there has been progress in the knowledge and treatmen of cardiovascular risk factors (CVRF) in the general population, less is known about the distribution of these among physicians.

Objectives: To describe the CVRF present in residents of cardiology and cardiologists belonging to Cardiology residences throughout the country.

Methods: A closed and pre-determined, voluntary and anonymous survey was carried out with a non-probabilistic sampling for convenience in centers belonging to the Argentine Council of Cardiology Residents (CONAREC), during the months of August-November of 2017.

Results: 523 professionals belonging to 44 centers across the country were surveyed. $63.1 \%$ of the participants were men, and the median age was 31 years (interquartile range $[\mathrm{RIC}]$ 28-38 years). 52.8\% were residents, 5.9\% chiefs or instructors of residents and $41.3 \%$ specialists or fellows. The main CVRF detected were: dys lipidemia $14.3 \%$, hypertension $5 \%$, previous coronary disease $1 \%$ and Diabetes Mellitus type II $0.8 \% .16 .8 \%$ also smoked, and $12.6 \%$ were former smokers. $36.7 \%$ of the participants said they did not do any kind of physical activity, and $33.8 \%$ said they never took care not to add salt to food. In addition, $35.6 \%$ said they did not eat fruits or vegetables daily. The median height of the women was $1.63 \mathrm{me}$ ters (IQR 1.6-1.68), while that of the men was 1.75 meters (IOR 1.71-1.81): the median weight of women was $58 \mathrm{~kg}$ (IQR 55-63), while that of men was $81 \mathrm{~kg}$ (IQR 73-90). The median body mass index was 21.7 (IQR 20.3-24) for women and 26.1 (IQR 24.2-28.1) for men. According to this, $46.5 \%$ of the respondents met criteria of overweight or obesity. The abdominal perimeter of men was $90 \mathrm{~cm}$ (IQR 84-99) and that of women 70 (IQR 66-78). Regarding blood pressure values, the systolic average was $115.7 \pm 11.9 \mathrm{mmHg}$ and diastolic $71.6 \pm 8.6 \mathrm{mmHg}$. On the other hand, $94.7 \%$ of the participants said they had some type of medical coverage, while $41.9 \%$ of the total respondents admitted that more than 1 year had passed since their last health check-up.

Conclusion: We found a high rate of overweight and obesity among the participants, as well as sedentary lifestyle, smoking and dyslipidemia. Although the prevalence of other risk factors was low, it should be kept in mind that the participants were mostly young. We consider it essential to implement strategies to favor the practice of more favorable lifestyles among health professionals in ou country.

Keywords: risk factors; obesity; hypertension; tobacco use disorder; hypercholes terolemia; cardiology

REVISTA CONAREC 2018;33(147):308-312 | DOI:10.32407/RCON/2018147/0308-0312

\footnotetext{
* En representación de CONAREC

$\triangle$ Correspondencia:Dr. Hernán Pulenta. Consejo Argentino de Residentes de Cardiología, Azcuénaga 980, C1115AAD CABA, Rep.Argentina.pablohernanpulenta@gmail.com
}

La línea cardiovascular y metabólica de Laboratorio Roemmers participó de la ideación del proyecto, la confección del CRF y de la implementación del proyecto. Sin embargo, no participaron del procesamiento de datos ni de la redacción de resultados y conclusiones.

Recibido: 28/12/2018| Aceptado: 30/12/2018

\section{INTRODUCCIÓN}

La aterosclerosis es una compleja enfermedad multifactorial que involucra una interacción de factores genéticos y ambientales, y es la principal causa de morbimortalidad y discapacidad en la sociedad actual $^{1,2}$. Afecta a arterias de diferentes localizaciones simultáneamente pero con diferente grado de progresión $n^{3}$. Sus manifestaciones clí- 


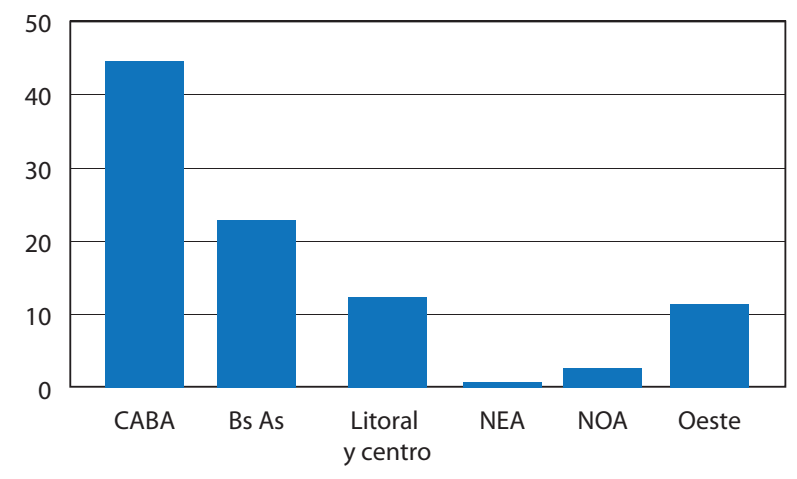

Figura 1. Distribución por regiones de los encuestados. Abreviaturas: CABA: Ciudad de Buenos Aires; Bs. As: Provincia de Buenos Aires y Gran Buenos Aires; NEA: Noreste Argentino; NOA: Noroeste Argentino. Provincias y ciudades incluidas según región: Litoral y centro: Santa Fe, Rosario, Paraná y Córdoba. NEA: Corrientes y Posadas. Oeste: Mendoza, San Juan y La Rioja. NOA: Jujuy y Catamarca.

nicas dependen del lecho vascular afectado: en las coronarias se manifiesta por la aparición de síndrome coronario agudo, infarto agudo de miocardio (IAM) o muerte súbita; en el cerebro cursa clínicamente como un accidente cerebrovascular agudo (ACV) o como un accidente isquémico transitorio (AIT), y los episodios repetidos pueden desembocar en una demencia multiinfarto; y en las arterias periféricas, la expresión clínica es la claudicación intermitente o la isquemia aguda de los miembros inferiores ${ }^{4,5}$.

La aterosclerosis es un proceso crónico que se inicia en etapas muy tempranas de la vida. Algunos estudios sugieren que este proceso podría iniciarse antes del nacimiento, o en los primeros años de vida, y acentuarse con el correr del tiempo $0^{6,7}$.

Las causas exactas y los factores de riesgo (FR) de la aterosclerosis no son del todo conocidos; sin embargo, ciertas condiciones o hábitos pueden aumentar la posibilidad de desarrollarla. Entre ellos destacan: hipertensión arterial, tabaquismo, diabetes mellitus, obesidad, la edad y algunos componentes del estilo de vida contemporáneo, especialmente las actividades diarias con escasa demanda energética. Además, cambios en patrones alimentarios como consumo de productos manufacturados, ricos en grasas saturadas y azúcares simples, con escaso consumo de frutas y verduras explican al menos parcialmente la globalización de esta enfermedad ${ }^{8-10}$.

El conocimiento y detección de los FR desempeña un importante papel para la valoración del riesgo cardiovascular, pieza clave para las estrategias de intervención sobre dichas enfermedades ${ }^{4}$. La presencia de varios FR en un mismo individuo multiplica su riesgo de forma importante, teniendo un papel indiscutible en el cálculo de las puntuaciones de riesgo global y, por tanto, un gran peso en la prevención primaria y secundaria. Los hábitos y estilos de vida determinan la incidencia de muchos de esos factores, por lo cual su distribución se relaciona con las condiciones sociales y culturales específicas de cada población ${ }^{11}$, y deben ser considerados como las causas más importantes y modificables de la mayoría de las muertes por enfermedades cardíacas y ACV ${ }^{12}$.

Si bien los médicos en general tenemos la obligación de realizar promoción de la salud entre nuestros pacientes, los cardiólogos desempeñamos un rol preponderante, tanto por la mayor proximidad de la especialidad con estas patologías, como así también debido al papel
Tabla 1. Características basales de los encuestados

\begin{tabular}{lc} 
Características basales) & $\mathrm{n}=523$ \\
\hline Edad (años) [mediana (RIC)] & $31(28-38)$ \\
Sexo masculino [n (\%)] & $330(63,1 \%)$ \\
Cargo [n (\%)] & \\
$\quad$ Residente & $276(52,8 \%)$ \\
$\quad$ Jefe de Residentes & $20(3,8 \%)$ \\
Instructor de Residentes & $10(1,9 \%)$ \\
Fellow & $20(3,8 \%)$ \\
Especialista & $197(37,7 \%)$ \\
Año de residencia [n (\%)] & \\
$\quad$ Primero & $39(14,2 \%)$ \\
Segundo & $92(33,3 \%)$ \\
Tercero & $74(26,8 \%)$ \\
Cuarto & $71(25,7 \%)$
\end{tabular}

que ocupan nuestras aseveraciones en el imaginario colectivo. Pese a esto, varios registros han reportado que una proporción importante de médicos no ponen en práctica las recomendaciones que habitualmente realizan a sus pacientes.

Debido a esto nos propusimos describir los factores de riesgo cardiovascular (FRCV) presentes en residentes de Cardiología y cardiólogos de planta pertenecientes a residencias de Cardiología de todo el país, y relevar el grado de adherencia de los participantes del estudio a hábitos alimentarios saludables.

\section{MÉTODOS}

Estudio de corte transversal prospectivo, observacional y multicéntrico. Se incluyeron médicos cardiólogos en formación o especialistas, pertenecientes a residencias de Cardiología de todo el país, durante los meses de agosto-noviembre de 2017.

\section{POBLACIÓN}

Criterios de inclusión: médicos cardiólogos en formación o especialistas, pertenecientes a residencias de Cardiología de todo el país, independientemente de que se encuentren asociadas o no a CONAREC. Se definió como cardiólogos en formación a: residentes, concurrentes, becarios, jefes de residentes e instructores de residentes de servicios de Cardiología. Se consideró como médicos especialistas a todos aquellos cardiólogos que se desempeñen en una institución con residencia, o asociados a una institución con residencia de Cardiología. Asimismo se incluyó en este subgrupo a aquellos cardiólogos que se encontraban realizando un fellowship (especialización) o una residencia posbásica en Cardiología (es decir, que hayan concluido ya su residencia de Cardiología en cualquier institución del país o del exterior), aclarándose su condición.

No se realizó distinción entre fellowship y residencia posbásica.

Criterios de exclusión: médicos que se encontraban realizando o desempeñando una especialidad diferente de Cardiología, aun en el caso de que hubieran completado una residencia de Cardiología previamente. Asimismo se excluirán a aquellos profesionales que se encuentren jubilados de sus tareas.

\section{RECOLECCIÓN DE DATOS Y DEFINICIÓN DE VARIABLES}

La recolección de datos se llevó a cabo mediante entrevista personal o realización del cuestionario de forma autoadministrada 
Tabla 2. Perfil cardiovascular. IMC: índice de masa corporal.

\begin{tabular}{lc|}
\hline Factores de riesgo cardiovascular & $n=523$ \\
\hline Hipertensión arterial $(n ; \%)$ & $26(5 \%)$ \\
\hline Diabetes mellitus $(n ; \%)$ & $4(0.8 \%)$ \\
\hline Dislipemia $(n ; \%)$ & $75(14.3 \%)$ \\
\hline Ex tabaquismo $(n ; \%)$ & $66(12.6 \%)$ \\
\hline Tabaquismo $(n ; \%)$ & $88(16.8 \%)$ \\
\hline Categoría de peso según IMC $(n ; \%)$ & \\
$\quad$ Sobrepeso & $186(35.6 \%)$ \\
$\quad$ Obesidad & $59(11.3 \%)$ \\
Sedentarismo (n; \%) & $192(36.7 \%)$ \\
\hline Enfermedad cardiovascular $(n ; \%)$ & \\
Enfermedad coronaria & $5(1 \%)$ \\
Enfermedad cerebrovascular & $2(0.4 \%)$ \\
Enfermedad vascular periférica & $0(0 \%)$
\end{tabular}

(Apéndice I, Encuesta). La encuesta fue cerrada y prefijada, voluntaria y anónima. Se empleó para esto un muestreo no probabilístico por conveniencia.

La carga de datos se realizó on-line a través de una plataforma Web dedicada para tal fin -LimeSurvey-a través de un formulario electrónico (electronic case report form [eCRF]) diseñado especialmente con un acceso exclusivo a través de una clave individual para cada centro formador.

Las definiciones operativas de las variables relevadas en el presente estudio se definieron con anterioridad, y se brindaron pautas detalladas para la realización de las mediciones antropométricas

(Apéndice II, Definiciones operativas; y Apéndice III, Mediciones antropométricas).

\section{ANÁLISIS ESTADÍSTICO}

Las variables continuas fueron expresadas con media y desvío estándar o mediana y rango intercuartílico (RIC), dependiendo de su distribución. La normalidad de las mismas fue evaluada mediante herramientas gráficas (histogramas, gráficos de distribución normal, etc.) y el test de Shapiro-Wilk. Las variables categóricas se expresaron como números y porcentajes. Para las comparaciones entre grupos de las variables continuas con distribución normal se utilizó el test de Student. Cuando la distribución fue no gaussiana se aplicó el test de suma de rangos de Wilcoxon. Las comparaciones entre proporciones se efectuó mediante el test de Chi cuadrado o el test exacto de Fisher dependiendo de la frecuencia de valores esperados.

En todos los casos se asumió un error alfa del 5\% para establecer la significación estadística.

\section{CONSIDERACIONES ÉTICAS}

Debido a que los sujetos de estudio son pares o superiores de aquellos que desarrollan el presente estudio, y entendiendo que el anonimato de los participantes es un factor crucial para la veracidad de las respuestas proporcionadas, no se solicitará consentimiento informado por escrito. En cambio se considerará que, todos aquellos individuos que acepten participar de la encuesta, siendo ésta expresamente voluntaria, y teniendo libre acceso al presente protocolo, habrán prestado su conformidad para la misma.

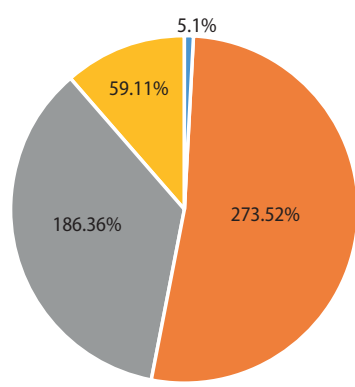

Bajo peso $\square$ Normopeso $\square$ Sobrepeso $\square$ Obesidad

Figura 2. Distribución de peso según índice de masa corporal (IMC). Clasificación: Bajo peso: IMC <18 kg/m². Normopeso: IMC $18-25 \mathrm{~kg} / \mathrm{m}^{2}$. Sobrepeso: IMC 25,1-29,9 kg/m². Obesidad: IMC $>30 \mathrm{~kg} / \mathrm{m}^{2}$

\section{RESULTADOS}

Se encuestaron 523 profesionales pertenecientes a 44 centros de todo el país. El 63,1\% de los participantes eran hombres, y la mediana de edad fue 31 años (RIC: 28-38 años) (Tabla 1). La distribución por regiones fue: Ciudad Autónoma de Buenos Aires 46,1\%, provincia de Buenos Aires 23,7\%, Litoral y Centro 13,2\%, Noreste Argentino 1\%, Oeste 12,4\% y Noroeste Argentino 3,6\% (Figura 1). El 52,8\% eran residentes, 5,9\% jefes o instructores de residentes y $41,3 \%$ especialistas o fellow.

Los principales FRCV detectados fueron: tabaquismo en el 16,8\% de los encuestados, dislipemia 14,3\%, hipertensión arterial 5\%, y diabetes mellitus tipo \| 0,8\% (Tabla 2). Así mismo eran ex tabaquistas 12,6\%. La mediana de edad de comienzo del hábito fue 18 años (RIC: 16-20) en las mujeres y 18 años (RIC: 16-22) en hombres; $\mathrm{p}=0,52$. Así mismo, la mediana de consumo de cigarrillos diarios entre mujeres fue 5 (RIC: 2-10) mientras que en hombres fue 7 (RIC: 3-15), sin ser esta diferencia estadísticamente significativa, $p=0,42$. Respecto a los antecedentes de enfermedad cardiovascular, el 1\% tuvo enfermedad coronaria, no se reportó enfermedad vascular periférica, y el 0,4\% enfermedad cerebrovascular.

La mediana del índice de masa corporal fue $21.7 \mathrm{~kg} / \mathrm{m}^{2}$ (RIC: 20,3-24) para mujeres y $26,1 \mathrm{~kg} / \mathrm{m}^{2}$ (RIC: $24,2-28,1$ ) en hombres. De acuerdo con esto, 46,9\% de los encuestados cumplían criterio de sobrepeso u obesidad (Figura 2)

Respecto a la proporción de tabaquistas de acuerdo al cargo desempeñado, eran fumadores activos 17,75\% de los residentes, $25,81 \%$ de los jefes o instructores de residentes, y 14,35\% de los médicos especialistas o fellows de los servicios ( $p=0,23)$. La proporción de extabaquistas fue $8 \%, 9,7 \%$ y $19 \%$ respectivamente $(p=0,001)$. Por otra parte, la mediana de edad de los no tabaquistas fue 30 años (RIC: 28-37), la de los tabaquistas 31 años (RIC: 29-35) y la de los extabaquistas $37,5$ años (RIC: $32-50) ; p=0.0001$.

El 63,3\% de los participantes manifestó hacer algún tipo de actividad física, siendo el $87,6 \%$ recreativo, y el porcentaje restante a nivel competitivo. El 74,5\% realiza 2-3 días a la semana actividad física, con una carga horaria promedio semanal de 3.7 horas.

Además el 33,8\% expresó que no se cuidaba respecto al agregado sal a los alimentos y el 35,6\% no comían frutas ni verduras diariamente. 
Cuando se indagó acerca del último control de salud, el 41,9\% manifestó que fue había sido más de un año atrás.

\section{DISCUSIÓN}

Los médicos y en particular los cardiólogos, poseen formación sobre la modificación de los FRCV, la implicancia de los mismos, y los riesgos de eventos cardiovasculares vinculados a los mismos. Sin embargo, en la práctica clínica frecuentemente se pierde la oportunidad de su prevención, existiendo una brecha entre el conocimiento de los FRCV por parte del médico y la efectividad de los resultados del consejo preventivo. Las diferentes actitudes de los médicos frente a los FRCV pueden hacer variar el impacto de intervenciones en los pacientes. La alta frecuencia de factores de riesgo cardiovascular encontrados en nuestro estudio demuestra la falta de aplicación del conocimiento médico en su propia salud. Es imperativo encontrar estrategias para modificar los factores de riesgo cardiovascular en el equipo de salud, para prevenir la aparición de ECV y disminuir el impacto de esta.

En la Tercera Encuesta Nacional de Factores de riesgo para enfermedades no transmisibles en la población argentina publicada en el año 2015, podemos evidenciar que la prevalencia de consumo de tabaco fue del $25,1 \%$, siendo mayor en el sexo masculino (29,9 vs. 20,9\%) y más evidente en el grupo etario de los 25 a los 34 años $(30,8 \%)^{13}$. En relación a nuestro estudio en donde la edad media (31 años) coincide con el grupo etario que más tabaco consume, la prevalencia de tabaquismo fue significativamente menor (16,8\%).

Con respecto a la dislipidemia la comparación entre ambos estudios se dificulta, ya que en la Tercera Encuesta Nacional toma como parámetros hombres mayores de 35 años y mujeres mayores de 45 años, con una prevalencia de dislipidemia de $77,5 \%$, mientras que en nuestro estudio encontramos una prevalencia de $14,3 \%$ pero en una población significativamente más joven. Lo mismo ocurre con la prevalencia de hipertensión arterial (34,1 vs. 5\%) y diabetes mellitus (9,8 vs. $0,8 \%)$, comparaciones no valorables con la diferencia de edad en la población en comparación.

En el estudio RENATA la prevalencia de HTA en la población general fue de 33,5\%, pero en menores de 35 años fue de $11,1 \%{ }^{14}$, siendo menor la encontrada entre los participantes de nuestro trabajo (5\%). De forma similar, en el estudio RENATA 2 la prevalencia de HTA en menores de 35 años fue 12,2\%, mayor que la reportada Estudio RENATA 1, realizado 5 años antes ${ }^{15}$. Comparando ambos estudios con nuestra encuesta encontramos una prevalencia de HTA mucho menor entre médicos cardiólogos y residentes.

La encuesta publicada por Intramed sobre detección del riesgo cardiovascular en médicos argentinos realizada entre los año 2005 y 2006 mostró una tasa de tabaquismo en profesionales de la salud de $23,22 \%{ }^{16}$, lo cual resultó menor que la comunicada en la población general para esos años, al igual que lo que ocurre en nuestro trabajo. Sin embargo, por tratarse de poblaciones diferentes no es posible asegurar que exista una tendencia real hacia un menor consumo de tabaco en los últimos años.
Un dato llamativo de la encuesta de Intramed fue que el 54,9\% de los profesionales encuestados refirió tener sobrepeso, siendo esto mayor que en la población general. En nuestro trabajo la prevalencia fue algo menor, pero con una media de edad más joven. Ambas observaciones resultan alarmantes, y deberían implementarse estrategias para revertir esto.

Más preocupante aún que la proporción de factores de riesgo encontrados es la alta tasa de estilos de vida no saludable en nuestra muestra. Globalmente casi 1 de cada 3 participantes de la encuesta no realizaba actividad física, no procuraban reducir el consumo de sodio diario, ni comían frutas y verduras diariamente. Además la mitad de los participantes negaban haber realizado un control médico de cualquier tipo en el último año. Tratándose de una población eminentemente joven, es dable suponer que de persistir estas tendencias, exista un progresivo aumento de los FRCV en los próximos años.

Nuestro estudio posee algunas limitaciones que merecen ser resaltadas: en primer término, al tener un muestreo no probabilístico resulta imposible establecer con precisión la prevalencia de los FRCV en la población estudiada. Ligado a esto merece destacarse que, debido a un mayor número de centros formadores en CABA y Buenos Aires, existe una desproporción entre los participantes de estas regiones, comparados con las restantes. En segundo lugar, mucha información recabada fue referida por los participantes, sin corroborar las respuestas. Algo similar ocurre con las mediciones antropométricas, ya que se emplearon para ellas diferentes instrumentos (según la disponibilidad de cada servicio), sin haber corroborado en todos los casos la adecuada calibración de los mismos.

Sin embargo, siendo todos los participantes profesionales de la salud, es dable suponer que los posibles errores vinculados a esto sean menores. Además, el tamaño muestral grande del estudio compensa parcialmente algunas de las debilidades antes enumeradas.

\section{CONCLUSIÓN}

Encontramos una elevada tasa de factores de riesgo cardiovascular entre los participantes, considerando la edad y profesión de los mismos. Los principales factores detectados fueron el sobrepeso y obesidad y el sedentarismo, seguidos de la adicción al tabaco y la dislipidemia. Si bien la tasa de otros factores de riesgo como hipertensión arterial y diabetes fue baja, debe tenerse presente que los participantes fueron en su mayoría jóvenes.

Respecto al tabaquismo, no encontramos diferencias sustanciales entre cardiólogos en formación y especialistas.

Creemos que estos hallazgos deben ser analizados con especial atención, habida cuenta que ciertas prácticas se ven condicionadas por las condiciones laborales y la remuneración económica percibida, como resulta el caso de la alimentación o la práctica de actividad física.

Consideramos esencial implementar estrategias para favorecer estilos de vida saludables entre profesionales de la salud de nuestro país. Sería deseable repetir esta evaluación en un tiempo prudencial, para valorar las tendencias temporales en los factores de riesgo y estilos de vida entre los residentes de Cardiología y cardiólogos del país. 


\section{BIBLIOGRAFÍA}

1. Navarro-López F. Bases genéticas de la enfermedad coronaria. Rev Esp Cardiol 2002;55(4):413-31.

2. Priori SG, Blomström-Lundqvist C, Mazzanti A, Blom N, Borggrefe M, Camm J, et al. 2015 ESC Guidelines for the management of patients with ventricular arrhythmias and the prevention of sudden cardiac death: The Task Force for the Management of Patients with Ventricular Arrhythmias and the Prevention of Sudden Cardiac Death of the European Society of Cardiology (ESC). Endorsed by: Association for European Paediatric and Congenital Cardiology (AEPC). Eur Heart J 2015;36(41):2793-867.

3. Touboul PJ, Hennerici MG, Meairs S, Adams H, Amarenco P, Bornstein N, et al. Mannheim carotid intima-media thickness and plaque consensus (2004-20062011). An update on behalf of the advisory board of the 3rd, 4th and 5th watching the risk symposia, at the 13th, 15th and 20th European Stroke Conferences, Mannheim, Germany, 2004, Brussels, Belgium, 2006, and Hamburg, Germany, 2011. Cerebrovasc Dis 2012;34(4):290-6

4. Lahoz C, Mostaza J. La aterosclerosis como enfermedad sistémica. Rev Esp Cardiol 2007;60(2):184-95.

5. Aguiar-Souto P, Cabanas-Grandío P, González-Juanatey JR. La enfermedad polivascular aterotrombótica: un enemigo común y distintos frentes. Rev Esp Cardiol 2009;9(D):4-10.

6. Palinski W, Napoli C. Pathophysiological events during pregnancy influence the development of atherosclerosis in humans. Trends Cardiovasc Med 1999;9(7):205-14.

7. Napoli C, D'Armiento FP, Corso G, Ambrosio G, Palumbo G, Zuliani P, et al. Occurrence of the same peroxidative compounds in low density lipoprotein and in atherosclerotic lesions from a homozygous familial hypercholesterolemic patient: a case report. Int J Cardiol 1997;62(1):77-85.
8. Weber C, Noels H. Atherosclerosis: current pathogenesis and therapeutic options. Nat Med 2011:17(11):1410-22

9. Owen DR, Lindsay AC, Choudhury RP, Fayad ZA. Imaging of atherosclerosis. Annu Rev Med 2011;62:25-40.

10. Ross R. The pathogenesis of atherosclerosis: A perspective for the 1990s. Nature 1993;362(6423):801-9.

11. Lastiri H, Flichtentrei D. Prevención cardiovascular en el siglo XXI: construyendo nuevos escenarios para la acción Sociedad de Cardiología del Oeste Bonaerense. Federación Argentina de Cardiología.

12. Pearson TA, Bazzarre TL, Daniels SR, Fair JM, Fortmann SP, Franklin BA, et al. American Heart Association Guide for Improving Cardiovascular Health at the Community Level. Circulation 2002;107(4):645-51.

13. Ministerio de Salud de la Nación. Tercera Encuesta Nacional de Factores de Riesgo para enfermedades no transmisibles. Argentina 2013.

14. Marin MJ, Fábregues G, Rodríguez PD, Díaz M, Páez O, Alfie J, et al. Registro Nacional de Hipertensión Arterial. Conocimiento, tratamiento y control de la hipertensión arterial. Estudio RENATA. Rev Argent Cardiol 2012;80(2):121-9.

15. Delucchi AM, Majul CR, Vicario A, Cerezo GH, Fábregues G. Registro Nacional de Hipertensión Arterial. Características epidemiológicas de la hipertensión arterial en Argentina. Estudio RENATA 2. Rev Argent Cardiol 2017;85(4):354-60.

16. Zulma O, Luna D, Braga F, Prats M, Flichtentrei D. Estudio Doctor: Detección del riesgo cardiovascular en médicos argentinos. Intramed Investigaciones 2009. Disponible en https://www.intramed.net/userfiles/2009/file/estudio_ doctor.pdf. 


\section{PAXOND}

LOSARTÁN I HIDROCLOROTIAZIDA

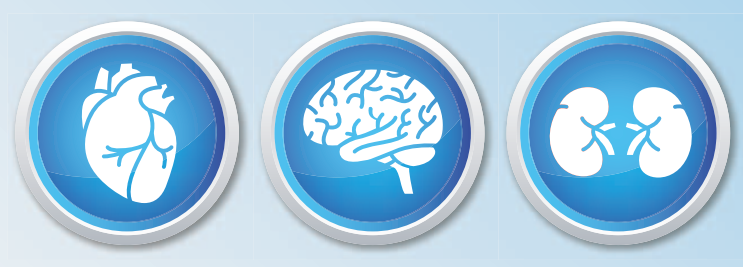

\section{Eficacia antihipertensiva con protección de órgano blanco ${ }^{1-4}$}

\section{PAMI 80\% IOMA}

Paxon ${ }^{\odot} 50$ - 100: envases por 30 y 60 comprimidos recubiertos ranurados conteniendo losartán

Paxon $\mathrm{XR}^{\Theta}$ : envase por 30 comprimidos de liberación controlada conteniendo losartán.

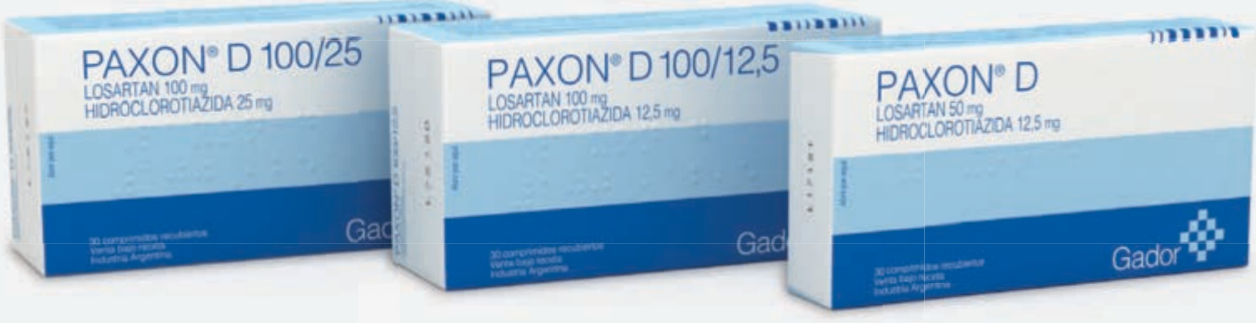

PAMI 60\%

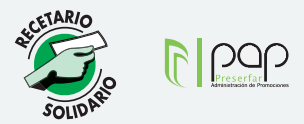

Paxon DQ: envases por 30 y 60 comprimidos recubiertos ranurados conteniendo losartán e hidroclorotiazida

Paxon $D^{\oplus} 100 / 12,5-100 / 25$ : envases por 30 comprimidos recubiertos ranurados conteniendo losartán e hidroclorotiazida.

Referencias: 1. Little WC y col; Effect of losartan and hydrochlorothiazide on exercise tolerance in exertional hypertension and left ventricular diastolic dysfunction; Am J Cardiol 2006 Aug 1;98(3):383-5. 2. Moen MD, Wagstaff AJ; Losartan: a review of its use in stroke risk reduction in patients with hypertension and left ventricular hypertrophy; Drugs 2005;65(18):2657-74. 3. Brenner BM y col; RENAAL Study Investigators. Effects of losartan on renal and cardiovascular outcomes in patients with type 2 diabetes and nephropathy; N Engl J Med 2001 Sep 20;345(12):861-9. 4. Elliott WJ, Meyer PM; Incident diabetes in clinical trials of antihypertensive drugs: a network meta-analysis; Lancet 2007 Jan 20;369(9557):201-7.

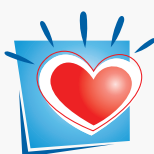

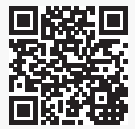

Para más información sobre PAXON ${ }^{\circledast}$, PAXON ${ }^{\circledR}$ XR y PAXON ${ }^{\circledR} D$ visite www.gador.com.ar

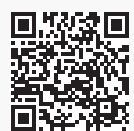

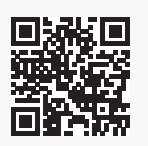

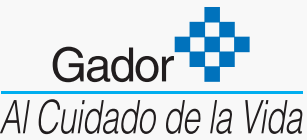




\title{
INFARTO AGUDO DE MIOCARDIO CON ELEVACIÓN DEL SEGMENTO ST: PREVALENCIA DE ARTERIA SEGÚN EL SEXO
}

\author{
ST-SEGMENT ELEVATION MYOCARDIAL INFARCTION: PREVALENCE OF \\ ARTERY ACCORDING TO GENDER
}

\author{
ALFREDO ASTESIANO ${ }^{1}$, NICOLÁS F. RENNA², MARÍA J. TORRES ${ }^{3}$, RODRIGO GARCÍA4 ${ }^{4}$, MARIANO GRUCCI ${ }^{5}$, ALBERTO G. VILLASÍS $^{5}$, \\ MARCIA ZULOAGA PUGLISI ${ }^{5}$, ROMANO M. TRIONFI ${ }^{6}$
}

\section{RESUMEN}

Introducción. A pesar de los grandes avances en el conocimiento de la fisiopatología del infarto agudo de miocardio con elevación del segmento ST (IAMCEST), aún se desconocen variables que influyen en el desenlace de esta patología y en particular la relación entre la anatomía coronaria afectada y el sexo. En Argentina existe información limitada sobre este aspecto.

Objetivo. Analizar las características clínicas de pacientes con IAMCEST en un centro privado de la provincia de Mendoza, con la intención de evaluar la arteria coronaria afectada según el sexo.

Métodos. Estudio observacional y retrospectivo, de pacientes que ingresaron a nuestro centro con diagnóstico de IAMCEST, en los que se les practicó cinecoronariografía de urgencia. Se analizaron variables clínicas como sexo, edad, factores de riesgo cardiovascular, arteria culpable, tipo de tratamiento y stent colocado. Resultados. Se incluyeron 153 pacientes. La edad media fue 70 años $( \pm 13)$ en mujeres y $61( \pm 12)$ en hombres. El factor de riesgo cardiovascular más prevalente en ambos grupos fue la hipertensión arterial, siendo $79,5 \%$ en mujeres y $61,5 \%$ en hombres ( $p=0,04)$; seguido por tabaquismo ( $35,9 \%$ mujeres y $53 \%$ hombres), diabetes mellitus $(35,9 \%$ mujeres y $21,4 \%$ hombres; $p=0,07)$ y obesidad $(28,2 \%$ mu jeres y $29,1 \%$ hombres; $p=0,91)$. No hubo diferencias de la arteria afectada según sexo $(p=0,38)$. La arteria culpable más prevalente fue la descendente anterior (DA) $39,5 \%$ en mujeres y $37,9 \%$ en hombres). Resultados similares se observaron con la arteria coronaria derecha, con una prevalencia ligeramente menor que la DA (34,2\% mujeres y $35,3 \%$ hombres); la arteria circunfleja fue el vaso culpable en $18,42 \%$ sexo femenino y $17,2 \%$ sexo masculino, El $2,6 \%$ de las mujeres tuvo compromiso de tronco de la arteria coronaria izquierda $(\mathrm{TCl})$, siendo mayor el porcentaje de hombres con compromiso de este vaso: $6 \%$. El puente venoso tuvo una baja prevalencia sin diferencias entre sexo (2,6\% mujeres y 3,4\% hombres).

Conclusión. Más del $75 \%$ de los infartos de miocardio con elevación del segmento ST fueron hombres, sin embargo las mujeres presentaron un perfil de riesgo cardiovascular diferente, siendo más prevalente la HTA y la edad avanzada. No hubo diferencias en la arteria coronaria afectada según el sexo, observando una tendencia no significativa en mayor enfermedad de TCl en el hombre.

Palabras clave: infarto de miocardio, sexo, vasos coronarios.

\section{ABSTRACT}

Introduction. Despite the great advances in the knowledge of the pathophysiology of acute myocardial infarction with ST-segment elevation (STEMI), there are still unknown variables that influence the outcome of this pathology and in particular the relationship between the affected coronary anatomy and gender. In Argentina there is limited information on this aspect.

Objective. To analyze the clinical characteristics of patients with STEMI in a private center in the province of Mendoza, with the intention of evaluating the affected coronary artery according to gender.

Methods. Observational and retrospective study of patients admitted to our center with a diagnosis of STEMI, in which they underwent emergency coronary angiography. We analyzed clinical variables such as gender, age, cardiovascular risk factors, culprit artery, type of treatment and stent placed.

Results. 153 patients were included. The mean age was 70 years $( \pm 13)$ in women and $61( \pm 12)$ in men. The most prevalent cardiovascular risk factor in both groups was hypertension, being $79.5 \%$ in women and $61.5 \%$ in men $(p=0.04)$; followed by smoking (35.9\% women and $53 \%$ men), diabetes mellitus ( $35.9 \%$ women and $21.4 \%$ men, $p=0.07)$ and obesity $(28.2 \%$ women and $29.1 \%$ men; $p=0.91)$. There were no differences in terms of the affected artery according to gender $(p=0.38)$. It was observed that the most prevalent culprit artery was the anterior descending artery (ADA), being $39.5 \%$ in women and $37.9 \%$ in men. Similar results were observed with the right coronary artery, with a slightly lower prevalence than the ADA (34.2\% women and $35.3 \%$ men); circumflex artery was the culprit vessel in $18.42 \%$ female sex and $17.2 \%$ male sex, $2.6 \%$ of women had a compromise of the left main coronary artery (LMCA), the percentage of men with compromise being higher: $6 \%$. Vein grafts had a low prevalence without gender differences (2.6\% women and $3.4 \%$ men).

Conclusion. More than $75 \%$ of myocardial infarctions with ST-segment elevation were men; however, women presented a cardiovascular risk profile different from men, with hypertension and older age being more prevalent. There were no differences in the coronary artery affected according to gender, observing a non-statistically significant trend in greater LMCA disease in men.

Keywords: myocardial infarction, sex, coronary vessels.

REVISTA CONAREC 2018;33(147):314-316 | DOI:10.32407/RCON/2018147/0314-0316

1. Jefe de Unidad Coronaria

2. Coordinador de Unidad Coronaria

3. Jefa de residentes de Cardiología

4. Ex Jefe de Residentes de Cardiología

5. Médico residente de Cardiología

6. Médico concurrente Cardiología. Hospital Español de Mendoza

$\triangle$ Correspondencia: Dra. Romano María Trionfi. Dirección: O’Higgins 1844. M5504PIR Godoy Cruz, Mendoza. Rep. Argentina. Tel: (261)-152180381. rtrionfi@hotmail.com.

Los autores declaran no poseer conflictos de intereses.

Recibido: 29/10/2017| Aceptado: 06/08/2018

\section{INTRODUCCIÓN}

El número total de muertes por infarto agudo de miocardio con elevación del segmento ST (IAMCEST) ha ido descendiendo ininterrumpidamente durante los últimos 30 años, pero se ha estabilizado en la última década. Según estimaciones de la American Heart Association, el índice de mortalidad a corto plazo oscila entre el 5 y $6 \%$ durante la hospitalización inicial y entre el 7 y $18 \%$ al cabo de 1 año ${ }^{1}$

En nuestro país no disponemos de datos fehacientes que nos permitan saber la incidencia anual de los IAMCEST. La última aproximación y solo de carácter deductivo estimó 42.025 paciente en el año 2005, con una incidencia de 10,8 por 10.000 habitantes de todas las edades y de 24,5 por 10.000 habitantes en mayores de 35 años. En la actualidad se está llevando a cabo, en una tarea conjunta entre la Sociedad Argentina de 


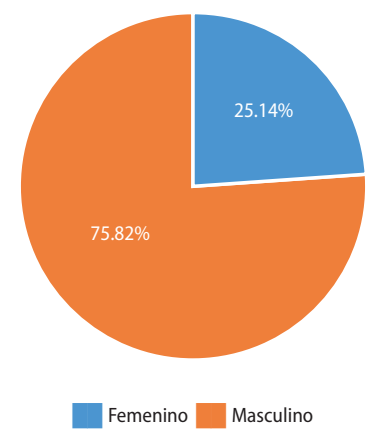

Figura 1. Prevalencia según sexo.

Cardiología, la Federación Argentina de Cardiología y el Ministerio de Salud de la Nación, el Registro Nacional Permanente de Enfermedades Cardiovasculares para el Monitoreo de Políticas Públicas, comenzando por el Estudio del Infarto Agudo de Miocardio con Elevación del ST (ARGEN-IAM-ST); que tiene como objetivo estimar el número de infartos y las características globales de su atención. Los datos se obtienen a través de reportes de encuestas y relevamientos de redes institucionales habitualmente con actividad académica y por lo tanto con sesgos que impiden proyectar estos datos a toda la comunidad. En esta fase del registro se han incluido 1.759 pacientes en 247 centros de todo el país (2015). La conclusión observada y publicada (ARGEN-IAM-ST) fue una mayor prevalencia de tabaquismo (TBQ), un mayor uso de angioplastia primaria con menor indicación de reperfusión con fibrinolíticos, y una reducción significativa del shock cardiogénico en los últimos 5 años. Las variables predictivas de mayor riesgo para el desarrollo de enfermedad cardiovascular incluyen edad avanzada, sexo masculino, dislipemia (DLP), diabetes mellitus (DBT), TBQ, hipertensión arterial (HTA) e historia familiar de enfermedad coronaria².

A pesar de los grandes avances en el conocimiento de la fisiopatología del infarto agudo de miocardio con elevación del segmento ST (IAMCEST), aún se desconocen muchas de las variables que influyen en el desenlace de esta patología y en particular la relación entre la anatomía coronaria afectada y el sexo. En Argentina no existen bases de datos que evalúen este punto en particular; es por ello que este estudio tiene por objetivo analizar la población de un hospital privado de la provincia de Mendoza con diagnóstico de IAMCEST con la intención de establecer una relación directa entre la arteria afectada y el sexo.

\section{MATERIALES Y MÉTODOS}

Se realizó un estudio observacional, analítico, retrospectivo y unicéntrico desde enero de 2014 hasta julio de 2017. Se incluyeron pacientes con diagnóstico de IAMCEST definido según la tercera definición de infarto como detección de un aumento y/o descenso de los valores de biomarcadores cardiacos (preferiblemente troponina cardíaca), con al menos uno de los valores por encima del percentil 99 del límite de referencia superior, y al menos uno de los siguientes parámetros: síntomas de isquemia, cambios significativos en el segmento ST nuevos, bloqueo de rama izquierda nuevo, desarrollo de ondas Q patológicas en el ECG, evidencia por imagen de pérdida de miocardio viable de nueva aparición o anomalías regionales en la motilidad de
Tabla 1. Factores de riesgo cardiovasculares y comorbilidades según sexo.

\begin{tabular}{|c|c|c|c|c|c|c|}
\hline & & \multicolumn{2}{|c|}{ Femenino } & \multicolumn{2}{|c|}{ Masculino } & \multirow{2}{*}{$\begin{array}{c}p \\
0,001\end{array}$} \\
\hline Edad (años) & Media $\pm D E$ & & $9(13)$ & & (12.4) & \\
\hline DLP & $\mathrm{n} ; \%$ & 8 & $25.0 \%$ & 34 & $31.8 \%$ & 0,46 \\
\hline TBQ & $\mathrm{n} ; \%$ & 14 & $35.9 \%$ & 62 & $53.0 \%$ & 0,64 \\
\hline HTA & $\mathrm{n} ; \%$ & 31 & $79.5 \%$ & 72 & $61.5 \%$ & 0,04 \\
\hline DBT & $\mathrm{n} ; \%$ & 14 & $35.9 \%$ & 25 & $21.4 \%$ & 0,07 \\
\hline $\begin{array}{l}\text { Cardiopatía } \\
\text { isquémica }\end{array}$ & $\mathrm{n} ; \%$ & 6 & $15.4 \%$ & 24 & $20.5 \%$ & 0,48 \\
\hline Obesidad & $\mathrm{n} ; \%$ & 11 & $28.2 \%$ & 34 & $29.1 \%$ & 0,91 \\
\hline Hipotiroidismo & $\mathrm{n} ; \%$ & 14 & $35.9 \%$ & 8 & $6.8 \%$ & $<0,0001$ \\
\hline ERC & $\mathrm{n} ; \%$ & 1 & $2.6 \%$ & 4 & $3.5 \%$ & 0,78 \\
\hline
\end{tabular}

DLP: dislipemia. TBQ: Tabaquismo. HTA: hipertensión arterial. DBT: diabetes. ERC: enfermedad renal crónica.

la pared de nueva aparición e identificación de un trombo intracoronario mediante angiografía o autopsia; de menos de 12 horas de evolución a los que se le realizó cinecoronariografía de urgencia ${ }^{3,4}$.

Se excluyeron pacientes con infartos de miocardio sin elevación del segmento ST, IAMCEST de más de 12 horas de evolución, a los que recibieron trombolíticos como estrategia de reperfusión y aquellos derivados de otros centros.

\section{ANÁLISIS ESTADÍSTICO}

Los datos remitidos se incorporaron a una base de datos de Excel. Se analizaron variables como sexo, edad, factores de riesgo cardiovascular, arteria culpable, tipo de tratamiento. Las variables categóricas se expresaron mediante números y porcentajes, y las continuas, según su distribución, como media o mediana, con su correspondiente desvío estándar o intervalo intercuartílico. Para evaluar la asociación entre las variables continuas se utilizó el test de $U$ de Mann-Whitney o test de T, y para las categóricas se utilizó el test exacto de Fisher o Chi Cuadrado, según correspondiera.

\section{RESULTADOS}

Se incluyeron 153 pacientes. La media de edad fue 63,31 años (DE: $\pm 12,99$ ). El $75,82 \%$ de los pacientes enrolados fueron hombres y el 24,14\% mujeres (Figura 1)

El factor de riesgo cardiovascular más prevalente en ambos grupos fue la hipertensión arterial, siendo 79,5\% en mujeres y $61,5 \%$ en hombres ( $p=0,04)$; seguido por tabaquismo (35,9\% mujeres y $53 \%$ hombres; $p=0,64)$, diabetes mellitus $(35,9 \%$ mujeres y $21,4 \%$ hombres; $p=0,07)$ y obesidad $(28,2 \%$ mujeres y $29,1 \%$ hombres; $p=0,91)$. Hubo una mayor prevalencia de hipotiroidismo en el sexo femenino (mujeres $35,9 \%$ y hombres 6,8\% p<0,0001). El número de pacientes con antecedentes de cardiopatía isquémica fue mayor en el sexo masculino, del 20,5\%, y del 15,4\% en mujeres, diferencia no estadísticamente significativa $(p=0,48)$. Se observó un porcentaje pequeño de pacientes con enfermedad renal crónica en ambos sexos (2,6\% mujeres y 3,5\% hombres; $p=0,78$ ) (Tabla 1 ).

No hubo diferencias en la arteria afectada según sexo $(p=0,38)$. Se observó que la arteria culpable más prevalente fue la descendente anterior (DA) sin encontrar diferencias cuando se comparó según sexo: $39,5 \%$ en mujeres y $37,9 \%$ en hombres. Resultados similares se observaron con la arteria coronaria derecha (CD), con una prevalencia li- 


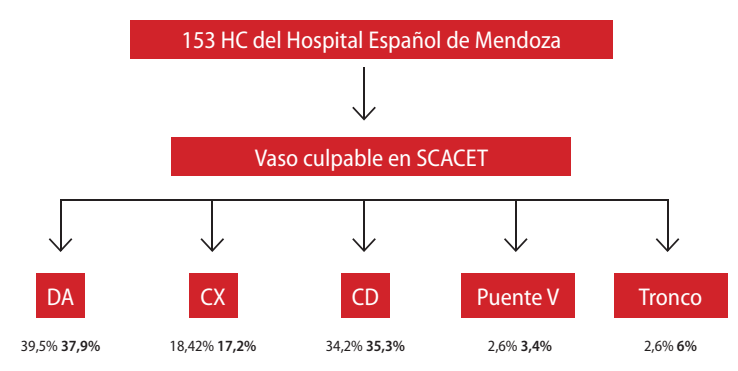

Figura 2. Prevalencia de arteria culpable según sexo. Los porcentaje en fuente regular corresponden al sexo femenino y en negrita al sexo masculino. HC: historia clínica. SCACEST: síndrome coronario agudo con elevación del ST. DA: arteria descendente anterior. CX: arteria circunfleja. CD: arteria coronaria derecha, PUENTE V: puente venoso. Cabe mencionar que la sumatoria de los porcentajes de arteria afectada en mujeres es mayor al 100\% porque en una paciente se identificó a la CD y la Cx como arterias culpables.

geramente menor que la DA (34,2\% mujeres y $35,3 \%$ hombres); la arteria circunfleja (CX) fue el vaso culpable en $18,42 \%$ sexo femenino y $17,2 \%$ sexo masculino. El 2,6\% de las mujeres tuvo compromiso de tronco coronario izquierdo (TCl) siendo mayor el porcentaje de hombres con compromiso se este vaso: $6 \%$. El puente venoso tuvo una baja prevalencia sin diferencias entre sexo (2,6\% mujeres y 3,4\% hombres)

(Figura 2 y 3). Cabe mencionar que la sumatoria de los porcentajes de arteria afectada en mujeres es mayor al 100\% dado que en una paciente se identificó la CD y la Cx como arterias culpables.

\section{DISCUSIÓN}

En nuestro estudio observamos que la prevalencia de IAMCEST es mayor en el sexo masculino, y el principal factor de riesgo es la HTA, seguida por TBQ, DBT y obesidad. Las mujeres presentaron mayor edad y prevalencia de HTA e hipotiroidismo. En cuanto a la arteria responsable, el vaso que más se encontró afectado fue la DA (38,56\%), y con un porcentaje similar la CD (35,94\%). Comparando según sexo no se encontraron diferencias estadísticamente significativas entre ambos grupos $(p=0,33)$. Pero observó una tendencia a mayor compromiso de $\mathrm{TCl}$ entre los hombres.

Estos datos obtenidos coinciden con los publicados en la Revista

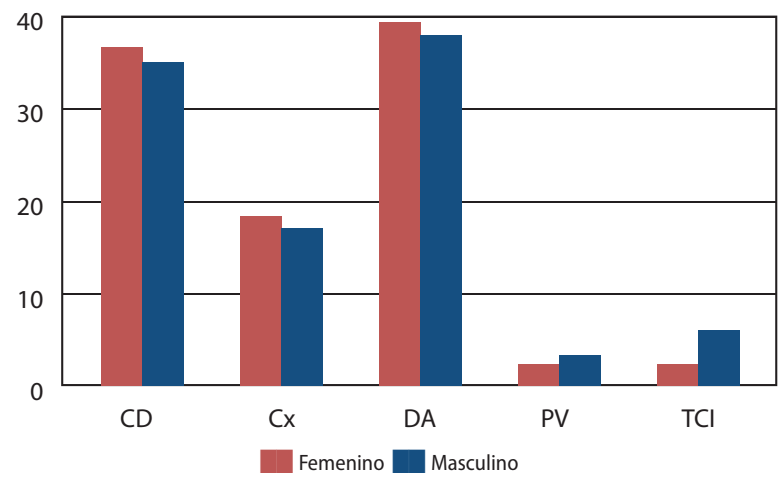

Figura 3. Prevalencia de arteria según el sexo. CD: coronaria derecha. CX: circunfleja. DA: des cendente anterior. PV: puente venoso. TCl: tronco coronaria izquierda.

Cubana de Cardiología en el año 2011, de un registro de 659 pacientes con IAMCEST. El 75,6\% eran hombres y $24,4 \%$ eran mujeres, la distribución de arteria culpable según el sexo fue $77,7 \%$ en los hombres y $22,3 \%$ en las mujeres en la DA; $75,7 \%$ y $22,4 \%$ en la $\mathrm{Cx} ; 75,2 \%$ y $24,8 \%$ en la CD. Al igual que en nuestro estudio, se observó una mayor prevalencia en el TCl en hombres: 88,9 vs. 11,1\% $(p=0,034)^{5}$.

Como limitación de nuestro estudio consideramos que los datos fueron obtenidos de nuestro centro que, aclaramos, es privado. Por ello, los resultados pertenecen a un grupo poblacional sesgado. Si bien reconocemos el aporte a las políticas de salud, exhortamos al resto de la comunidad cientíica y al estado a establecer datos estadísticos fluidos y globales sobre infarto agudo de miocardio en la República Argentina. Es por esto nuestro compromiso para ampliar la base de datos y continuar con futuros aportes.

\section{CONCLUSIÓN}

Más del 75\% de los infartos de miocardio con elevación del segmento ST eran hombres. Las mujeres presentaron un perfil de riesgo cardiovascular diferente, eran más añosas y en ellas era más prevalente la HTA. No hubo diferencias en la arteria coronaria afectada según el sexo. Se observó una tendencia no estadísticamente significativa a mayor enfermedad de TCl en el hombre.

\section{BIBLIOGRAFÍA}

1. O'Gara PT, Kushner FG, Ascheim DD, Casey DE Jr, Chung MK, de Lemos JA, et al. 2013 ACCF/AHA Guideline for the Management of ST-Elevation Myocardial Infarction: Executive Summary. Circulation 2013;127(4):e362-425.

2. Federación Argentina de Cardiología (FAC), Sociedad Argentina de Cardiología (SAC), Centro de Teleinformática de FAC (CETIFAC). Relevamiento Nacional permanente de Enfermedades Cardiovasculares para el monitoreo de políticas públicas. Estudio piloto de Infarto Agudo de Miocardio con elevación del ST (ARGEN-IAM-ST) Sociedad Argentina de Cardiología, la Federación Argentina de Cardiología y el Ministerio de Salud de la Nación. Rev Fed Arg Cardiol 2014:43(4):197-201.

3. Steg G, James SK, Atar D, Badano L, Blomstrom Lundqvist C, Borger M, et al. Guía de práctica clínica de la ESC para el manejo del infarto agudo de miocardio en pacientes con elevación del segmento ST. Rev Esp Cardiol 2013;66(1):53.e1-e46.

4. Thygesen K, Alpert JS, Jaffe AS, Simoons ML, Chaitman BR, White HD. Documento de consenso de expertos. Tercera definicion universal del infarto de miocardio. Rev Esp Cardiol 2013;66(2):132.e1-e15.

5. Sánchez Torres N, Pérez del Todo JM, Del Pino Sánchez E, Martínez García G, Suárez Rivero A, Guevara Mirabal G. Caracterización por sexo de los pacientes con sindrome coronario agudo con elevación del segmento ST sometidos a intervencionismo coronario. Rev Cubana Cardiol Cir Cardiovasc 2011;17(3):225-33.

6. Chacón-Diaz 1, Vega A, Aráoz O, Ríos P, Baltodano R, Villanueva F et al. Epidemiological characteristics of ST-segment elevation myocardial infarction in Peru: Results of the PEruvian Registry of ST-segment Elevation Myocardial Infarction (PERSTEMI). Arch Cardiol Mex 2018,88(5):403-12. 


\title{
TRONCO CORONARIO ÚNICO QUE NACE DEL SENO CORONARIO DERECHO
}

\section{SINGLE LEFT MAIN CORONARY ARTERY THAT IS BORN FROM THE RIGHT CORONARY SINUS}

\author{
CAROLINA CHACON ${ }^{1}$, MAURICIO PRIOTTI ${ }^{2}$, MARIANA DOMANICO ${ }^{2}$, FRANCISCO ARA ${ }^{3}$, NICOLÁS FERRERI ${ }^{3}, \mathrm{CINTIA} \mathrm{FOCO}^{3}$, \\ ESTEFANÍA PERETTI ${ }^{3}$, MANUEL TRAGHETTI ${ }^{3}$
}

\section{RESUMEN}

La anomalía más frecuente es el nacimiento de la arteria circunfleja desde el seno coronario derecho, pero algunas publicaciones plantean que más común sería la arteria coronaria derecha naciendo desde el seno coronario izquierdo. gualmente, se ha planteado que la presencia de una arteria coronaria con un nacimiento anómalo se asocia a mayor grado de aterosclerosis. Actualmente la tomografía computada multicorte con 64 canales ofrece un excelente método para detección de las anomalías de las arterias coronarias, pudiendo detectar de manera rápida y mínimamente invasiva.

Palabras clave: circulación coronaria, isquemia miocárdica, muerte súbita.

\section{ABSTRACT}

The most frequent anomaly is the birth of the circumflex artery from the righ coronary sinus; however, some publications suggest that the right coronary ar tery would be more common, being born from the left coronary sinus. It has also been suggested that the presence of a coronary artery with an anomalous birth is associated with a greater degree of atherosclerosis. Currently, 64-channel multislice computed tomography offers an excellent method for detecting anomalies of the coronary arteries, and can detect them quickly and minimally invasively.

Keywords: coronary circulation, myocardial ischemia, sudden death.

REVISTA CONAREC 2018;33(147):317-318| DOI:10.32407/RCON/2018147/0317-0318

\section{INTRODUCCIÓN}

La presencia de anomalías congénitas en el nacimiento de las arterias coronarias es un hecho reconocido desde largo tiempo. Las anomalías de las arterias coronarias son raras, se observan con una frecuencia de 0,5 a 1,5\% en pacientes sometidos a angiografía coronaria'. Al inicio se le daba poca importancia, pero con el avance del conocimiento se han reconocido como causa de síntomas isquémicos y de muerte súbita, especialmente en jóvenes, y posible causa de isquemia en la población adulta ${ }^{2,3}$. La anomalía más frecuente es el nacimiento de la arteria circunfleja desde el seno coronario derecho, aunque algunas publicaciones plantean que más común sería la arteria coronaria derecha naciendo desde el seno coronario izquierdo 4,5 . Igualmente, se ha planteado que la presencia de una arteria coronaria con un nacimiento anómalo se asocia a mayor grado de aterosclerosis $s^{6,7}$.

Cada grupo médico, de acuerdo con las técnicas disponibles y su experiencia, debe utilizar la técnica, preferentemente menos invasiva, de la que disponga para su diagnóstico. La mayor parte de las anomalías coronarias se descubren incidentalmente en una cinecoronariografía (CCG) realizada a pacientes con cardiopatía isquémica. Se conoce que este es el examen más utilizado para el diagnóstico de origen anómalo de arteria coronaria, pero

1 Jefe de Residentes de Cardiología Clínica.

2. Coordinador de Residentes de Cardiología Clínica.

3. Residente de Cardiología Clínica. Sanatorio Delta. Ciudad de Rosario, Santa Fe, Rep. Argentina.

$\triangle$ Correspondencia: Dra. Cintia Foco. Mendoza 1540, S2000BIF Rosario, Santa Fe, Rep.Argentina.cintiafoco@gmail.com.

Los autores declaran no poseer conflictos de intereses.

Recibido: 01/11/2018|Aceptado: 20/12/2018 tiene una limitada utilización para ese fin debido a su característica invasiva. Actualmente la tomografía computarizada multicorte (TCMC) con 64 canales ofrece un excelente método para detección de las anomalías de las arterias coronarias, que las evidencia de manera rápida y mínimamente invasi$v^{8}{ }^{8}$. La importancia del estudio de las arterias coronarias, teniendo en cuenta el cuadro clínico del paciente, y el análisis de la baja incidencia en las anomalías coronarias hacen un tema de gran interés para el cardiólogo.

\section{CASO CLÍNICO}

Paciente masculino de 62 años con hipertensión arterial, diabetes mellitus, extabaquismo, obesidad y sedentarismo. Presentaba una clase funcional previa grado II-III, según la clasificación New York Heart Association, con disnea de 1 año de evolución y antecedentes de angioplastia coronaria con implante de un stent liberador de drogas en tercio distal de coronaria derecha en contexto de un infarto agudo de miocardio evolucionado. Posteriormente tuvo una internación por disnea progresiva hasta clase funcional IV. Al examen físico se presentó con signos de insuficiencia cardíaca global, con rales crepitantes bilaterales y edemas en miembros inferiores. El ecocardiograma de ingreso evidenció una fracción de eyección del ventrículo izquierdo del 30\% producida por severa hipoquinesia global. Se indicó la realización de CCG por refractariedad al tratamiento médico la cual informó: tronco coronario único que nace del seno coronario derecho sin obstrucciones y arteria coronaria derecha con obstrucción severa en segmento medio (Figura 1). Se realizó angioplastia coronaria con dos stent farmacológicos en segmento medio de dicha arteria (Figura 2). Posterior a ello el paciente evoluciona favorablemente.

\section{DISCUSIÓN}

Las anomalías en el origen de las arterias coronarias representan entidades poco consideradas, cuya principal importancia subyace en el riesgo 


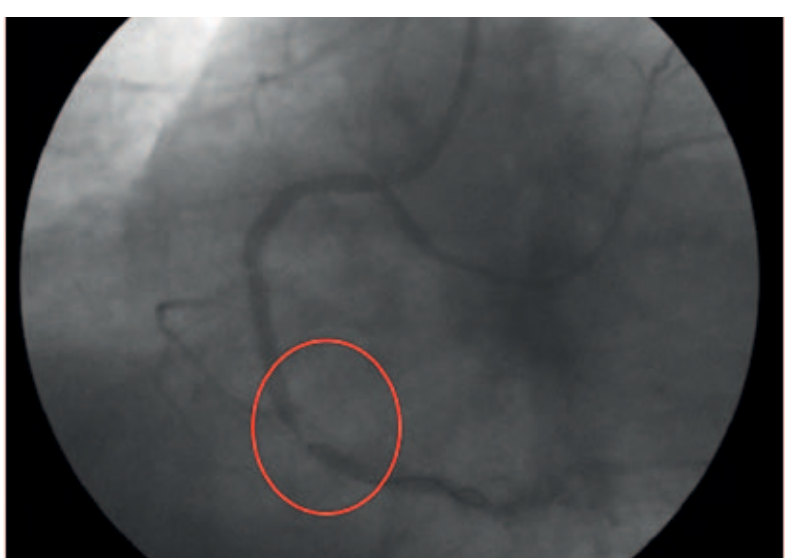

Figura 1. Cinecoronariografía. El círculo rojo señala la arteria coronaria derecha con obstrucción severa en segmento medio.

de desarrollo de isquemia y eventual muerte súbita. Es frecuente que se diagnostiquen incidentalmente en la práctica de una CCG en pacientes afectados por cardiopatía isquémica. Suelen utilizarse otros métodos de imagen para confirmar y/o diagnosticar el trayecto de las arterias coronarias, como la TCMC 64 canales. Siempre se debería intentar definir cuál es el trayecto seguido por la anomalía coronaria y así entregar a los pacientes y a sus médicos recomendaciones, e incluso plantear tratamientos más definitivos ${ }^{9}$. El origen y el trayecto proximal de las arterias coronarias anómalas son los principales factores predictivos de gravedad ${ }^{10}$. Cuando se desarrolla enfermedad arterial coronaria, las consecuencias son significativas y el pronóstico es grave si la obstrucción es proximal, visto que el ostium es único y hay mínima posibilidad de circulación colateral. Muchas teorías se han plasmados con respecto a su asociación con enfermedad coronaria, sea por una marcada angulación presentada por la arteria anómala tras su salida de la aorta", el pasaje interarterial entre la aorta y la arteria pulmonar ${ }^{12}$, los trayectos intramurales o los espasmos coronarios por daño endotelial; todas provocan distintas forma de obstrucción coronaria ${ }^{13}$ que pueden producir isquemia aguda o crónica con la posterior aparición de fibrosis miocárdica, determinando deterioro de la fun-

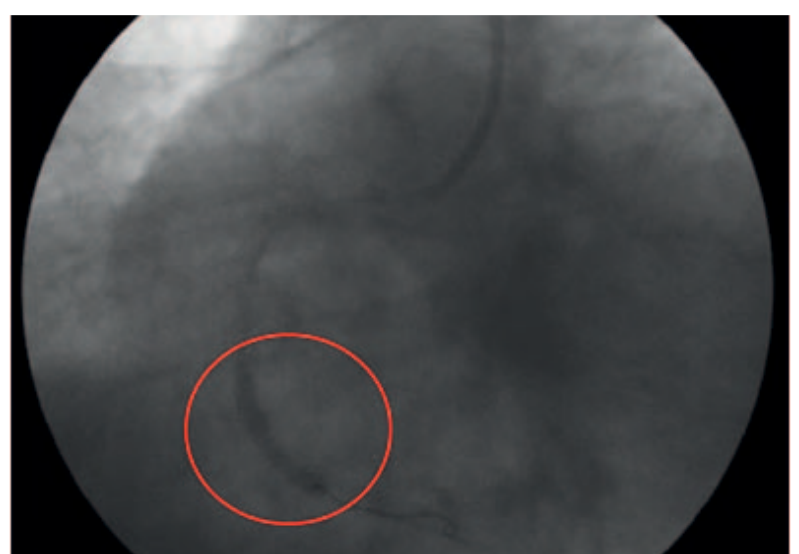

Figura 2. Angioplastia coronaria. El círculo rojo señala la colocación de uno de los stents far macológicos en segmento medio de la arteria coronaria derecha.

ción ventricular con la consiguiente aparición de insuficiencia cardíaca y un aumento marcado en la incidencia de arritmias fatales ${ }^{14}$.

En relación con el caso clínico, se ha decidido la realización de una TCMC para mayor precisión sobre el origen, el curso y la terminación de esos vasos, teniendo en cuenta que la CCG tiene limitación en su proyección. Dado que la anomalía de las arterias coronarias es una entidad relativamente rara, es necesario plantear el adecuado método diagnóstico y el planeamiento terapéutico.

\section{CONCLUSIÓN}

La anomalía en el nacimiento de las arterias coronarias es una entidad de baja prevalencia en nuestro medio, sin embargo su fuerte asociación con cardiopatía isquémica y muerte súbita en adultos jóvenes nos invita a reflexionar si debemos incorporar nuevos métodos diagnósticos para su detección en pacientes asintomáticos así como implementar un registro de casos clínicos a fin de orientar conductas diagnósticas y terapéuticas dirigidas a disminuir la incidencia de arritmias malignas en esta población que dejó de ser aislada.

\section{BIBLIOGRAFÍA}

1. Angelini P, Velasco JA, Flamm S. Coronary anomalies: incidence, pathophysiology and clinical relevance. Circulation 2002; 105(20):2449-54.

2. Kragel $A$, Roberts $W$. Anomalous origin of either the right or left main coronary artery from the aorta with subsequent coursing between aorta and pulmonary trunk: Analysis of 32 necropsy cases. Am J Cardiol 1988;62(10):771-7.

3. Maron BJ. Sudden death in young athletes. N Engl J Med 2003;349(11):1064-75.

4. Garg N, Tewari S, Kapoor A, Gupta D, Sinha N. Primary congenital anomalies of the coronary arteries: a coronary anteriographic study. Int J Cardiol 2000;74(1):39-46.

5. Angelini P, Velasco J, Flamm S. Coronary anomalies. Incidence, pathophysiology and clinical relevance. Circulation 2001;105(20):2449-54.

6. Silverman K, Bulkley B, Hutchins G. Anomalous left circumflex coronary artery: "normal" variant of uncertain clinical and pathologic significance. Am J Cardiol 1978;41(7):1311-4.

7. Click R, Holmes D, Vlietstra R, Kosiski A, Kronmal R. Anomalous coronary arteries: Location, degree of atherosclerosis and effect on survival. A report t from Coronary Artery Surgery Study (CASS). J Am Coll Cardiol 1989;13(3):531-7.

8. Rabelo DR, Barros MVL, Nunes MCP, Oliveira CCC, Siqueira MHA. Angiotomografía coronaria multislice en la evaluación del origen anómalo de las arterias coronarias. Arq Bras Cardiol 2012;98(3)266-72.

9. Doorey A, Pasquale M, Lally I, Mintz G, Marshall E, Ramos D. Six-month success of intracoronary stenting for anomalous coronary arteries associated with myocardial ischemia. Am J Cardiol 2000;86(5):580-2.

10. Dawn B, Talley JD, Prince CR, Hoque A, Morris GT, Xenopoulos NP, et al. Two-dimensional and doppler transesophageal echocardiographic delineation and flow characterization of anomalous coronary arteries in adults. J Am Soc Echocardiogr 2003;16(12):1274-86

11. Virmani R, Chun PK.C, Goldstein RE, Robinowitz M, McAllister HA. Acute takeoffs of the coronary arteries along the aortic wall and congenital coronary ostial valvelike ridges: association with sudden death. J Am Coll Cardiol 1986;3(3):766-71.

12. Bloomfield P, Erhlich C, Folland AD, Bianco J, Tow DE, Parisi AF. Anomalous right coronary artery: a surgically correctable cause of angina pectoris. Am J Cardiol 1983;51(7):1235-7.

13. Frommelt PC, Frommelt MA, Tweddell JS, Jaquiss RD. Prospective echocardiographic diagnosis and surgical repair of anomalous origin of a coronary artery from the opposite sinus with an interarterial course. J Am Coll Cardiol 2003;42(1):148-54.

14. Basso C, Corrado D, Thiene G. Congenital coronary anomalies as an important cause of sudden death in the young. Cardiol Rev 2001;9(6):312-7. 


\title{
CAUSA INFRECUENTE DE INFARTO ANTERIOR: HEMATOMA POR DISECCIÓN AÓRTICA
}

\author{
RARE CAUSE OF ANTERIOR INFARCTION: HEMATOMA BY AORTIC \\ DISSECTION
}

\author{
LUISA HSU', FLAVIO DELFINO², LEONARDO CÁCERES'1, FERNANDO PINTO', AGOSTINA BARSOTTI', FRANCISCO SALTOS ', \\ LISANDRO OLGUÍN' ${ }^{1}$, SANTIAGO GUELERMAN' ${ }^{1}$, MELISA CUSCHIE'
}

\section{RESUMEN}

El infarto de miocardio asociado a disección aórtica (DA) se manifiesta predominantemente en cara inferior, con lo cual su diagnóstico es muy complejo dado que no corresponde a la causa más frecuente de síndrome coronario agudo (SCA). La DA implica un diagnóstico clínico que requiere confirmación urgente con angiotomografía de aorta con contraste endovenoso o ecocardiograma transtorácico o transesofágico, según la disponibilidad.

A continuación, se presenta el caso de un paciente masculino de 56 años con SCA con elevación del segmento ST en cara anterior asociado a una DA.

Palabras clave: ruptura de la aorta, infarto del miocardio, enfermedades de la aorta.

\section{ABSTRACT}

Myocardial infarction associated with aortic dissection (AD) is manifested predominantly in the inferior face, which makes its diagnosis very complex since it does not correspond to the most frequent cause of acute coronary syndrome (ACS). AD implies a clinical diagnosis that requires urgent confirmation with aortic CT angiography with intravenous contrast or transthoracic or transesophageal echocardiography, depending on availability.

Next, we present the case of a 56-year-old male patient with ACS with ST-segment elevation in the anterior face associated with AD.

Keywords: aortic rupture, myocardial infarction, aortic diseases.

REVISTA CONAREC 2018;33(147):319-321 | DOI:10.32407/RCON/2018147/0319-0321

\section{INTRODUCCIÓN}

La disección aórtica (DA) presenta una mortalidad intrahospitalaria del 27,4\% según el registro internacional de disección aórtica aguda (IRAD) ${ }^{1}$. En nuestro país, alcanza al 32,6\% según el Registro Multicéntrico de Disección Aórtica Aguda (RADAR); específicamente, en las disecciones de tipo A fue de 37,8\% (31\% en los operados vs. $87,5 \%$ en los no operados) $)^{2}$.

Su incidencia es difícil de estimar dada su alta mortalidad previa al diagnóstico. En estudios de autopsias en la población general, se muestra que la prevalencia de DA es de $0,2-0,8 \%{ }^{4}$, mientras que en el estudio de Oxford Vascular es de 6 por cada 100.000 personas por año ${ }^{6}$.

Los pacientes con DA pueden presentarse con supradesnivel del segmento ST en el electrocardiograma, su porcentaje varía según las distintas series: 1-2\% según Braunwald ${ }^{6}$, 4,8\% en el IRAD y 10\% en el RADAR².

El infarto agudo de miocardio (IAM) asociado se manifiesta predominantemente en la cara inferior, con lo cual su diagnóstico es muy

1. Residente de Cardiología

2. Jefe de Residentes de Cardiología. Clínica Santa Isabel. Ciudad Autónoma de Buenos Aires, Rep. Argentina

$\triangle$ Correspondencia: Dra. Luisa Hsu. Av Directorio 2037, C1406GZJ CABA, Rep. Argentina.hos.luisahsu@gmail.com

Los autores declaran no poseer conflictos de intereses.

Recibido: 01/11/2018|Aceptado: 15/11/2018 complejo dado que no corresponde a la causa más frecuente de síndrome coronario agudo (SCA). La DA implica un diagnóstico clínico que requiere confirmación urgente con angiotomografía de aorta con contraste endovenoso o ecocardiograma transtorácico o transesofágico, según la disponibilidad.

La mortalidad hospitalaria de los pacientes con IAM con elevación del segmento ST varía entre el 6 y el 14\% y está influenciada por muchos factores, como la edad, antecedentes de enfermedad coronaria, diabetes mellitus, insuficiencia renal, el número de arterias coronarias afectadas, la clase de Killip-Kimball, el retraso de la reperfusión, la fracción de eyección y el tratamiento.

La causa más frecuente de los SCA es el accidente de placa aterosclerótica. El tratamiento inicial busca recuperar el flujo de sangre hacia la zona del infarto con una estrategia de reperfusión, ya sea mediante

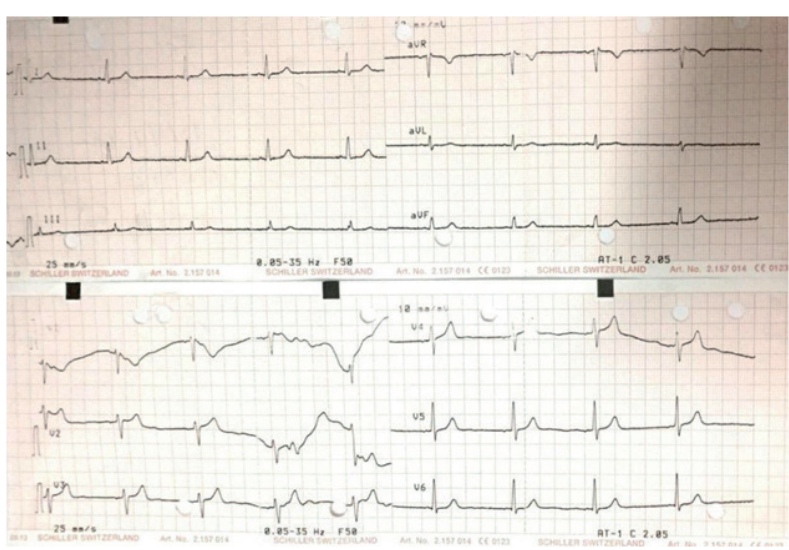

Figura 1. Electrocardiograma de ingreso. 


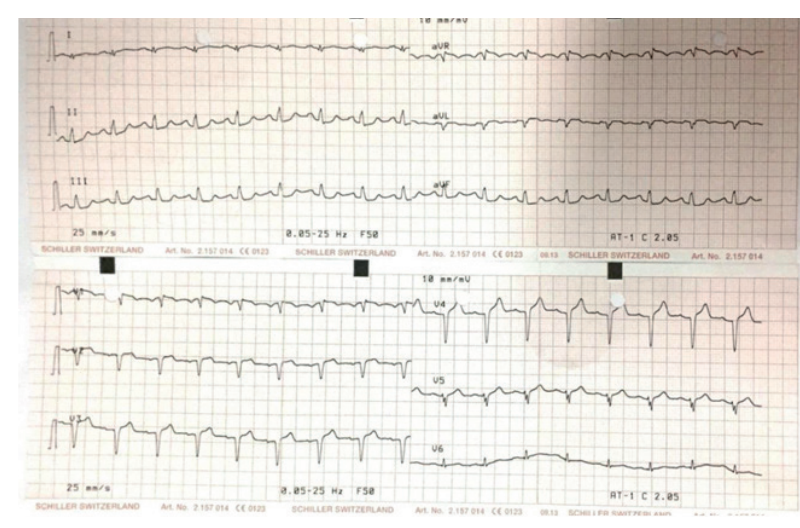

Figura 2. Electrocardiograma con dolor de pecho. Se evidencia supradesnivel del segmento ST en cara anterior con amputación de R en precordiales, infradesnivel del segmento ST especular en cara inferior, leve ensanchamiento del QRS.

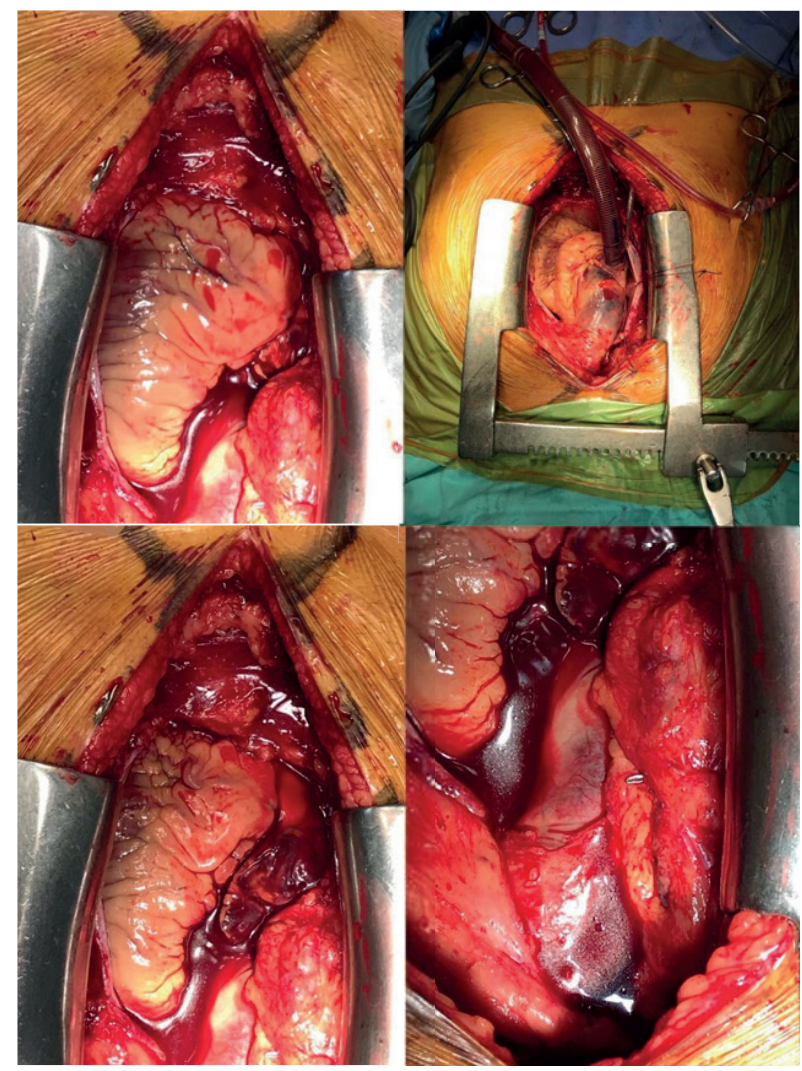

Figura 5. Cirugía de urgencia. Se observa un hematoma en la pared de la aorta. Se realizó reemplazo de la aorta ascendente con un tubo no valvulado más resuspensión de las comisuras aórticas.

una intervención coronaria percutánea o trombolíticos dependiendo del tiempo de inicio de los síntomas.

A continuación, se presenta el caso de un paciente masculino de 56 años con SCA con elevación del segmento ST en cara anterior asociado a una disección aórtica.

\section{CASO CLÍNICO}

Paciente de sexo masculino de 56 años, sin factores de riesgo ni antecedentes cardiovasculares, consultó en la guardia por dolor epigástrico de 1 hora de duración que cedió espontáneamente asociado a pérdi-



Figura 3. Aortograma. Se evidencia flap de disección espiralada desde la aorta ascendente hacia distal.

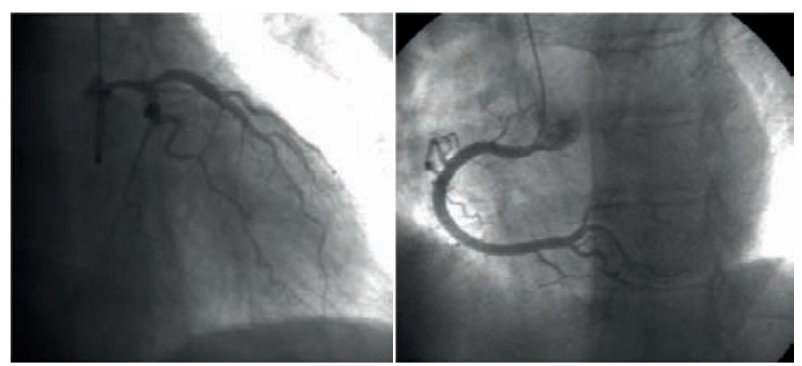

Figura 4. Cinecoronariografía. Se evidencia afinamiento del tronco de la coronaria izquierda sugestivo de compresión del mismo por el hematoma secundario a la disección aórtica. En el resto de las arterias coronarias no se observan lesiones angiográficamente significativas.

da transitoria de la conciencia y relajación de esfínteres. A su ingreso se encontraba lúcido y normotenso con electrocardiograma sin hallazgos patológicos (Figura 1), biomarcadores cardíacos negativos y tomografía de encéfalo sin lesiones agudas. Con diagnóstico presuntivo de crisis comicial se internó en la sala general de clínica médica.

A las seis horas de su ingreso, presentó dolor precordial opresivo por lo que se le realizó electrocardiograma que evidenció taquicardia sinusal con ondas Q y supradesnivel del segmento ST (SST) en cara anterior e infradesnivel del segmento ST en DII, DIII y aVF de 0,5 mm

(Figura 2). Se interpretó el cuadro como SCA con elevación del segmento ST por lo que se inició tratamiento con aspirina, clopidogrel y se lo evaluó mediante un ecocardiograma que evidenció hipoquinesia anterior, septal y lateral con fracción de eyección (FEy) del 27-30\% y presión sistólica de la arteria pulmonar de 47-50 mmHg. Se solicitó cinecoronariografía de emergencia, la cual se realizó con acceso femoral presentando resistencia al pasaje del catéter por la aorta descendente, por lo que se efectuó aortograma evidenciando flap de disección desde la aorta torácica ascendente por encima del plano valvular hasta la aorta abdominal, comprometiendo las arterias ilíacas (Figura 3). Por dificultad de canalizar las arterias coronarias por vía femoral, se accedió por vía radial y al inyectar contraste al tronco de la coronaria izquierda se evidenció compresión del mismo por hematoma disecante, sin evidencia de otras lesiones coronarias (Figura 4). Con el diagnóstico de disección aórtica tipo A, se solicitó cirugía cardiovascular de emergencia realizándose reemplazo de aorta ascendente con resuspensión de comisuras aórticas (Figura 5). El electrocardiograma evolutivo presentó Q en cara anterior y en el ecocardiograma se evidenció aquinesia anterior, disfunción ventricular izquierda grave con FEy del 30\%, aorta no dilatada. En su seguimiento a 6 meses, el paciente evolucionó asintomático, persistiendo con disfunción ventricular. 


\section{DISCUSIÓN}

La DA es una patología de muy baja prevalencia, manifestándose en este caso clínico de forma atípica. El paciente ingresó por dolor precordial y SST y al evaluarlo se diagnosticó disección aórtica. La prevalencia de dicha patología en pacientes con SCA es extremadamente baja, el IAM se produce en el 1-10\% de la DA aguda tipo $A^{1,2,6}$. Afecta generalmente a la arteria coronaria derecha por el flap, dando lugar a un infarto inferior. La cara anterior puede verse comprometida por la presencia de un hematoma, como en nuestro caso, y es tan infrecuente que solo existen reportes de casos en la literatura. Existen algunos reportes de casos similares al nuestro, con la diferencia de que durante la cirugía de urgencia se reemplazó la aorta ascendente asociada a bypass, evolucionando favorablemente y persistiendo con disfunción ventricular severa ${ }^{8}$.

Por otro lado, existen reportes de casos en los que la mortalidad posterior al reemplazo de aorta ascendente y bypass es muy alta9,10.

Dado que el IAM es mucho más frecuente que la DA cuando se aso- cia a esta, puede ser dificultoso su diagnóstico y no es infrecuente que se realice de forma tardía, generalmente luego de una cinecoronariografía de urgencia, aumentando así la mortalidad. Asimismo, la dificultad y el retraso diagnóstico puede derivar en la administración de antiagregantes, anticoagulantes y trombolíticos generando consecuencias letales. Incluso el cateterismo puede empeorar el cuadro por riesgo de ingresar a la falsa luz y progresar la disección.

En un estudio que incluyó pacientes con DA, el 11,3\% tenía signos isquémicos agudos, los cuales tenían alteraciones en el segmento ST u ondas T: $25 \%$ en cara inferior y $41 \%$ entre caras anterior, lateral, septal o posterior ${ }^{11}$.

\section{CONCLUSIÓN}

El compromiso de la arteria coronaria izquierda en contexto de una disección aórtica es infrecuente y presenta peor pronóstico que el de la coronaria derecha. Este hecho es de vital importancia a la hora de enfrentarnos a este escenario clínico.

\section{BIBLIOGRAFÍA.}

1. Hagan PG, Nienaber CA, Isselbacher EM, Bruckman D, Karavite D, Russman PL, et al. The International Registry of Acute Aortic Dissection (IRAD): new insights into an old disease. JAMA 2000;283(7):897-903.

2. Higa C, Guetta J, Borracci RA, Meribilhaa R, Marturano MP, Marenchino R, et al. Registro multicéntrico de disección aórtica aguda. Estudio RADAR. Resultados preliminares. Rev Argent Cardiol 2009:77(5):354-60.

3. Trimarchi S, Eagle KA, Nienaber CA, Rampoldi V, Jonker FH, De Vincentiis C, et al. Role of age in acute type $A$ aortic dissection outcome: report from the international Registry of Acute Aortic Dissection (IRAD). J Thorac Cardiovasc Surg 2010;140(4):784-9.

4. Cheng SWK. Aortic arch pathologies - incidence and natural history. Gefasschirurgie 2016:21(4):212-6.

5. Howard DPJ, Banerjee A, Fairhead JF, Perkins J, Silver LE, Rothwell PM. Population-based study of incidence and outcome of acute aortic dissection and pre-morbid risk-factor control: 10-year results from the Oxford Vascular Study. Circulation 2013:127(20):2031-7.

6. Braverman AC, Thompson RW, Sanchez LA. Enfermedades de la aorta, En Bonow RO, Mann DL, Zipes DP, Libby P. Braunwald, Tratado de Cardiología: texto de medicina cardiovascular (2013, Novena edición, 1324-1354). España: Editorial Elsevier.

7. Mandelzweig L, Battler A, Boyko V, Bueno H, Danchin N, Filippatos G, et al. The second Euro Heart Survey on acute coronary syndromes: Characteristics, treatment, and outcome of patients with ACS in Europe and the Mediterranean Basin in 2004. Eur Heart J 2006;27(19):2285-93

8. Tominaga R, Tomita Y, Toshima Y, Nishimura Y, Kurisu K, Morita S, et al. Acute type A aortic dissection involving the left main trunk of the coronary artery--a report of two successful cases. Jpn Circ J 1999;63(9):722-4

9. Zegers ES, Gehlmann HR, Verheugt FWA. Acute myocardial infarction due to an acute type A aortic dissection involving the left main coronary artery. Neth Heart J 2007; 15(7-8):263-4.

10. Wang JY, Chen H, Song D, Su X. Acute Myocardial Infarction Secondary to Aortic Dissection. J Vasc Med Surg 2016;4(2):1-3.

11. Neri E, Toscano T, Papalia U, Frati G, Massetti M, Capannini G, et al. Proximal aortic dissection with coronary malperfusion: presentation, management, and outcome. J Thorac Cardiovasc Surg 2001;121(3):552-60. 


\title{
PERICARDITIS CONSTRICTIVA ASOCIADA A MIOCARDIOPATÍA CHAGÁSICA
}

\author{
CONSTRICTIVE PERICARDITIS ASSOCIATED WITH CHAGASIC \\ CARDIOMYOPATHY
}

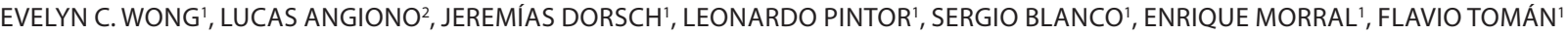

\section{RESUMEN}

La pericarditis constrictiva $(P C)$ en un síndrome clínico causado por un pericardio engrosado y rígido que dificulta el llenado ventricular. Es una enfermedad crónica, generalmente idiopática, que se presenta clínicamente como insuficiencia cardíaca congestiva (IC) con escasa respuesta al tratamiento médico y con evolución tórpida. La enfermedad de Chagas es una miocardiopatía dilatada que causa sintomatología clínica de IC que no difiere demasiado de otras cardiopatías dilatadas, con manifestaciones que aparecen de forma progresiva.

Presentamos el caso clínico de una mujer de 41 años de edad que consultó por IC biventricular, la cual al ser estudiada mediante métodos complementarios se reinterpreta como PC.

Palabras clave: pericarditis constrictiva, insuficiencia cardíaca, cateterismo cardíaco.

\section{ABSTRACT}

Constrictive pericarditis (CP) is a clinical syndrome caused by a thickened and rigid pericardium that hinders ventricular filling. It is a chronic disease, usually idiopathic, that presents clinically as congestive heart failure (HF) with little response to medical treatment and with a difficult and slow evolution.

Chagas disease is a dilated cardiomyopathy that causes clinical symptoms of HF that does not differ too much from other dilated heart diseases, with manifestations that appear progressively.

We present the clinical case of a 41-year-old woman who consulted for biventricular HF, which, when studied by means of auxiliary methods, is reinterpreted as CP.

Keywords: constrictive pericarditis, heart failure, cardiac catheterization.

REVISTA CONAREC 2018;33(147):322-324 | DOI:10.32407/RCON/2018147/0322-0324

\section{INTRODUCCIÓN}

La pericarditis constrictiva (PC) en una patología que se caracteriza por la compresión del corazón por un pericardio engrosado y rígido que dificulta el Ilenado diastólico ventricular. A diferencia del taponamiento, en el que la compresión del corazón se produce durante toda la diástole, en la constricción la repleción diastólica es normal en el primer tercio de la diástole (o incluso está aumentada en esta fase), mientras que está limitada de forma importante en los últimos dos tercios de la misma, cuando el corazón se topa con el pericardio rígido e inextensible'. Se trata de una entidad clínica poco frecuente que puede constituir el estadio evolutivo final de muchos procesos de estirpe inflamatoria, traumática e infecciosa, entre otras². Su diagnóstico habitualmente es tardío y se correlaciona con una clase funcional avanzada conllevando un aumento en la morbimortalidad. En la mayoría de los casos no se puede establecer una etiología concreta ${ }^{3}$. La miocardiopatía dilatada chagásica es causada por la infección del Trypanosoma cruzi. Se trata de una cardiopatía fibrosante, que gene-

1. Residente de Cardiología

2. Jefe de residentes de Cardiología. Servicio de Cardiología, Hospital Interzonal General de Agudo (HIGA) Eva Perón, San Martín, provincia de Buenos Aires, Rep. Argentina.

$\triangle$ Correspondencia: Dra. Evelyn C. Wong. Av. Ricardo Balbin 3200, San Martin, provincia de Buenos Aires, Rep. Argentina.ecw84@hotmail.com

Los autores declaran no poseer conflictos de intereses.

Recibido: 01/11/2017| Aceptado: 10/1/2018 ralmente se localiza en la región posteroinferior y apical del ventrículo izquierdo, el nódulo sinusal y el sistema de conducción por debajo del haz de His y cursa con afectación predominantemente segmentaria de la contractilidad. En la evolución natural de la enfermedad las alteraciones cardíacas aparecen de forma progresiva y en fases más avanzadas se detectan los signos habituales de insuficiencia cardíaca (IC), que es la principal manifestación de la miocardiopatía chagásica crónica (disnea especialmente en clase funcional II-III, edemas bimaleolares, ascitis, hepatomegalia congestiva, ingurgitación yugular), que no difiere demasiado de otras cardiopatías dilatadas ${ }^{4,5}$.

\section{CASO CLÍNICO}

Paciente de sexo femenino de 41 años, con hipertensión arterial, dislipemia y sobrepeso. Portadora de una miocardiopatía dilatada de origen chagásico diagnosticada 5 años antes con deterioro moderado de la función sistólica del ventrículo izquierdo (FSVI) sin tratamiento médico y de un marcapasos unicameral (modo VVI) por fibrilación auricular de baja respuesta ventricular, con enfermedad renal crónica (ERC) no dialítica asociada a anemia. Consultó a la guardia por presentar progresión de su disnea habitual de clase funcional II a III-IV de la clasificación de la New York Heart Association, con episodios de ortopnea y aumento del perímetro abdominal y de ambos miembros inferiores, por lo cual se decidió su internación. Al examen físico cardiovascular presentaba tercer ruido a la auscultación, ingurgitación yugular 2/3 sin colapso inspiratorio, reflujo hepatoyugular positivo, choque de punta apexiano desplazado y signo de Dressler positivo. A la auscultación pulmonar, presentaba hipoventilación generalizada y rales crepitantes bibasales. En la exploración abdominal, se ha- 


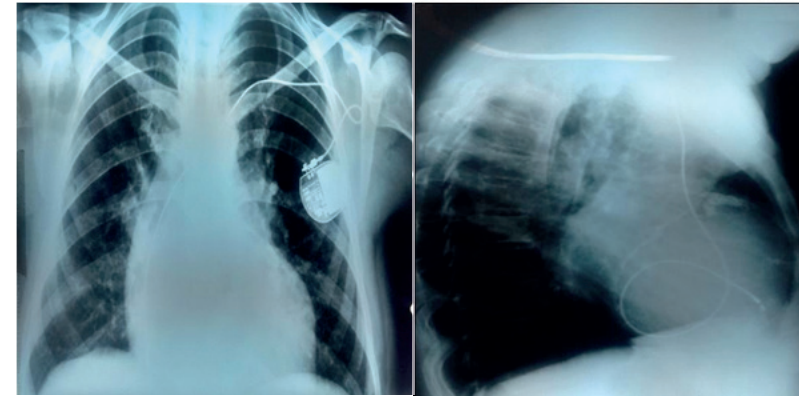

Figura 1. Radiografía de tórax. (A) frontal donde se evidencia imagen radioopaca paracardíaca izquierda. (B) lateral donde se evidencia calcificación pericárdica.

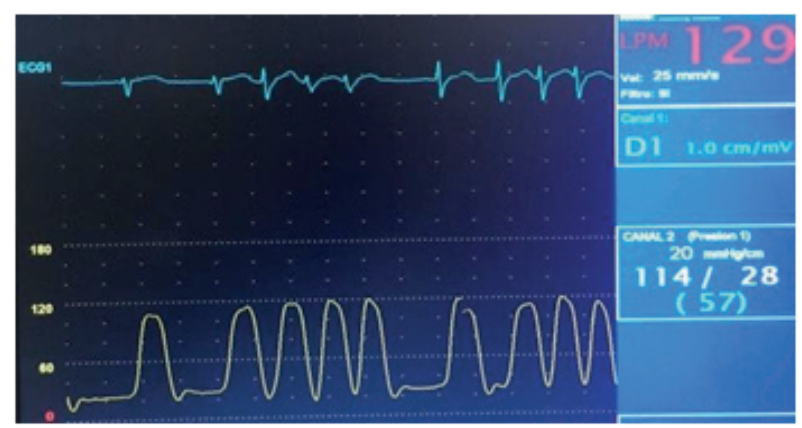

Figura 3. Medición de presión ventricular izquierda donde se evidencia el signo de la raíz cuadrada.

Iló hepatomegalia dolorosa a la palpación. Se le realizó electrocardiograma que evidenció ritmo de marcapasos, con adecuado sensado y captura ventricular, que alternaba con ritmo propio, a una frecuencia cardíaca de 60 latidos por minuto, QRS 140 milisegundos, QT 400 milisegundos. En la radiografía de tórax se evidenció un índice cardiotorácico de 0.6, con hipertensión venocapilar grado II y una imagen radioopaca paracardíaca izquierda (Figura 1).

Se interpretó el cuadro como IC derecha reagudizada, decidiéndose tratamiento con diuréticos endovenosos por infusión continua para realizar balance negativo.

Por presentar a las 24 horas de su ingreso una evolución tórpida con reagudización de la ERC y signos de bajo gasto cardíaco, se realizó tratamiento con dobutamina durante 72 horas. Evolucionó con mejoría de los parámetros clínicos y de laboratorio, se solicitó par radiográfico y ecocardiograma Doppler color transtorácico donde se observó engrosamiento del pericardio parietal y visceral con espacio anecoico interpuesto sobre la pared anterior del ventrículo derecho (Figura 2), compatible con PC. Posteriormente se le realizó una tomografía de tórax que evidenció calcificación en la superficie del pericardio de aspecto secuelar. Se decidió realizar cateterismo cardíaco derecho con los siguientes hallazgos: aurícula derecha $25 \mathrm{mmHg}$; presión sistólica del ventrículo derecho 46 mmHg y diastólica $4 \mathrm{mmHg}$; presión sistólica de la arteria pulmonar 40 mmHg, diastólica 18 mmHg y media 25 mmHg; presión capilar pulmonar $23 \mathrm{mmHg}$, gasto cardíaco $5.3 \mathrm{l} / \mathrm{min}$, resistencias vasculares pulmonares 90 dyn.s. $\mathrm{cm}^{-5}$, resistencias vasculares sistémicas $754 \mathrm{dyn} \cdot \mathrm{s} \cdot \mathrm{cm}^{-5}$. Evidenciándose el signo de la raíz cuadrada o de dip-plateau (Figura 3). Se prosiguió con la realización de una cinecoronariografía la cual no presentaba lesiones angiográficamente significativas, descartando isquemia miocárdica. Ante dichos hallazgos, se decide pericardiectomía, la cual se realizó sin complicaciones, la anatomía patológica no

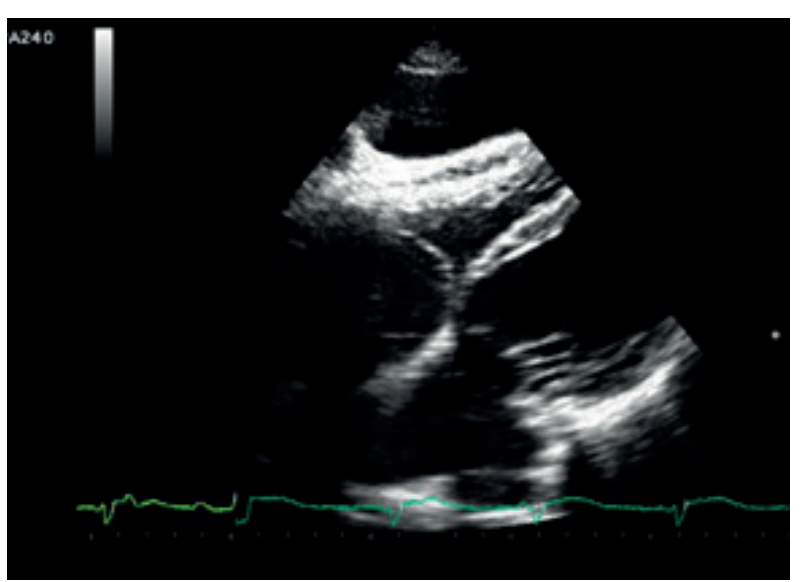

Figura 2. Ecocardiograma donde se evidencia engrosamiento del pericardio parietal y visceral con espacio anecoico interpuesto sobre pared anterior del ventrículo derecho.

demostró malignidad. La paciente evolucionó en forma favorable por lo que se le dio el alta hospitalaria con diuréticos orales.

\section{DISCUSIÓN}

El diagnóstico de PC es difícil de realizar tanto por su rareza como por su baja sospecha, dado que está oculta por otras patologías más frecuentes como la IC secundaria a deterioro de la FSVI. El caso que presentamos es el de una PC en una paciente portadora de una miocardiopatía dilatada de origen chagásico.

La PC es una enfermedad irreversible y lentamente progresiva, en principio tributaria de cirugía ya que éste es el único tratamiento eficaz. Sin embargo, la pericardiectomía tiene alto riesgo, con una mortalidad del 25-40\% en pacientes de edad avanzada con calcificación pericárdica muy extensa y en clase funcional III-IV 6,7. En la PC crónica hay engrosamiento y fusión de ambas hojas del pericardio, aunque suele predominar la afección de la parietal que está muy rígida e inextensible y en un 30-40\% de los casos calcificada9. La fisiopatología de esta enfermedad, al causar un saco pericárdico engrosado y no compatible, evita la fase de llenado diastólico del corazón lo cual sirve para igualar las presiones en las cuatro cámaras durante la diástole, un signo sutil que puede ser identificado por ecocardiografía. Funcionalmente, los cambios durante la diástole conducen a un llenado deficiente del corazón, lo que provoca una contrapresión venosa y un fallo del flujo de salida9,10.

El cuadro clínico de la PC se caracteriza por signos y síntomas de IC lo que puede confundir con cualquier causa que provoque falla cardía$\mathrm{ca}^{10}$, por lo que es necesario realizar estudios por imágenes que ayuden a confirmar el diagnóstico. Desde el punto de vista hemodinámico, el hallazgo de la igualación de las presiones diastólicas del lado derecho e izquierdo del corazón ayuda al diagnóstico, y el dip-plateau que es una curva de presión diastólica del ventrículo que muestra en su parte inicial un descenso rápido, temprano y profundo con una elevación rápida hasta una meseta, el dip de la curva de presión diastólica corresponde con el seno " $y$ " de la curva presión auricular mientras que la meseta con presión diastólica del ventrículo derecho a lo largo de la diástole ${ }^{10}$. El beneficio de la pericardiectomía, por otra parte, puede ser pobre en los pacientes en los que no se puede realizar de manera comple- 
ta ya sea por presentar una pericarditis crónica con gran calcificación o en aquellos con PC tras radioterapia. A diferencia de otras formas de deterioro miocárdico (por ejemplo, la enfermedad coronaria, la enfermedad valvular y la insuficiencia cardíaca) existe a la fecha escasa evidencia científica sobre el manejo clínico de esta patología"1 .

\section{CONCLUSIÓN}

La pericarditis constrictiva es una enfermedad crónica, generalmente idiopática, que suele evolucionar generando síntomas gra- ves e incapacitantes por insuficiencia cardíaca congestiva. Al ser una patología de baja prevalencia, requiere de una alta sospecha clínica. Los exámenes complementarios de fácil acceso como la radiografía de tórax, el ecocardiograma Doppler color y la tomografía computada permiten orientar y confirmar el diagnóstico sin la necesidad de la realización de estudios invasivos como el cateterismo cardíaco derecho; en caso de realizarse, el hallazgo característico es la elevación e igualación de las presiones diastólicas de ambos ventrículos en modo de dip-plateau, colapso-meseta o signo de la raíz cuadrada.

\section{BIBLIOGRAFÍA}

1. Marnejon T, Kassis H, Gemmel D. The constricted heart. Postgraduate medicine 2008:120(1):8-10

2. Maisch B, Seferovic PM, Ristic AD, Erbel R, Rienmüller R, Adler Y et al. Guía de prác tica clínica para el diagnóstico y tratamiento de las enfermedades del pericardio. Rev Esp Cardiol 2004:57(11):1090-114.

3. Sagristà Sauleda J, Permanyer Miralda G, Soler Soler J. Orientación diagnóstica y manejo de los síndromes pericárdicos agudos. Rev Esp Cardiol 2005;58(7):830-41.

4. Gascón J, Albajar P, Cañas E, Flores M, Gómez i Prat J, Herrera RN et al. Diagnóstico, manejo y tratamiento de la cardiopatía chagásica crónica en áreas donde la infección por Trypanosoma cruzi no es endémica. Rev Esp Cardiol 2007;60(3):285-93

5. Miocardiopatía chagásica dilatada. Rev Argen Cardiol 2002;70(1):70-2.
6. Ling LH, Oh JK, Schaff HV, Danielson GK, Mahoney DW, Seward JB et al. Con strictive pericarditis in the modern era: evolving clinical spectrum and impact on outcome after pericardiectomy. Circulation 1999;100(13):1380-6.

7. Tirilomis T, Unverdorben S, von der Emde J. Pericardiectomy for chronic constrictive pericarditis: risks and outcome. Eur J Cardiothorac Surg 1994;8(9):487-92.

8. Sagristà-Sauleda J. Cardiac constriction syndromes. Rev Esp Cardiol 2008;61(2):33-40.

9. Altemimi HA, Altaf SY, James RK, Nata R, Kumar EB, Codispoti M. A difficult diagnosis - constrictive pericarditis and its treatment: a case report. Cases Journal 2009;2:9105.

10. LeWinter MM, Hopkins WE. Enfermedades pericárdicas, En Mann DL, Zipes DP, Libby P, Bonow RO. Braunwald, Tratado de Cardiología: texto de medicina cardiovascular (2016, Décima edición, 1636-1657). España: Editorial Elsevier.

11. Nishimura RA. Constrictive pericarditis in the modern era: a diagnostic dilemma. Heart 2001;86(6):619-23. 


\title{
ALGORITMO DE MANEJO LIPÍDICO EN EL PACIENTE CON SÍNDROME CORONARIO AGUDO
}

\section{LIPID MANAGEMENT ALGORITHM IN PATIENT WITH ACUTE CORONARY SYNDROME}

\author{
JUAN IGNACIO DAMONTE', MATEO ANQUIZ², JUAN MANUEL DOMÍNGUEZ³, LUCIANO N. FALLABRINO4', WALTER MASSON JUÁREZ ${ }^{5}$, \\ PABLO CORRAL ${ }^{6}$, JUAN JOSÉ BADIMON ${ }^{7}$
}

REVISTA CONAREC 2018;33(147):325-327 | DOI:10.32407/RCON/2018147/0325-0327

A partir del abordaje del grupo de pacientes con muy alto riesgo cardiovascular, se plantea la necesidad práctica de desarrollar un algoritmo terapéutico específico para el tratamiento de las dislipemias en quienes, dentro de este grupo, han sufrido un evento coronario agudo de reciente aparición.

La medicina basada en la evidencia -sustentada en datos de los principales ensayos clínicos aleatorizados con estatinas- demostraron que la disminución del colesterol elevado reduce la mortalidad cardiovascular, la incidencia de infarto agudo de miocardio (IAM), los accidentes cerebrovasculares (ACV) y la necesidad de revascularización miocárdica.

En una primera etapa, el estudio 4S' -orientado a pacientes con enfermedad coronaria- reveló una reducción de riesgo absoluto de 3,3\% en mortalidad de cualquier causa (11,5 vs. 8,2\%; $p=0,0003 ; \mathrm{NNT}=30)$

1. Médico Residente de Cardiología, Servicio de Cardiología, Hospital Italiano de Buenos Aires.

2. Médico Residente de Cardiología, Servicio de Cardiología, Instituto Cardiovascular Denton A. Cooley.

3. Médico Residente de Cardiología, Servicio de Cardiología, Instituto Cardiovascular de Rosario.

4. Instructor de Residentes del Servicio de Cardiología del Sanatorio Trinidad Mitre. Vocal Titular del Consejo de Ateroesclerosis y Trombosis de la Sociedad Argentina de Cardiología. Presidente del CONAREC 2015.

5. Miembro Titular de la Sociedad Argentina de Cardiología. Hospital Italiano de Buenos Aires.

6. Cátedra de Farmacología, Departamento de Investigación, Universidad FASTA. Mar Del Plata.

7. Profesor de Medicina. Director de la Unidad de Investigación en Aterotrombosis de Icah School of Medicine at Mount Sinai, New York. Comité Revisor de la Revista CONAREC

$\triangle$ Correspondencia: Juan Ignacio Damonte. Tte. Gral. Juan Domingo Perón 4190 C1199ABB CABA, Rep. Argentina. Juan.damonte@hospitalitaliano.org.ar

El Dr. Pablo Corral es speaker de Amgen, Aegerion, Baliarda, Genzyme, Gador MSD, Boehringer Ingelheim, Raffo, Sanofi. El Dr. Walter Masson es speaker de Sanofi, Pfizer, Richmond, Raffo. Los otros autores no declaran tener conflictos de intereses..

Sanofi no financió el estudio ni a los autores. Sanofi solamente colaboró con la coordinación científica y bibliográfica entre los autores.

Recibido: 01/12/2018 | Aceptado: 10/12/2018 en aquellos tratados con simvastatina con respecto a los que recibieron placebo. Posteriormente, el estudio CARE² demostró una reducción significativa del $24 \%$ en el punto final primario (muerte coronaria o IAM) en la rama tratada con pravastatina respecto al grupo que recibió placebo en pacientes con infarto de miocardio previo.

En una segunda etapa, los estudios aleatorizados analizaron los beneficios del uso de las estatinas en dosis más altas. El estudio MIRACL fue el primero y único en demostrar el beneficio de las estatinas en el síndrome coronario agudo (SCA); en él se aleatorizaron pacientes cursando internación por SCA con estatinas en altas dosis (atorvastatina 80 mg) vs. placebo. Demostró que el grupo que recibió estatina redujo el punto final combinado de mortalidad de cualquier causa, infarto no fatal, paro cardiorrespiratorio y hospitalización por SCA.

Finalmente, se evaluó la importancia del uso de estatinas de alta intensidad. El punto final primario del estudio PROVE-IT4 (compuesto por muerte, IAM, angina inestable, ACV o revascularización) incluyó pacientes con SCA y demostró una reducción del riesgo en un 16\% en los pacientes bajo una estrategia "intensiva" (atorvastatina $80 \mathrm{mg}$ ) en relación al grupo cuya terapéutica se basó en una dosis "estándar" (pravastatina $40 \mathrm{mg}$ ). Correlativamente, el estudio TNT $^{5}$ reveló, en pacientes con enfermedad coronaria crónica, el beneficio de atorvastatina $80 \mathrm{mg}$ frente atorvastatina $10 \mathrm{mg}$ (8,7 vs. 10,9\%; RRR=22\%; $p<0,001)$.

Como primera conclusión afirmamos que resulta fundamental realizar un perfil lipídico dentro de las primeras 24 horas de internación a aquellos pacientes con SCA y comenzar un tratamiento con estatinas potentes en altas dosis durante la internación: atorvastatina 40/80 mg/día o rosuvastatina 20/40 mg/día (Figura 1). Estas recomendaciones han de estar siempre acompañadas de un estilo de vida saludable, incluyendo plan dietario y ejercicio físico.

Posteriormente, entre las 6 y 8 semanas luego del alta hospitalaria, se sugiere la realización de un nuevo control lipídico para evaluar los objetivos recomendados por las guías: lograr un colesterol de lipoproteína de baja densidad (C-LDL) menor de $70 \mathrm{mg} / \mathrm{dl}$ (o no colesterol de lipoproteína de alta densidad [C-HDL] menor de 100 mg/dl) o una reducción del 50\% del C-LDL en pacientes con C-LDL basal entre 70 y $130 \mathrm{mg} / \mathrm{dl}^{16-8}$. En este punto podrían presentarse dos posibles escenarios: que el paciente cumpla los objetivos planteados o que no alcancen dichos objetivos. 


\section{ALGORITMO DE MANEJO LIPÍDICO EN EL PACIENTE CON SÍNDROME CORONARIO AGUDO}

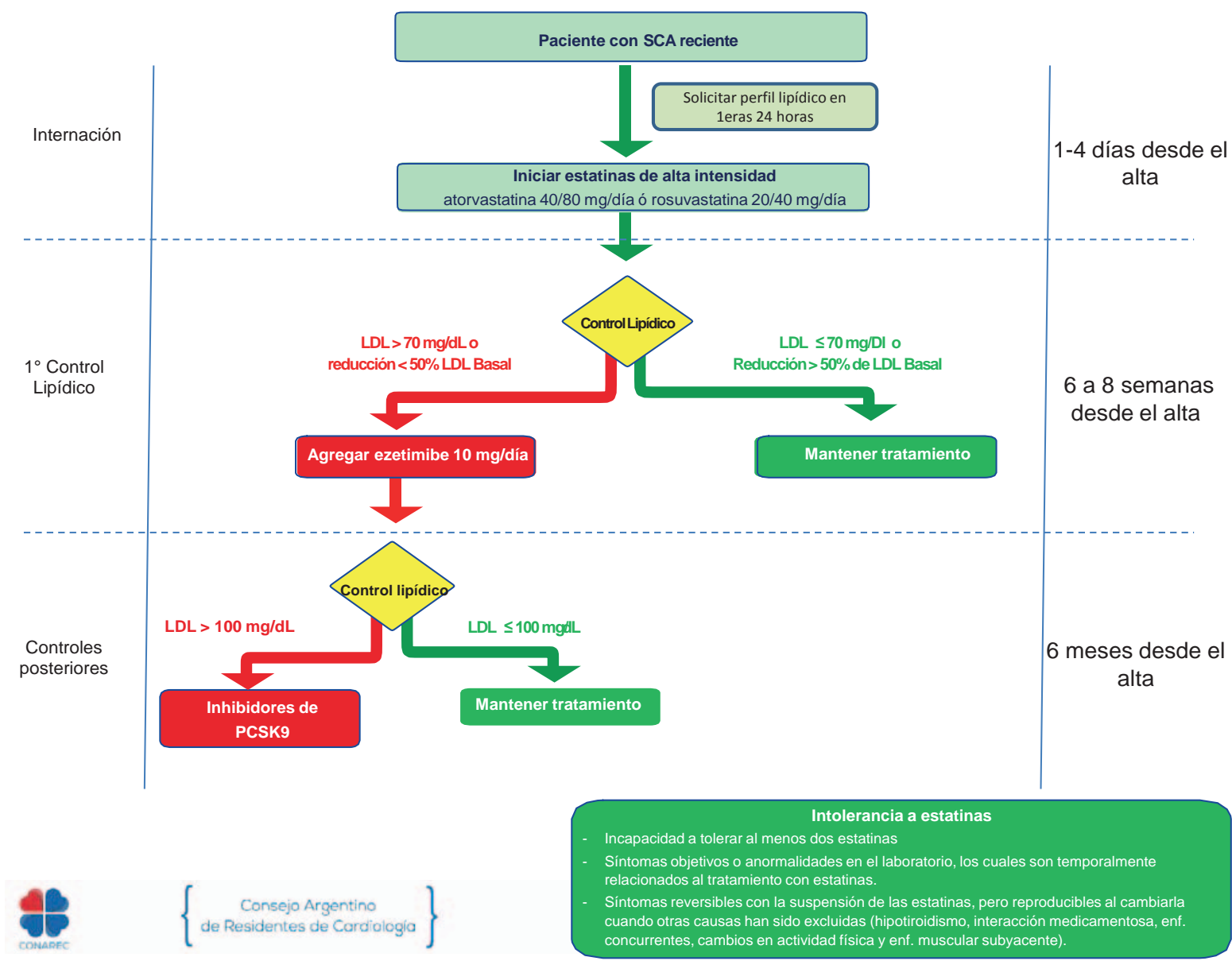

Figura 1. Algoritmo del manejo lipídico en el paciente con síndrome coronario agudo. SCA: síndrome coronario agudo. LDL: lipoproteína de baja densidad. PCSK9: proproteína convertasa subtilisina kexina tipo 9.

En el primer caso, y dado que las metas terapéuticas estarían alcanzadas, se indicará el mantenimiento del tratamiento recibido hasta el momento (es decir, el uso de estatinas en altas dosis o la dosis máxima tolerada). Es fundamental mantener la máxima dosis de estatina tolerada, sin modificarla posteriormente.

En aquellos casos en los cuales los pacientes demuestran adherencia completa al tratamiento, se encuentran con la máxima dosis de estatinas tolerada y a pesar de esto no alcanzan las metas terapéuticas, se podría añadir una segunda droga hipolipemiante. En este sentido, el estudio IMPROVE-IT ${ }^{9}$ demostró los beneficios del uso concomitante de estatinas y ezetimibe, evidenciando una reducción adicional de un 15 a 21\% en los niveles de C-LDL.

En los controles posteriores, se recomienda realizar un nuevo perfil lipídico con el tratamiento combinado de estatinas a dosis máxima toleradas y ezetimibe. La meta u objetivo terapéutico de C-LDL en estos pacientes es $<70 \mathrm{mg} / \mathrm{dl}$.
Sin embargo, a la fecha, para indicar un inhibidor de la proproteína convertasa subtilisina kexina tipo 9 (iPCSK9) en nuestro país, se recomienda evaluar un nivel de C-LDL "umbral", es decir un valor lipídico ante el cual se indicarían estos nuevos fármacos teniendo en cuenta el costo/beneficio ${ }^{10}$. Consecuentemente, podríamos encontrarnos ante dos escenarios clínicos: quienes tengan un C-LDL menor o mayor a $100 \mathrm{mg} / \mathrm{dl}$. En el segundo caso, se sugiere adicionar una tercera línea terapéutica, un iPCSK9.

Al momento actual, la evidencia ha demostrado que esta nueva clase de agentes hipolipemiantes son seguros y altamente eficaces. Particularmente, alirocumab es el único anticuerpo monoclonal aprobado por ANMAT y que ha sido evaluado en pacientes con SCA reciente al momento de la publicación del presente algoritmo. Se ha comprobado su eficacia para lograr reducciones del C-LDL de entre 50 a 70\% por sobre las estatinas más ezetimibe ${ }^{11}$. Asimismo, el estudio ODYSSEY OUTCOMES ${ }^{12}$ ha evidenciado que la mencionada droga produjo una reducción de even- 
tos coronarios, ACV isquémico y se ha asociado con la disminución de la mortalidad por todas las causas ${ }^{13}$.

Actualmente se incorporó una nueva categoría de riesgo en pacientes con enfermedad coronaria, llamada pacientes de Riesgo Extremo. Esta incluye pacientes con enfermedad aterosclerótica vascular progresiva (incluyendo angina inestable) a pesar de haber logrado el ob- jetivo de C-LDL menor a 70 mg/dl, enfermedad coronaria establecida y diabetes, enfermedad renal crónica estadio III o IV e hipercolesterolemia familiar heterocigota, y aquellos con historia de enfermedad aterosclerótica vascular precoz (hombres menores de 55 años y mujeres menores de 65 años). En esta categoría de pacientes sería razonable buscar un valor más bajo de C-LDL ( $<55 \mathrm{mg} / \mathrm{dl})$.

\section{BIBLIOGRAFÍA:}

1. Scandinavian Simvastatin Survival Study Group. Randomised trial of cholesterol lowering in 4444 patients with coronary heart disease: the Scandinavian Simvastatin Survival Study (4S). Lancet 1994;344(8934):1383-9.

2. Sacks FM, Pfeffer MA, Moye LA, Rouleau JL, Rutherford JD, Cole TG et al. The effect of pravastatin on coronary events after myocardial infarction in patients with average cholesterol levels. Cholesterol and Recurrent Events Trial investigators. N Engl J Med 1996;335(14):1001-9.

3. Schwartz GG, Olsson AG, Ezekowitz MD, Ganz P, Oliver MF, Waters D, et al. Effects of atorvastatin on early recurrent ischemic events in acute coronary syndromes: the MIRACL study: a randomized controlled trial. JAMA 2001; 285(13):1711-8.

4. Cannon CP, Braunwald E, McCabe CH, Rader DJ, Rouleau JL, Belder R, et al. Intensive versus moderate lipid lowering with statins after acute coronary syndromes. N Engl J Med 2004;350(15):1495-504.

5. LaRosa JC, Grundy SM, Waters DD, Shear C, Barter P, Fruchart JC, et al. Intensive lipid lowering with atorvastatin in patients with stable coronary disease. N Engl J Med 2005:352(14):1425-35.

6. Catapano AL, Graham I, De Backer G, Wiklund O, Chapman MJ, Drexel H, et al. 2016 ESC/EAS Guidelines for the Management of Dyslipidaemias. Eur Heart $J$ 2016;37(39):2999-3058.

7. Anderson TJ, Grégoire J, Pearson GJ, Barry AR, Couture P, Dawes M, et al. 2016 Canadian Cardiovascular Society Guidelines for the Management of Dyslipidemia for the Prevention of Cardiovascular Disease in the Adult. Can J Cardiol 2016;32(11):1263-82.
8. Jellinger PS, Handelsman Y, Rosenblit PD, Bloomgarden ZT, Fonseca VA, Garber AJ, et al. American Association of Clinical Endocrinologists and American College of Endocrinology quidelines for management of dyslipidemia and prevention of cardiovascular disease. Endocr Pract 2017;23(2):1-87.

9. Cannon CP, Blazing MA, Giugliano RP, McCagg A, White JA, Theroux P, et al. Ezetimibe added to statin therapy after acute coronary syndromes. N Engl I Med 2015:372(25):2387-97.

10. Giunta GA, Boskis M, Corral P, Di Cío A, Giorgi M, Iglesias R, et al. Recomendaciones para el uso de inhibidores de PCSK9. Documento de posición de la Sociedad Argentina de Cardiología. Rev Argent Cardiol 2017;85(6):1-13.

11. Sabatine MS, Giugliano RP, Keech AC, Honarpour N, Wiviott SD, Murphy SA, et al. Evolocumab and Clinical Outcomes in Patients with Cardiovascular Disease. N Engl J Med 2017;376(18):1713-22

12. Schwartz GG, Steg PG, Szarek M, Bhatt DL, Bittner VA, Diaz R, et al. Alirocum$a b$ and Cardiovascular Outcomes after Acute Coronary Syndrome. N Engl J Med 2018:379(22):2097-107.

13. Schwartz GG, Bessac L, Berdan $L G$, Bhatt DL, Bittner V, Diaz R, et al. Effect of alirocumab, a monoclonal antibody to PCSK9, on long-term cardiovascular outcomes following acute coronary syndromes: rationale and design of the ODYSSEY outcomes trial. Am Heart J 2014;168(5):682-9. 


\title{
REGLAMENTO DE PUBLICACIONES DE LA REVISTA DEL CONSEJO ARGENTINO DE RESIDENTES DE CARDIOLOGÍA
}

\author{
RULES OF PUBLICATIONS OF CONAREC JOURNAL
}

La Revista del Consejo Argentino de Residentes de Cardiología (CONAREC) publica artículos sobre temas relacionados con la Cardiología en su más amplio sentido. La Revista CONAREC es una publicación bimestral de marzo a diciembre (cinco números anuales) con objetivos asentados en la divulgación de material científco y educativo sobre la especialidad.

La publicación es de tipo impresa y electrónica (www.revistaconarec.com.ar), ambas de acceso gratuito. La distribución se realiza a nivel nacional y está dirigida a residentes y concurrentes de Cardiología, así como a cardiólogos clínicos e intervencionistas, técnicos en Cardiología, centros asistenciales, asociaciones científicas, bibliotecas y facultades de Medicina.

Los principios editoriales de la revista se basan en las recomendaciones para manuscritos enviados a revistas Biomédicas (Recommendations for the Conduct, Reporting, Editing, and Publication of Scholarly Work in Medical Journals) redactadas por el Comité Internacional de Editores de Revistas Médicas (Internacional Comittee of Medical Journal Editors - ICMJE) en su más reciente actualización, disponible en www.icmje.org.

\section{ORIGINALIDAD DEL MATERIAL}

Los artículos enviados deben ser originales e inéditos. No serán aceptados trabajos que se encuentren publicados o en evaluación en otras revistas científicas tanto en el mismo como en distinto idioma.

Artículos duplicados. Se consideran artículos duplicados aquellos que contienen material que ya ha sido publicado en su totalidad o en gran parte, o se encuentra incluido en o estrechamente vinculado a otro trabajo que ha sido enviado o aceptado para su publicación en otra revista. Estos artículos no serán aceptados para su publicación.

Publicaciones secundarias. La publicación secundaria de material publicado en otras revistas puede ser justificable y beneficiosa, especialmente cuando se intenta transmitis información relevante a la mayor audiencia posible (ej: guías de práctica clínica, registros con datos nacionales sobre patologías prevalentes en materia de salud pública). Los artículos se considerarán para publicación secundaria siempre y cuando se ajusten a las recomendaciones ICMJE y los editores de ambas revistas lo aprueben. Además debe ser debidamente aclarado en el texto que ya ha sido publicado en todo o en parte y deber citarse adecuadamente la publicación original.

\section{ÉTICA}

Los trabajos clínicos experimentales que sean enviados para su evaluación deben elaborarse respetando las recomendaciones internacionales sobre investigación clínica desarrolladas en la Declaración de Helsinki de la Asociación Médica Mundial revisada recientemente (www.wma.net/es/policy) y deben haber sido aprobados por un Comité de Ética institucional o regional responsable en experimentación humana. En el caso de utilización de animales de laboratorio, deberá ajustarse a las normas de la Sociedad Americana de Fisiología. Los autores de los artículos aceptan la responsabilidad definida por el Comité Internacional de Editores de Revistas Médicas (www.icmje.org).

\section{PROTECCIÓN DE LA PRIVACIDAD DE LOS PACIENTES}

No pueden publicarse descripciones, fotografías u otros detalles que contribuyan a identificar al paciente, a menos que esta información sea indispensable para la exposición del material; en ese caso, el paciente o el padre o tutor de los menores de edad expresarán su consentimiento por escrito, el cual deberá adjuntarse.

\section{REGISTRO DE ENSAYOS CLÍNICOS}

La Revista CONAREC apoya las políticas para registro de ensayos clínicos de la Organización Mundial de Salud (OMS) y del ICMJE, reconociendo la importancia de esas iniciativas para el registro y divulgación internacional de información sobre estudios clínicos, en acceso abierto. En consecuencia, solamente se aceptarán para publicación los artículos de investigaciones clínicas que hayan recibido un número de identificación en uno de los Registros de Ensayos Clínicos validados por los criterios establecidos por la OMS e ICMJE. El número de identificación se deberá consignar al final del resumen.

\section{SECCIONES}

\section{Artículos originales}

Son trabajos científicos o educativos de investigación básica o clínica original. Debe seguir la estructura "IMRD", es decir, debe tener Introducción, Material y métodos, Resultados y Discusión (véanse las normas de publicación ICMJE). Además son necesarias una Conclusión y Referencias bibliográficas. Cuando la situación lo amerite, se pueden agregar Agradecimientos y un Apéndice adjunto. Condiciones: texto general hasta 5.000 palabras, resumen hasta 500 palabras, 3-6 palabras clave, tablas más figuras hasta 8, referencias hasta 40, autores hasta 10.

\section{Revisión anual}

La Revisión Anual consiste en un tema relevante de la especialidad que será de sarrollado durante todo el año en cada volumen. Será escrita por profesionales destacados, Miembros Honorarios o del Comité Asesor del CONAREC a pedido del Comité de Redacción.

Condiciones: texto general hasta 5.000 palabras, resumen hasta 500 palabras, 3-6 palabras clave, tablas más figuras hasta 8, referencias hasta 40, autores hasta 3.

\section{Revisión por expertos}

Son artículos sobre temas relevantes de la especialidad solicitados por el Comite de Redacción a autores de reconocida trayectoria (nacionales o extranjeros). Excepcionalmente podrán ser considerados para publicación artículos no solicitados por el Comité siempre y cuando se ajusten al presente reglamento.

Condiciones: texto general hasta 5.000 palabras, resumen hasta 500 palabras, 3-6 palabras clave, tablas más figuras hasta 8, referencias hasta 40, autores hasta 3.

\section{Médicos de Guardia}

Son artículos sobre el manejo racional y protocolizado de diferentes circunstancias que se presentan en la práctica diaria. Son revisados y consensuados previamente con especialistas en el tema, que culminan con un diagrama de flujo sobre el manejo diagnóstico-terapéutico de la patología.

Condiciones: texto general hasta 3.000 palabras, resumen hasta 150 palabras, tablas más figuras hasta 6, referencias hasta 20, autores hasta 8.

\section{Caso clínico}

Es la descripción de un caso clínico de características inusuales, que incluye su abordaje diagnóstico y terapéutico, y su resolución final. Debe acompañarse de una introducción, una discusión bibliográfica y las conclusiones pertinentes.

Condiciones: texto general hasta 2.000 palabras, resumen hasta 350 palabras, tablas más figuras hasta 5, referencias hasta 20, autores hasta 10

\section{Imágenes en Cardiología}

Son imágenes, no necesariamente excepcionales, pero sí ilustrativas, que deben ir acompañadas de una leyenda explicativa, un resumen del caso clínico y una breve reseña bibliográfica.

Condiciones: texto general hasta 1.200 palabras, resumen hasta 350 palabras, figuras hasta 8 , referencias hasta 10, autores hasta 10.

\section{Editoriales}

Son comentarios y/o análisis de un artículo publicado en el número de la revista en el que aparece y es solicitado por el Comité de Redacción a un autor experto en el tema. Asimismo, pueden solicitarse comentarios sobre temas no relacionados con un artículo en particular.

Condiciones: texto general hasta 1.200 palabras, referencias hasta 10.

\section{Monografía seleccionada}

Son monografías seleccionadas y/o premiadas por el Comité Científico de la última Jornada Interresidentes de Cardiología, adaptadas para la publicación en la revista (ver normas de publicación ICMJE).

Condiciones: texto general hasta 10.000 palabras, resumen hasta 500 palabras, 3-6 palabras clave, tablas más figuras hasta 10 y referencias hasta 100.

\section{Selección de artículos relevantes, guías y consensos publicados}

La selección del material estará a cargo de miembros del Comité de Redacción teniendo en cuenta las principales revistas nacionales e internacionales. 
Condiciones: se confeccionará una lista en la que conste el título del artículo seleccionado y la correspondiente cita de la revista en la que fue publicado según las normas generales de publicación de CONAREC.

\section{Agenda CONAREC}

Se publicarán las actividades más importantes correspondientes al bimestre de la edición.

\section{RECEPCIÓN, EVALUACIÓN Y PUBLICACIÓN DE ARTÍCULOS}

El envío del artículo (texto, tablas y figuras) debe realizarse por correo electrónico a conarecrevista@gmail.com consignando en el asunto la sección a la que corresponda.

Cada manuscrito recibido será examinado por el Comité de Redacción con la supervisión del Comité Asesor y de ser adecuado a las normas de publicación será evaluado por dos árbitros externos especializados en el tema en forma doble ciego: el material será enviado a estos últimos sin consignar el nombre de los autores ni el centro al que pertenecen. Si los revisores consideran necesaria la realización de modificaciones, se enviarán las sugerencias al autor responsable preservando la identidad del revisor. El autor recibirá una respuesta preliminar dentro de los 3 meses de remitido el manuscrito correctamente, debiendo realizar los cambios sugeridos a la brevedad y reenviar el material para su nueva evaluación. Finalmente, se notificará al autor responsable sobre la aceptación o el rechazo del manuscrito.

El Comité de Redacción se reserva el derecho de introducir, con el consentimiento de los autores, todos los cambios editoriales exigidos por las normas gramaticales y las necesidades de edición de la revista.

Aprobada la publicación del trabajo, CONAREC retiene los derechos de autor para su reproducción total o parcial.

\section{PREPARACIÓN DEL MANUSCRITO}

El artículo debe estar escrito en castellano, en un procesador de texto Word (Microsoft ${ }^{\oplus}$ ) o similar (con formato compatible) y guardado con extensión *.doc o *.docx. El tamaño de la página debe ser A4 o carta, con doble espacio interlineado, márgenes de $25 \mathrm{~mm}$ con texto justificado y con tamaño de letra de 12 puntos tipo Times New Roman. Las páginas se numerarán en forma consecutiva comenzando con la portada.

Cada artículo debe ser presentado con una primera página que debe contener: a) título del artículo en mayúscula con negrita; b) apellido y nombres completos de los autores; c) institución en que se desempeñan; d) cargos que ocupan; e) título abreviado para cabeza de página; f) título en inglés; g) número total de palabras del artículo, sin las referencias bibliográficas; $h$ ) número de palabras del resumen; i) nombre y dirección completa, código postal y dirección de correo electrónico del autor con quien se deba mantener correspondencia; j) declaración de la existencia o no de conflictos de intereses.

Para consignar los nombres de los autores, se debe colocar el apellido seguido por el nombre de pila y la inicial del segundo si lo tuviere, separado por punto y coma del siguiente (por ejemplo: Herrera Paz Juan J: Thierer Jorge). Continuado con punto seguido el lugar donde se realizó el trabajo. Debajo se debe colocar el lugar donde desempeña su tarea laboral y cargo que ocupa cada uno de los autores señalado con notas al pie, usando números consecutivos. Quienes figuren como autores deben haber participado en la investigación o en la elaboración del manuscrito y hacerse públicamente responsables de su contenido, adaptándose a las normas para la autoría expuestas por la IMCJE.

La segunda página debe incluir a) resumen en español; b) palabras clave en español; c) resumen en inglés americano (abstract); d) palabras clave en inglés (keywords); e) número de identificación en el registro de Ensayos Clínicos cuando corresponda.

Las palabras clave deben ser términos incluidos en la lista del Index Medicus (Medical Subject Headings - MeSH) y Descriptores en Ciencias de la Salud (DeCS). Para la selección de estos se recomienda visitar los siguientes enlaces: http://www.nlm.nih.gov/mesh/2014/mesh_browser/MBrowser y http://decs. bvs.br

Luego, en la tercera página, se debe desarrollar el contenido del manuscrito de acuerdo con las especificaciones de cada tipo de artículo, iniciando una nueva página para cada sección. Cada sección de la estructura "IMDR" debe ir con negrita mayúscula, mientras que las siguientes subsecciones dentro de la estructura IMDR deben ir con negrita tipo título separadas de las secciones por espacio simple.

\section{Unidades de medida}

Como unidades de medida se utilizarán las del sistema métrico decimal, usando comas para los decimales. Todas las mediciones clínicas, hematológicas y químicas deben expresarse en unidades del sistema métrico y/o UI, aclarando, cuando sea necesario, los rangos de referencia del laboratorio que realizó las determinaciones.

\section{Abreviaturas}

Solo se utilizarán las abreviaturas comunes, evitándose su uso en el título y en e resumen. La primera vez que se empleen irán precedidas por el término completo, excepto que se trate de unidades de medida estándar.

\section{Tablas y Figuras}

Las tablas y figuras deben presentarse en hojas individuales y se enumerarán consecutivamente con números arábigos $(1,2$ etc) según el orden que fueron citadas en el texto, con un título breve para cada una de ellas. Deben ser rotuladas con la palabra Tabla o Figura en negrita continuada por el número correspondiente de figura o tabla. Todas las abreviaturas de la tabla no estandarizadas deben explicarse. Las notas aclaratorias deben ir al pie de la tabla utilizando los siguientes símbolos en esta secuencia: ${ }^{*}, \dagger, \neq, \S, 9,{ }^{* *},+\dagger, \neq \neq$, etc.

Las figuras deben estar en formato TIFF, PSD o JPEG, a 300 dpi en formato final. Deben ser numeradas correlativamente con una leyenda explicativa en hoja aparte. El tamaño usual de las fotografías debe ser de 127x173 mm. Los títulos y las explicaciones detalladas se colocan en el texto de las leyendas y no en la ilustración misma.

\section{Referencias bibliográficas}

Las referencias bibliográficas solo se limitarán a citar a aquellos artículos originales directamente relacionados con el trabajo, evitándose mencionar artículos de revisión sobre el tema expuesto. Se enumerarán las referencias de manera consecutiva con números arábigos entre paréntesis. Se incluirán todos los autores cuando sean seis o menos; si fueran más de seis, el sexto será seguido de la expresión "et al". Los títulos de las revistas serán abreviados según el estilo empleado en el Index Medicus. Ejemplos según tipo de publicación a citar:

1. Registro de Procedimientos Diagnósticos y Terapéuticos efectuados du rante el período 2006-2007. Colegio Argentino de Cardioangiólogos Intervencionistas (CACl). Disponible en http://www.caci.org.ar/addons/3/158.pdf. Consultado el 01/01/2009. (Para páginas web).

2. Ambrosy AP, Vaduganathan M, Huffman MD, Khan S, Kwasny MJ, Fought AJ, et al. Clinical course and predictive value of liver function tests in patients hospitalized for worsening heart failure with reduced ejection fraction: an analysis of the EVEREST trial. Eur J Heart Fail. 2012;14(3):302-11. (Para revistas en inglés).

3. Guardiani F, Mana M, Vázquez R. Trombosis simultánea en el infarto agudo de miocardio. Pancoronaritis. Rev Conarec. 2008;30(96):290-92. (Para revis tas en español).

4. Braverman A, Thompson R, Sanchez L. Enfermedades de la aorta. En: Bonow R, Mann D, Zipes D, Libby P. Braunwald, Tratado de Cardiología: texto de medicina cardiovascular (2013, Novena edición, 1324-1354). España: Editorial Elsevier. (Libro).

\section{APÉNDICE - ESTRUCTURA “IMRD”}

Introducción. Establece el propósito del artículo y realiza el resumen de los fundamentos lógicos para la observación del estudio Da únicamente las referencias estrictamente pertinentes. Se presentan los objetivos del trabajo, y se resumen las bases para el estudio o la observación. No debe incluir resultados o conclusiones del trabajo.

Materiales y métodos. Incluye una descripción de: a) La selección de los suje tos estudiados y sus caracteristicas. b) Los métodos, aparatos y procedimientos; en estudios clínicos se informarán detalles del protocolo (población estudiada, intervenciones efectuadas, bases estadísticas). c) Guías o normas éticas seguidas. d) Descripción de los métodos estadísticos utilizados. Describe claramente la selección de los sujetos destinados a la observación y la experimentación (pacientes o animales de laboratorio, incluido grupo de control). Debe identificar edad, sexo y otras características relevantes de la población, los métodos, aparatos (proporcionar el nombre, dirección de la empresa que lo produce) y procedimientos con suficientes detalles que permitan a otros investigadores la reproducción de los resultados. Deben mencionarse las drogas y las sustancias químicas, incluidos nombre químico, dosis y vías de administración.

Dentro de esta sección deberá aclararse, si correspondiera, el análisis estadístico realizado, así como el programa utilizado para ello, y el nivel de significancia preestablecido. Los trabajos clínicos aleatorizados (randomizados) deberán presentar información sobre los elementos más importantes del estudio, que contengan el protocolo y la hoja de flujo de la inclusión de los pacientes, y además deberán seguir los lineamientos del CONSORT (consúltese el artículo en la página web de instrucciones de la revista).

Los autores que presentan revisiones deberán incluir una sección en la que se describan los métodos utilizados para la ubicación, la selección y la síntesis de datos; estos métodos deberán figurar abreviados en el resumen.

Resultados. Los resultados deben presentarse con una secuencia lógica en el texto, las tablas y las ilustraciones. No se deben repetir en el texto todos los datos de las tablas o las ilustraciones, debiendo destacar solo las observaciones importantes. Las tablas y las figuras deben utilizarse en el número estrictamente necesario para explicar el material y para valorar su respaldo. Se recomienda emplear gráficos como alternativa para las tablas con numerosas entradas. 
Discusión. Resalta los aspectos nuevos e importantes del estudio, las conclusiones de ellos derivadas, y su relación con los objetivos que figuran en la Introducción. No se debe repetir información que ya figure en otras secciones del trabajo. Evitar declaraciones de prioridad y referencias a trabajos aún no completados. Incluir los hallazgos, sus implicaciones y limitaciones, incluso lo que implicaría una futura investigación. Relacionar las observaciones con las de otros estudios importantes. Las conclusiones deben estar relacionadas con los objetivos del estudio. Se deben evitar informes no calificados y conclusiones que no estén completamente respaldados por los datos. Los autores deben evitar dar informaciones sobre costos-beneficios económicos a menos que el artículo incluya datos económicos y su análisis. Plantear otras hipótesis cuando esté justificado, pero rotuladas claramente como tales. Las recomendaciones pueden incluirse cuando resulten apropiadas.
Agradecimientos. Precediendo a la bibliografía; si cabe se citarán: reconocimiento por apoyo técnico, aportes financieros, contribuciones que no lleguen a justificar autoría. En estos casos los autores serán responsables de contar con el consentimiento escrito de las personas nombradas.

Apéndice. En esta sección, de carácter opcional, deberá incluirse todo aquel material no contemplado en los apartados previos, y que resulte necesario o facilite la comprensión del manuscrito remitido. Ejemplo de esto son los formularios empleados para llevar adelante una encuesta, ilustraciones de una maquinaria empleada para una determinada tarea, o similar. 